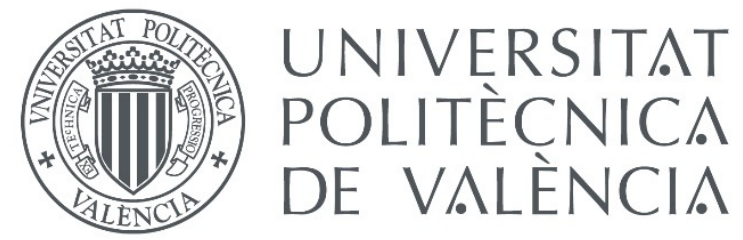

Ph. D. Thesis

IN

ENGINEERING AND INDUSTRIAL PRODUCTION

\title{
ADVANCED CERAMIC MATERIALS FOR DENTAL APPLICATIONS SINTERED BY MICROWAVE HEATING
}

\author{
PRESENTED BY: \\ ALVARO PRESENDA BARRERA
}

SUPERVISED BY:

Prof. MARÍA DOLORES SALVADOR MOYA

Dr. MARÍA AMPARO BORRELL TOMÁS

MECHANICAL AND MATERIALS ENGINEERING DEPARTMENT JUNE 2016 

To my parents \&ٔ my sister...

To my wife... 

Saber más es ser más libres

(To know more is to be freer)

- César Vallejo 



\section{ACKNOWLEDGEMENTS}

First of all, I would like to acknowledge my Ph. D. thesis supervisors, Prof. Ma. Dolores Salvador and Dr. Amparo Borrell, for giving me the opportunity to work with them in this project and to contribute to their engaging and motivating research. Thank you for your patience, guidance, and support in every aspect of this research, for making your resources available to me and trusting my judgment when making important decisions.

I would also like to thank the Santiago Grisolía Scholarship Program (GRISOLIA/2013/035) of the Generalitat Valenciana for providing the financial support to make this research possible and for giving me the opportunity to further my studies by obtaining a Ph. D. degree. Also, a special thank you to Oficina de Programas Internacionales e Intercambio (OPII) at UPV and the Erasmus Prácticas Scholarship program for providing funds for my research stay abroad.

My sincerest and deepest appreciation to Dr. Rut Benavente and Dr. Emilio Rayón for their day-to-day guidance and willingness to help me during the time in the lab, for their advice and camaraderie, and for listening and providing solutions in both professional and personal aspects. Also, thank you to the people at the Instituto de Tecnología de Materiales (ITM) and the Mechanical and Materials Engineering Department (DIMM) of the UPV for providing the facilities and equipment to carry out my research work, as well as my colleagues and friends Laís, Pablo and Leo.

I would also like to acknowledge the ITACA Institute, especially Dr. Pedro PlazaGonzalez and Prof. Felipe Peñaranda-Foix, for their collaboration regarding the operation of the microwave system. Additionally, I would like to extend my appreciation to the Microscopy Services of the UPV for providing the tools regarding sample characterization, and the Microscopy Services at Valencia University (Campus Burjassot) for electron microscopy and X-ray diffraction analysis. Thank you also to Prof. Javier Manjón and Dr. Juan Ángel Sans of the Physics department at UPV for their help regarding Raman spectroscopy characterization, and Prof. Anna Igual from the Chemical Engineering department at UPV for confocal microscopy analysis.

A special thanks to the Department of Materials Engineering (MTM) KU Leuven, particularly to Prof. Jozef Vleugels and his research group, for allowing me to do a three-month research visit in Belgium to carry out the tribological tests and characterization in their department.

To my family, friends, colleagues, professors, mentors and supervisors that have been part of this incredible journey... THANK YOU! 



\section{ABSTRACT}

Zirconia has become a widely utilized structural ceramic material with important applications in dentistry due to its superb mechanical properties, biocompatibility, aesthetic characteristics and durability. Zirconia needs to be stabilized in the $t$-phase to obtain improved mechanical properties such as hardness and fracture toughness. Fully dense yttria-stabilized tetragonal zirconia polycrystalline (Y-TZP) materials are normally consolidated through the energy-intensive processing of powders at very high temperatures $\left(>1000{ }^{\circ} \mathrm{C}\right)$. Innovative non-conventional approaches are being developed to reduce time and energy consumption and, consequently, environmental impact in ceramic powder processing. Microwave sintering is one such approach aimed at fully-densifying ceramics by using a different heating mechanism based on the material's inherent dielectric properties.

The main purpose of this work is to obtain highly dense Y-TZP dental materials from commercial and lab-prepared sources via microwave sintering with mechanical and microstructural qualities that are similar or even improved with respect to their conventionally sintered counterparts. Therefore, its effect on important aspects related to dental applications has been studied. First, Y-TZP ceramics have been characterized upon sintering to determine whether the resulting properties meet the minimum mechanical requirements for structural dental applications. Second, the influence of microwave sintering on hydrothermal degradation, a spontaneous ageing phenomenon that affects zirconia materials in wet conditions, has been investigated. And third, the behavior under fretting wear conditions of microwave and conventionally sintered materials has been assessed to evaluate their durability and performance.

The main conclusions indicate that microwave sintering allows proper consolidation of dental Y-TZP materials resulting in a finer microstructure due to shorter processing time and mechanical properties comparable, and in some cases enhanced, to those obtained in conventional sintered materials at lower dwell temperatures. Additionally, a higher resistance to hydrothermal degradation has been determined for microwave sintered materials due to a finer grain size and lower sintering temperatures that reduce the presence of cubic phase, which is responsible for destabilizing neighboring tetragonal phase grains. Finally, a similar wear rate has been obtained between microwave and conventional sintering of zirconia materials under fretting wear conditions. In addition, humidity can reduce the wear volume loss due to the lubricative effect of water and wear of degraded materials might increase the resistance due to the formation of a protective debris layer. In general, microwave sintering can be an interesting alternative for obtaining fully-densified $Y$ TZP dental materials providing certain advantages over conventional methods. Nonetheless, more studies are still necessary to have a better understanding of the advantages and disadvantages of microwave sintering of zirconia ceramics. 



\section{RESUMEN}

La circona es un material ampliamente utilizado como cerámica estructural con aplicaciones en el ámbito dental debido a sus propiedades mecánicas, biocompatibilidad, características estéticas y durabilidad. Para poder aprovechar las altas propiedades mecánicas de la circona, es necesario estabilizarla en su fase tetragonal. Los materiales de circona policristalina estabilizada con itria (Y-TZP) se consolidan normalmente a través de polvos mediante procesos energéticamente intensivos a altas temperaturas $\left(>1000{ }^{\circ} \mathrm{C}\right)$. Actualmente, se están desarrollando técnicas basadas en métodos no convencionales para reducir el tiempo y el consumo energético en el procesado de polvos cerámicos. La sinterización por microondas tiene por objetivo la densificación completa mediante la utilización de mecanismos de calentamiento basados en las propiedades dieléctricas del material.

El objetivo principal es la obtención de materiales dentales de Y-TZP altamente densos mediante la sinterización por microondas con propiedades mecánicas y microestructurales similares, o incluso por encima de las obtenidas por el método convencional. Para ello, se estudian aspectos relevantes al ámbito dental. En primer lugar, los materiales son caracterizados con el fin de determinar si las propiedades finales cumplen con los requisitos mecánicos para aplicaciones dentales. Además, se ha investigado la influencia de la sinterización por microondas en la degradación hidrotérmica, un fenómeno espontáneo de envejecimiento que afecta a los materiales de circona en condiciones de humedad. Finalmente, se ha evaluado el comportamiento en condiciones de desgaste fretting de los materiales sinterizados para determinar su durabilidad.

Las conclusiones principales indican que la sinterización por microondas permite la consolidación adecuada de estos materiales, resultando en una microestructura más fina debido a los tiempos más cortos de procesado y en propiedades mecánicas comparables a las de materiales obtenidos mediante el método convencional, incluso a temperaturas más bajas. Una mayor resistencia a la degradación hidrotérmica se ha determinado en materiales sinterizados por microondas. Al emplear temperaturas más bajas se reduce la presencia de fase cúbica, la cual es responsable por la desestabilización de granos adyacentes de fase tetragonal. Tasas de desgaste similares han sido observadas entre materiales sinterizados por microondas y convencionalmente bajo condiciones de desgaste fretting. Adicionalmente, la humedad puede reducir sustancialmente la pérdida de volumen de desgaste debido al efecto lubricante del agua y los materiales degradados pueden aumentar la resistencia a este tipo de desgaste como consecuencia de la formación de una capa protectora de material que se desprende más fácil. En general, la sinterización por microondas es una alternativa interesante para obtener materiales dentales de Y-TZP altamente densos con ciertas ventajas sobre los métodos convencionales pero deben considerarse también las desventajas de esta técnica. 



\section{RESUM}

La circona és un material àmpliament utilitzat com a ceràmica estructural amb aplicacions en l'àmbit dental a causa de les seues propietats mecàniques, biocompatibilidad, característiques estètiques i durabilitat. Per a poder aprofitar les altes propietats mecàniques de la circona, és necessari estabilitzar-la en la seua fase tetragonal. Els materials de circona policristalina estabilitzada amb itria (Y-TZP) es consoliden normalment mitjançant processos energèticament intensius a altes temperatures $\left(>1000^{\circ} \mathrm{C}\right)$. Actualment, s'estan desenvolupant tècniques basades en mètodes no convencionals per a reduir el temps $\mathrm{i}$ el consum energètic en el processament de la pols ceràmicas. La sinterització per microones té per objectiu la densificació completa mitjançant la utilització de mecanismes d'escalfament basats en les propietats dielèctriques del material.

L'objectiu principal d'aquesta tesi és l'obtenció de materials dentals de Y-TZP altament densos mitjançant la sinterització per microones amb propietats mecàniques i microestructurals superiors a les obtingudes per mètodes convencionals. En primer Iloc, els materials seràn caracteritzats per a determinar si les propietats finals compleixen amb els requisits mecànics per a aplicacions dentals. En segon lloc, s'investigarà la influència de la sinterització per microones en la degradació hidrotèrmica, un fenomen espontani d'envelliment que afecta als materials de circona en condicions d'humitat. I en tercer $\|$ oc, s'avaluarà el comportament en condicions de desgast fretting dels materials sinteritzats per a determinar la seua durabilitat.

Les conclusions principals indiquen que la sinterització per microones permet la consolidació adequada i millorada de materials de Y-TZP, amb una microestructura més fina a causa dels temps més curts de processament i propietats mecàniques comparables a les de materials obtinguts mitjançant el mètode convencional, fins i tot a temperatures més baixes. Un factor positiu ha sigut la major resistència a la degradació hidrotèrmica en materials sinteritzats per microones. A més, al emprar temperatures més baixes es redueix la presència de fase cúbica, la qual és la responsable de la desestabilització de grans adjacents de fase tetragonal. Finalment, sota condicions de desgast fretting, s'han observat taxes de desgast similars entre materials sinteritzats per microones i via convencional. Addicionalment, en condicions de $100 \%$ d'humitat es pot reduir substancialment la pèrdua de volum de desgast a causa de l'efecte lubrificant de l'aigua i materials degradats, els quals poden augmentar la resistència a aquest tipus de desgast com a conseqüència de la formació d'una capa protectora de material que es desprèn amb més facilitat. En general, la sinterització per microones és una alternativa molt interessant per a obtindre materials dentals Y-TZP òptims i amb certes avantatges sobre els mètodes convencionals, però han de considerar-se també algunes desavantatges d'aquesta tècnica. 



\section{PUBLICATIONS}

1. A. Presenda, M. D. Salvador, F. Peñaranda-Foix, J. M. Catalá, A. Borrell. Mechanical Characterization of Conventional and Non-conventional Sintering Methods of Commercial and Lab-synthesized Y-TZP Zirconia for Dental Applications. Adv. Sci. Tech. 87 (2014) 151-156.

2. A. Presenda, M. D. Salvador, F. Peñaranda-Foix, R. Moreno, A. Borrell. Effect of Microwave Sintering on Microstructure and Mechanical Properties in Y-TZP materials used for Dental Applications. Ceram. Int. 44 (2015) 7125-7132.

3. A. Presenda, M. D. Salvador, R. Moreno, A. Borrell. Hydrothermal Degradation Behavior of Y-TZP Ceramics Sintered by Non-conventional Microwave Technology. J. Am. Ceram. Soc. 98 (2015) 3680-3689.

4. A. Presenda, M. D. Salvador, J. Vleugels, R. Moreno, A. Borrell. Fretting Fatigue Wear Behavior of Y-TZP Dental Materials Processed by Non-conventional Microwave Sintering. Wear. Under review.

5. A. Presenda, M. D. Salvador, J. Vleugels, R. Moreno, A. Borrell. Influence of Humidity and Hydrothermal Degradation on Fretting Wear of Zirconia Dental Materials. Tribol. Int. In submission. 


\section{PARTICIPATION IN CONFERENCES}

1. R. Benavente, A. Borrell, M. D. Salvador, A. Presenda, F. L. Peñaranda. S. García. Sinterización de Cerámicas Oxídicas Mediante Técnicas No Convencionales de Microondas. Oral presentation. LIII Congreso de la Sociedad Española de Cerámica y Vidrio. Alcora, Spain. October 23 - 25, 2013.

2. A. Presenda, M. D. Salvador, F. Peñaranda-Foix, J. M. Catalá, A. Borrell. Mechanical Characterization of Conventional and Non-conventional Sintering Methods of Commercial and Lab-Synthesized Y-TZP Zirconia for Dental Applications. Poster presentation. $13^{\text {th }}$ International Ceramics Congress. CIMTEC 2014. Montecatini Terme, Italy. June 8-13, 2014.

3. A. Presenda. M. D. Salvador, A. Borrell. Materiales Cerámicos Avanzados con Aplicaciones Odontológicas Sinterizados por Microondas. Poster presentation. I Encuentro Estudiantes de Doctorado de la UPV. Valencia, Spain. June 12, 2014.

4. A. Presenda, E. Rayón, M. D. Salvador, F. L. Peñaranda-Foix, A. Borrell. Fabricación de Materiales de Matriz Circona para Aplicaciones Dentales por el Método Noconvencional de Microondas. Oral presentation. XIII Congreso Nacional de Materiales. Barcelona, Spain. June 18 - 20, 2014.

5. A. Presenda, M.D. Salvador, A. Borrell. Effect of Microwave Sintering on Y-TZP Materials used in Dentistry. Oral presentation. $8^{\text {th }}$ EEIGM International Conference on Advanced Materials Research. Valencia, Spain. June 11-12, 2015.

6. A. Presenda, M. D. Salvador, P. J. Plaza-Gonzalez, E. Pallone, J. Ferreira, A. Borrell. Effect of Microwave Sintering on Hydrothermal Degradation of ZirconiaToughened-Alumina (ZTA) Composites. Oral presentation. $14^{\text {th }}$ International Conference European Ceramic Society. Toledo, Spain. June 21 - 25, 2015.

7. A. Presenda. M. D. Salvador, A. Borrell. Materiales Cerámicos Avanzados con Aplicaciones Odontológicas Sinterizados por Microondas. Oral presentation. II Encuentro Estudiantes de Doctorado de la UPV. Valencia, Spain. June 25, 2015.

8. A. Presenda, M. D. Salvador, F. L. Penaranda-Foix, J. M Catalá-Civera, E. Pallone, J. Ferreira, A. Borrell. Aging Resistance of Zirconia-based Composites Sintered by Microwave Technology. Oral Presentation. $15^{\text {th }}$ International Conference on Microwave and High Frequency Heating AMPERE 2015. Krakow, Poland. September $14-17,2015$. 
9. A. Presenda, M. D. Salvador, R. Moreno, J. Vleugels, A. Borrell. Influence of Sintering Conditions on Fretting Fatigue of Y-TZP Dental Materials. Oral presentation. Biobone Symposium. Santiago de Compostela, Spain. October 13 $-15,2015$.

10. A. Presenda, M. D. Salvador, A. Borrell. Low Temperature Degradation of Zirconia Materials Sintered via Microwave Heating Technology. Oral presentation. $11^{\text {th }}$ Conference for Young Scientists in Ceramics. Novi Sad, Serbia. October 21 - 24, 2015.

11. A. Borrell, M. D. Salvador, A. Presenda, J. C. Fariñas, R. Moreno. Nuevas Alternativas en Tecnologías Rápidas de Microondas. Oral presentation. XIV Congreso Nacional de Materiales. Gijón, Spain. June 8-10, 2016.

12. A. Borrell, A. Presenda, M. D. Salvador, F. L. Peñaranda. Effect of Microwave Mechanism to Frabricate Efficient Bioceramic Components. Oral presentation. $3^{\text {rd }}$ Global Congress on Microwave Energy Applications. Cartagena, Spain. 25 - 29 June 2016. 



\section{TABLE OF CONTENTS}

ACKNOWLEDGEMENTS I

ABSTRACT III

RESUMEN

RESUM VII

PUBLICATIONS IX

PARTICIPATION IN CONFERENCES $\mathrm{X}$

LIST OF FIGURES XIX

LIST OF TABLES XXV

CHAPTER 1: MOTIVATION, OBJECTIVES AND THESIS 1 STRUCTURE

1.1 MOTIVATION 3

1.2 OVERALL OBJECTIVES 5

1.3 STRUCTURE OF THESIS 6

REFERENCES

CHAPTER 2: STATE OF THE ART - ZIRCONIA MATERIALS 10

2.1 PROPERTIES OF ZIRCONIA 12

2.1.1 ZIRCONIA PHASES 12

2.1.2 Y-TZP CERAMICS 15

2.1.3 ZIRCONIA-BASED MATERIALS IN DENTISTRY 19

2.2 LOW-TEMPERATURE HYDROTHERMAL DEGRADATION IN 20 ZIRCONIA

2.2.1 MAIN FACTORS INFLUENCING DEGRADATION 21

2.2.2 HYDROTHERMAL DEGRADATION KINETICS 24 
2.2.3 EFFECT OF WATER ON HYDROTHERMAL

DEGRADATION

2.3 TRIBOLOGICAL BEHAVIOR OF ZIRCONIA CERAMICS FOR 30 DENTAL APPLICATIONS

2.3.1 FRETTING WEAR 30

REFERENCES

CHAPTER 3: STATE OF THE ART - MICROWAVE SINTERING

43

3.1 SOLID-STATE SINTERING FUNDAMENTALS

3.2 CONVENTIONAL SINTERING 51

3.3 MICROWAVE SINTERING 52

3.3.1 MICROWAVE HEATING FUNDAMENTALS 54

3.3.2 THEORETICAL APSECTS IN DIELECTRIC HEATING 57

3.3.3 MICROWAVE SYSTEMS FOR HEATING 60

3.3.4 MICROWAVE HYBRID HEATING: BIDIRECTIONAL 63 HEATING

3.3.5 MICROWAVE SINTERING OF ZIRCONIA 65

REFERENCES 66

CHAPTER 4: MICROWAVE AND CONVENTIONAL SINTERING 73 OF ZIRCONIA MATERIALS

4.1 INTRODUCTION 75

4.2 OBJECTIVES 77

4.3 MATERIALS AND METHODS 77

4.3.1 MATERIALS

4.3.2 CONVENTIONAL AND MICROWAVE SINTERING 78

4.3.3 MATERIAL CHARACTERIZATION 83

4.4 RESULTS AND DISCUSSION 95

4.4.1 SINTERING CONDITIONS 95

4.4.2 PHASE DETERMINATION OF STARTING MATERIAL 96 
$\begin{array}{lll}\text { 4.4.3 DENSIFICATION UPON SINTERING } & 97\end{array}$

4.4.4 MICROSTRUCTURE AND GRAIN SIZE 99

4.4.5 MICROINDENTATION MECHANICAL PROPERTIES 103

4.4.4 NANOINDENTATION MECHANICAL PROPERTIES 106

$\begin{array}{lll}4.5 & \text { CONCLUSIONS } & 108\end{array}$

$\begin{array}{ll}\text { REFERENCES } & 110\end{array}$

CHAPTER 5: MICROWAVE SINTERING AND HYDROTHERMAL 115 DEGRADATION OF $\mathrm{ZRO}_{2}$

5.1 INTRODUCTION

5.2 OBJECTIVES

$\begin{array}{lll}5.3 & 119\end{array}$

$\begin{array}{lll}\text { 5.3.1 MATERIALS } & 119\end{array}$

5.3.2 SIMULATED DEGRADATION CONDITIONS 120

$\begin{array}{lll}\text { 5.3.3 SPECTROSCOPIC TECHNIQUES } & 121\end{array}$

$\begin{array}{lll}\text { 5.3.4 MICROSCOPY TECHNIQUES } & 124\end{array}$

5.3.5 EVALUATION OF MECHANICAL PROPERTIES 128

$\begin{array}{lll}5.4 & \text { RESULTS AND DISCUSSION } & 128\end{array}$

$\begin{array}{lll}\text { 5.4.1 PHASE COMPOSITION } & 128\end{array}$

5.4.2 TOPOGRAPHY AND SURFACE ROUGHENING 133

5.4.3 MICROSTRUCTURE AND PENETRATION DEPTH 135

5.4.4 EFFECT ON MECHANICAL PROPERTIES 138

5.4.5 INFLUENCE OF MICROWAVE SINTERING ON 140 RESISTANCE TO DEGRADATION

5.4.6 SUB-SUPERFICIAL CRACK PROPAGATION IN DEGRADED 142 Y-TZP DENTAL CERAMICS

$\begin{array}{lll}5.5 & \text { CONCLUSIONS } & 146\end{array}$

$\begin{array}{ll}\text { REFERENCES } & 148\end{array}$ 


\section{$\mathrm{ZRO}_{2}$ MATERIALS}

6.1 INTRODUCTION 153

6.2 OBJECTIVES 155

6.3 MATERIALS AND METHODS 156

$\begin{array}{lll}\text { 6.3.1 MATERIALS } & 156\end{array}$

$\begin{array}{lll}\text { 6.3.2 } & \text { FRETTING TESTS SETUP } & 156\end{array}$

$\begin{array}{ll}\text { 6.3.3 WEAR TRACK CHARACTERIZATION } & 157\end{array}$

6.4 RESULTS AND DISCUSSION 163

6.4.1 Y-TZP CERAMICS DENSIFICATION AND MECHANICAL 163 PROPERTIES UPON SINTERING

6.4.2 WEAR BEHAVIOR UNDER FRETTING CONDITIONS AT 164 AMBIENT RELATIVE HUMIDITY

6.4.3 INFLUENCE OF HUMIDITY ON FRETIING WEAR BEHAVIOR

6.4.4 EFFECT OF LTD ON RESISTANCE TO FRETTING WEAR 177

6.5 CONCLUSIONS 183

$\begin{array}{ll}\text { REFERENCES } & 186\end{array}$

CHAPTER 7: CONCLUSIONS AND FUTURE WORK 190

$\begin{array}{lll}7.1 & \text { CONCLUSIONS } & 192\end{array}$

$\begin{array}{lll}7.2 & \text { FUTURE WORK } & 194\end{array}$ 




\section{LIST OF FIGURES}

\section{Chapter 1:}

Figure 1.1 Comparative diagram with the elements of a natural tooth and their respective artificial replacements.

Figure 1.2 Classification of sintering techniques for advanced ceramics by conventional and non-conventional methods.

Figure 1.3 Stages of the research work with the corresponding elements addressed in each one.

\section{Chapter 2:}

Figure 2.1 Lattice configurations of zirconia polymorphs: a) monoclinic, b) tetragonal, and c) cubic.

Figure 2.2 Phase diagram of $\mathrm{Y}_{2} \mathrm{O}_{3}-\mathrm{ZrO}_{2}$ system.

Figure 2.3 Transformation toughening mechanism representation in $t$-zirconia responsible for increasing the fracture toughness of this material.

Figure 2.4 Zirconia tooth-shaped restorations with three different color shades after doping with other elements.

Figure 2.5 Y-TZP zirconia microstructure representation showing $t$-phase grains with lower stabilizer content $\left(t^{*}\right)$ surrounding the yttria-rich $c$-phase grain. Grains with lower $\mathrm{Y}_{2} \mathrm{O}_{3}$ content are more vulnerable to LTD.

Figure 2.6 Hydrothermal degradation kinetics showing experimental data from tests carried at $134^{\circ} \mathrm{C}$ in water vapor and the curve resulting from the Johnson-Mehl-Avrami model.

Figure 2.7 Hydrothermal degradation mechanism proposed by Chevalier et al. a) Unstable surface grains transform and expand. b) Neighboring grains are destabilize and surface uplift occurs. c) Water penetrates into the bulk generating microcracking.

Figure 2.8 Diagram of the reaction sequence between water molecules and zirconia on the surface proposed by Sato and Shimada.

Figure 2.9 LTD mechanism of Y-TZP materials proposed by Yoshimura. a) Water adsorbs the surface of the material. b) A chemical reaction results in the formation of $\mathrm{Zr}-\mathrm{OH}$ bonds and a stress is generated due to the location of a vacancy. c) The $\mathrm{OH}^{-}$ion migrates inwards occupying the vacancy. d) A nucleation zone forms around this vulnerable region.

Figure 2.10 Fretting modes schematic illustration for a ball-on-plate setup: a) I. Linear mode, b) II. Radial mode, and c) III. Circumferential mode. 
Figure 2.11 Surface contact models under normal load and tangential force. a) Elastic model and b) Elastic-plastic model.

Figure 2.12 Wear rate variation for the three main fretting regimes with increasing oscillation amplitude.

\section{Chapter 3:}

Figure $3.1 \quad$ Two particle grain boundary diagram showing the six mass transport mechanisms involved in sintering of polycrystalline materials: 1) surface diffusion, 2) lattice diffusion, 3) vapor transport, 4) grain boundary diffusion, 5) lattice diffusion from the grain boundary, and 6) plastic flow.

Figure 3.2 Evolution of particles during the three sintering stages: a) initial stage, b) intermediate stage, and c) final stage.

Figure 3.3 Grain growth versus relative density evolution for three different scenarios: grain growth with no densification (curve $x$ ), grain growth with simultaneous densification (curve y), and densification followed by grain growth (curve z).

Figure 3.4 Schematic diagram of electrical induction tube furnace used for conventional sintering with controlled atmosphere.

Figure 3.5 Electromagnetic spectrum diagram highlighting the region encompassed by microwaves.

Figure 3.6 Material/microwave interaction representation classified according to their behavior: a) transparent, b) opaque, and c) absorbent.

Figure 3.7 Relationship between factor loss and absorbed power at a frequency of $2.45 \mathrm{GHz}$ and room temperature for some common materials.

Figure 3.8 Position of the molecules a) in its natural state, and b) with the application of an external electric field.

Figure 3.9 Representation of the reorientation of the molecules in the presence of an alternating electric field, such as that induced by microwaves.

Figure 3.10 Magnetron schematic showing all the elements required for generation of microwave radiation.

Figure 3.11 Sequence diagram of microwave hybrid heating for material 65 sintering: a) before exposure to microwave radiation, b) susceptor heating under $\mathrm{MW}$ radiation, and c) specimen to be sintered able to absorb MW energy giving place to bidirectional hybrid heating. 


\section{Chapter 4:}

Figure 4.1 Experimental MW system employed in the sintering of Y-TZP materials and its main components.

Figure 4.2 Schematic of a microwave system with rectangular cavity that has been employed for sample sintering.

Figure 4.3 Rectangular cavity diagram of the microwave oven employed for sintering of zirconia materials: a) outside view and b) cross-section view indicating sample location.

Figure 4.4 Optris CT Laser 2 MH $\quad$ CF2 pyrometer characteristics and measurement span.

Figure 4.5 Set up for pyrometer calibration with aid of oven thermocouples.

Figure 4.6 X-ray beam interaction with atoms in a solid at incident angle $\theta$.

Figure 4.7 Different types of pores within a solid material. (a: enclosed or totally isolated pores; $b, c, d$, e and $f$ : open pores connected to the surface; $b$ and $f$ : connected only on one side; e: channeled porosity connected at both sides; g: usually roughness, but can be regarded as porosity when the depth of the irregularities is greater than the width).

Figure 4.8 Load scale for the different types of indentation testing techniques.

Figure 4.9 Vickers microindentation test: a) during indentation and b) resulting diagonals after removing load.

Figure 4.10 Method for determining $K_{I C}$ by microindentation: a) optical microscope image of indentation imprint with crack propagation in the corners and b) FE-SEM image of the crack in 3Y-TZP material.

Figure 4.11 Diagram indicating the crack length parameters required for determining $\mathrm{KIC}$ by the microindentation method.

Figure 4.12 Schematic of the two type of cracks and sub-superficial morphologies that can be induced in materials with microindentation: a) semielliptical and b) Palmqvist.

Figure 4.13 a) Main parameters of a nanoindentation test during loading and unloading. b) Typical Load-displacement curve obtained from a nanoindentation curve.

Figure 4.14 Schematic of the main elements in a nanoindenter.

Figure 4.15 Load cycle for nanoindentation testing showing the influence of unwanted thermal drift.

Figure 4.16 Schematic of SEM system highlighting main components

Figure 4.17 Processing time comparison at $1300{ }^{\circ} \mathrm{C}$ between $\mathrm{MW}$ and $\mathrm{CS}$ of zirconia materials. 
Figure 4.18 Diffractograms of the zirconia materials studied in this work as received before sintering with corresponding peak labels for phase identification.

Figure 4.19 Relative density values for LAVA, VITA and LAB materials sintered via MW and CS.

Figure 4.20 FE-SEM micrographs revealing the granular microstructure of LAVA zirconia material sintered via $\mathrm{MW}$ and CS methods at various temperatures: $\mathrm{MW}$ sintering for $10 \mathrm{~min}$ at a) $1200{ }^{\circ} \mathrm{C}$ and b) 1300 ${ }^{\circ} \mathrm{C}$; CS for $2 \mathrm{~h}$ at c) $1300^{\circ} \mathrm{C}$ and d) $1400{ }^{\circ} \mathrm{C}$.

Figure 4.21 FE-SEM micrographs revealing the granular microstructure of VITA zirconia material sintered via $\mathrm{MW}$ and CS methods at two temperatures: $\mathrm{MW}$ sintering for $10 \mathrm{~min}$ at a) $1200{ }^{\circ} \mathrm{C}$ and b) 1300 ${ }^{\circ} \mathrm{C}$; CS for $2 \mathrm{~h}$ at c) $1300^{\circ} \mathrm{C}$ and d) $1400{ }^{\circ} \mathrm{C}$.

Figure 4.22 FE-SEM micrographs revealing the granular microstructure of LAB zirconia material sintered via $\mathrm{MW}$ and CS methods at two temperatures: $\mathrm{MW}$ sintering for $10 \mathrm{~min}$ at a) $1200{ }^{\circ} \mathrm{C}$ and b) 1300 ${ }^{\circ} \mathrm{C}$; CS for $2 \mathrm{~h}$ at c) $1300^{\circ} \mathrm{C}$ and d) $1400{ }^{\circ} \mathrm{C}$.

Figure 4.23 Vickers hardness values for LAVA, VITA and LAB materials sintered via MW and CS.

Figure 4.24 Fracture toughness values for LAVA, VITA and LAB materials sintered via MW and CS.

\section{Chapter 5:}

Figure 5.1 Autoclave diagram for performing accelerated LTD tests on Y-TZP zirconia samples.

Figure 5.2 Raman spectrometer schematic showing main components, as well as scattered light beams from interaction with the sample.

Figure 5.3 AFM setup for sample imaging, including its main components.

Figure 5.4 Schematic showing the dual beam column configuration of a FIB

Figure 5.5 Raman spectra for several LTD exposure times for LAVA material sintered via a) microwave sintering and b) conventional sintering.

Figure 5.6 Raman spectra for several LTD exposure times for LAB material sintered via a) microwave sintering and b) conventional sintering.

Figure 5.7 Monoclinic phase volume content, $V_{m}$, as a function of hydrothermal degradation exposure time for materials under both sintering conditions.

Figure 5.8 Topographical AFM images of LAB material specimens at several LTD exposure times for MW: a) $0 \mathrm{~h}$, c) $40 \mathrm{~h}$, and e) $140 \mathrm{~h}$; and CS b) $0 \mathrm{~h}, 40 \mathrm{~h}$ and $140 \mathrm{~h}$. 
Figure 5.9 Mean surface roughness at various hydrothermal degradation exposure times for all specimens.

Figure 5.10 Nomarski microscopy images of the surface of Y-TZP materials for: MW LAVA at a) $0 \mathrm{~h}$ and b) $140 \mathrm{~h}$ of LTD; CS LAVA at c) $0 \mathrm{~h}$ and d) 140 $\mathrm{h}$ of LTD; MW LAB at e) $0 \mathrm{~h}$ and f) $140 \mathrm{~h}$ of LTD; and CS LAB at g) $0 \mathrm{~h}$ and $h) 140 \mathrm{~h}$ of LTD.

Figure 5.11 FE-SEM micrographs of the degraded cross-section profiles after 140 of LTD for a) MW LAVA, b) CS LAVA, c) MW LAB, and d) CS LAB.

Figure 5.12 Young's modulus and hardness values for all specimens as a function of LTD exposure time.

Figure 5.13 Young's modulus as a function of indenter penetration depth profile for a) MW LAB and b) CS LAB at several LTD exposure times.

Figure 5.14 FE-SEM micrograph of the imprint on the affected zone of the degraded material.

Figure 5.15 FE-SEM micrographs of the trenches created with FIB technology on microindentation imprints for a) degraded and b) non-degraded material.

Figure 5.16 FE-SEM micrographs of sub-superficial crack propagation in nondegraded and degraded material.

\section{Chapter 6:}

Figure 6.1 Fretting wear setup and conditions.

Figure 6.2 a) CLSM schematic showing the path of laser. b) Pinholes allow for selectivity of focal planes for acquisition of a sharp image by eliminating out-of-focus planes and, after taking several images at different focus levels, a 3-D representation can be generated.

Figure 6.3 White light interferometry schematic showing beam slitting and recombination, as well as the main components of the apparatus.

Figure 6.4 Schematic of different views of fretting wear setup for a ball-onplate configuration used to determine geometrical parameters for wear volume calculation. a) and b) correspond to parallel and perpendicular cross-section views to the sliding direction, respectively, and c) is a top view of the wear track.

Figure 6.5 Fretting hysteresis loops of the $11^{\text {th }}$ and $20,000^{\text {th }}$ cycle for LAB material sintered by $\mathrm{MW}$ heating revealing that both regimes, partial slip and gross slip, occur at the selected wear conditions.

Figure 6.6 COF determined for all specimens during tangential fretting tests.

Figure 6.7 Profilometry images of a) LVMW and c) LVCS14 with measurements of radius at two different points and Nomarski interference contrast micrographs for b) LVMW and d) LVCS14. 
Figure 6.8 Wear volume for LAVA and LAB specimens sintered under different conditions.

Figure 6.9 Fretting wear regimes given by amplitude and wear rate of all 169 specimens at $200 \mu \mathrm{m}$ of fretting amplitude.

Figure 6.10 Confocal microscopy images of wear pits for a) LVMW, b) LABMW, c) LVCS13, d) LABCS13, e) LVCS14 and f) LABCS14 showing delamination and microcracking.

Figure 6.11 Wear pit characterization of LVCS13, specimen with lowest fretting wear rate, showing a) white light interferometry profile and b) confocal micrograph.

Figure 6.12 Plot of the average grain size and fracture toughness against wear volume loss for the studied Y-TZP materials under different sintering conditions.

Figure 6.13 COF comparison between wet and dry specimens for LAVA and LAB materials sintered under two different temperatures.

Figure 6.14 Wear track profilometric model and Nomarski interference contrast micrographs for $\angle A B$ sintered at $1300{ }^{\circ} \mathrm{C}$ ( $a$ and $b$, respectively) and LAVA (c and $d$, respectively) and LAB (e and $f$, respectively) sintered at $1400^{\circ} \mathrm{C}$.

Figure 6.15 Micrographs of wear scars on zirconia balls employed as counter material for a) dry and b) wet conditions corresponding to fretting tests on LAB material sintered at $1400{ }^{\circ} \mathrm{C}$.

Figure 6.16 Wear volume determined for LAB and LAVA material sintered conventionally at two different temperatures under wet and dry conditions.

Figure 6.17 Raman spectrograms of LAVA and LAB material sintered at a) 1300 ${ }^{\circ} \mathrm{C}$ and b) $1400{ }^{\circ} \mathrm{C}$ before and after exposure to LTD.

Figure 6.18 Surface micrographs of LAVA and LAB sintered at $1300{ }^{\circ} \mathrm{C}(\mathrm{a}, \mathrm{b}, \mathrm{e}$, and $\mathrm{f}$, respectively) and $1400^{\circ} \mathrm{C}(\mathrm{c}, \mathrm{d}, \mathrm{g}$ and $\mathrm{h}$ ) before and after $25 \mathrm{~h}$ of LTD exposure.

Figure 6.19 COF for LAVA and LAB material sintered conventionally at two different temperatures before and after $25 \mathrm{~h}$ of exposure to accelerated LTD conditions.

Figure 6.20 Wear volume for LAVA and LAB material sintered conventionally at two different temperatures before and after $25 \mathrm{~h}$ of exposure to accelerated LTD conditions.

Figure 6.21 Wear track profilometric model and Nomarski interference contrast micrographs of degraded LAVA sintered at $1400{ }^{\circ} \mathrm{C}$ (a and $b$, respectively) and $L A B$ sintered at $1400{ }^{\circ} \mathrm{C}$ (c and d, respectively).

Figure 6.22 Confocal microscopy images of the wear tracks on LAVA (a) and LAB

(b) sintered at $1400^{\circ} \mathrm{C}$ after $25 \mathrm{~h}$ of LTD exposure. 


\section{LIST OF TABLES}

\section{Chapter 2:}

$\begin{array}{lll}\text { Table } 2.1 & \text { Lattice constants for zirconia polymorphs. }\end{array}$

Table 2.2 Physical and mechanical properties of $m-\mathrm{ZrO}_{2}, \mathrm{Mg}$-PSZ and 3Y-TZP. 16

$\begin{array}{lll}\text { Table 2.3 Dental zirconia manufacturers and product name. } & 20\end{array}$

Table 2.4 Basic fretting regimes, their characteristics, and corresponding 34 loops.

\section{Chapter 3:}

Table 3.1 Variables that affect sintering and microstructure.

\section{Chapter 4:}

Table 4.1 Y-TZP materials considered for MW and CS sintering, their corresponding main characteristics, and relevant manufacturer's specifications.

Table 4.2 Emissivity values in temperature range $1100-1400{ }^{\circ} \mathrm{C}$ for 3 Y-TZP zirconia.

Table 4.3 X-ray diffraction $2 \theta$ angles for $\mathrm{m}$ - and t-phases in zirconia for the 96 range $20^{\circ}<2 \theta<80^{\circ}$.

Table 4.4 Average grain size results for all zirconia materials under various conditions.

Table 4.5 $\quad H_{v}$ and $K_{I C}$ values of 3Y-TZP ceramics from different authors and those determined in the present study.

Table 4.6 $H_{\text {nano }}$ and $\mathrm{E}$ values of 3Y-TZP ceramics determined by the nanoindentation technique.

\section{Chapter 5:}

Table 5.1 X-ray diffraction Rietveld refinement results for determining phase weight percent of LAVA and LAB materials before and after microwave and conventional sintering and after $200 \mathrm{~h}$ LTD.

\section{Chapter 6:}

Table 6.1 Summary of physical and mechanical properties determined in Chapter 4 for LAVA and LAB materials after microwave and conventional sintering.

Table 6.2 Physical and mechanical properties of counter material balls used for fretting tests 



\section{CHAPTER 1: MOTIVATION, OBJECTIVES AND THESIS STRUCTURE}



This chapter establishes the basis and justification for carrying out this research work, its objectives, as well as the approaches taken to achieve them. The need and motivation is presented first by describing the importance of zirconia as an advanced ceramic material for dental applications. The reasons and advantages for employing a novel, non-conventional material processing technology, such as microwave sintering, are also given. The following section presents the main objectives of this study. And, finally, the structure of this thesis and stages of the investigation are presented to provide a structured pathway to achieve the objectives.

\subsection{MOTIVATION}

In the last decades, advanced ceramic materials have become widely applied in different technological fields due to their outstanding performance while in service as structural and functional elements. Particularly, in the field of biomaterials engineering, bioceramics have been developed as an alternative to traditionally applied materials, such as metals and polymers, in order to provide the necessary characteristics to replace biological structures within the human body. This relatively new group of ceramic materials adequately meets several requirements that are crucial for biological applications in terms of biocompatibility. One of the most important applications of bioceramics is found in restorative dentistry as prostheses and implants [1]. Implants are the fixing elements that attach dental structures to the gums, whereas, prostheses are direct replacements of teeth or parts of teeth that are necessary to maintain proper oral function (Figure 1.1). In this regard, the material must cover certain criteria in terms of mechanical, aesthetic and chemical properties. Some of the most common bioceramics are alumina, zirconia, tricalcium phosphate and hydroxyapatite.

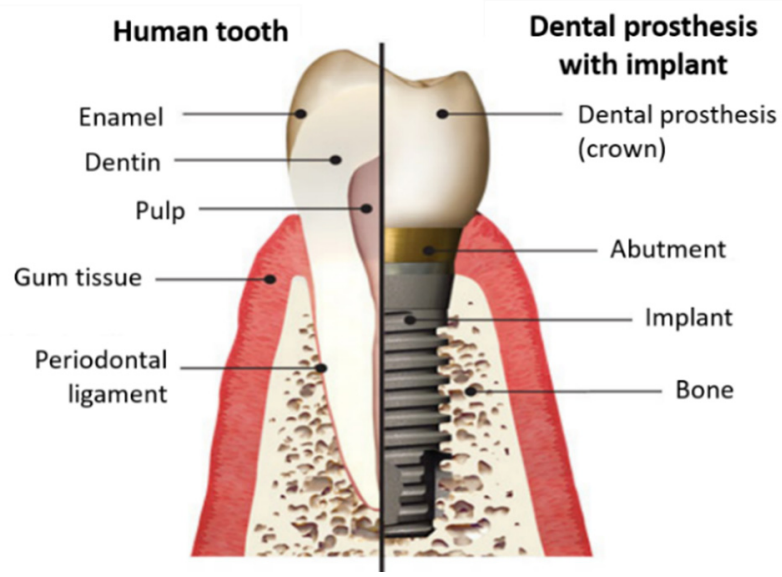

Figure 1.1 Comparative diagram with the elements of a natural tooth and their respective artificial replacements. 
Zirconium dioxide $\left(\mathrm{ZrO}_{2}\right)$, commonly known as zirconia, is a bioceramic that is extensively employed in the odontological field due to its null chemical interaction with human tissue, superb mechanical properties, ability to withstand humid and corrosive environments, relatively good wear behavior, and appealing aesthetic features. Therefore, zirconia has found an important market niche in restorative dentistry as a consequence of the quality of the resulting implant or prostheses. Companies such as $3 \mathrm{M}$, Nobel Biocare and Vita Zahnfabrik are currently commercializing zirconia materials for dental applications and are constantly looking for new ways to improve their materials. Nonetheless, zirconia also presents challenges of its own that need to be addressed in order to optimize its performance.

The dental materials industry currently represents over 1 billion USD in the U.S. alone and demand is only set to increase for the majority of the segments in this market. The segment exhibiting the fastest growth is direct restorative dentistry, which includes dental prostheses and implants. This particular field also has the biggest impact in costs to the patient. Therefore, optimizing processing techniques in restorative dental materials can play a critical role in the potential of this market.

Processing of ceramic materials has also a strong impact in the quality of the consolidated body, as it plays a key role in the resulting microstructure and, as a consequence, in its final properties. Advanced ceramic materials, such as zirconia, are commonly processed as powders and densified via a high temperature process. Traditional processing techniques include hot isostatic pressing, mold casting and sintering in conventional ovens. As ceramics require very high processing temperatures compared to metals and polymers, these processes tend to be very energy intensive and result in higher production costs to the manufacturers.

Therefore, new technologies known as non-conventional sintering techniques are being developed in order to reduce energy consumption, while maintaining or even improving the characteristics of the resulting ceramic material. These include FieldAssisted Sintering Techniques (FAST), such as Spark Plasma Sintering (SPS) and flash sintering, microwave sintering, reaction sintering and laser sintering (Figure 1.2). These novel and innovative technologies aim at helping industrial sectors lower their production costs and, at the same time, lessen their environmental impact by cutting down the amount of greenhouse gas (GHG) emissions released into the atmosphere, which also serves to comply with European Union directives that have planned to reduce GHG emissions by at least $20 \%$ compared to 1990 levels by 2020 [2].

Particularly, due to the intrinsic dielectric properties of zirconia, microwave sintering represents an interesting opportunity at consolidating zirconia powders with a reduced processing time and energy consumption by utilizing electromagnetic radiation to provide high-enough temperatures that allow full densification of the 
material. The most important advantages of microwave sintering against conventional sintering methods are listed below [3-7]:

- Shorter sintering time and lower energy consumption.

- Higher heating rates can be used.

- Materials with a finer (nanometric) microstructure with a high degree of densification and enhanced mechanical properties may be obtained due to the densification mechanisms involved.

- Flexible due to the possibility of processing near-net-shape materials.

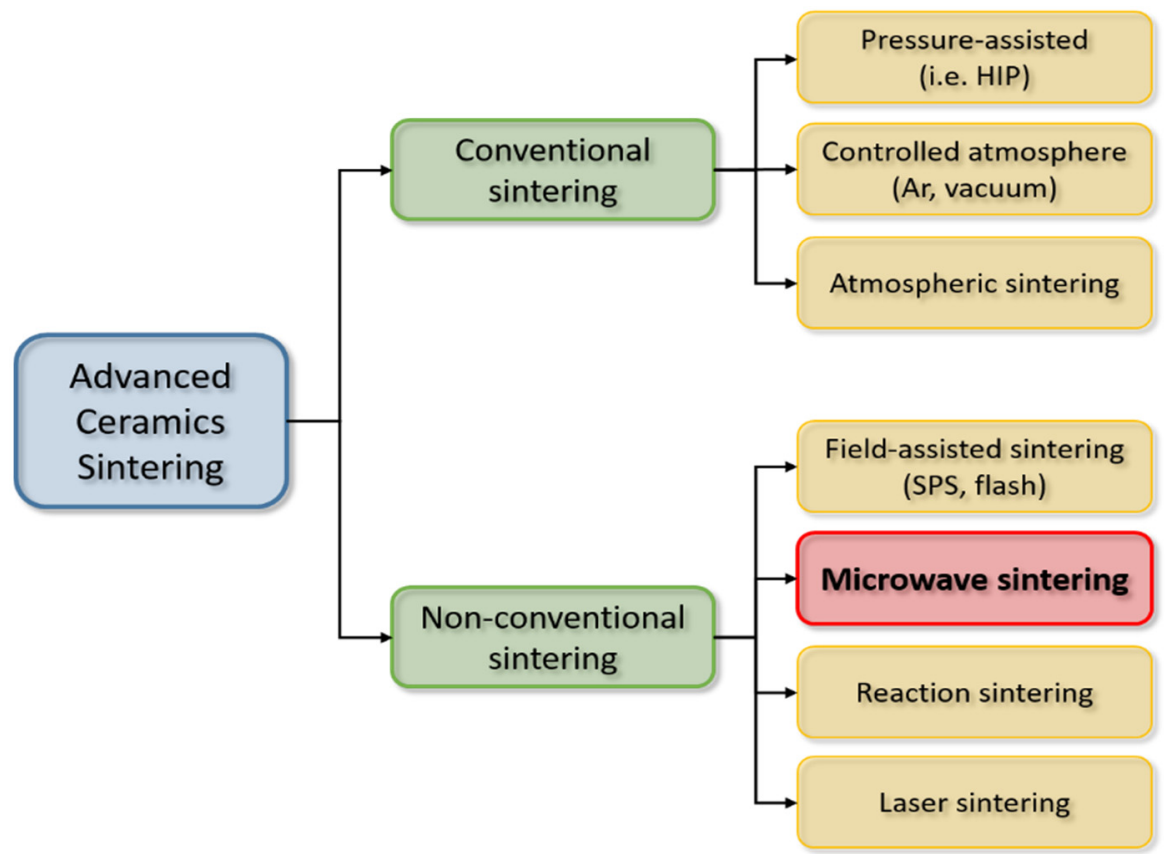

Figure 1.2 Classification of sintering techniques for advanced ceramics by conventional and nonconventional methods.

\subsection{OVERALL OBJECTIVES}

The work presented in this thesis is justified as a means to explore the viability of microwave sintering for consolidation of advanced zirconia-based materials and study important effects for dental applications. Therefore, the three main objectives of this thesis are summarized as follows:

1. Consolidation of zirconia-based materials via microwave sintering and a comparative study with their conventionally sintered counterparts, so as to determine whether the resulting materials comply with the mechanical requirements for dental applications. 
2. Study of the effect of microwave sintering in low-temperature hydrothermal degradation of zirconia materials, which is highly relevant due to the humidity these materials are exposed to in the mouth, by increasing exposure time and determining phase transformation vulnerability, microstructure and topographical changes, as well as deterioration of mechanical properties.

3. Evaluation of the tribological behavior under reciprocating fretting conditions of materials consolidated via microwave and conventional sintering and analysis of the influence of sintering temperature, humidity, sintering method and resulting microstructure and properties.

A detailed description of the specific objectives, research methods and experimental techniques is given in the corresponding chapter.

\subsection{STRUCTURE OF THESIS}

The structure of this thesis is presented in Figure 1.3 and comprehends three main parts. The first one includes a state of the art review on zirconia-based materials (Chapter 2) and microwave sintering (Chapter 3). Properties of tetragonal stabilized zirconia and microwave-material interaction fundamentals are also discussed.

The second part consists on the research work that has been carried out and has been divided in three main stages, following the objectives stated in the previous section. The first stage corresponds to a comparative study between zirconia materials sintered by conventional methods and microwave heating technology (Chapter 4). The phase composition of the starting zirconia materials is determined first, followed by a thorough characterization of the resulting materials, which consists in evaluating the degree of densification and a quantification of the mechanical properties of the consolidated material at the sintering conditions that have been selected for each method in order to determine if the obtained microwave-sintered zirconia materials comply with the mechanical requirements for applications in dentistry. The second stage consists of a hydrothermal degradation study of the previously sintered materials to determine the effects of microwave sintering in this spontaneous ageing process that occurs in zirconia and is very important in dentistry due to the constant exposure to humid environments (Chapter 5). The third stage addresses the wear behavior under fretting fatigue conditions of zirconia materials sintered conventionally and via microwave heating under different humidity conditions that aims at simulating the wear that would occur under service conditions (Chapter 6). 
The third part presents the main conclusions obtained from the results in the research work, as well as an outlook into future investigations deriving from this study (Chapter 7).

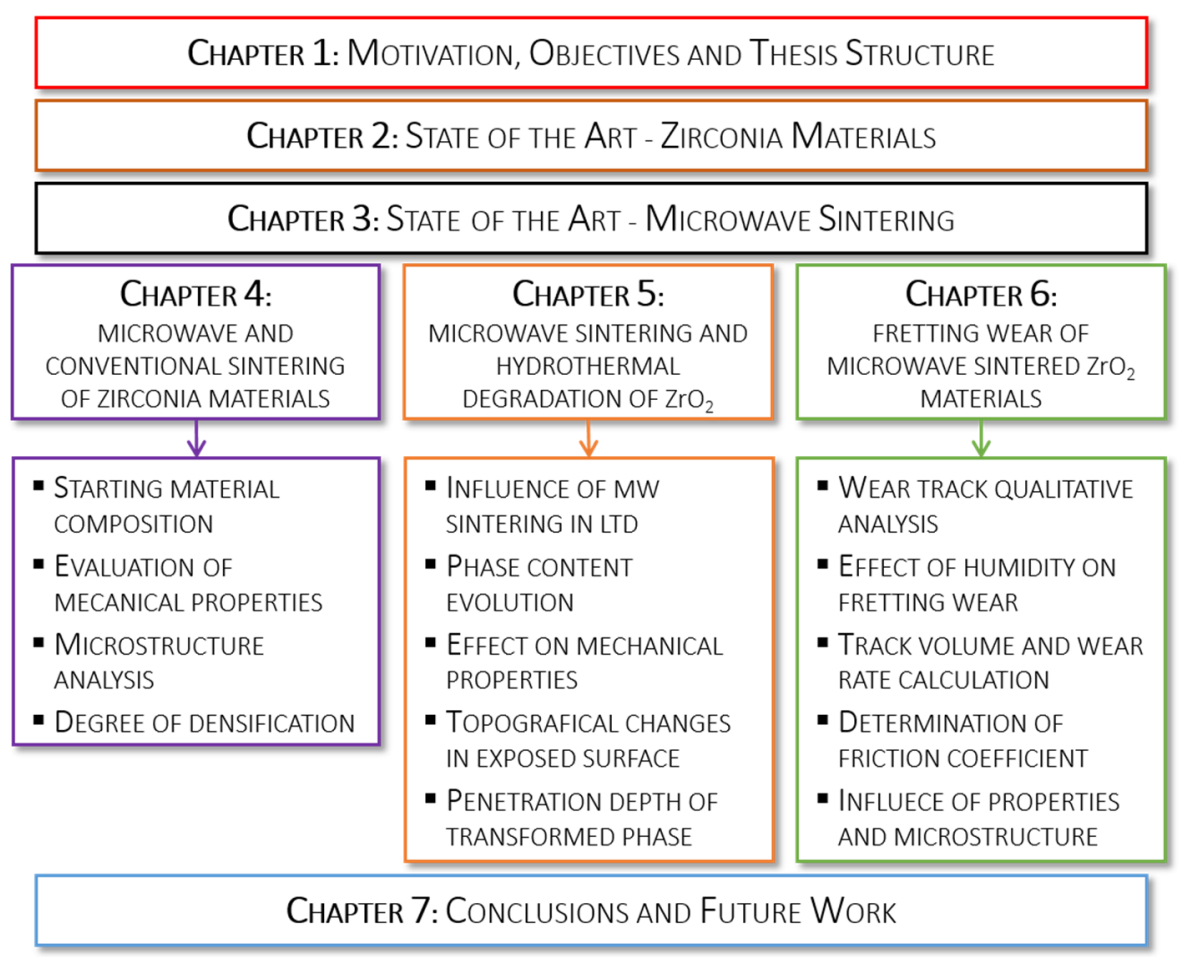

Figure 1.3 Stages of the research work with the corresponding elements addressed in each one. 


\section{REFERENCES}

[1] Hench LL, Best SM. Ceramics, Glasses, and Glass-Ceramics: Basic Principles. In: Ratner BD, Hoffman AS, J.Schoen F, Lemons JE, editors. Biomaterials Science (Third Ed.). Academic Press; 2013, p. 128-51.

[2] EUROPE 2020: A strategy for smart, sustainable and inclusive growth. Brussels: European Commission; 2010.

[3] Oghbaei M, Mirzaee O. Microwave versus conventional sintering: A review of fundamentals, advantages and applications. J Alloys Compd 2010;494:17589.

[4] Upadhyaya A, Tiwari SK, Mishra P. Microwave sintering of W-Ni-Fe alloy. Scr Mater 2007;56:5-8.

[5] Gupta M, Wong WLE. Enhancing overall mechanical performance of metallic materials using two-directional microwave assisted rapid sintering. Scr Mater 2005;52:479-83.

[6] Anklekar RM, Agrawal DK, Roy R. Microwave sintering and mechanical properties of PM copper steel. Powder Metall 2001;44:355-62.

[7] Clark DE, Sutton WH. Microwave processing of materials. Annu Rev Mater Sci 1996;26:299-331. 




\section{CHAPTER 2: STATE OF THE ART - ZIRCONIA MATERIALS}



The following chapter describes basic information and some of the important characteristics of zirconia for dental applications. First, a brief introduction to the properties of zirconia is given making reference to its lattice configurations, phase stabilization, transformation toughening mechanism, and the importance of its application in dentistry. This is followed by a general description of the hydrothermal ageing process induced by the presence of water that occurs in zirconia and is responsible for a loss of material quality. Finally, tribological behavior of Y-TZP ceramics is discussed, since replacing dental structures requires exposure to wear conditions.

\subsection{PROPERTIES OF ZIRCONIA}

Zirconia is a white crystalline solid with highly stable ionic bonds that is mainly obtained in powder form for technological applications. Due to its physical and chemical properties, zirconia is classified as a ceramic material and possesses a series of exceptional characteristics, including a relatively high hardness and fracture toughness compared to other ceramic materials, a low friction coefficient and a high melting point. Moreover, it is a relatively unreactive material when exposed to humid and corrosive environments when compared to other materials such as metals and polymers, with a good resistance to high temperatures and abrasion. All these properties position zirconia as a very versatile material with a wide spectrum of applications that encompasses heat exchangers, fuel cells, turbine components for aeronautical systems and electricity generation, as well as medical and dental applications.

\subsubsection{ZIRCONIA PHASES}

Zirconia exhibits polymorphism because its crystallographic structure may change due to external factors. In this sense, pure zirconia at atmospheric pressure can be present in three different phases depending on the temperature [1]:

- Monoclinic $(m)$ phase: stable at room temperature and below $1170{ }^{\circ} \mathrm{C}$; results in a fluorite type lattice (Figure 2.1a).

- Tetragonal $(t)$ phase: stable between 1200 and $2370{ }^{\circ} \mathrm{C}$; also results in a fluorite type lattice (Figure 2.1b).

- Cubic (c) phase: stable at temperatures above $2370{ }^{\circ} \mathrm{C}$ and up to its melting point of $2715^{\circ} \mathrm{C}$; corresponds to a cubic fluorite type lattice (Figure 2.1c).

The $t$ - to $m$-phase lattice transformation corresponds to a martensitic change $[2,3]$ and is characterized by three important factors [4-6]: (1) no diffusion occurs, that is, it only involves changes in the coordinates of the lattice positions; (2) takes place athermally, which means that it does not occur at a specific temperature but within 
a temperature range; and (3) involves a change in shape. Table 2.1 summarizes the lattice constants of all three crystalline configurations.

a)

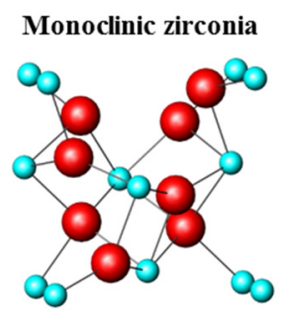

b)

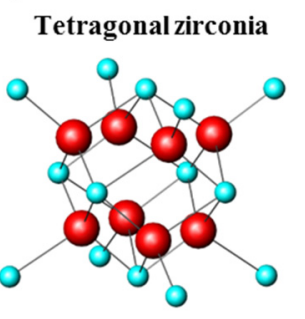

c)

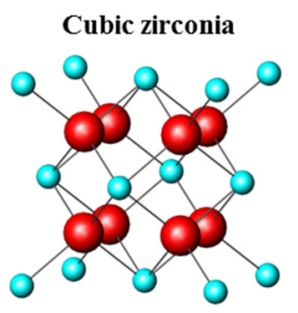

O: ion $\mathbf{Z r}^{4+}$

Figure 2.1 Lattice configurations of zirconia polymorphs: a) monoclinic, b) tetragonal, and c) cubic.

Table 2.1 Lattice constants for zirconia polymorphs.

\begin{tabular}{|c|c|c|c|}
\hline $\begin{array}{c}\mathrm{ZrO}_{2} \text { crystalline } \\
\text { structure }\end{array}$ & $\begin{array}{c}\text { Temperature } \\
\text { range } \\
\left({ }^{\circ} \mathrm{C}\right)\end{array}$ & $\begin{array}{l}\text { Density } \\
\left(\mathrm{g} / \mathrm{cm}^{3}\right)\end{array}$ & Lattice constant \\
\hline Cubic & $2370-2715$ & 5.83 & $\begin{array}{c}\mathrm{a}=5.1289 \AA \\
\mathrm{b}=5.1289 \AA \\
\mathrm{c}=5.1289 \AA \\
\beta=90^{\circ}\end{array}$ \\
\hline Tetragonal & $1170-2370$ & 6.1 & $\begin{array}{c}\mathrm{a}=3.5961 \AA \\
\mathrm{b}=3.5961 \AA \\
\mathrm{c}=5.1758 \AA \\
\beta=90^{\circ}\end{array}$ \\
\hline Monoclinic & 1170 & 6.09 & $\begin{array}{c}\mathrm{a}=5.1459 \AA \\
\mathrm{b}=5.2115 \AA \\
\mathrm{c}=5.3128 \AA \\
\beta=99.22^{\circ}\end{array}$ \\
\hline
\end{tabular}

The properties of zirconia vary depending on the phase in which it is found. With respect to mechanical properties, a significant loss of hardness, fracture toughness, mechanical resistance and Young modulus takes place when changing from cubic or tetragonal phase to monoclinic. Pure zirconia at standard conditions contains only $m$-phase and has a lower quality as a structural material compared to the other phases. For example, fracture toughness decreases significantly from $7 \mathrm{MPa} \cdot \mathrm{m}^{1 / 2}$ in a $t$-phase, $3 \mathrm{~mol} \%$ yttria-stabilized zirconia [7] to $2 \mathrm{MPa} \cdot \mathrm{m}^{1 / 2}$ in pure, $m$-phase zirconia [8]. Additionally, after exposing zirconia to a high temperature process, such 
as sintering, the phase change that occurs from $t$ to $m$ due to cooling of the material is accompanied by a volume change of approximately $4 \%$, which, in turn, generates internal tensions that makes it more vulnerable to fractures and cracks. Hence, it is necessary to add phase stabilizing agents that allow the material to maintain a $c$ - or $t$-configuration at room temperature.

For most applications, several oxides are employed to provide $t$-phase stabilization of zirconia bioceramics. During the first stages of development, several solid solutions were formulated with the aim of stabilizing the $t$-phase of medical grade zirconia, among which the most important were $\mathrm{ZrO}_{2}-\mathrm{MgO}, \mathrm{ZrO}_{2}-\mathrm{CaO}$ and $\mathrm{ZrO}_{2}-\mathrm{Y}_{2} \mathrm{O}_{3}$. Thanks to these developments, new zirconia materials have emerged based on the transformation toughening mechanism from $t$ to $m$ phase that this material undergoes. These materials can be classified in three main groups [9]:

(1) Zirconia Toughened Ceramics (ZTC): These materials are characterized for containing zirconia particles dispersed throughout a continuous phase of another ceramic. A very common example are Zirconia Toughened Alumina (ZTA) ceramics. On the other hand, it is also possible to obtain zirconia matrix composites reinforced with particles from another ceramic material. These materials are known as zirconia-based composites and they have recently attracted the attention of the material science community because of their great potential as enhanced biomaterials [10]. An example of a zirconia-based composite is Alumina Toughened Zirconia (ATZ).

(2) Partially Stabilized Zirconia (PSZ): Widely studied and commercially relevant, PSZ ceramics possess some of the most important transformation toughening mechanisms. They consist of intragranular $t$-zirconia precipitates embedded within a stabilized c-zirconia matrix. Partial stabilization is carried out intentionally and consists on the addition of a dopant, such as $\mathrm{CaO}, \mathrm{MgO}, \mathrm{La}_{2} \mathrm{O}_{3}$ and $\mathrm{Y}_{2} \mathrm{O}_{3}$, in concentrations that are higher than those required for complete stabilization of the $t$-phase. The nomenclature of these ceramics consists of the metal element in the oxide used as dopant plus the acronym PSZ, for example Mg-PSZ and Y-PSZ [11].

(3) Tetragonal Zirconia Polycrystals (TZP): During the second half of the 1970s, after the introduction of PSZ ceramics, different stabilizing oxide concentrations were formulated giving rise to a series of new materials among which tetragonal polycrystalline zirconia emerged as the most importantt. Contrary to PSZ ceramics, these materials contain very low stabilizer concentrations ( $1-3.5$ mol\%), result in very fine grain sizes with very good properties, and a $t$-phase content of almost $98 \%$ after sintering $[12,13]$. TZP 
materials stabilized with yttria $\left(\mathrm{Y}_{2} \mathrm{O}_{3}\right)$ have become some of the most important ceramics due to their superb mechanical properties. The next section describes some of the most important aspects of yttria-stabilized tetragonal zirconia polycrystalline (Y-TZP) materials.

\subsubsection{Y-TZP CERAMICS}

The phase diagram for the $\mathrm{Y}_{2} \mathrm{O}_{3}-\mathrm{ZrO}_{2}$ is presented in Figure 2.2 [14]. In this diagram, the regions of the three different zirconia phases can be observed $\left(c_{s s}, t_{s s}\right.$ and $\left.m_{s s}\right)$ as a function of yttria content (in mol\%) and temperature. Additionally, the solid solutions that they can form among them, as well as the TZP and PSZ regions are shown. However, discrepancies exist on the location of the limits of the $t$ - and $c$ phase coexistence zone [15]. The amount of yttria required for full stabilization of TZP materials oscillates usually between $2-3$ mol\%, which, in turn, result in an improved mechanical behavior compared to $m$-phase zirconia ceramics. Higher concentrations ( $5-8 \mathrm{~mol} \%)$ give rise to PSZ structures. For nomenclature purposes, the yttria concentration is added at the beginning of the respective acronym. For example, 3Y-TZP corresponds to an yttria molar concentration of $3 \mathrm{~mol} \%$.

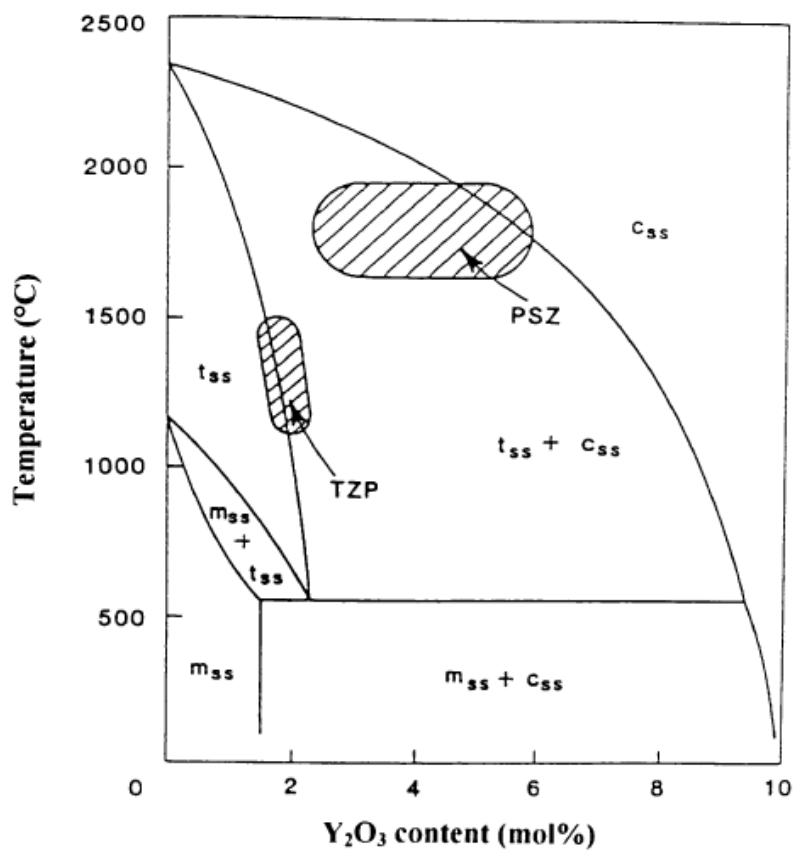

Figure 2.2 Phase diagram of $\mathrm{Y}_{2} \mathrm{O}_{3}-\mathrm{ZrO}_{2}$ system [14].

Relevant physical and mechanical properties of $m$-phase $\mathrm{ZrO}_{2}, \mathrm{Mg}$-PSZ and 3Y-TZP materials are shown in Table $2.2[7,8,16-18]$. In general, the combined properties of 
3Y-TZP are significantly better in terms of structural capacity than those of Mg-PSZ and $m-\mathrm{ZrO}_{2}$ ceramics, due to higher bending and compression strength, Young modulus and fracture toughness. This mechanical behavior justifies the full stabilization of the $t$-phase. As can be observed, the presence of $m-\mathrm{ZrO}_{2}$ can compromise mechanical performance. The high bending strength of 3Y-TZP results from the very fine $t$-grains that make up its microstructure, which are only a few hundred nanometers. In contrast, other zirconia ceramics such as Mg-PSZ, Y-PSZ or Ce-TZP are composed by big c-phase grains that, even though a higher fracture toughness is obtained, compromise the bending strength of the material.

Table 2.2 Physical and mechanical properties of m-ZrO2, Mg-PSZ and 3Y-TZP.

\begin{tabular}{lccc}
\hline & $\boldsymbol{m - Z r O}_{2}$ & $\boldsymbol{M g}-\boldsymbol{P S Z}$ & $3 \mathbf{Y}-\mathbf{T Z P}$ \\
\hline Density, $\mathrm{g} / \mathrm{cm}^{3}$ & 5.7 & $5.5-6.0$ & 6.1 \\
Grain size, $\mu m$ & $0.1-0.3$ & $40-70$ & $0.2-0.5$ \\
Porosity, $\%$ & $>7$ & - & $<0.1$ \\
Bending strength, $\mathrm{MPa}$ & $220-234$ & $450-700$ & $900-1200$ \\
Compression strength, $\mathrm{MPa}$ & - & 2000 & $>2000$ \\
Young's modulus, $\mathrm{GPa}$ & $190-200$ & $170-210$ & $220-260$ \\
Fracture toughness*, $\mathrm{MPa} \cdot \mathrm{m}^{-1 / 2}$ & $2-3$ & $7-10$ & $6-9$ \\
Hardness, $\mathrm{HV} 0.1$ & $600-700$ & 1100 & $>1100$ \\
Poisson ratio & - & $0.22-0.25$ & $0.25-0.30$ \\
\hline
\end{tabular}

*different values may be obtained depending on method used

One of the most important characteristics of $t$-stabilized $\mathrm{ZrO}_{2}$ materials is the toughening that occurs due to the $t$ - to $m$-phase transformation, which is able to constraining the propagation of the crack within the material inhibiting its growth. This phase transformation is responsible for an increase in volume between $4-6 \%$, and also results in an increase of fracture toughness [19]. The area surrounding the crack after transformation is composed of transformed $m$-phase particles, keeping a constant volume in the transformed zone, and resulting in a closure of the crack faces that oppose its propagation (Figure 2.3). The maximum toughness is reached when the transformed zone has completely developed and the crack is completely enclosed [20]. This transformation toughening mechanism is responsible for the high fracture toughness values of Y-TZP materials and provides unique characteristics. The transformation is martensitic and reversible and occurs by diffussionless shear [21]. Due to its martensitic nature, the change in structure involves the simultaneous 
and cooperative movement of atoms by a distance that is smaller than its diameter, which results in an abrupt change in the unit cell parameters [22].

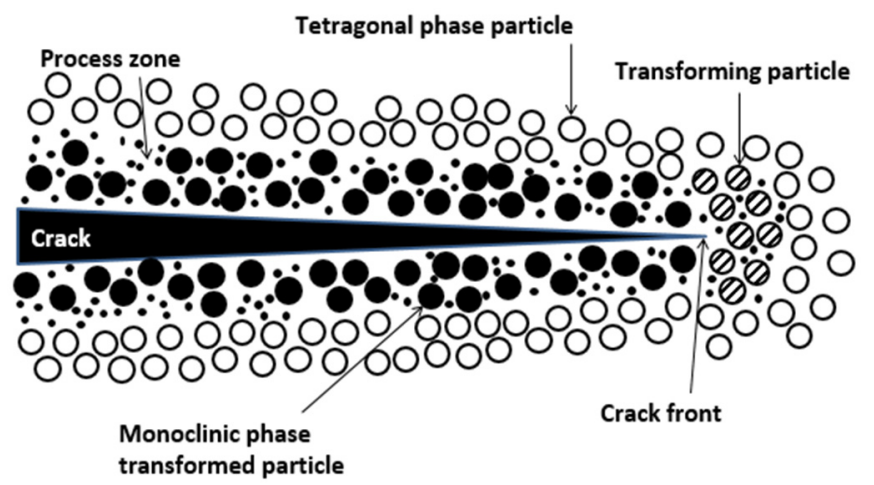

Figure 2.3 Transformation toughening mechanism representation in $t$-zirconia responsible for increasing the fracture toughness of this material [23].

There are three main factors that influence transformation toughening in Y-TZP ceramics: grain size, yttria content and yttria distribution. Commercial Y-TZP materials contain, approximately, between $1.5-3.5$ mol\% yttria and their sintering temperatures are normally between 1400 and $1700^{\circ} \mathrm{C}$. An increase in the amount of stabilizer usually results in a decrease of fracture toughness [24]. Grain size also has an effect on phase transformations, establishing a critical size threshold above which the transformation is spontaneous, considerably decreasing the mechanical properties. Hence, the $t$-phase grain size must be maintained within a narrow range of a few hundred nanometers. The distribution of yttria within the grain can also change the $t-m$ transformation vulnerability of the material. A study comparing yttria-coated against co-precipitated powders showed that coated grains, in which yttria is concentrated at the grain boundary, result in higher fracture toughness values compared to their co-precipitated counterparts [25].

The transformation toughening mechanism observed in zirconia materials can be described as follows:

1. The stress field in front of the crack tip induces the transformation of the metastable t-phase.

2. The transformation occurs instantly and is accompanied by dilation.

3. The change in volume of the transformed zone embedded in the matrix generates residual compressive tensions.

4. Lastly, the work performed by the interaction of the stress field of the crack and the one generated by the deformation from the transformation 
dissipates part of the energy that could be available for the propagation of the crack.

McMeeking and Evans [19] concluded that the transformed zone at the crack tip does not contribute to an increase in fracture toughness. The crack-inhibiting effect of the transformation is due to the lateral faces surrounding the crack when it begins to propagate. The particles that were initially transformed are left behind the tip and induce residual stresses that act upon the crack faces closing the fissure.

A thermodynamic approach has been proposed by Lang [26] in terms of the change in free energy of a spherical $t$ particle embedded in a matrix to describe the transformation mechanism and is given by the following expression:

$$
\Delta G_{t \rightarrow m}=\Delta G^{c}+\Delta U_{s e}+\Delta U_{s}
$$

where:

$\Delta G_{t \rightarrow m}=$ change in free energy given by the $t-m$ transformation

$\Delta G^{c}=$ difference in free energy between the $t$ - and $m$-phase

$\Delta U_{\text {se }}=$ change in deformation energy associated change in volume and shape

$\Delta U_{s}=$ change in the energy associated with the formation of new surfaces

The change in free energy between the phases, $\Delta G^{c}$, is the driving force of the transformation. It is negative for temperatures below the equilibrium temperature, $M s$, and depends on temperature and composition. This energy difference can be expressed as:

$$
\Delta G^{c}=\Delta S_{t \rightarrow m}\left(M_{S}-T\right)=q\left(1-\frac{T}{M_{S}}\right)
$$

where:

$\Delta S_{t \rightarrow m}=$ change in entropy resulting from the $t$ - to $m$-transformation

$M_{s}=$ transformation equilibrium temperature

$q=$ heat of transformation

If $\Delta G_{t \rightarrow m}>0,\left|\Delta G^{c}\right|<\Delta U_{s e}+\Delta U_{s}$, the particle remains in the $t$-phase. On the other hand, if $\Delta G_{t \rightarrow m} \leq 0$, the particle transforms to the $m$-phase.

Finally, the $\Delta U_{s}$ is described in the following manner:

$$
\Delta U_{s}=\frac{A_{m} \gamma_{m}-A_{t} \gamma_{t}}{V}=\frac{6\left(\gamma_{m}-g_{s} \gamma_{t}\right)}{D}
$$

where:

$A_{t}, A_{m}=$ areas of the $t$ and $m$-phase, respectively

$Y_{t}, Y_{m}=$ corresponding specific superficial energy 
$V=$ transformed volume

$D=$ diameter of transformed particle

$g_{s}=A_{t} / A_{m}$

A more comprehensive review of the thermodynamic nature of this phase transformation can be found in other works [27-29], including a description of the effect of external stresses and microcracking [30], as well as a martensitic approximation to the transformation [31,32].

\subsubsection{ZIRCONIA-BASED MATERIALS IN DENTISTRY}

Generally, dental materials must comply with two fundamental criteria: mechanical performance and aesthetic appeal. However, many dental materials are not able to satisfy both of these requirements. Other aspects such as hydrothermal stability must also be considered. In the case of Y-TZP elements, its high fracture toughness resulting from transformation toughening and its superb mechanical properties are well-above most of those materials utilized for dental applications, such as porcelain, glass-infiltrated ceramics and metals. In terms of aesthetic requirements and coloring, zirconia is quite flexible as it can be doped to match the coloring of the teeth (Figure 2.4). Therefore, zirconia is one of very few ceramic materials that can comply with these two important demands. Additionally, other characteristics make zirconia a first-choice material over other dental materials in restorative dentistry. Such characteristics include:

- Resistance to corrosion because oxide ceramics are not prone to oxidation reactions that lead to corrosion as in metals.

- Chemical inertness and stability since there is no reactivity with surrounding gum tissue, bone or bacteria commonly present in the human mouth [7].

- Bone apposition without the interposition of fibrous tissue, which facilitates fixation to the maxillofacial structure [33].

- Thermal properties, such as a relatively low thermal conductivity, that allow it to withstand abrupt temperature changes that teeth are frequently exposed to.

- A wide range of aesthetic possibilities that include the manipulation of translucency, color and texture due to the addition of dopants [34,35], such as iron, titanium, cerium and $\mathrm{Al}_{2} \mathrm{O}_{3}$, to match the patient's denture.

- Durability and wear resistance in order to reduce the frequency of component replacement, as these materials will be in constant contact with other surfaces for long periods. 


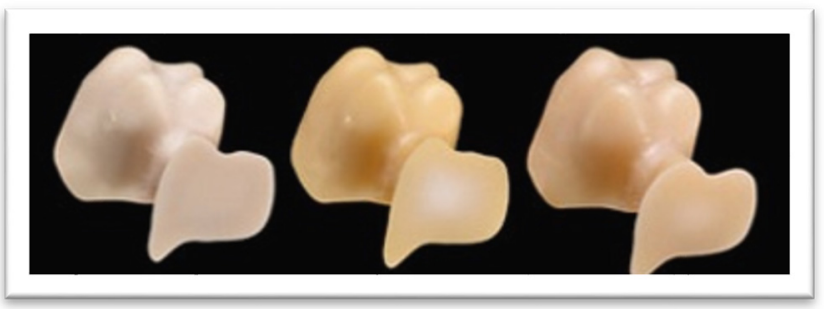

Figure 2.4 Zirconia tooth-shaped restorations with three different color shades after doping with other elements.

In dentistry, the use of zirconia is quite ample encompassing root posts, orthodontic brackets and dental implants [36]. Materials for dental applications need to be tailored to the specific requirements and shape of the replaced dental piece. Therefore, a pre-sintering machining process is necessary. The breakthrough of CAD/CAM technology has significantly contributed to fast implementation of zirconia-based crowns, bridges and even all-ceramic dental pieces. It is important to mention that the material performance as a dental replacement is strongly dependent on the selection of the ceramic synthesis process, consolidation and sintering conditions, all of which are specific to each manufacturer. A list of some of the most important dental zirconia materials manufacturers with their respective commercial brand names is given in Table 2.3.

Table 2.3 Dental zirconia manufacturers and product name [37].

\begin{tabular}{ll}
\hline Manufacturer & Product trade name \\
\hline VITA & In-Ceram YZ \\
3M Espe & LAVA \\
Ivoclar & IPS ZirCAD \\
Nobel Biocare & Procera All-zircon \\
Noritake & Katana \\
KaWo & Everest Z-block \\
\hline
\end{tabular}

\subsection{LOW-TEMPERATURE HYDROTHERMAL DEGRADATION IN ZIRCONIA}

The spontaneous $t$ - to $m$-phase transformation of Y-TZP materials has also a counterproductive effect when it occurs under certain conditions that cannot be controlled, and results in a significant loss of mechanical performance in the longrun. Exposure to high levels of humidity at a temperature range between $20-300$ ${ }^{\circ} \mathrm{C}$ gives rise to an accelerated ageing phenomenon, known as low-temperature 
hydrothermal degradation (LTD) [38-40]. This is a very important aspect to consider in zirconia-based ceramics, especially when applications in humid environments are intended, such as in dentistry, because it can compromise the structural integrity of the replacement. The term degradation is utilized to indicate a decrease in mechanical properties, which influences the performance of the material, such as its wear behavior, fracture toughness or bending strength.

The interest on LTD rose primarily in orthopedic applications of zirconia. Between 2001 and 2002, catastrophic failure of zirconia hip joint replacements after a considerably short time of implantation was reported in approximately 400 femoral heads questioning the potential of zirconia a biomaterial, but also becoming an instant matter of study and debate in the field of material science [41-44]. Since then, several works have been published addressing the causes and factors that are responsible for the initiation of this spontaneous and accelerated "ageing" phenomenon, as well as alternatives in material synthesis and processing to inhibit or reduce its development.

The first work describing the LTD phenomenon was published by Kobayashi et al. in 1981 [45] for yttria-stabilized zirconia materials at $250{ }^{\circ} \mathrm{C}$ in air, while its main characteristics were documented by Yoshimura [46] and are summarized in the following list:

- $\quad$ LTD progresses faster within a critical temperature range of $200-300{ }^{\circ} \mathrm{C}$ and is a function of time of exposure.

- The phase transformation from $t$ - to $m-\mathrm{ZrO}_{2}$ is responsible for material degradation and is also accompanied by microcracking.

- Transformation initiates at the surface and propagates inwards into the material bulk.

- The rate of transformation is accelerated by water or water vapor.

- The progression of transformation is slowed down by reducing grain size or by increasing the amount of stabilizer.

- $\quad$ Long exposure to LTD decreases mechanical properties.

\subsubsection{MAIN FACTORS INFLUENCING DEGRADATION}

Several variables affect the LTD kinetics of zirconia materials due to their substantial influence in the stability of the $t$-phase. Grain size and shape, stabilizer content and distribution, cubic phase content, porosity and residual stresses are known to affect the degradation behavior of Y-TZP ceramics.

Critical grain size, which also depends on the amount of stabilizer, is one of the most important variables that has a direct effect in phase transformation. Once a critical 
grain size is surpassed, a $t$ to $m$-phase transformation occurs spontaneously. The following expression describes critical grain size assuming that $Y_{m}>g_{s} Y_{t}$, combining Equations 2.3 and 2.1 and imposing the transformation condition restriction $\Delta G_{t \rightarrow m}$ $\leq 0$ :

$$
D \geq D_{c}=\frac{6\left(\gamma_{m}-g_{s} \gamma_{t}\right)}{-\left(\Delta G^{c}+\Delta U_{s e}\right)}
$$

This relationship is associated with the difference in surface energy, $\Delta U_{s}$, of the particle in Equation 2.3 and is interpreted as a competition between the specific surface energy of the $t$ - and $m$-phases and the energy released from the volume

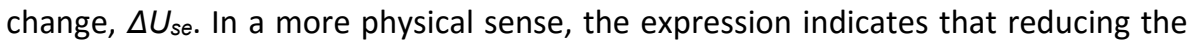
particle size increases the surface area with respect to its volume and, as a consequence, the effectiveness of the interphase to constrain the change in shape that results from the transformation [47]. An alternative explanation given by Girault [48] establishes that the number of monoclinic variants that can be accommodated in a transformed grain reduced with its diameter.

Another important factor that influences LTD behavior is the amount and distribution of oxide stabilizer. The kinetics of degradation in trivalent ions changes due to the presence of a higher number of oxygen vacancies in the crystalline structure of the material. In the case of tetravalent ions such as $\mathrm{Ce}^{4+}$, it is due to a greater lattice distortion. The interaction with a higher number of oxide or hydroxide ions is necessary to destabilize a particular grain during degradation. Moreover, increasing both, the dopant content and sintering temperature, or the use of fast cooling procedures can stabilize the $t$ or $c$-phase.

On a similar note, the distribution of yttrium in the starting powder of Y-TZP ceramics also affects the rate of degradation because heterogeneous distribution may lead to the presence of zones with low stabilizer content that can act as nucleation sites due to the a lower concentration of vacancies [49]. However, recent studies are challenging this view, as non-homogenous distribution of stabilizer may, in fact, improve the mechanical properties of the material [50] and enhance the resistance to LTD [51]. Such is the case of works from Zhang et al. [25], where the stabilizer has been concentrated purposely at the grain boundary of zirconia powder particles by powder coating methods in order to enhance the LTD resistance of the consolidated material showing promising results. Anglada et al. [52] have also explored the coating of 3Y-TZP pre-sintered specimens with Cerium solutions to counteract the effect of LTD and successfully reducing the presence of m-phase $\mathrm{ZrO}_{2}$.

Related to stabilizer content is the content of the $c$-phase in zirconia, which is crucial in LTD. The presence of $c$-phase in a $t-\mathrm{ZrO}_{2}$ matrix is known to accelerate $t$ - to $m$ - 
phase transformation. An explanation postulated by Chevalier et al. [42] states that during high temperature sintering, there is a higher probability to reach the $c$-phase zone according to the phase diagram, which results in c-grains rich in yttria. Since the amount of yttria cannot be changed, $t$-phase grains are deprived from stabilizer, which translated into a lower number of vacancies available that leaves the t-grains more vulnerable to transformation (Figure 2.5). Hence, lower sintering temperatures of approximately $1400{ }^{\circ} \mathrm{C}$ are recommended for Y-TZP ceramics to reduce the presence of $c$-phase grains and to obtain completely dense materials. Also, reducing sintering time can contribute to avoid the c-phase region. Non-conventional sintering techniques, such as microwave and FAST sintering methods, allow for shorter sintering times and, in some cases, lower dwell temperatures due to the heating mechanisms involved. Therefore, they represent an interesting alternative for enhancing LTD resistance by reducing the content of $c$-phase.

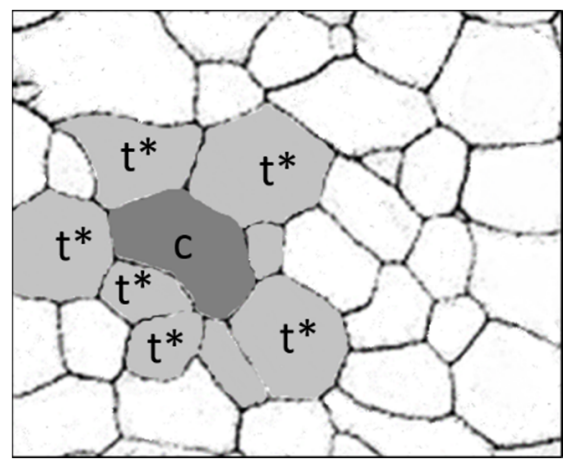

Figure 2.5 Y-TZP zirconia microstructure representation showing $t$-phase grains with lower stabilizer content $\left(t^{*}\right)$ surrounding the yttria-rich c-phase grain. Grains with lower $\mathrm{Y}_{2} \mathrm{O}_{3}$ content are more vulnerable to LTD.

Porosity can also be an important factor responsible for altering the kinetics of LTD. Materials with a higher degree of porosity on the surface allow water molecules to reach the material bulk faster, especially when porosity is interconnected, increasing the rate of degradation. In this scenario, the cohesion of the material grains is broken and a significant decrease of mechanical properties occurs [40].

The effect of residual stresses can also change the behavior of Y-TZP materials against LTD. The phase stability of a particular grain is determined by the types of stresses found within it. Tensile and shear stresses destabilize the $t$-phase, while compressive stresses stabilize the grains. Schmauder and Schubert [53] determined that all the previously mentioned factors induce changes in the stress field within the grains and, as a consequence, in their susceptibility to LTD. The study shows that grains located closer to the surface were less constrained and developed a higher resistance to LTD than grains located in the bulk, which transformed completely. 
Grain shape also affects the distribution of stresses. For example, a spherical grain results in a more homogeneous distribution of residual stresses, contrary to grains with sharp edges and anisotropic shapes, where these edges act as sites for stress concentration and nucleation points of $m$-phase. Lastly, the same study also addressed the effect of $\mathrm{Y}_{2} \mathrm{O}_{3}$ content in the stress field within the grains. It was found that, in grains with similar size, the shear stress component generated by thermal expansion is greater in grains of zirconia stabilized with 2 mol\% $\mathrm{Y}_{2} \mathrm{O}_{3}$ than in those stabilized with 3 mol\%.

\subsubsection{HYDROTHERMAL DEGRADATION KINETICS}

In order to describe the zirconia degradation behavior in a mathematical way, several experiments have been carried out to quantify the transformation of $t$ - to $m$ phase induced by LTD [54-56]. The model proposed by Johnson-Mehl-Avrami [5759] for nucleation and propagation processes can be used to quantify the $m$-phase volume content and is given by the following expression:

$$
V_{m}=1-\exp \left(-(\mathrm{b} \cdot \mathrm{t})^{n}\right)
$$

where:

$V_{m}=$ volumetric fraction of $m$-phase

$t=$ exposure time to degradation conditions

$n=$ Johnson-Mehl-Avrami exponent, depends on temperature (between $0.5-4$ )

The parameter $b$ also depends on temperature and follows Arrhenius law:

$$
b=b_{0} \exp \left(-\frac{Q}{R T}\right)
$$

where:

$b_{0}=$ constant

$Q=$ apparent activation energy describing nucleation and propagation mechanisms

$R=$ universal gas constant

$T=$ absolute temperature

A typical experimental LTD plot of 3Y-TZP materials corresponding to $m$-phase volumetric fraction as a function of exposure time to degradation conditions is shown in Figure 2.6. A curve predicted by the Johnson-Mehl-Avrami model has also been traced for comparison purposes. The typical nucleation and growth processes can be observed as well. Even though a martensitic transformation does not depend on the temperature, in this particular case, the transformation is activated by the diffusion of chemical species derived from water, which is a thermally activated process. 
Additionally, the nucleation of the $m$-phase on the surface does not occur randomly, but tends to begin on preferential nucleation sites such as unstable grains with lower yttria content, grains above the critical size or due to the existence of higher tensile or shear stresses. The amount of transformed material increases continually with exposure time to degradation conditions. At the same time, stresses generated by the transformation of a particular grain can induce the transformation of neighboring grains, as long as they have already been affected by the effect of water, giving place to the propagation stage.

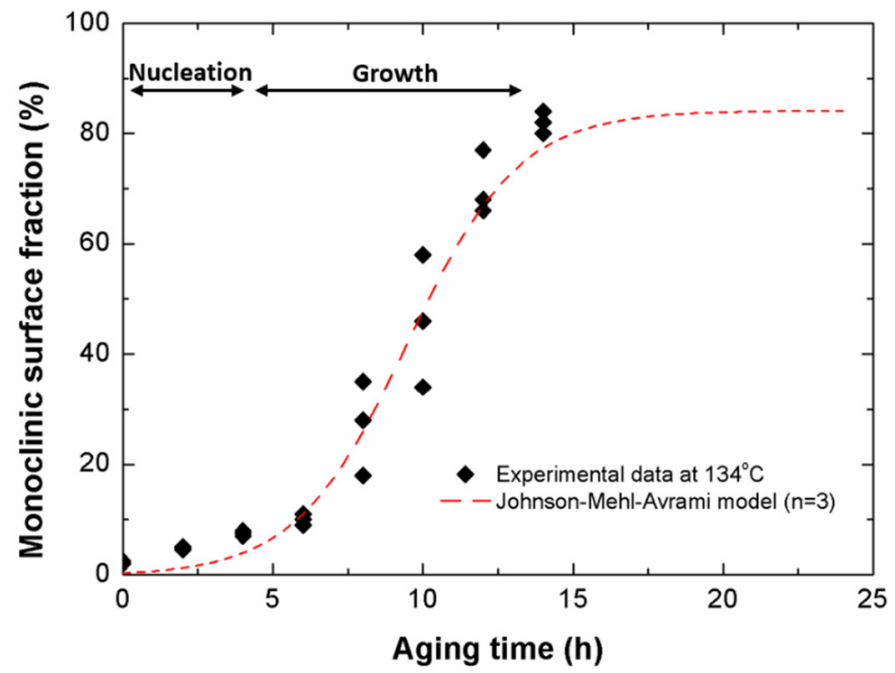

Figure 2.6 Hydrothermal degradation kinetics showing experimental data from tests carried at $134{ }^{\circ} \mathrm{C}$ in water vapor and the curve resulting from the Johnson-Mehl-Avrami model. Taken and modified from [40].

In order to have a better understanding of the transformation and degradation process, Chevalier et al. $[44,60,61]$ have proposed the mechanism shown in Figure 2.7.This mechanism begins with the transformation of a vulnerable grains on the surface in contact with water and their respective volume change of $4 \%$ (Figure 2.7a). As a consequence from the expansion, neighboring grains are subjected to stresses and, hence, become destabilized and prone to transformation (Figure 2.7b). At the same time, surface uplift occurs to accommodate for volume expansion and results in microcraking. Water penetrates further into the bulk due to the microcracking network that has been formed and continually affects more and more grains (Figure 2.7c). Finally, the microcracking network has become very extensive and a layer of transformed degraded material is formed resulting in a significant deterioration of mechanical properties and grain pull-out. 
Even though this mechanism includes the fundamental characteristics of degradation, such as transformation and microcracking, and has been widely accepted and utilized to explain experimentally observed processes, it is not strictly accurate. On one side, the $4 \%$ volume expansion between $t$ - and $m$-phase does not occur instantly, as the model proposes, because the $t$ to $m$ transformation occurs following a sequence of events that begin with the formation of two or more $\mathrm{m}$ variants [62]. Moreover, the deformation caused by these variants have a dilation component of $4 \%$, as well as a shear component that can reach almost $16 \%$, which is reduced to zero once the particle transformation has concluded, in a process called self-accommodating variants. The generated deformations during this process (partial grain transformation) can have a strong impact in material degradation, which is not accounted for in the mechanism proposed by Chevalier et al.

a)

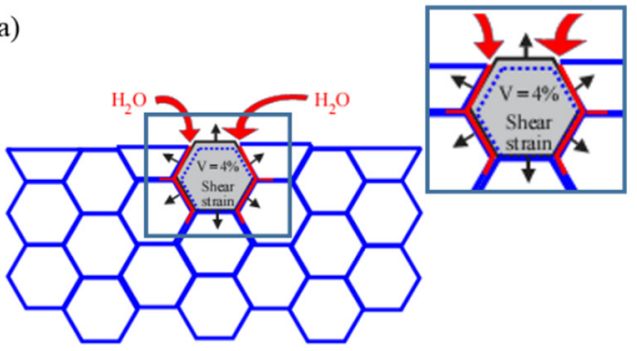

b)

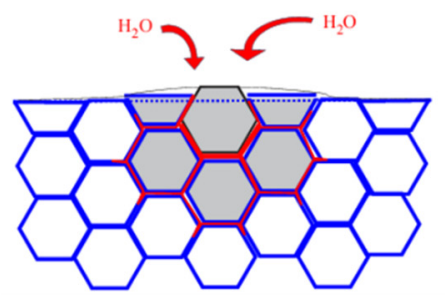

c)

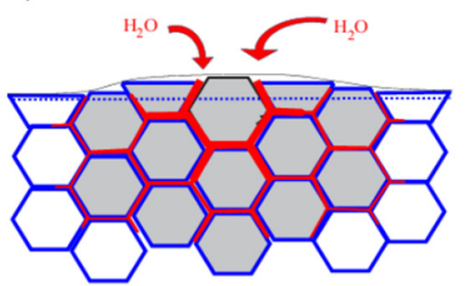

Figure 2.7 Hydrothermal degradation mechanism proposed by Chevalier et al. [44,60,61]. a) Unstable surface grains transform and expand. b) Neighboring grains are destabilize and surface uplift occurs. c) Water penetrates into the bulk generating microcracking.

\subsubsection{EFFECT OF WATER ON HYDROTHERMAL DEGRADATION}

Even though the degradation of zirconia has been extensively studied, the fundamental physical and chemical mechanisms underlying this phenomenon are not completely understood yet, specifically when it comes to explaining the role of water. Nonetheless, several theories and models have been proposed to describe how the presence of water promotes the $t-m$ transformation during LTD. In the next few paragraphs, three proposed mechanisms are briefly described. 


\section{Mechanism proposed by Sato and Shimada}

The first model to be addressed is that of Sato and Shamida $[63,64]$. This model is based on the corrosion mechanism that occurs in silica under stress conditions. Beginning with the chemical adsorption of $\mathrm{H}_{2} \mathrm{O}$ on the surface, a chemical reaction occurs to form $\mathrm{Zr}-\mathrm{OH}$ and/or $\mathrm{Y}-\mathrm{OH}$ bonds (Figure 2.8). Stresses that stabilize the $t$ phase are relieved in the specific points where this reaction occurs due to bonds breaking. Once the $\mathrm{m}$-phase has been nucleated in a grain, it increases its volume and generates stresses in neighboring grains and creates microcracks. This new crack network acts as a pathway for the penetration of water further into the material. The authors determined, based on the activation energy, that water reacts primary with the $\mathrm{Zr}-\mathrm{O}-\mathrm{Zr}$ bonds on the surface and not with the stabilizer.

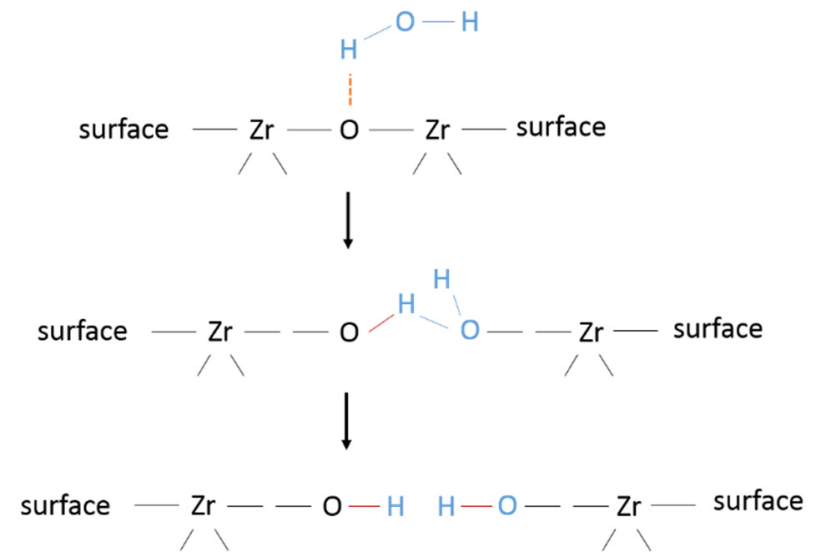

Figure 2.8 Diagram of the reaction sequence between water molecules and zirconia on the surface proposed by Sato and Shimada [64].

\section{Mechanism proposed by Yoshimura}

In another study, also based on this mechanism, Yoshimura [46] showed an increment in the unit cell parameters induced by degradation that can be reestablished after an annealing treatment. The results suggested that this behavior is attributed to the inclusion and posterior exclusion of hydroxide ions. Once water has reacted with the material to form $\mathrm{Zr}-\mathrm{OH}$ bonds, preferential stress sites are formed due to the migration of $\mathrm{OH}^{-}$ions from the surface inwards (Figure 2.9). Therefore, both these models agree on the formation of $\mathrm{Zr}-\mathrm{OH}$ bonds on the surface, but they are differentiated because Sato suggests that the reactions relieve the stresses by destabilizing the $t$-phase, while Yoshimura claims that the reaction generates preferential stress sites that activate the transformation. 
a)

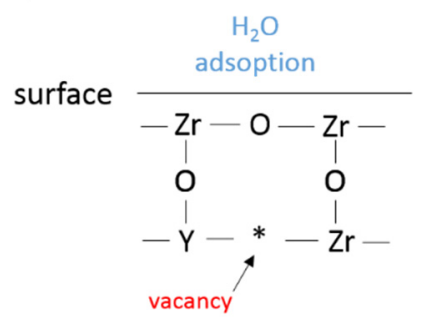

c)

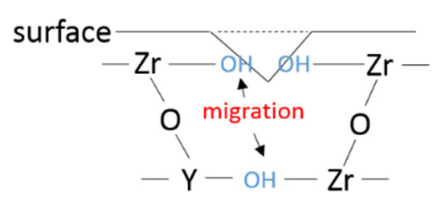

b)

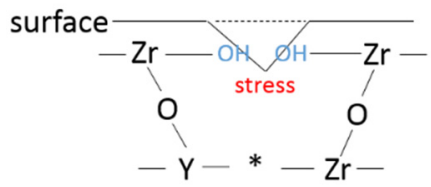

d)

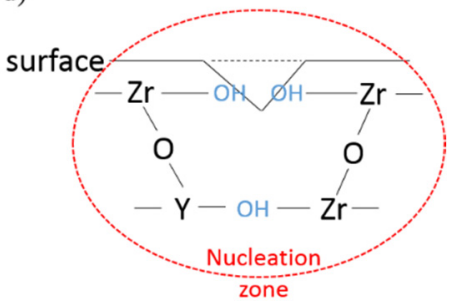

Figure 2.9 LTD mechanism of Y-TZP materials proposed by Yoshimura. a) Water adsorbs the surface of the material. b) A chemical reaction results in the formation of $\mathrm{Zr}-\mathrm{OH}$ bonds and a stress is generated due to the location of a vacancy. c) The $\mathrm{OH}^{-}$ion migrates inwards occupying the vacancy. d) A nucleation zone forms around this vulnerable region.

\section{Mechanism proposed by Lange}

Another mechanism aimed at explaining LTD of zirconia is that of Lange et al. [65] based on Transmission Electron Microscopy (TEM) characterization. In this work, the presence of small crystals rich in yttria was revealed after an ageing treatment of 6.6Y-TZP. These crystals were identified as $\mathrm{Y}(\mathrm{OH})_{3}$ and were frequently observed close to transformed grains. The authors then concluded that during LTD, the water vapor reacts with yttrium ions destabilizing the neighboring grains and promoting the $t-m$ transformation. However, this model has been discarded due to the slow diffusion of yttrium in the zirconia matrix [46] and because these crystals have not been observed in other experiments of degraded zirconia.

\section{Mechanism proposed by Schmauder and Schubert}

A similar approach to that of Lange has been proposed by Schmauder and Schubert [66] where the transformation of grains on the surface is induced by water due to a corrosion mechanism under stress. This process favors the formation of $\mathrm{Y}(\mathrm{OH})_{3}$ because of the diffusion of water within the crystalline structure not because of the diffusion of the $\mathrm{Y}^{3+}$ ion. This is possible given the concentration of vacancies in the structure that can be occupied by oxygen anions. Once $\mathrm{Y}(\mathrm{OH})_{3}$ is formed, a zone with low yttria content will develop and will be governed by the stresses in the grain. As a consequence, this zone will be very susceptible to transformation. 


\section{Mechanism proposed by Guo}

Currently, the most accepted mechanism to describe LTD is the transformation by annihilation of vacancies due to the diffusion of species derived from water. The first approximation to this model was given by Lepisto [67] suggesting that oxygen anions formed on the surface are responsible for a chemical reaction that reduces $\mathrm{Zr}^{4+}$ ions and annihilates atom vacancies as a consequence. Later on, Guo $[68,69]$ proposed a mechanism based on the reaction of water molecules adsorbed on the surface, $\mathrm{H}_{2} \mathrm{O}_{a d}$, with oxygen ions from the termination of the periodical $\mathrm{ZrO}_{2}$ lattice at the surface and/or adsorbed oxygen from the air, $\mathrm{O}^{2-}$ surf, which results in the production of $\mathrm{OH}^{-}$ions according to the following reaction:

$$
\mathrm{H}_{2} \mathrm{O}_{\text {ad }}+\mathrm{O}_{\text {surf }}^{2-} \rightarrow 2(\mathrm{OH})_{\text {surf }}^{-}
$$

Since zirconia possesses a high concentration of oxygen vacancies, $V_{0}{ }^{\prime \prime}$, due to the addition of dopants, such as $\mathrm{Y}_{2} \mathrm{O}_{3}$, the diffusion of such vacancies results in a further defect reaction:

$$
O H_{\text {surf }}^{-}+V_{O}^{\prime \prime} \rightarrow(O H)_{O}^{\prime}+S_{O, s u r f}^{x}
$$

where:

$(\mathrm{OH})^{\circ} \mathrm{O}=$ an $\mathrm{OH}^{-}$ion on the oxygen site in the $\mathrm{ZrO}_{2}$ lattice

$S^{x}{ }_{0, \text { surf }}$ a vacant oxygen site on the surface

This reaction annihilates vacancies and introduces ions in the crystalline structure, particularly on the surface. When the concentration of vacancies is reduced below a critical value, a $t-m$ transformation occurs. This mechanism explains the role of low temperature, the effect of dopant content and grain size on the degradation kinetics of zirconia.

However, there are still several issues that need to be addressed. For example, the exact role of water in the destabilization of the $t$-phase during degradation is not clear understood. Some authors [70] have proposed that the introduction of chemical species derived from water in the crystalline structure can generate hydrostatic tensile stresses as a result of a decrease in cell parameters. This is contrary to what has been reported by Guo [69], claiming that cell parameters are increased instead. Additionally, up until now it has been proposed that it is $\mathrm{OH}^{-}$ions that diffuse, but new evidence suggests that $\mathrm{H}^{+}$and $\mathrm{O}^{2-}$ ions diffuse separately in the material $[56,71]$. 


\subsection{TRIBOLOGICAL BEHAVIOR OF ZIRCONIA CERAMICS FOR DENTAL APPLICATIONS}

The resistance to wear and durability is critical for an optimum long-term performance of structural Y-TZP ceramics. The study of tribological behavior is very important in orthopedic and odontological uses of materials, as interactions between surfaces is quite common. In the case of zirconia, its applications for orthopedic purpose have been completely abandoned after the catastrophic failures in the early 2000's. However, restorative dentistry has proven to be a very interesting field as the materials are exposed to less frequent mechanical fretting, but still demanding environment regarding material wear.

Since teeth are subjected to contact and friction between surfaces due to grinding during the mastication process and, in some cases, mouth disorders such as bruxism, which consists in the involuntary excessive grinding of teeth and/or clenching of the jaw due to oral parafunctional activity, there is a need to investigate the wear resistance of Y-TZP materials that are set to act as replacements of teeth. Moreover, the effects of external factors, such as humidity and LTD, under constant wear conditions need to be assessed since these materials are exposed to high levels of humidity in the human mouth.

Several works have reported the influence of microstructure on the tribological behavior of zirconia ceramics [72-75], as well as the effect of alumina/zirconia composites [76]. Since microstructure depends on the processing of the ceramic powder, the influence of sintering also needs to be considered in wear applications. In this respect, studies on different techniques have been carried out for many materials, including microwave sintering [77] and spark plasma sintering [75].

\subsubsection{FRETTING WEAR}

Fretting is one of the most common wear mechanism encountered in engineering applications of materials and refers to any wear condition in which the contact between materials are subjected to a low amplitude oscillatory relative motion that is lower than a few hundred micrometers [78]. Fretting occurs in a system where contact vibrations are present or which enable small tangential relative motion. For engineering applications, this wear mechanism can be observed in hubs and disks press-fitted to rotating shafts, in riveted and bolted joints, the flanges between the beveled gear and the drive shaft in gas turbine transmitters in helicopters, damage at the femoral stems in total hip replacements, and dental restorations.

Fretting damage can be categorized in three main forms [79] and are strongly related to fretting regimes [80]: 
1. Fretting corrosion, which accounts for the degradation due to chemical reactions between surface constituents and the environment.

2. Fretting fatigue, which refers to fatigue of materials as a consequence of cyclic changes of the stress field in just a few micrometers of sliding amplitude.

3. Fretting wear, which represents the surface damage produced by the fretting process where slip occurs over the whole of most of the contact.

The potential fretting damage can be divided into two scenarios according to Holland [81]. The first one consists on contacting surface that are not designed to move relative to each other, such as shrink fits, bolted flanges and riveted joints. The second deals with the relative movement for part of the time of the interacting surfaces, as in the case of bearings and flexible couplings.

\subsubsection{Fretting modes}

Three main configurations for the interaction of contacting surfaces can be described in fretting wear based on the mode of trajectories of oscillatory motion. These modes are the following:

I. Linear mode: This configuration consists on the tangential displacement of a ball-on-flat fretting contact characterized by a small-amplitude, linear relative displacement (Figure 2.10a). This mode is the most reported laboratory wear test in the literature. When the sliding is confined to an outer ring-shaped zone slip annulus surrounding the central part, known as stick zone, the displacement is called partial slip. When the sliding occurs throughout the contact area, the displacement is then referred to as gross slip.

II. Radial mode: This mode results from the oscillatory contact as the ball exerts a normal force on the plate. The normal force varies because the ball moves perpendicular to the plate and a pressure gradient develops. The radius of the contacting boundary oscillates between $a_{\min }$ and $a_{\max }$ (Figure $2.10 \mathrm{~b})$. The induced displacement is zero at the center and increases to maximum at the contacting periphery. In this particular mode, the exposure time of the slip region varies with $1 / f$, while the locked region remains always unexposed. As a consequence, no gross slip is observed in this mode.

III. Circumferential mode: In the ball-on-plate configuration, the ball rotates around an axis perpendicular to the surface (Figure 2.10c). The angle of rotation is also an important variable and can be adjusted. The circumferential displacement amplitude increases from zero at the center to a maximum value at the contact periphery. The normal force stays 
constant throughout the displacement. In this mode, fretting corrosion is unlikely as the contact area is not exposed to the environment.

a)

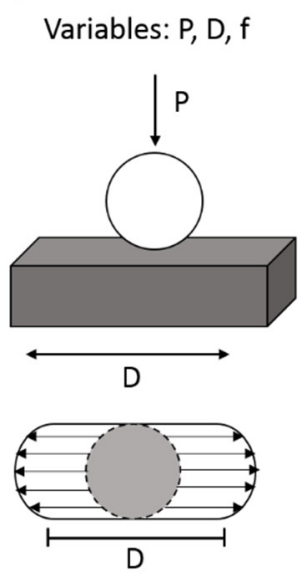

b)

Variables: $P, \Delta P, f$
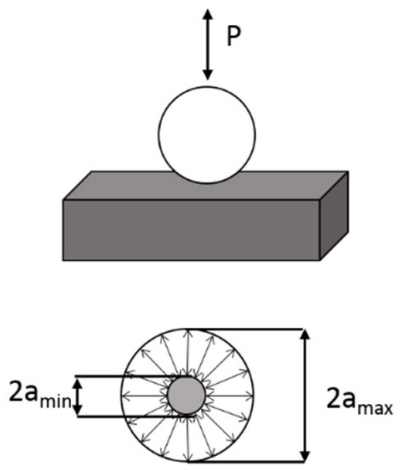

c)
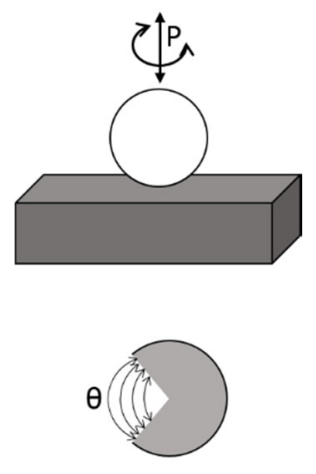

Figure 2.10 Fretting modes schematic illustration for a ball-on-plate setup: a) I. Linear mode, b) II. Radial mode, and c) III. Circumferential mode. Taken and modified from [79].

An elastic Hertzian model can be used to describe fretting mechanics in a simplified manner. At the contact of an ideal, smooth ball-on-plate configuration, a stressstrain region can easily be identified, where the contact surface of these two bodies forms a circle with a radius $a$. The following relationship can be used to calculate $a$ :

$$
a=\sqrt[3]{\frac{3\left(1-v^{2}\right) F_{N} R}{2 E}}
$$

where:

$F_{N}=$ Normal force

$E=$ Elastic modulus

$v=$ Poisson ration

$R=$ radius of the ball

And the distribution of normal pressure, $P$, over the contact areas as a function of the radial distance, $r$, from the center can be expressed as:

$$
P(r)=\frac{3 F_{N}}{2 \pi a^{2}} \sqrt{1-\frac{r^{2}}{a^{2}}}
$$

In this expression, the contact pressure reaches a maximum at the center of the circle, that is when $r=0$, and falls to zero at the edges. If a tangential force, $F_{T}$, is applied such that $F_{T}<\mu F_{N}$ (where $\mu$ corresponds to a static coefficient of friction, 
COF), a contact surface with an inner and an outer rim develops. The inner circle with a radius $r=a^{\prime} \leq a$ is in a stick zone, while the outer part of the surface is in a slip zone (Figure 2.11a). In the transient phase of applying the tangential load, microslip starts at the outer rim of the contact circle and penetrates inward as the slip annulus forms. When the applied tangential force approaches the friction force $F_{T}=\mu F_{N}$, the inner radius of the annulus approaches zero and the condition for incipient gross slip over the entire contact area is satisfied.

a)

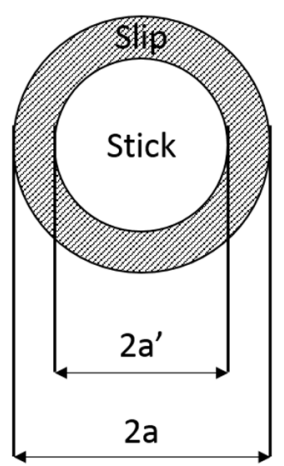

b)

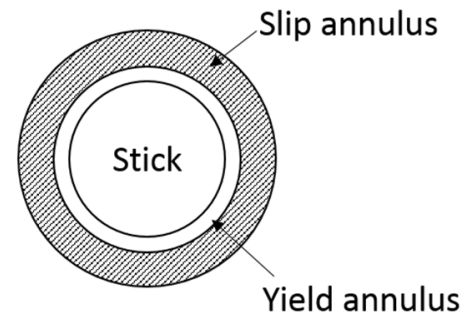

Figure 2.11 Surface contact models under normal load and tangential force. a) Elastic model and b) Elastic-plastic model.

A more complete model of fretting mechanics takes into account the contribution of plastic deformation, implying that the contact surface is now divided into three zones (Figure 2.11b). In addition to the slip and stick regions, a yield annulus must be considered. The central stick zone is where the elastic displacement and deformation occurs. The yield annulus is formed by asperities that have yielded plastically but have not fractured. Surrounding the yield annulus, the slip annulus consists of the region where the asperities are subjected to shear fracture.

\subsubsection{Fretting regimes}

The elastic-plastic approach has been used to confirm the aforementioned characteristics of plastic deformation to allow for a more realistic description of the stick and slip zones. The definition of various fretting regimes based on the amplitude of oscillation was proposed by Vingsbo et al. [82,83] and became a very powerful tool for understanding the contact conditions and response of materials from a different perspective. This perspective consisted in the use of fretting maps for the wear regimes encountered in fretting conditions. According to this approach, fretting regimes have been classified as shown in Table 2.4 . 
Table 2.4 Basic fretting regimes, their characteristics, and corresponding loops.

\begin{tabular}{|c|c|c|c|c|}
\hline Regime & $\begin{array}{l}\text { Contact } \\
\text { radius }\end{array}$ & Characteristics & Fretting loop & \\
\hline Stick & $a^{\prime}=a$ & $\begin{array}{l}\text { - Low oscillation } \\
\text { amplitudes } \\
\text { - Elastic deformation } \\
\text { displacement } \\
\text { - No energy dissipation } \\
\text { - Limited surface damage } \\
\text { by oxidation and wear } \\
\text { - Low-damage fretting }\end{array}$ & $F_{\mathrm{T}} \uparrow$ & 8 \\
\hline Partial slip & $0<\mathrm{a}^{\prime}<\mathrm{a}$ & $\begin{array}{l}\text { - Plastic deformation } \\
\text { begins to occur } \\
\text { - Yield annulus is } \\
\text { formed, where } \\
\text { microslip occurs } \\
\text { - Central stick region } \\
\text { with elastic deformation } \\
\text { - Hysteresis loop forms } \\
\text { - Dissipation of energy } \\
\text { due to friction and } \\
\text { plastic deformation } \\
\text { - Small oxidation and } \\
\text { wear effects } \\
\text { - Fatigue cracks initiation } \\
\text { between stick and slip } \\
\text { zones }\end{array}$ & & $\stackrel{8}{\rightarrow}$ \\
\hline Gross slip & $a^{\prime}=0$ & $\begin{array}{l}\text { - Coefficient of friction } \\
\text { drops from maximum to } \\
\text { lower value } \\
\text { - } F_{T}=\mu F_{N} \\
\text { - Hysteresis loop expands } \\
\text { - Entire contact area in } \\
\text { macroslip region } \\
\text { - Severe oxidation and } \\
\text { wear damage } \\
\text { - Fretting wear occurs } \\
\text { - Elimination of fretting } \\
\text { fatigue cracks due to } \\
\text { wear process }\end{array}$ & $F_{\mathrm{T}} \uparrow$ & \\
\hline
\end{tabular}


The fretting regimes can also be identified on wear rate against displacement amplitude graphs (Figure 2.12). The regime can be determined from the selected amplitude displacement and the measured wear rate after the fretting test has been performed. The region of reciprocating sliding occurs at high oscillation amplitudes and is not part of fretting wear.

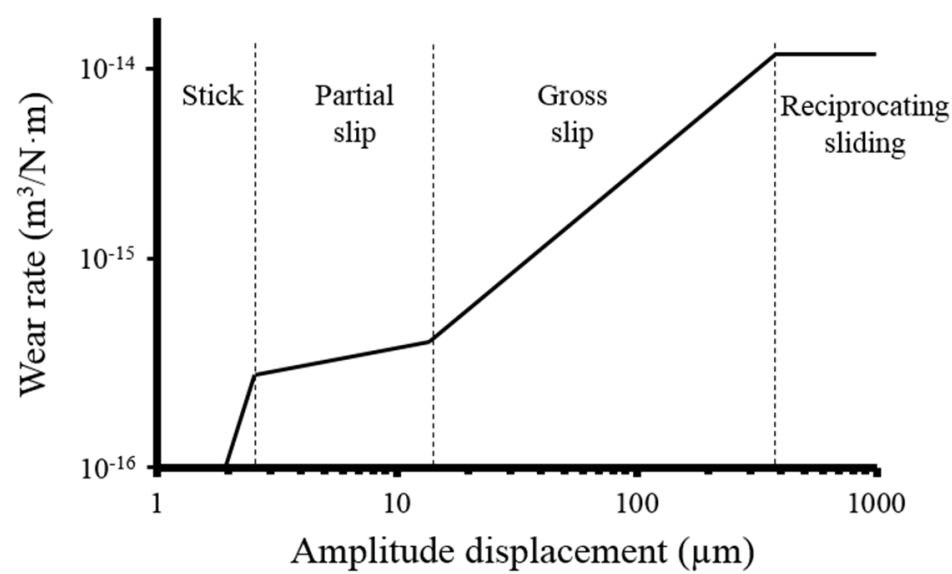

Figure 2.12 Wear rate variation for the three main fretting regimes with increasing oscillation amplitude [82]. Reciprocating sliding can also be observed. 


\section{REFERENCES}

[1] Subbarao EC. Ferroelectrics and superionic conductors. In: Wallace ECSE, Subbarao EC, editors. Science and Technology of Rare Earth Materials. Academic Press; 1980, p. 375-92.

[2] Heuer $\mathrm{AH}$, Rühle M. On the nucleation of the martensitic transformation in zirconia $\left(\mathrm{ZrO}_{2}\right)$. Acta Metall 1985;33:2101-12.

[3] Heuer AH, Rühle $\mathrm{M}$, Marshall DB. On the thermoelastic martensitic transformation in tetragonal zirconia. J Am Ceram Soc 1990;73:1084-93.

[4] Evans AG, Heuer AH. Transformation toughening in ceramics: martensitic transformations in crack-tip stress fields. J Am Ceram Soc 1980;63:241-8.

[5] Christian JW. Analyses of lattice and shape deformations and of atomic shuffles in martensitic transformation. Mater Sci Eng A 1990;127:215-27.

[6] Christian JW, Mahajan S. Deformation twinning. Prog Mater Sci 1995;39:1157.

[7] Piconi C, Maccauro G. Zirconia as a ceramic biomaterial. Biomaterials 1999;20:1-25.

[8] Eichler J, Eisele U, Rödel J. Mechanical properties of monoclinic zirconia. J Am Ceram Soc 2004;87:1401-3.

[9] Kelly JR, Denry I. Stabilized zirconia as a structural ceramic: An overview. Dent Mater 2008;24:289-98.

[10] Morita Y, Nakata K, Kim YH, Sekino T, Niihara K, Ikeuchi K. Wear properties of alumina/zirconia composite ceramics for joint prostheses measured with an end-face apparatus. Biomed Mater Eng 2004;14:263-70.

[11] Heuer $\mathrm{AH}$. Transformation toughening in $\mathrm{ZrO}_{2}$-containing ceramics. J Am Ceram Soc 1987;70:689-98.

[12] Rieth PH, Reed JS, Naumann AW. Fabrication and flexural strength of ultrafine-grained yttria-stabilized zirconia. Am Ceram Soc Bull 1976;55:71721,727 .

[13] Gupta TK, Bechtold JH, Kuznicki RC, Cadoff LH, Rossing BR. Stabilization of tetragonal phase in polycrystalline zirconia. J Mater Sci 1977;12:2421-6.

[14] Scott HG. Phase relationships in the zirconia-yttria system. J Mater Sci 1975;10:1527-35.

[15] Claussen N, Rühle $\mathrm{M}$, Heuer AH. Microstructural studies of $\mathrm{Y}_{2} \mathrm{O}_{3}$-containing 
tetragonal $\mathrm{ZrO}_{2}$ polycrystals (Y-TZP). In: Science and technology of zirconia II. United States: American Ceramic Society, Inc; 1983.

[16] Stevens R. Engineering properties of zirconia. Eng Mater Handb 1991;4:77585.

[17] Guazzato M, Albakry M, Swain MV, Ironside J. Mechanical properties of Inceram alumina and In-ceram zirconia. Int J Prosthodont 2002;15:339-46.

[18] Guazzato M, Albakry M, Ringer SP, Swain MV. Strength, fracture toughness and microstructure of a selection of all-ceramic materials. Part II. Zirconiabased dental ceramics. Dent Mater 2004;20:449-56.

[19] McMeeking RM, Evans AG. Mechanics of transformation-toughening in brittle materials. J Am Ceram Soc 1982;65:242-6.

[20] Hannink RHJ, Kelly PM, Muddle BC. Transformation toughening in zirconiacontaining ceramics. J Am Ceram Soc 2000;83:461-87.

[21] Piconi C, Labanti M, Magnani G, Caporale M, Maccauro G, Magliocchetti G. Analysis of a failed alumina THR ball head. Biomaterials 1999;20:1637-46.

[22] Green DJ, Hannink RHJ, Swain MV. Transformation toughening of ceramics. 1989.

[23] Butler EP. Transformation-toughened zirconia ceramics. Mater Sci Technol 1985;1:417-32.

[24] Tsukuma K, Kubota $Y$, Tsukidate T. Thermal and mechanical properties of $\mathrm{Y}_{2} \mathrm{O}_{3}$-stabilized tetragonal zirconia polycrystals. In: Science and technology of zirconia II. United States: American Ceramic Society, Inc; 1983.

[25] Zhang F, Vanmeensel K, Inokoshi M, Batuk M, Hadermann J, Van Meerbeek B, Naert I, Vleugles, J. 3Y-TZP ceramics with improved hydrothermal degradation resistance and fracture toughness. I Eur Ceram Soc 2014;34:2453-63.

[26] Lang FF. Transformation toughening: Part 1. Size effects associated with the thermodynamics of the constrained transformation. J Mater Sci 1982;17:22534.

[27] Eshelby JD. The determination of the elastic field of an ellipsoidal inclusion, and related problems. In: Proceedings of the Royal Society of London A: Mathematical, Physical and Engineering Sciences. The Royal Society; 1957;241:376-96.

[28] Evans AG, Burlingame N, Drory M, Kriven WM. Martensitic transformations in 
zirconia-particle size effects and toughening. Acta Metall 1981;29:447-56.

[29] Garvie RC, Swain MV. Thermodynamics of the tetragonal to monoclinic phase transformation in constrained zirconia microcrystals. J Mater Sci 1985;20:1193-200.

[30] Lang FF. Transformation toughening: Part 2. Contribution to fracture toughness. J Mater Sci 1982;17:235-9.

[31] Hayakawa M, Oka M. Structural study on the tetragonal to monoclinic transformation in arc-melted $\mathrm{ZrO}_{2}-2 \mathrm{~mol} . \% \mathrm{Y}_{2} \mathrm{O}_{3}-I I$. Quantitative analysis. Acta Metall 1989;37:2229-35.

[32] Hayakawa M, Adachi K, Oka M. Crystallographic analysis of the monoclinic herringbone structure in an arc-melted $\mathrm{ZrO}_{2}-2 \mathrm{~mol}_{\%} \mathrm{Y}_{2} \mathrm{O}_{3}$ alloy. Acta Metall Mater 1990;38:1753-9.

[33] Akagawa $\mathrm{Y}$, Ichikawa $\mathrm{Y}$, Nikai H, Tsuru H. Interface histology of unloaded and early loaded partially stabilized zirconia endosseous implant in initial bone healing. J Prosthet Dent 1993;69:599-604.

[34] Shah K, Holloway JA, Denry IL. Effect of coloring with various metal oxides on the microstructure, color, and flexural strength of $3 Y$-TZP. J Biomed Mater Res Part B Appl Biomater 2008;87:329-37.

[35] Vichi A, Louca C, Corciolani G, Ferrari M. Color related to ceramic and zirconia restorations: A review. Dent Mater 2011;27:97-108.

[36] Sandhaus S, Pasche K. Tenon radiculaire en zircone pour la realisation d'inlayscores tout ceramiques. Trib Dent 1994;2:2-17.

[37] Shen J. Advanced ceramics for dentistry. Butterworth-Heinemann; 2013.

[38] Chevalier J, Cales B, Drouin JM. Low-temperature aging of Y-TZP ceramics. J Am Ceram Soc 1999;82:2150-4.

[39] Lawson S. Environmental degradation of zirconia ceramics. J Eur Ceram Soc 1995;15:485-502.

[40] Chevalier J, Gremillard L, Deville S. Low-temperature degradation of zirconia and implications for biomedical implants. Annu Rev Mater Res 2007;37:1-32.

[41] Masonis JL, Bourne RB, Ries MD, McCalden RW, Salehi A, Kelman DC. Zirconia femoral head fractures: A clinical and retrieval analysis. J Arthroplasty 2004;19:898-905.

[42] Chevalier J, Deville S, Münch E, Jullian R, Lair F. Critical effect of cubic phase on aging in 3mol\% yttria-stabilized zirconia ceramics for hip replacement 
prosthesis. Biomaterials 2004;25:5539-45.

[43] Clarke IC, Green DD, Pezzoti G, Donaldson D. 20 year experience of zirconia total hip replacements. In: Chang JD, Billau K, editors. Bioceramics and Alternative Bearings in Joint Arthroplasty. Springer; 2005, p. 67-78.

[44] Chevalier J. What future for zirconia as a biomaterial? Biomaterials 2006;27:535-43.

[45] Kobayashi K, Kuwajima H, Masaki T. Phase change and mechanical properties of $\mathrm{ZrO}_{2}-\mathrm{Y}_{2} \mathrm{O}_{3}$ solid electrolyte after ageing. Solid State lonics 1981;3:489-93.

[46] Yoshimura M, Noma T, Kawabata K, Sōmiya S. Role of $\mathrm{H}_{2} \mathrm{O}$ on the degradation process of $Y$-TZP. In: Somiya S, editor. Hydrothermal Reactions for Materials Science and Engineering. Springer; 1989, p. 396-8.

[47] Jeong WC, Matlock DK, Krauss G. Observation of deformation and transformation behavior of retained austenite in a $0.14 \mathrm{C}-1.2 \mathrm{Si}-1.5 \mathrm{Mn}$ steel with ferrite-bainite-austenite structure. Mater Sci Eng A 1993;165:1-8.

[48] Girault E. Bainitic transformation in TRIP-assisted steels and its influence on mechanical properties. Ph. D. Thesis. K U Leuven MTM, 1999.

[49] Wang J, Stevens R. Surface toughening of TZP ceramics by low temperature ageing. Ceram Int 1989;15:15-21.

[50] Vleugels J, Yuan ZX, Van der Biest O. Mechanical properties of $\mathrm{Y}_{2} \mathrm{O}_{3} / \mathrm{Al}_{2} \mathrm{O}_{3}$ coated Y-TZP ceramics. J Eur Ceram Soc 2002;22:873-81.

[51] Burger W, Richter HG, Piconi C, Vatteroni R, Cittadini A, Boccalari M. New YTZP powders for medical grade zirconia. J Mater Sci Mater Med 1997;8:1138.

[52] Camposilvan E, Marro FG, Mestra A, Anglada MJ. Development of a novel zirconia dental post resistant to hydrothermal degradation. In: 6th EEIGM International Conference on Advanced Materials Research, 2012;31:12-6.

[53] Schmauder S, Schubert H. Significance of internal stresses for the martensitic transformation in yttria-stabilized tetragonal zirconia polycrystals during degradation. J Am Ceram Soc 1986;69:534-40.

[54] Tsubakino H, Hamamoto M, Nozato R. Tetragonal-to-monoclinic phase transformation during thermal cycling and isothermal ageing in yttriapartially stabilized zirconia. J Mater Sci 1991;26:5521-6.

[55] Zhu WZ, Lei TC, Zhou Y. Time-dependent tetragonal to monoclinic transition in hot-pressed zirconia stabilized with 2 mol\% yttria. J Mater Sci 
1993;28:6479-83.

[56] Chevalier J, Gremillard L, Virkar A V, Clarke DR. The tetragonal-monoclinic transformation in zirconia: lessons learned and future trends. J Am Ceram Soc 2009;92:1901-20.

[57] Avrami M. Kinetics of phase change. I General theory. J Chem Phys 1939;7:1103-12.

[58] Avrami M. Kinetics of phase change. II Transformation-time relations for random distribution of nuclei. J Chem Phys 1940;8:212-24.

[59] Avrami M. Granulation, phase change, and microstructure kinetics of phase change. J Chem Phys 1941;9:177-84.

[60] Deville S, Guénin G, Chevalier J. Martensitic transformation in zirconia: Part II. Martensite growth. Acta Mater 2004;52:5709-21.

[61] Deville S, Gremillard L, Chevalier J, Fantozzi G. A critical comparison of methods for the determination of the aging sensitivity in biomedical grade yttria-stabilized zirconia. J Biomed Mater Res Part B Appl Biomater 2005;72:239-45.

[62] Kelly PM, Rose LRF. The martensitic transformation in ceramics-Its role in transformation toughening. Prog Mater Sci 2002;47:463-557.

[63] Sato T, Shimada M. Crystalline phase change in yttria-partially-stabilized zirconia by low-temperature annealing. J Am Ceram Soc 1984;67:C212-3.

[64] Sato T, Ohtaki S, Shimada M. Transformation of yttria partially stabilized zirconia by low temperature annealing in air. J Mater Sci 1985;20:1466-70.

[65] Lange FF, Dunlop GL, Davis BI. Degradation during aging of transformationtoughened $\mathrm{ZrO}_{2}-\mathrm{Y}_{2} \mathrm{O}_{3}$ materials at 250 C. J Am Ceram Soc 1986;69:237-40.

[66] Schubert $\mathrm{H}$. Investigations on the stability of yttria stabilized tetragonal zirconia (Y-TZP). Zirconia Ceram 1986;7:65-81.

[67] Lepistö TT, Mantyla TA. A Model for Structural Degradation of Y-TZP Ceramics in Humid Atmosphere. In: Wachtman JB, editor. A Collection of Papers Presented at the 13th Annual Conference on Composites and Advanced Ceramic Materials, Part 1 of 2: Ceramic Engineering and Science Proceedings. Wiley Online Library; 1989;10:658-67.

[68] Guo X. Hydrothermal degradation mechanism of tetragonal zirconia. J Mater Sci 2001;36:3737-44.

[69] Guo X, Schober T. Water incorporation in tetragonal zirconia. J Am Ceram Soc 
2004;87:746-8.

[70] Schubert H, Frey F. Stability of Y-TZP during hydrothermal treatment: Neutron experiments and stability considerations. J Eur Ceram Soc 2005;25:1597-602.

[71] Duong T, Limarga AM, Clarke DR. Diffusion of water species in yttria-stabilized zirconia. J Am Ceram Soc 2009;92:2731-7.

[72] Bundschuh W, Zum Gahr KH. Influence of porosity on friction and sliding wear of tetragonal zirconia polycrystal. Wear 1991;151:175-91.

[73] Krell A, Klaffke D. Effects of grain size and humidity on fretting wear in finegrained alumina, $\mathrm{Al}_{2} \mathrm{O}_{3}$ /TiC, and zirconia. J Am Ceram Soc 1996;79:1139-46.

[74] Basu B, Vleugels J, Van der Biest O. Microstructure-toughness-wear relationship of tetragonal zirconia ceramics. J Eur Ceram Soc 2004;24:203140.

[75] Basu B, Lee JH, Kim DY. Development of nanocrystalline wear-resistant Y-TZP ceramics. J Am Ceram Soc 2004;87:1771-4.

[76] Bartolomé JF, De Aza AH, Martín A, Pastor JY, Llorca J, Torrecillas R, et al. Alumina/zirconia micro/nanocomposites: A new material for biomedical applications with superior sliding wear resistance. J Am Ceram Soc 2007;90:3177-84.

[77] Nath S, Sinha N, Basu B. Microstructure, mechanical and tribological properties of microwave sintered calcia-doped zirconia for biomedical applications. Ceram Int 2008;34:1509-20.

[78] Waterhouse RB. Fretting corrosion. Pergamon Press; 1972.

[79] Basu B, Kalin M. Tribology of Ceramics and Composites: A Materials Science Perspective. John Wiley and Sons; 2011.

[80] Waterhouse RB. Fretting wear. Wear 1984;100:107-18.

[81] Holland CD. A survey of present day knowledge of fretting fatigue. J Jr Inst Eng $1965 ; 76$.

[82] Vingsbo O, Söderberg S. On fretting maps. Wear 1988;126:131-47.

[83] Vingsbo O, Schön J. Gross slip criteria in fretting. Wear 1993;162-164:347-56. 




\section{CHAPTER 3: STATE OF THE ART - MICROWAVE SINTERING}



High temperature processes are required to consolidate ceramic powders, such as $\mathrm{Y}$-TZP, in order to obtain full densification of the material. Sintering is a common material processing technique aimed at fulfilling this task. The fundamental principle behind sintering consists in the thermal activation of mass transfer mechanisms when exposing a powder compact, known as a "green" body, to a high temperature process, at a dwell temperature below the melting point of the material. The main purpose of sintering is to obtain a dense and resistant body with properties as close as possible to those of a theoretical, fully-dense solid. However, in some cases, sintering can also be employed to adjust some of the properties based on the performance requirements of the material by not reaching full consolidation, such as in porous materials.

Two main types of sintering can be identified based on the nature of the process: liquid phase and solid phase. Even though the term liquid phase may suggest exceeding the melting point of the material, it is used to describe the addition of compounds with significantly lower melting points that aid in the consolidation of the main powder, which is regarded as the matrix phase and provides the main properties of the consolidated body. In this work, however, only solid phase sintering is considered.

\subsection{SOLID-STATE SINTERING FUNDAMENTALS}

The driving force in any sintering process is the reduction of the total free energy of the system. During this process, the change in energy is due to two main factors: (1) densification of the body and (2) growth and coalescence of grains. In the case of densification, particles change in shape, their centers come closer and the volume of the body decreases. The surface area of the initial, spherical-shaped particles becomes the grain boundary as the powder compact consolidates. As a consequence, the energy of the system decreases because the energy of the grain boundary is lower than that of two free particle surfaces. It is necessary, however, that the energy of the grain boundary is two times less that of the surface energy of two individual particles in order for densification to occur.

The characteristics of solid phase sintering are complex due to the mass transfer mechanisms involved in the process. Six possible mechanisms of mass transport in polycrystalline materials can be identified during solid state sintering [1], leading to the formation of bridges between the particles and allowing the growth of necks between them in order to bond them (Figure 3.1). These mechanisms are:

1. Surface diffusion: Material transport along the surface of the particles fills the neck region at an early stage. 
2. Lattice diffusion: Consists on the movement of vacancies through the lattice resulting in the transfer of material from a surface source to the neck region.

3. Vapor transport: Mass transfer where the material in the region close to the neck evaporates and is deposited into the neck region via condensation.

4. Boundary diffusion: Material transport along the boundary is driven by the high disorientation of atoms that is characteristic of grain boundaries.

5. Lattice diffusion (grain boundaries): Consists of material transported from the lattice along the grain boundary to the surface.

6. Lattice diffusion (bulk): Dislocations act as sources for vacancies which diffuse to the grain boundaries.

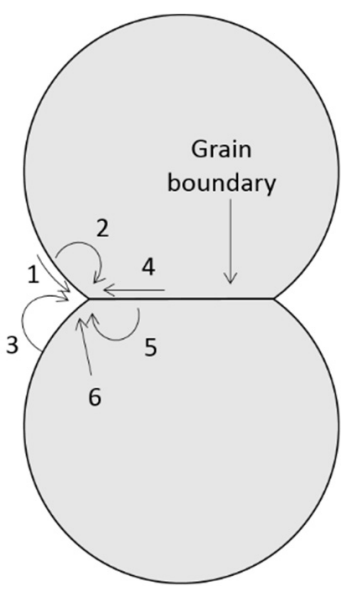

Figure 3.1 Two particle grain boundary diagram showing the six mass transport mechanisms involved in sintering of polycrystalline materials: 1) surface diffusion, 2) lattice diffusion, 3) vapor transport, 4) grain boundary diffusion, 5) lattice diffusion from the grain boundary, and 6) plastic flow. Taken and modified from [1].

All six mechanisms lead to bonding and growth of necks between the particles. However, only certain mechanisms lead to densification, making possible a distinction between densifying and non-densifying mechanisms. Among the most important densifying mechanisms in polycrystalline ceramics are grain boundary diffusion, which also leads to neck growth, and lattice diffusion from the grain boundary to the surface. Plastic flow can also lead to densification and grain growth, but is more common in the sintering of metal powders. The non-densifying mechanisms are surface diffusion, lattice diffusion from the particle surface to the neck, and vapor transport and they play an important role in reducing the curvature of the neck surface, which is the driving force for sintering. 
The sintering process can be divided into three main stages, as proposed by Coble [2]:

I. Initial stage (Figure 3.2a): This stage consists in the rapid interparticle neck growth by diffusion, vapor transport, plastic flow, or viscous flow and is responsible for removing the large initial differences in curvature at the surface. According to the two-sphere model, mass transport occurs from regions with a higher chemical potential to regions with a lower chemical potential, generating a chemical potential gradient between the particle surface and the neck region that acts as the driving force during this stage [3]. Neck growth is accompanied by shrinkage of the particles resulting in a slight densification of the material. Once a ratio of $0.4-0.5$ between the radius of the neck and the radius of the particle is reached, it is assumed that the initial phase has ended. For a green compact density of $0.5-0.6$, the relative density reached after this stage is approximately 0.65 .

II. Intermediate stage (Figure 3.2b): This stage begins when the pores have reached their equilibrium shapes as dictated by the surface and interfacial tensions. The pore phase is still continuous, but as this stage progresses, pores begin to shrink to reduce their cross-section and become unstable resulting in their isolation and enhancing densification. Also, grains become interconnected. The major part of the sintering processes is covered during this stage. It is during this stage that most of the densification and microstructural changes occur. A relative density of 0.9 is assumed to be reached at the end of this stage.

III. Final stage (Figure 3.2c): This stage begins when the pores pinch off and become isolated at the grain corners. The development of the final microstructure occurs in a variety of ways. In a very simple description, the pores shrink continuously, disappearing altogether. Relative density values $>0.9$ are obtained after this stage. This stage determines the final properties of the material. Increasing sintering time or temperature can eliminate the residual porosity during this stage, but it can also lead to excessive grain growth and coarsening [4]. 
a)

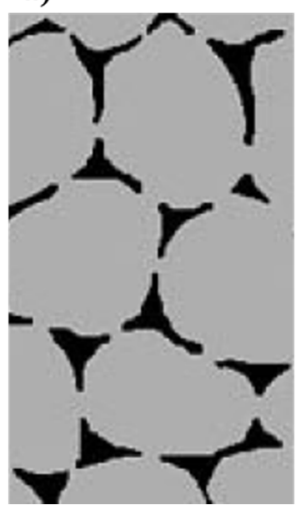

b)

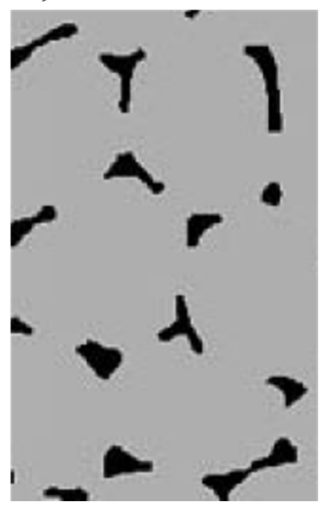

c)

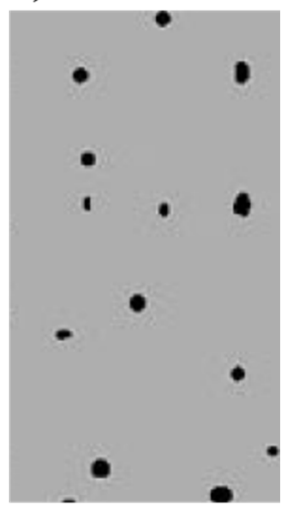

Figure 3.2 Evolution of particles during the three sintering stages: a) initial stage, b) intermediate stage, and c) final stage.

Grain growth is known as the process in which the average grain size of a singlephase polycrystalline material increases as a function of time and is driven by the reduction in the total grain boundary [5]. At the beginning of the final stage, the rate of grain growth is slow and the boundary is at first dragged by the pore. However, densification increases as the size and number of pores decreases. At a specific densification level, the boundary can drift away from the pore and dramatic acceleration of grain growth occurs [6]. Generally, as sintering times are increased, so does the average grain size of the material as smaller grains are absorbed by bigger ones, in what is known as Ostwald ripening. Since the material volume remains constant, for a grain to grow another one must contract. Grains grow due to the movement of the grain boundaries and, although they may disappear, no new grains are formed. This growth gives place to a reduction of the total boundary area and, hence, to a reduction in the energy of the total grain boundary. Thus, grain growth is a thermodynamically favorable process and will always occur unless it is kinetically limited.

Mass transport parallel to the grain boundaries during sintering favors densification, while perpendicular transport through the boundaries results in grain growth. As a consequence, grain growth can increase the transport distance for mass flow that contributes to densification and, hence, lower the densification rate [7].

The final grain size of the sintered ceramic, along with residual porosity, has a direct relationship with the resulting mechanical properties of the consolidated material. The yield stress of nanocrystalline materials with a grain size above $10 \mathrm{~nm}$ generally exhibits a Hall-Petch relationship given by the following equation: 


$$
\sigma_{y}=\sigma_{0}+\frac{k_{y}}{\sqrt{d}}
$$

where:

$\sigma_{y}=$ yield stress

$\sigma_{0}=$ material constant for the starting stress of dislocation movement

$k_{y}=$ strengthening coefficient, specific to each material

$d=$ average grain diameter

This expressions establishes an inverse square root relationship between grain size and fracture stress, which means that a bigger grain size results in a lower yield stress. However, regarding ceramics differing grain size relationships have been observed. For example, in a review of oxide and non-oxide ceramics by Rice et al. [8], it was found that for $\mathrm{ZrO}_{2}$ the dependence of Vickers hardness, $H_{v}$, on grain sizes between 0.5 and $50 \mu \mathrm{m}$ is quite low. On the other hand, $\mathrm{Al}_{2} \mathrm{O}_{3}$ exhibited approximately a $10 \%$ reduction in $H_{v}$ with a 10 fold increase in grain size.

The behavior of a material in terms of densification and grain growth can be represented in curves such as the one shown in Figure 3.3. When a material follows curve $y$, densification and grain growth occur simultaneously. Nonetheless, in order to obtain densities close to theoretical values, grain growth needs to be inhibited until most of the contraction has taken place. In other words, the goal is to have a system that follows the trajectory observed for curve $z$, where densification is followed by grain growth. When the material follows curve $x$, there is no sufficient densification and the final microstructure is found to be porous and grains are substantially big. Eliminating pores is quite difficult once they have been formed. Since high density and small grain size are the microstructural characteristics that enhance most engineering properties, pushing the curve further towards relative densities closer to $100 \%$ with minimum grain growth is desired. However, this requires the modification of the diffusion mechanisms involved. Several possibilities exist to allow this modification. Among them, there are three that can be highlighted:

1. Introduction of second phases at the grain boundary or doping with several element that change the state of charges at the grain boundaries.

2. Two-step sintering, where the first sintering step usually takes place at a lower temperature.

3. Non-conventional sintering methods, such as FAST sintering techniques [9], microwave sintering and reaction sintering. 


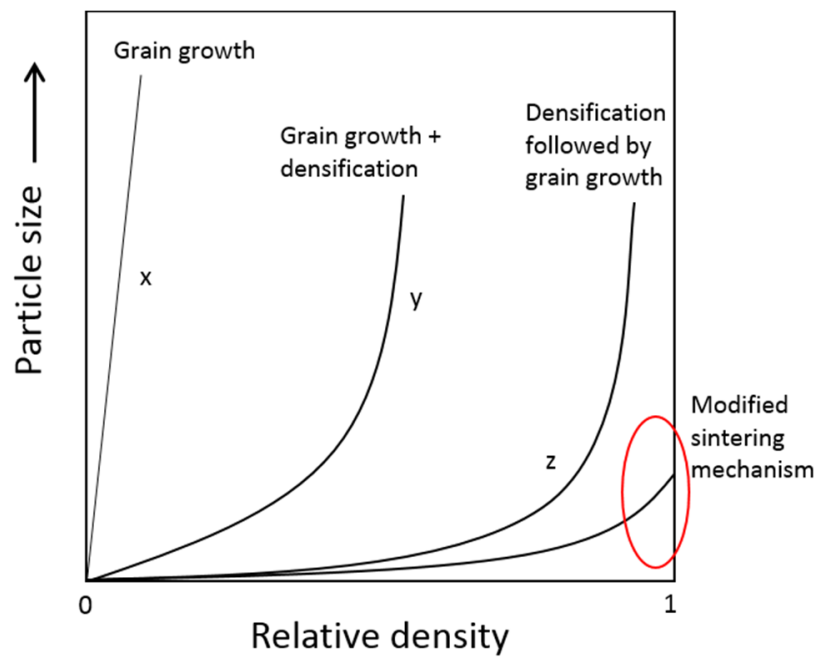

Figure 3.3 Grain growth versus relative density evolution for three different scenarios: grain growth with no densification (curve $x$ ), grain growth with simultaneous densification (curve $y$ ), and densification followed by grain growth (curve $z$ ). A fourth scenario is shown for modified sintering mechanism aiming at limited grain growth and a very high degree of densification.

In this work, the modification of diffusion mechanisms takes place by means of nonconventional sintering methods, specifically microwave sintering. Several factors intervene in the sintering process. Some of the variables are inherent to the material and some are related to the sintering process itself. Table 3.1 summarizes these variables by classifying them in these two categories. Material variables influence compaction and sintering, and, therefore, densification and grain growth. Process variables are of thermodynamic character and their effects on the sintering process have been widely studied elsewhere [10-12].

Table 3.1 Variables that affect sintering and microstructure. Taken and modified from [7].

\begin{tabular}{cc}
\hline Material related variables & Process related variables \\
\hline Particle shape & Temperature \\
Particle size & Time \\
Size distribution & Pressure \\
Particle dispersion & Atmosphere \\
Composition & Heating/cooling rate \\
Purity grade & \\
Homogeneity & \\
\hline
\end{tabular}




\subsection{CONVENTIONAL SINTERING}

Throughout centuries, several ceramic materials, such as clay and porcelain, have been sintered via traditional sintering methods as a means for the fabrication of pottery and other tools. These methods consisted on the heating in ovens of a low density body for several hours until the material was hard enough for its specific use. Nowadays, conventional sintering usually involves the utilization of special industrial ovens for material consolidation. Among the most well-known ovens employed for conventional sintering are electrical resistance furnaces, which make use of inductive heating in order to reach the desired temperature (Figure 3.4).

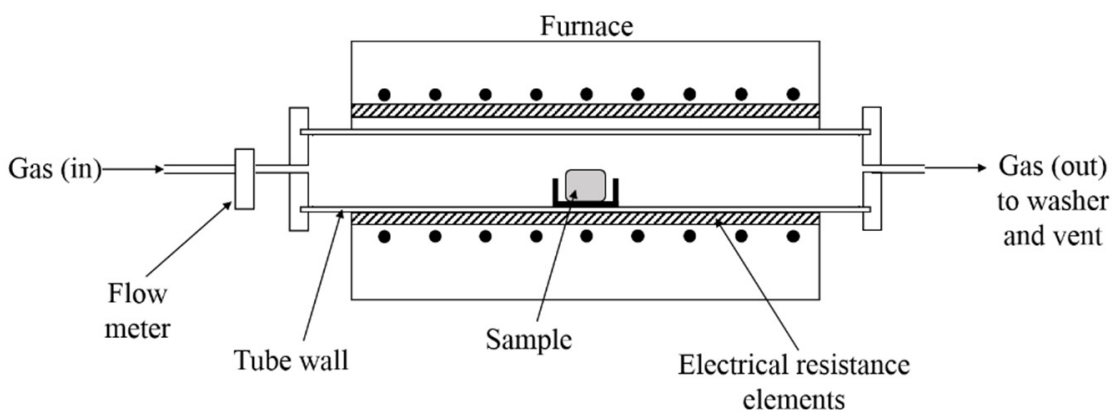

Figure 3.4 Schematic diagram of electrical induction tube furnace used for conventional sintering with controlled atmosphere.

In conventional sintering, green bodies are placed inside an oven with a particular controlled atmosphere (vacuum, air, $\mathrm{Ar}, \mathrm{N}_{2}$ ) and heated up to a specific temperature for a certain period. Heating rates can be established beforehand in order to control the heating process. For ceramic materials, sintering temperatures are quite high, comprehending a range between 1000 and $1800{ }^{\circ} \mathrm{C}$ and dwell times can vary from a few to several hours.

During conventional sintering, heating occurs by the three conventional heat transfer mechanisms: conduction, convection and radiation. Conduction results by heat diffusion between surfaces in contact, for example in walls inside the furnace that are in contact with the compact. Convective heat transfer occurs from the bulk flow of the gas in the furnace to the compact surface. Thermal radiation is emitted by high-temperature furnace elements and converted into electromagnetic energy that is transferred to the surroundings. The compact receives this electromagnetic energy causing it to heat up. Heat from radiation is, however, quite low and most of the heating of the compact occurs by means of conduction and convection.

Due to the nature of heat transfer mechanisms involved in this method, the surface of the material always heats first and a temperature gradient between the compact 
surface and the interior of the material arises resulting in heat flow from the surface to the bulk. As a consequence, considerably long dwell times ( $>2 \mathrm{~h}$ ) are required in order to obtain a complete temperature homogenization and uniform heat distribution.

Another important sintering approach is pressure-assisted sintering, which consists in the external application of pressure during the heating process. Three main ways can be employed to apply pressure. The first one is hot pressing results from uniaxially applying pressure to the powder in a die. The second one is sinter forging, which is similar to hot pressing but without confining the sample in a die. The third one is called hot isostatic pressing (HIP), which consists in the isostatic application of pressure by means of a gas. Pressure-assisted sintering enhances the rate of densification significantly relative to the coarsening rate [1]. However, an important disadvantage of pressure-assisted sintering is the high cost of production being only available for specific industrial applications that require specialized, high-cost components. Another limitation is that only simple shapes can be processed due to the use of dyes.

Currently, most dental commercial materials are processed by conventional sintering. One of the major drawbacks of these systems, particularly for ceramics, is the high energy consumption required to reach such high temperatures and dwell times in order to obtain an adequate densification and mechanical properties. Therefore, new approaches on sintering of these materials need to be explored. Dental pieces are quite small and employing furnaces for heating components with such dimensions would not be energetically efficient. Hence, sintering systems with focalized energy delivery to the material, such as microwave sintering, can decrease energy use significantly. Moreover, techniques must be flexible and allow for the processing of near-net-shape materials because complex and unique pieces are needed in dentistry since shapes vary completely from one patient to the next. Therefore, microwave sintering confirms as an interesting alternative for the processing odontological ceramics, such as yttria-stabilized tetragonal zirconia.

\subsection{MICROWAVE SINTERING}

Microwaves have been used since the 1960's for heating purposes, particularly for food and water-based products. Industrially, the use of microwave energy has become increasingly important because it represents an alternative to traditional, energy-intensive, high-temperature processes. For example, so far it has been employed in wood drying, resin curing and polymer synthesis. The growing interest in industrial microwave heating is due mostly to the reduction of production costs resulting from lower energy consumption and shorter processing times [13-15]. 
However, several aspects need to still be investigated as each material behaves differently in the presence of microwaves.

The application of microwave heating has now expanded to material science and technology, beginning with process control and moving onto ceramic drying, powder calcination and decomposition of gases with microwave plasma, in addition to powder synthesis [16]. Scientific interest on this powerful tool has been recorded in the literature as there has been an increase of bibliographical entries for the term "microwaves" in the last decades because the applications of this technology have diversified enormously. In the last 25 years, research and development on the dielectric heating attributed to microwaves began with topics in chemical synthesis and material processing, such as reactive sintering of superconductors, magneto resistors, nanomaterials production, vitreous phase formation, hydrothermal generation of zeolites, among others [17]. In this sense, one of the major areas for research and development of microwave heating involves sintering of ceramic powders $[18,19]$.

Microwave sintering is considered a relatively new ceramic material processing technique that differs significantly from conventional sintering methods due to the nature of the heat transfer mechanisms involved. Hence, microwave sintering is classified as a non-conventional sintering technique. This method presents itself as a fast, economical and flexible processing tool. Some of the most important advantages against conventional sintering systems include lower energy consumption and production costs, reduction of processing times, higher heating rates, and, in some cases, even an improvement in the physical properties of the consolidated material $[13,20]$. As a consequence, scientific interest in this novel technique has been developed progressively.

In a general sense, microwave sintering increases the densification of the material at lower dwell temperatures when compared to conventional sintering [21,22], employing shorter times and less energy [23,24], and resulting in an improvement of the microstructure and mechanical properties $[25,26]$.

The first sinterability studies of ceramics by exposure to microwave energy were carried out on the so called "black ceramics", which are the compounds based on tungsten carbide (WC). Two of the main issues regarding sintering of these materials by conventional means are the high temperatures $\left(>1500^{\circ} \mathrm{C}\right)$ and long dwell times that result in grain coarsening. For the first time, in 1991, J. P. Cheng showed that the WC/Co system could be sintered by microwave heating technology [27]. In his work, a commercial WC powder with a 6-12 mol\% Co content was investigated and an improvement in the mechanical properties was achieved when compared to conventional methods by utilizing sintering temperature between 1250 and $1320^{\circ} \mathrm{C}$ 
and dwell times of only $10-30 \mathrm{~min}$ [28]. Relative density values were close to theoretical and a fine and homogeneous microstructure was observed, without the use of grain growth inhibitors. Also, the materials exhibited a higher resistance to corrosion and erosion [29].

The next step involved the processing of more traditional ceramic materials such as alumina and zirconia. Even though alumina behaves as a transparent material in the presence of microwaves, susceptors, which are materials with high microwave absorbance, or dopants can be employed. Tian et al. were able to obtain $99.9 \%$ relative density values with an average grain size of $1.9 \mu \mathrm{m}$ for $\mathrm{MgO}$-doped $\mathrm{Al}_{2} \mathrm{O}_{3}$ sintered at $1700{ }^{\circ} \mathrm{C}$ in a microwave oven [30]. Additionally, Katz and Blake were able to reach a densification of $99 \%$ for $\alpha$-alumina with grain sizes between 5 and $50 \mu \mathrm{m}$ after microwave sintering, where the total processing time was $100 \mathrm{~min}$ at a dwell temperature of $1400^{\circ} \mathrm{C}$ [31]. Transparent alumina materials have also been obtained via microwave processing at lower sintering temperature and shorter times [32].

In the case of nanometric yttria-stabilized zirconia (YSZ), microstructure and mechanical properties can be enhanced when processed via microwave sintering [33]. By application of hybrid heating with the aid of a susceptor, sintered materials with densities close to theoretical values can be obtained at temperatures $200{ }^{\circ} \mathrm{C}$ below those employed in conventional sintering [34,35]. Moreover, grain size decreases considerably and hardness values are almost 2 GPa higher [26].

In the last five years, research on microwave sintering has also focused in the processing of ceramic composites to improve their functional as well as structural properties and extend its applications to several industrial sectors. Also, design and optimization of current microwave ovens has also been an important research topic. These systems need to be adjusted to the characteristics of the material that is to be processed, since the behavior under a microwave field varies from one to another. Therefore, studying the fundamental principles and involved mechanisms in microwave energy conversion may allow the production of more energy efficient ovens.

\subsubsection{MICROWAVE HEATING FUNDAMENTALS}

Microwaves are a form of electromagnetic radiation that correspond to frequencies between $300 \mathrm{MHz}(\lambda=1 \mathrm{~m})$ and $300 \mathrm{GHz}(\lambda=1 \mathrm{~mm})$, as shown in Figure 3.5. Among their most important industrial applications are telecommunications and heating. The possibility to use microwave energy for heat generation was first discovered in the late 1940s while tests were being carried out with magnetrons [15]. Consequently, the first microwave systems for food heating were developed. As research in microwave energy and its applications continued, uses expanded to 
industrial processes such as drying and curing. In the last few decades, sintering of materials with microwave radiation has also become an active field of investigation.

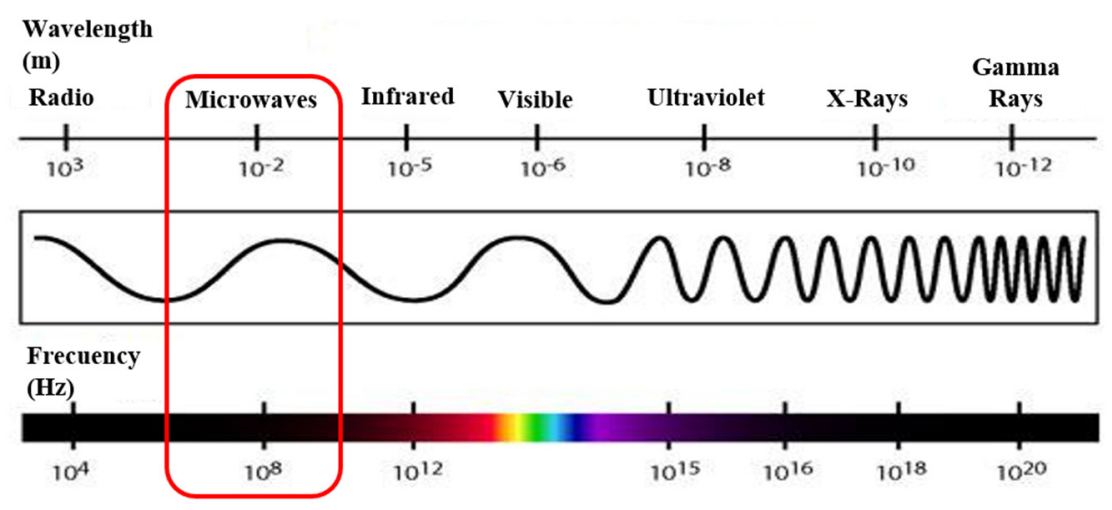

Figure 3.5 Electromagnetic spectrum diagram highlighting the region encompassed by microwaves.

\subsubsection{Interaction of Microwaves with Matter}

Microwaves, as any other type of electromagnetic radiation, have electrical and magnetic field components, amplitude, phase angle, and the ability to propagate, that is, to transfer energy from one point to another. These properties govern the interaction of microwaves with materials and produce heating in some of them. Depending on the electrical and magnetic properties of the material, their interaction with microwaves can be classified as one of three types [16]:

- Transparent: Microwaves penetrate and are transmitted through the material completely with no energy transfer occurring (Figure 3.6a). These materials are known as low loss insulators.

- Opaque: Microwaves are reflected with no penetration into the material and no energy transfer. These are known as conductors (Figure 3.6b). Metals are mostly considered to be opaque to microwave energy.

- Absorbent: Microwaves are absorbed by the material and an exchange of electromagnetic energy occurs (Figure 3.6c). The amount of absorption depends on the dielectric properties of the material. 
a)

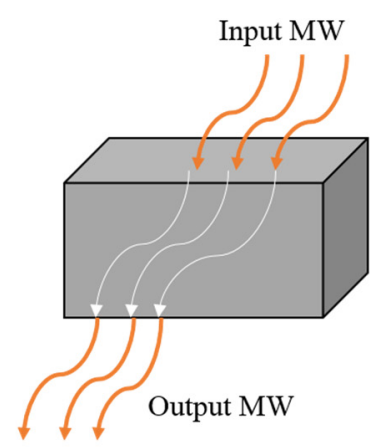

b)

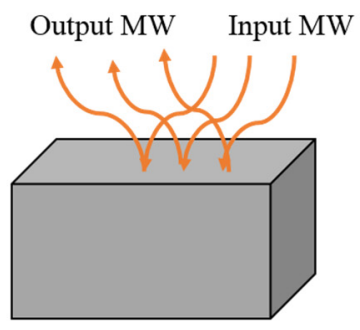

c)

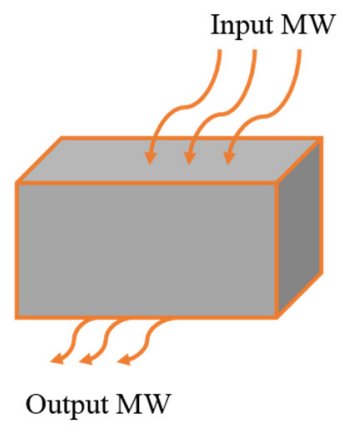

Figure 3.6 Material/microwave interaction representation classified according to their behavior: a) transparent, b) opaque, and c) absorbent.

A fourth type of interaction known as mixed absorption has also been proposed. In this particular case, mixed or multi-phase materials with different degrees of microwave absorption are sought after. Most electrically insulating ceramics such as alumina, $\mathrm{MgO}$, silica and glasses are transparent to microwaves at room temperature, but, when heated above a certain critical temperature $T_{c}$, they begin to absorb and couple more effectively with microwave radiation. Other ceramics, such as SiC, are able to absorb microwave energy more efficiently at room temperature. Therefore, the addition of a microwave-absorbing second phase to ceramics that behave transparent at room temperature can greatly enhance the interaction of the system with microwaves allowing a hybrid heating of the material. In Section 3.3.4, a more in depth description of hybrid heating is given.

\subsubsection{Microwave Heating Mechanisms}

In order to explain the interaction of absorbing materials with microwave radiation and the energy transfer that occurs during this interaction, several physical mechanisms have been proposed. These mechanisms include: bipolar rotation, resistive heating, electromagnetic heating and dielectric heating. Depending on the material, the response to incoming radiation can be attributed to one mechanism or a combination of several of them.

Bipolar rotation occurs when electrically neutral polar molecules with positive and negatives charges are separated. Within a microwave field, this dipoles rotate in the direction of increasing amplitude. As a consequence of this rotations, friction among the molecules arises generating heat uniformly throughout the material. 
Resistive heating occurs in conductors or semiconductors with relatively high electrical resistivity. These materials possess free electrons or a high ionic content where the ions receive enough freedom so current can be generated.

Electromagnetic heating takes place in materials with magnetic properties that are highly susceptible to external electromagnetic fields, such as those induced by microwave radiation. This type of heating can be described as magnetic pole rotation of the material analogous to the rotation of polar molecules in oscillating electrical fields.

Finally, the fourth mechanism, dielectric heating, is a mix of bipolar rotations and resistive heating. In microwave sintering of ceramics, this is the predominant mechanism. In the next section, the principles of dielectric heating in microwaveabsorbent materials are described.

\subsubsection{THEORETICAL ASPECTS IN DIELECTRIC HEATING}

The degree of interaction between the microwave electric and magnetic field components with the dielectric or magnetic material determines the rate at which energy is dissipated in the material by the various mechanisms. The properties of the material that are most important for the interaction are the permittivity $\varepsilon$ for a dielectric material and the permeability $\mu$ for a magnetic material [1]. Considering that dielectric heating is the most relevant mechanism for ceramics, this description will only focus in aspects related to permittivity and properties that arise from it.

When microwaves penetrate the material, the electromagnetic field induces motion in the free and bound charges (electrons and ions) and in dipoles. The induced motion is resisted because it causes a departure from the natural equilibrium of the system, and this resistance due to frictional, elastic and inertial forces, leads to the dissipation of energy. As a result, the electric field associated with microwave radiation is attenuated, and heating of the material occurs.

The dielectric interaction between materials and microwave radiation can be described by two main parameters [13,36-39]:

- $\quad$ Absorbed power, $P$

- $\quad$ Depth of microwave penetration, $D$

Both parameters play a critical role in the uniform heating of the material. The absorbed power is the volumetric absorption of microwave energy (in $\mathrm{W} / \mathrm{m}^{3}$ ) and is expressed according to the following equation:

$$
P=\sigma|E|^{2}=2 \pi f \varepsilon_{0} \varepsilon^{\prime \prime}|E|^{2}=2 \pi f \varepsilon_{0} \varepsilon^{\prime} \tan \theta|E|^{2}
$$


where:

$f=$ frequency of the electric field

$E=$ amplitude of the electric field

The loss tangent, $\tan \theta$, is a term associated with the capacity of the material to be polarized and heat itself. In other words, this terms describes the microwave energy conversion into heat. The relationship describing the loss tangent is given by:

$$
\tan \theta=\varepsilon^{\prime \prime} / \varepsilon^{\prime}
$$

where:

$\varepsilon^{\prime \prime}=$ loss factor

$\mathcal{E}^{\prime}=$ dielectric constant, inherent to the material

The loss factor, $\varepsilon$ ", measure the ability of the material to convert the incoming microwave energy into heat, and the dielectric constant, $\varepsilon^{\prime}$, measures the polarizability of the material. In microwave material processing, maximum values for $\varepsilon$ " in combination with mild values of $\varepsilon$ ' are desired (Figure 3.7)

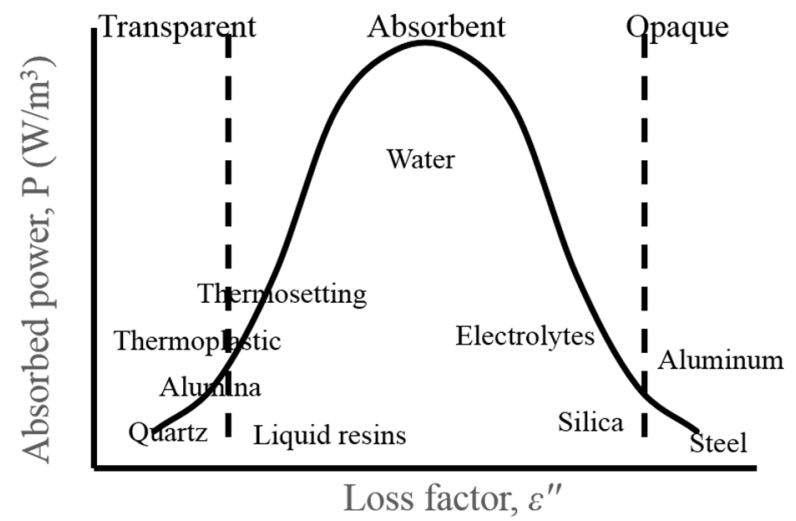

Figure 3.7 Relationship between factor loss and absorbed power at a frequency of $2.45 \mathrm{GHz}$ and room temperature for some common materials.

Both, $\varepsilon^{\prime}$ and $\varepsilon^{\prime \prime}$, depend on temperature and the frequency of the field. At low frequencies, all microwave energy is absorbed by the rotating movement of the dipoles and $\varepsilon$ ' reaches a maximum, however, there are no collisions because the displacement is very slow. At high frequencies the material does not have enough time to respond to the oscillating electric field, therefore, $\varepsilon^{\prime}$ reaches a minimum. The loss of energy caused by the collisions is represented by $\varepsilon$ ". The key relies on finding a frequency for each material at which the absorption of energy $\left(\varepsilon^{\prime}\right)$ as well as the loss of energy ( $\left.\varepsilon^{\prime \prime}\right)$ are high. 
A general explanation is based on a fundamental body, such as a grain particle, in its neutral state contains polarized molecules distributed in random positions. These molecules can easily be reoriented by the effect of an external electric field, as shown in Figure 3.8.

a)

Molecules with random orientation

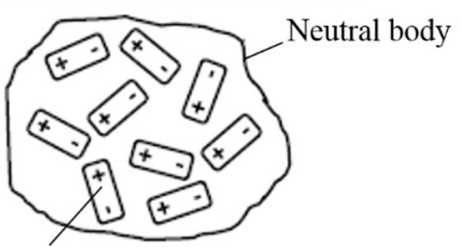

Polarized molecules b)

Reoriented molecules Polarized body

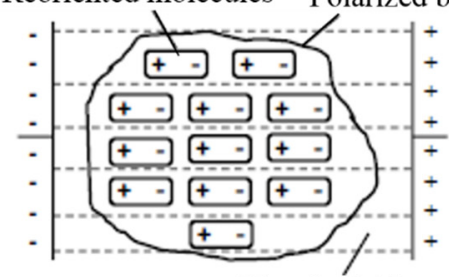

Electric field

Figure 3.8 Position of the molecules a) in its natural state, and b) with the application of an external electric field.

If the polarity of the electric field is changing constantly, molecules will modify their orientation accordingly in a very fast manner so as to align with the field (Figure 3.9) and, as a consequence, heat will be generated due to the friction among them and electrical resistive effects from unbound charges. The material heats up as a function of the absorbed energy during this process.

Molecules oscillating at signal frequency

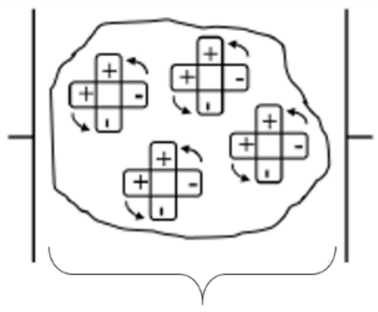

Alternating signal

Figure 3.9 Representation of the reorientation of the molecules in the presence of an alternating electric field, such as that induced by microwaves.

The main difference with respect to conventional sintering is the direction of heat flow [40] because in conventional sintering heat is transferred from the surface of the material towards the inside due to the heating mechanisms involved. In contrast, in microwave sintering, in the presence of a strong electric field, molecules vibrate with the same intensity and at the same time generating heat throughout the whole material as a consequence of the characteristics of dielectric heating. 
The second main parameter in microwave/material interaction is microwave penetration depth, $D$. This parameter determines the penetration depth at which the power is reduced by half and is expressed in the following manner:

$$
D=\frac{3 \pi_{0}}{8.686 \pi \tan \theta\left(\frac{\varepsilon^{\prime}}{\varepsilon_{0}}\right)^{\frac{1}{2}}}=\frac{C}{2 \pi f \sqrt{2 \varepsilon^{\prime}}\left(\sqrt{1+\tan ^{2} \theta-1}\right)^{\frac{1}{2}}}
$$

High frequencies in combination with high dielectric property values translate into superficial heating of the material, while low frequencies with small dielectric property values give place to volumetric heating.

Based on the properties of materials, it is well-known that those with a high conductivity and permeability present a lower penetration depth for a given frequency. The penetration depth of many materials oscillates around $1 \mu \mathrm{m}$, which means that heating tends to stay at the surface. If powders with a particle size of approximately that of $D$ are employed, there is the possibility to heat the whole surface directly and homogenously.

\subsubsection{MICROWAVE SYSTEMS FOR HEATING}

A microwave oven is composed of three main elements: 1) microwave source, which is in charge of generating the electromagnetic radiation, 2) transmission lines, which transmit the microwaves, and 3 ) a resonant cavity, which is where the interaction with matter takes places [36].

The theoretical principle that governs each of the components is based on Maxwell equations $[38,41]$ :

$$
\begin{array}{rr}
\nabla \times \mathbf{E}=\frac{\partial \mathbf{B}}{\partial t} ; & \nabla \cdot \mathbf{B}=0 \\
\nabla \times \mathbf{H}=\frac{\partial \mathbf{D}}{\partial t}+\mathbf{J} ; & \nabla \cdot \mathbf{D}=\rho
\end{array}
$$

where:

$\mathbf{E}=$ electric field vector

$\mathbf{B}=$ magnetic flux density vector

$\mathbf{H}=$ magnetic field vector

$\mathbf{J}=$ current density vector

$\mathbf{D}=$ electric flux density vector

$\rho=$ charge density

Maxwell equations are the physical laws that describe an electromagnetic field and its variations with time. The design of an efficient microwave system to process materials requires understanding of electromagnetic theory. 
In the following paragraphs a description of the different components that are part of a microwave system is given.

Magnetron: This is the most important part of a microwave source. This device transforms the electrical energy from the low frequency electric grid into high frequency electromagnetic energy (microwaves). It consists of a metallic cylinder where a series of resonant cavities are disposed radially and communicated to a major central cavity, which has a titanium filament in its axis (Figure 3.10). The cylinder acts as anode and the central filament as a cathode. The filament, which is connected to the negative pole of a continuous current source, becomes incandescent and emits electrons by thermionic effect. The cylinder, connected to the positive pole, attracts the electrons. The whole setup is located between the poles of a powerful electromagnet.

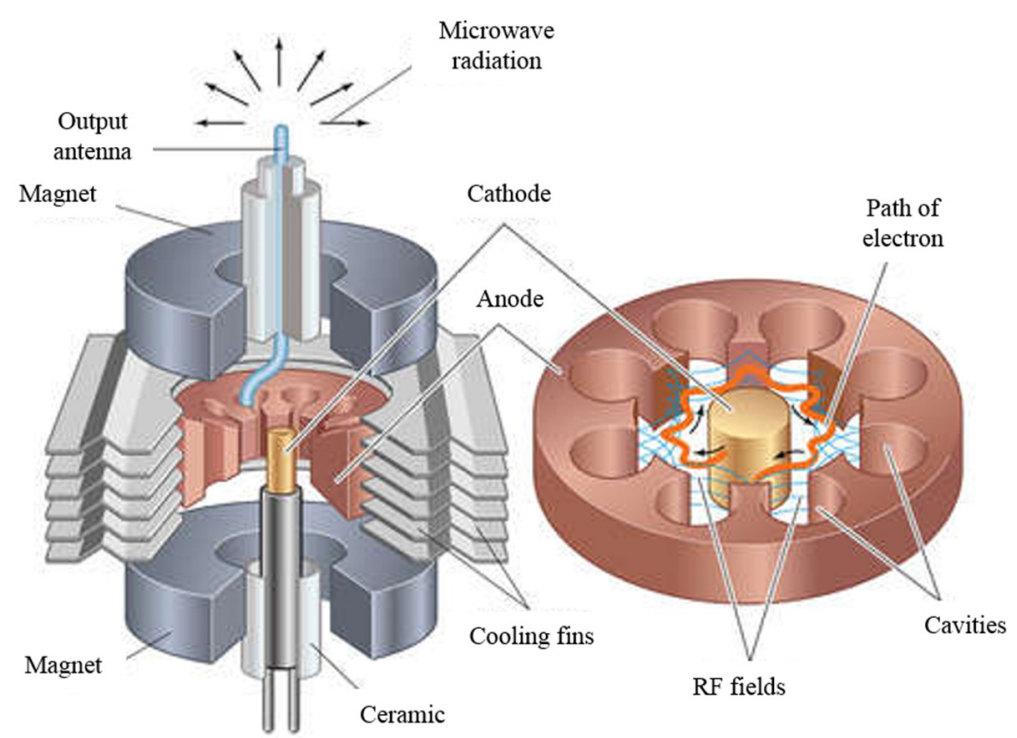

Figure 3.10 Magnetron schematic showing all the elements required for generation of microwave radiation.

The open space between the plate and the cathode is referred to as interaction space. In this space, electric and magnetic fields interact to exert a force on the electrons. Given that an electric charge creates an electromagnetic field around it, all the electrons, moving in circles in the cavities, produce electromagnetic waves, in this case microwaves, perpendicular to their own displacement and with a frequency that depends on the size of the cavities.

Usually, for microwave heating applications, the frequency of the generated electromagnetic radiation is $2.45 \mathrm{GHz}$. This frequency corresponds to one of the so- 
called Industrial, Scientific and Medical (ISM) frequencies, which are free of utilization for these type of applications. The insertion of magnetrons in commercial microwave ovens for home use has translated in more economical sources of this frequency by allowing the fabrication of magnetrons in a big scale. Moreover, other ISM frequencies are also employed for heating applications, such as Bluetooth and WiFi [39]. The power generated by the magnetron can be controlled by changing the amplitude of the cathode's current or the intensity of the magnetic field.

Transmission lines: This element is responsible for transmitting the generated microwave radiation by the source to the main cavity. In low power systems, transmission lines are usually coaxial cables. However, for high frequency systems the loss occurring in the coaxial cables is quite substantial. Therefore, circular or rectangular waveguides are necessary for proper wave transmission.

Circulator: This component provides protection to the source against possible unwanted load reflections. The circulator is capable of redirecting the microwave power that was not consumed by the material to be sintered towards a water load. This water load heats up avoiding that the reflected power gets back causing damages to the source.

Reflectometer: This element measures the effective consumed power by the material sample to be heated. This information provides reliable information about the power consumed during the sintering of the sample.

Tuning system: This element is fixed to the microwave oven and is employed to couple the microwave incident radiation to the cavity. Different types of tuners can be utilized. For example, the simplest one consists of an iris that couples the incident power directly to the cavity. More complex tuners are the three-stub adapter that allows a dynamic adaptation of the coupling process to the cavity.

Resonant cavity: This is the microwave system nucleus, where the incident electromagnetic radiation heats and sinters the material. Cavity design is one of the most critical parts of microwave equipment for material processing. The temperature distribution within the material, which is heated by microwave radiation, is inherently linked to the distribution of the electric field inside the cavity. In material processing, resonant cavities with different mode configurations, including single-mode, multi-mode and multi-mode with variable frequency, are employed [41,42].

The size of a single-mode resonant cavity must be in the order of one wavelength. Additionally, in order to maintain a resonant mode, these systems require a microwave source that allows frequency variations or that the cavity dynamically changes its size to couple the frequency of the microwaves. Generally, the 
distribution of the electromagnetic field in this type of cavity is well-known. With an adequate cavity design, the microwave field may be focalized to a particular zone where the material sample can be sintered. An additional advantage for this type of cavity is the fact that the dielectric properties of the material can be monitored during sintering.

Multi-mode cavities are able to maintain several modes simultaneously. The design of home microwave ovens is based on this type of cavity. The greater the size of the cavity, the higher the number of possible resonant modes. Hence, multi-mode cavities are bigger than a wavelength, which contrast with the size of single-mode systems.

The presence of different resonant modes results in the existence of multiple hotspots inside the cavity. Local fluctuations in the electromagnetic field can result in overheating of certain areas. In order to minimize these hotspots, the electromagnetic field must be uniform. Field uniformity can be achieved by increasing the size of the cavity and varying the sample position dynamically, for example, with a rotating plate or stirrers. By increasing cavity size, the number of modes increases and, as a consequence, the heating patterns of each mode begin to superimpose and the stirrers or the plates change the distribution of the field inside the cavity.

\subsubsection{MICROWAVE HYBRID HEATING: BIDIRECTIONAL HEATING}

One of the main issues associated with microwave sintering of materials is their initial microwave radiation absorption and heating. Most of the processing is carried out at a relatively low frequency of $2.45 \mathrm{GHz}$, which makes the initial heating of the material very difficult to control. Another important problem that may arise consists in the thermal instability that materials are prone to due to the changes in their properties, such as their dielectric constant, $\varepsilon^{\prime}$. Variations in dielectric properties as a function of temperature may translate into poor temperature control and overheating of the specimen. Such behavior is present in several materials such as alumina and zirconia.

Temperature gradients that arise during heating can produce microcracking and an unequal distribution of resulting physical properties, such as density and hardness. Therefore, thermal insulators or coatings may be necessary to avoid the presence of these gradients. Nonetheless, these insulators can provoke control loss of the temperature. 
Ceramics tend to exhibit an abrupt increase in $\varepsilon$ " as a function of increasing temperature. The temperature at which dielectric properties change is known as the critical temperature, $T_{c}$. Below $T_{c}$, at a given frequency, most ceramics are poor absorbers behaving as transparent materials and need to be heated by an external source. No mathematical relationship has been found that relates temperature to fundamental material properties, hence $T_{c}$ values must be measured experimentally $[43,44]$. This $T_{c}$ can pose some problems when processing complex and large samples. Unless heated uniformly by an external source, localized hotspots can develop in the material. These spots begin to absorb microwave radiation before the rest of the material in phenomenon known as thermal runaway. As a consequence, this can lead to the fracture and/or warping of specimens. Thermal runaway can be limited by using uniform external heating and a homogeneous microwave field.

A plausible solution that materials scientists and engineers have developed consists on a hybrid method that combines direct microwave heating coupled with heat transfer coming from another material that surrounds the specimen to be sintered [45]. This system is an example of mixed absorption heating, with a high dielectric loss at both, low and high temperature [14].

In this scenario, microwaves are absorbed by the material with highest dielectric losses at room temperature while microwaves propagate through the material with lower losses at room temperature. Heat and energy is transferred from the absorbing material to the transparent material. This type of heating makes use of a specific component known as a susceptor. This heating-aid element is the absorbent material and possesses a very high dielectric loss at room temperature, transmitting heat to the material to be sintered via conventional heat transfer mechanisms. Once the material has heated sufficiently surpassing its $T_{c}$, changing its dielectric properties and inducing high dielectric losses, it is able to absorb microwave energy and heat itself.

This combined action, known as microwave hybrid heating, can be employed for fast sintering of compacted powders. In this particular case, the direction of heat flow in the specimen to be sintered occurs in two directions: from the surface to the nucleus due to the effect of the susceptor and from the nucleus to the surface once it is able to absorb microwave radiation [45]. A representation of bidirectional hybrid heating can be seen in Figure 3.11. 
a)

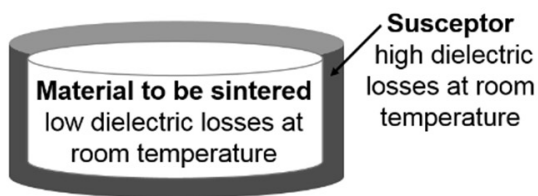

Material and susceptor before exposure to MW radiation b)

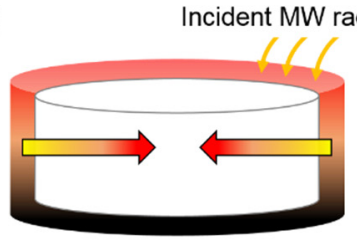

The susceptor absorbs MW radiation, heats up, and begins to heat the material to be sintered.

c) Bidirectional hybrid heating

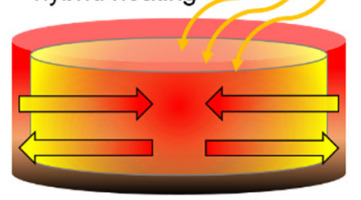

The material reaches temperature threshold and is able to absorb MW radiation by itself. Heating occurs in both directions

Figure 3.11 Sequence diagram of microwave hybrid heating for material sintering: a) before exposure to microwave radiation, b) susceptor heating under $\mathrm{MW}$ radiation, and c) specimen to be sintered able to absorb MW energy giving place to bidirectional hybrid heating.

\subsubsection{MICROWAVE SINTERING OF ZIRCONIA}

The dielectric loss factor of zirconia is quite different from those of other oxide and non-oxide ceramics. At a frequency of $2.45 \mathrm{GHz}$, zirconia does not couple adequately with microwaves at room temperature. The loss factor, $\varepsilon$ ", of Y-TZP at room temperature is similar to microwave-transparent materials, with a value of approximately 0.04 [34]. However, the dielectric loss increases tremendously with temperature, reaching a value of almost 100 at $1000{ }^{\circ} \mathrm{C}$. Therefore, zirconia can become a very absorptive material by raising its temperature. In order to achieve this, two different approaches can be found:

1. With the aid of a susceptor, generally (SiC), as it has been described in the previous section. This method is the most commonly found in the literature [34,46-48].

2. Employing conventional resistive elements to initially heat the zirconia until its $T_{c}$ is reached and zirconia is able to interact with the microwave field by itself [49].

In general, the literature suggests that microwave sintering of zirconia can result in comparable mechanical properties and high degrees of densification comparable to those achieved with conventional sintering systems at lower dwell temperatures and 
significantly shorter sintering times [50-54]. Moreover, some studies have demonstrated that microwave sintered specimens exhibit enhanced crystallinity [55] and improved mechanical properties $[26,56,57]$. 


\section{REFERENCES}

[1] Rahaman MN. Sintering of ceramics. CRC press; 2007.

[2] Coble RL. Sintering crystalline solids. I. Intermediate and final state diffusion models. J Appl Phys 1961;32:787-92.

[3] He Z, Ma J. Grain-growth law during Stage 1 sintering of materials. J Phys D Appl Phys 2002;35:2217.

[4] Wakai F, Yoshida M, Shinoda Y, Akatsu T. Coarsening and grain growth in sintering of two particles of different sizes. Acta Mater 2005;53:1361-71.

[5] Chen L-Q. A novel computer simulation technique for modeling grain growth. Scr Metall Mater 1995;32:115-20.

[6] Fang ZZ, Wang H. Densification and grain growth during sintering of nanosized particles. Int Mater Rev 2008;53:326-52.

[7] Suárez-Menéndez M. Materiales cerámicos policristalinos de $\mathrm{Al}_{2} \mathrm{O}_{3}$ y $Y A G$ con funcionalidad óptica. Ph. D. Thesis. Universidad de Oviedo, 2009.

[8] Rice RW, Wu CC, Boichelt F. Hardness-grain-size relations in ceramics. J Am Ceram Soc 1994;77:2539-53.

[9] Meng F, Liu C, Zhang F, Tian Z, Huang W. Densification and mechanical properties of fine-grained $\mathrm{Al}_{2} \mathrm{O}_{3}-\mathrm{ZrO}_{2}$ composites consolidated by spark plasma sintering. J Alloys Compd 2012;512:63-7.

[10] Kingery WD, Francois B. The sintering of crystalline oxides. I. Interactions between grain boundaries and pores. pp 471-98 In: Kuczynski GC, Hooton NA, Gibbon CF, editors. Sintering and Related Phenomena. Proceedings of the International Conference, Univ. Notre Dame. New York, Gordon Breach, Massachusetts Inst. of Tech., Cambridge; 1968.

[11] Zuo R, Rödel J. Temperature dependence of constitutive behaviour for solidstate sintering of alumina. Acta Mater 2004;52:3059-67.

[12] Nivot C, Valdivieso F, Goeuriot P. Nitrogen pressure effects on nonisothermal alumina sintering. J Eur Ceram Soc 2006;26:9-15.

[13] Oghbaei M, Mirzaee O. Microwave versus conventional sintering: A review of fundamentals, advantages and applications. J Alloys Compd 2010;494:17589.

[14] Rybakov KI, Olevsky EA, Krikun E V. Microwave sintering: Fundamentals and modeling. J Am Ceram Soc 2013;96:1003-20. 
[15] Osepchuk JM. History of microwave heating applications. IEEE Trans Microw Theory Tech 1984;32:1200-24.

[16] Clark DE, Sutton WH. Microwave processing of materials. Annu Rev Mater Sci 1996;26:299-331.

[17] Whittaker AG. Diffusion in microwave-heated ceramics. Chem Mater 2005;17:3426-32.

[18] Boch P, Lequeux N. Do microwaves increase the sinterability of ceramics? Solid State Ionics 1997;101-103:1229-33.

[19] Agrawal DK. Microwave processing of ceramics. Curr Opin Solid State Mater Sci 1998;3:480-5.

[20] Gupta M, Wong WLE. Enhancing overall mechanical performance of metallic materials using two-directional microwave assisted rapid sintering. Scr Mater 2005;52:479-83.

[21] Wang J, Binner J, Vaidhyanathan B, Joomun N, Kilner J, Dimitrakis G, et al. Evidence for the microwave effect during hybrid sintering. J Am Ceram Soc 2006;89:1977-84.

[22] Charmond S, Carry CP, Bouvard D. Densification and microstructure evolution of Y-tetragonal zirconia polycrystal powder during direct and hybrid microwave sintering in a single-mode cavity. J Eur Ceram Soc 2010;30:121121.

[23] Xie Z, Yang J, Huang Y. Densification and grain growth of alumina by microwave processing. Mater Lett 1998;37:215-20.

[24] Peelamedu RD, Roy R, Agrawal D. Anisothermal reaction synthesis of garnets, ferrites, and spinels in microwave field. Mater Res Bull 2001;36:2723-39.

[25] Chatterjee A, Basak T, Ayappa KG. Analysis of microwave sintering of ceramics. AIChE J 1998;44:2302-11.

[26] Borrell A, Salvador MD, Peñaranda-Foix FL, Cátala-Civera JM. Microwave sintering of zirconia materials: Mechanical and microstructural properties. Int J Appl Ceram Technol 2013;10:313-20.

[27] Cheng J. Study on microwave sintering technique of ceramics materials. Ph. D. Thesis. Wuhan University of Technology, 1991.

[28] Cheng JP, Agrawal DK, Komarneni S, Mathis M, Roy R. Microwave processing of WC-Co composities and ferroic titanates. Mater Res Innov 1997;1:44-52.

[29] Breval E, Cheng JP, Agrawal DK, Gigl P, Dennis M, Roy R, et al. Comparison 
between microwave and conventional sintering of WC/Co composites. Mater Sci Eng A 2005;391:285-95.

[30] Tian $\mathrm{YL}$, Johnson DL, Brodwin ME. Ultrafine microstructure of $\mathrm{Al}_{2} \mathrm{O}_{3}$ produced by microwave sintering. In: Ceramic Transactions. Amercian Ceramic Society; 1988, p. 925-32.

[31] Katz JD, Blake RD. Microwave sintering of multiple alumina and composite components. Am Ceram Soc Bull 1991;70:1304-8.

[32] Cheng J, Agrawal D, Zhang Y, Roy R. Microwave sintering of transparent alumina. Mater Lett 2002;56:587-92.

[33] Binner J, Annapoorani K, Paul A, Santacruz I, Vaidhyanathan B. Dense nanostructured zirconia by two stage conventional/hybrid microwave sintering. J Eur Ceram Soc 2008;28:973-7.

[34] Goldstein A, Travitzky N, Singurindy A, Kravchik M. Direct microwave sintering of yttria-stabilized zirconia at $2.45 \mathrm{GHz}$. J Eur Ceram Soc 1999;19:2067-72.

[35] Upadhyaya DD, Ghosh A, Gurumurthy KR, Prasad R. Microwave sintering of cubic zirconia. Ceram Int 2001;27:415-8.

[36] Thostenson ET, Chou T-W. Microwave processing: fundamentals and applications. Compos Part A Appl Sci Manuf 1999;30:1055-71.

[37] Acierno D, Barba AA, D’Amore M. Heat transfer phenomena during processing materials with microwave energy. Heat Mass Transf 2004;40:413-20.

[38] Kitchen HJ, Vallance SR, Kennedy JL, Tapia-Ruiz N, Carassiti L, Harrison A, et al. Modern microwave methods in solid-state inorganic materials chemistry: From fundamentals to manufacturing. Chem Rev 2013;114:1170-206.

[39] Astigarraga-Urquiza J, Astigarraga-Aguirre J. Hornos de alta frecuencia y microondas. Teoría, cálculo y aplicaciones. Mc Graw-Hill; 1995.

[40] Link G, Miksch S, Thumm M, Takayama S. Microwave sintering techniques More than just a different way of heating? Ceram Eng Sci Proc 2008;28:5566.

[41] Chandrasekaran S, Ramanathan S, Basak T. Microwave material processingA review. AIChE J 2012;58:330-63.

[42] Bykov YV, Rybakov KI, Semenov VE. High-temperature microwave processing of materials. J Phys D Appl Phys 2001;34:R55-75. 
[43] Katz JD. Microwave sintering of ceramics. Annu Rev Mater Sci 1992;22:15370.

[44] Clark DE. Microwave solutions for ceramic engineers. American Ceramic Society; 2005.

[45] Lasri J, Ramesh PD, Schächter L. Energy conversion during microwave sintering of a multiphase ceramic surrounded by a susceptor. J Am Ceram Soc 2000;83:1465-8.

[46] Upadhyaya DD, Ghosh A, Dey GK, Prasad R, Suri AK. Microwave sintering of zirconia ceramics. J Mater Sci 2001;36:4707-10.

[47] Nightingale SA, Worner HK, Dunne DP. Microstructural development during the microwave sintering of yttria-zirconia ceramics. J Am Ceram Soc 1997;80:394-400.

[48] Wilson J, Kunz SM. Microwave sintering of partially stabilized zirconia. J Am Ceram Soc 1988;71:C40-C41.

[49] Zhang R, Fu SL, Lu HX, Xu HL, Han DF, Zheng LL. Processes affecting microwave sintering of ZTA ceramics. J Inorg Mater 2001;16:178-82.

[50] García-Gañán C, Meléndez-Martínez JJ, Gómez-García D, DomínguezRodríguez A. Microwave sintering of nanocrystalline YTZP (3 mol\%). J Mater Sci 2006;41:5231-4.

[51] Borrell A, Salvador MD, Miranda M, Penaranda-Foix FL, Catala-Civera JM. Microwave technique: A powerful tool for sintering ceramic materials. Curr Nanosci 2014;10:32-5.

[52] Ai Y, Xie X, He W, Liang $\mathrm{B}$, Chen W. Microstructure and properties of $\mathrm{Al}_{2} \mathrm{O}_{3}$ $\mathrm{ZrO}_{2}$ ceramics prepared by microwave sintering. Key Eng Mater 2014;633:193-7.

[53] Benavente R, Salvador MD, Penaranda-Foix FL, Pallone E, Borrell A. Mechanical properties and microstructural evolution of alumina-zirconia nanocomposites by microwave sintering. Ceram Int 2014;40:11291-7.

[54] Borrell A, Salvador MD, Peñaranda-Foix FL, Plaza-Gonzalez PJ, Garcia-Baños $\mathrm{B}$, Garcia-Nieto S. Adaptive microwave system for optimum new material sintering. Microw Symp Dig (IMS), 2013 IEEE MTT-S Int, 2013, p. 1-4.

[55] Vasudevan R, Karthik T, Ganesan S, Jayavel R. Effect of microwave sintering on the structural and densification behavior of sol-gel derived zirconia toughened alumina (ZTA) nanocomposites. Ceram Int 2013;39:3195-204. 
[56] Borrell A, Salvador MD, Rayón E, Peñaranda-Foix FL. Improvement of microstructural properties of 3Y-TZP materials by conventional and nonconventional sintering techniques. Ceram Int 2012;38:39-43.

[57] Monaco C, Prete F, Leonelli C, Esposito L, Tucci A. Microstructural study of microwave sintered zirconia for dental applications. Ceram Int 2015;41:1255-61. 



\section{CHAPTER 4: MICROWAVE AND CONVENTIONAL SINTERING OF ZIRCONIA MATERIALS}



The following chapter deals with the consolidation of advanced zirconia materials, both commercial and prepared in laboratory, for applications in dentistry via microwave sintering and the subsequent characterization of physical and mechanical properties. The study is accompanied by a comparative analysis with conventional sintering. In Chapter 2, the fundamental properties of yttria-stabilized tetragonal zirconia polycrystalline (Y-TZP) materials have been discussed, as well as their significance for odontological applications. Additionally, structural dental materials must comply with minimum mechanical criteria, which are strongly dependent on the microstructure. Chapter 3 has provided the fundamentals between material and microwave interaction and the main advantages with respect to conventional sintering. Also, the dielectric properties of zirconia have been described as the driving mechanism behind the heating of these materials.

Although several studies have been published regarding microwave sintering of zirconia-based ceramics, very few have focused in the sintering of commercial dental materials. Moreover, an in-depth characterization of the resulting mechanical properties and microstructure is still needed in order to evaluate the effects of the modified densifying mechanism induced by microwave sintering. Therefore, the relevance of this study relies on exploring the resulting properties of microwavesintered (MW) commercial and lab-prepared dental materials and a profound characterization of their physical, microstructural and mechanical properties, as these materials must meet minimum requirements for structural and mechanical performance. Moreover, an improvement in the mechanical behavior compared to conventional-sintered (CS) specimens is also explored.

\subsection{INTRODUCTION}

Y-TZP materials have become increasingly important in the last few decades as biomaterials for dental replacements. Due to their superior mechanical properties, null interaction with human tissue and enhanced optical properties, these materials have become commercially successful. Very fine-grain microstructures may be obtained (particle size $<0.5 \mu \mathrm{m}$ ) from powders. Regarding mechanical properties, fracture toughness and hardness values are relatively high compared to other bioceramics. According to Guazzato et al. [1], this mechanical behavior allows them to satisfy the requirements necessary for dental applications. Y-TZP materials contain between 1.5 and 3.5 mol\% $\mathrm{Y}_{2} \mathrm{O}_{3}$ in solid solution as phase stabilizer because this range allows for almost $100 \% \mathrm{t}$-phase content. This phase enhances their resistance to crack propagation due to the transformation toughening phenomenon that they are subjected to [2]. 
Mechanical properties and microstructure of Y-TZP sintered materials are strongly influenced by the degree of densification and grain nucleation that result due to the sintering process. This is, in turn, determined by the heating mechanisms that take place within the material. Current commercial sintering of ceramic dental materials, such as Y-TZP, is based on conventional heat transfer mechanisms: conduction, convection and radiation. In this case, heat is generated from heating elements and a temperature gradient arises, as heat is transferred from the surface to the material's core. This method, however, requires long processing times. As a consequence, grain broadening occurs [3], which leads to a decrease in the final mechanical properties of the material [4,5]. It also requires a high energy consumption to reach such high temperatures, which must also be maintained for long periods of time (around $2 \mathrm{~h}$ or more) if fully-dense materials are desired.

Currently, innovative sintering methods are being explored and studied in order to reduce energy consumption and production costs, as well as processing tools that allow modification of the densification mechanisms that may improve the microstructure and mechanical properties of sintered materials. The main purpose for modifying sintering mechanisms is to obtain relative densities close to theoretical values, while maintaining a controlled, but limited, grain growth [6].

One advantageous and useful non-conventional method that can modify the densification mechanisms and results in faster processing of Y-TZP ceramics is microwave sintering [7]. The energy conversion of electromagnetic radiation into heat by the material itself due to the material's dielectric properties is the driving force for densification $[8,9]$. The rise in temperature is determined by the amount of energy absorbed in the process. The acceleration of diffusion mechanisms during sintering by the oscillating electric field has also been proposed by some authors to explain enhancement of the sintering process, in what is called a "microwave effect" [10]. Because it is a non-contact technique, the effects of differential sintering are minimized [11] to a certain extent due to the volumetric nature of the heating process. However, heating also depends on the local electrical field strength, which can also result in a non-homogeneous distribution of temperature.

Previous reports [12-14] have demonstrated that with microwave sintering highly dense materials can be obtained without substantial grain coarsening because dwell time is considerably shorter and heating rates are quite high in comparison with conventional sintering [15]. Energy consumption is also significantly reduced as a consequence of the mechanisms involve in microwave heating and the aforementioned shortening of processing times. As a result, several advantages arise including improved mechanical properties and reduced environmental impact $[16,17]$. Replacement of dental pieces is particularly costly. This method may provide 
lower costs for professionals and customers maintaining or even improving the quality of the final product.

\subsection{OBJECTIVES}

The purpose of this chapter is to determine whether zirconia dental materials can be successfully sintered with microwave heating technology in an experimental microwave system under specific selected conditions. In order to assess whether the materials have achieved full consolidation, physical, mechanical and microstructural properties are evaluated and compared to their conventionally sintered counterparts. Consequently, there are two specific objectives that the study aims to fulfill:

- Preparation and consolidation of three different Y-TZP materials, two commercial and one lab-prepared, via microwave sintering with the aid of a susceptor.

- Characterization of the densification, mechanical properties and microstructure of the obtained materials.

\subsection{MATERIALS AND METHODS}

\subsubsection{MATERIALS}

Three Y-TZP materials stabilized with 3 mol\% $\mathrm{Y}_{2} \mathrm{O}_{3}$ have been considered and evaluated in this study: two commercial and one lab-prepared (Table 4.1). Commercial materials, LAVA and VITA, were obtained as pre-sintered blocks. The preparation of the LAB powder consists of a starting material, in this case TZ-3YS, Tosoh, Tokyo, Japan, dispersed by colloidal processing in water with the aim of optimizing the rheological behavior of the suspension in order to obtain a more homogeneous powder in terms of particle size. The powder is finally obtained by freeze-drying. Tosoh TZ-3Y powders are commonly employed as the main constituent of several commercial dental zirconia ceramics. A more detailed description of the preparation procedure can be found in Reference [18].

Green samples of the powder material were obtained by uniaxial compression at 300 $\mathrm{MPa}$ in order to consolidate cylindrical bodies with $10 \mathrm{~mm}$ diameter. Samples from the commercial materials have been obtained by cutting the blocks and machining them so as to obtain cylindrical bodies with a $10 \mathrm{~mm}$ diameter. The purpose for selecting these materials was also to compare the resulting properties of the commercial ones to those of a more adjusted and carefully prepared starting material. 
Table 4.1 Y-TZP materials considered for MW and CS sintering, their corresponding main characteristics, and relevant manufacturer's specifications.

\begin{tabular}{|c|c|c|c|}
\hline & \multicolumn{2}{|c|}{ Commercial } & \multirow{2}{*}{$\frac{\text { Lab-prepared }}{L A B}$} \\
\hline & $L A V A$ & VITA & \\
\hline Trade name & 3M ESPE LAVA Plus & In-Ceram YZ & N/A \\
\hline Manufacturer & $3 \mathrm{M}$ (USA) & $\begin{array}{l}\text { VITA Zahnfabrik } \\
\text { (Germany) }\end{array}$ & Tosoh (Japan) \\
\hline Received as & Block & Block & Powder \\
\hline Pre-sintering & Yes & N/A & No \\
\hline Powder type & Co-precipitated & N/A & Co-precipitated \\
\hline \multicolumn{4}{|c|}{ Manufacturer's specification sheet properties } \\
\hline Yttria content, mol\% & 3 & 3 & 3 \\
\hline Density, $\mathrm{g} / \mathrm{cm}^{3}$ & 6.08 & 6.05 & 6.05 \\
\hline Avg, grain size, $\mu m$ & $0.2-0.4$ & $\sim 0.5$ & $0.1-0.2$ \\
\hline Hardness, GPa & $>12$ & $\sim 12$ & $>12$ \\
\hline $\begin{array}{l}\text { Fracture toughness } \\
\left(\mathrm{K}_{\mathrm{IC}}\right), \mathrm{MPa} \cdot \mathrm{m}^{1 / 2}\end{array}$ & $5-10$ & $>5$ & N/A \\
\hline Young's modulus, GPa & 210 & 210 & $>230$ \\
\hline
\end{tabular}

\subsubsection{CONVENTIONAL AND MICROWAVE SINTERING}

Sintering of samples by the conventional method (CS) was carried out in an electrical furnace (Thermolyne type 46100, Thermo Fisher Scientific) for $2 \mathrm{~h}$ in atmospheric conditions at two different temperatures: 1300 and $1400{ }^{\circ} \mathrm{C}$, with a heating rate of $10^{\circ} \mathrm{C} / \mathrm{min}$.

Microwave sintering (MW) of samples was performed in air in an experimental microwave system with a $2.45 \mathrm{GHz}$ frequency and a variable power output from 0 $1200 \mathrm{~W}$, shown in Figure 4.1. The power has been set to $700 \mathrm{~W}$. Samples were introduced in a mono-mode, rectangular cavity that is automatically adjusted to optimize microwave absorption by the material that allows controlling the heating rates $\left(100{ }^{\circ} \mathrm{C} / \mathrm{min}\right)$ and sintering temperature $\left(1200\right.$ and $\left.1300{ }^{\circ} \mathrm{C}\right)$. Sintering parameters, such as sintering temperature, heating rate and holding time, were previously introduced in the control software [19]. These conditions have been selected based on previous studies in our research group, which demonstrate that under such temperatures and dwell times materials with density values close to theoretical can be obtained [14,17]. 
Temperature was measured on the sample surface with the aid of an optical pyrometer previously calibrated for the selected temperatures. A silicon carbide susceptor, which acts as a hybrid-heating element, is employed in order to aid sample heating in the microwave cavity.

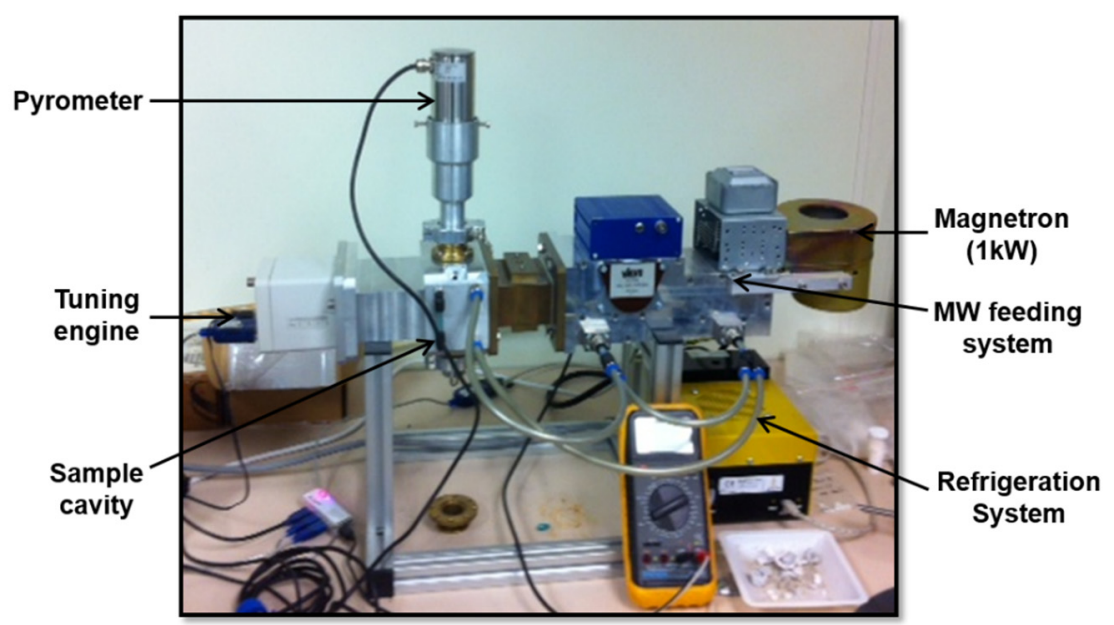

Figure 4.1 Experimental MW system employed in the sintering of Y-TZP materials and its main components.

A schematic of the rectangular-cavity microwave system designed, built and optimized by ITACA - UPV (Instituto de Aplicaciones de las Tecnologías de la Información y de las Comunicaciones Avanzadas de la Universitat Politécnica de Valencia) is shown in Figure 4.2.

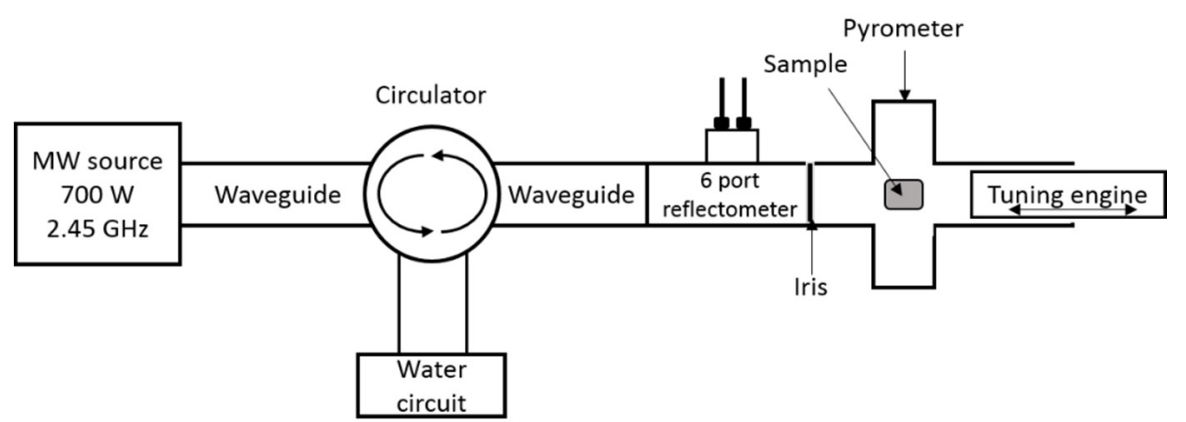

Figure 4.2 Schematic of a microwave system with rectangular cavity that has been employed for sample sintering.

The basic functioning elements are described in the following bullet points:

- Source: A variable microwave power source is set at $700 \mathrm{~W}$ at a fixed frequency of $2.45 \mathrm{GHz}$. This source can be remotely controlled to adjust to the characteristics of the material to be sintered. 
- Circulator: Serves as a protection to the source against possible unwanted electrical overloading. This component redirects the non-consumed microwave power to a water load, which heats up and prevents the reflected power from returning to the power source and damaging it.

- $\quad$ Reflectometer: This device consists of 6 ports that are employed to measure the incident and reflected power in the sample cavity. In this manner, a reliable reading of the consumed power for sintering can be obtained.

- Iris: This optical component is utilized for coupling the microwave power to the cavity.

- Rectangular cavity: The dimensions of the cross-section are $86.36 \times 43.18$ $\mathrm{mm}$ with a variable length. These dimensions can be adjusted during sintering with the aid of the tuning engine so that more or less power resonates inside the cavity so as to control heating of the sample. The cavity is designed in such a way that microwave leakage is prevented. The sample is introduced in a microwave-transparent quartz tube through an insertion orifice located at the top of the cavity (Figure 4.3).

- Pyrometer: This component allows remote temperature measurements and is located in the top part of the cavity. For a more detailed description, see Section 4.3.2.1.

- Tuning engine: This elements controls the dimensions of the cavity in order to optimize microwave power consumption. It is remotely controlled by a variable short circuit located inside the cavity and dimensions are modified dynamically.

a)

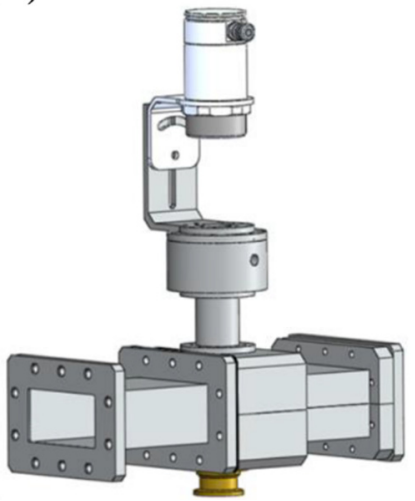

b)

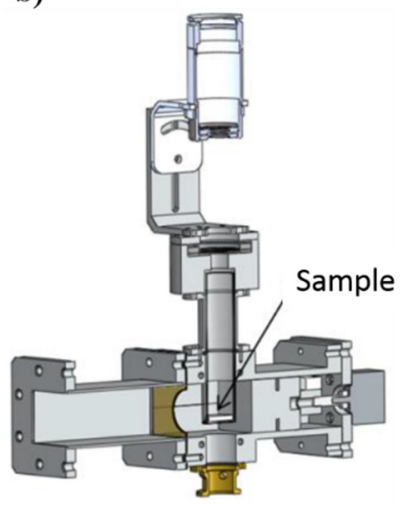

Figure 4.3 Rectangular cavity diagram of the microwave oven employed for sintering of zirconia materials: a) outside view and b) cross-section view indicating sample location. 


\subsubsection{Pyrometer calibration}

In conventional sintering, temperature readings are obtained through thermocouples located inside the oven. However, this is not possible in microwave sintering because introducing other devices inside the main cavity can interfere with the process. Since the heating that takes place in microwave sintering is volumetric and the radiation is absorbed and converted into heat from within the material, the temperature of the sample and the oven is never the same.

In order to determine the temperature of the sample and control the heating rates during microwave sintering, a pyrometer has been employed to provide real-time temperature readings. A pyrometer consists of an optical system accompanied by a detector that employs Stefan-Boltzmann Law to relate thermal radiation, or irradiance, $j^{*}$, to the temperature, $T$, of a body without the device being directly in contact with it. In this law, the emissivity, $\varepsilon$, of the material, which is the effectiveness in emitting energy as thermal radiation, is a very important parameter that must be known. This law is given in the following expression, where the StefanBoltzmann, $\sigma$, constant is equivalent to $5.670 \mathrm{~W} \cdot \mathrm{m}^{-2} \cdot \mathrm{K}^{-4}$ :

$$
j^{*}=\varepsilon \sigma T^{4}
$$

Therefore, in order to determine the temperature on the surface of the sample with a pyrometer, the emissivity of the material at the selected temperatures must be known. Emissivity tests have been carried out previous to sintering with an Optris CT Laser $2 \mathrm{MH}$ CF2 pyrometer in a temperature range between 1100 and $1400^{\circ} \mathrm{C}$. Figure 4.4 shows the measurement span of the pyrometer inside a cone.

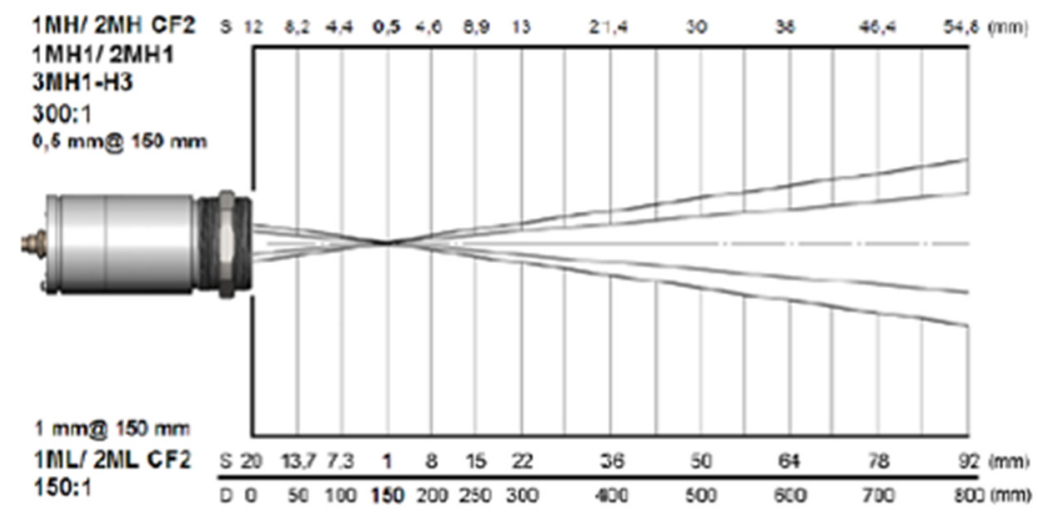

Figure 4.4 Optris CT Laser 2 MH CF2 pyrometer characteristics and measurement span. Taken from product manual.

The manufacturer, Optris, recommends the following calibration methods for this device: 
1) With the aid of a thermocouple: In this scenario, the temperature is measured with a thermocouple and a pyrometer at the sample surface simultaneously. The emissivity in the pyrometer is adapted continuously until the temperature readings of the pyrometer and the thermocouple are equal.

2) With a reference emissivity: By utilizing a different object with a known emissivity. Due to the changing characteristics of materials in the presence of microwaves, this method will not be employed.

To measure the emissivity of Y-TZP zirconia at different temperatures, the first method has been utilized with the aid of the Thermolyne oven that has been previously calibrated. This oven has an aperture in the top wall that facilitates the measurement directly on the sample surface with the pyrometer. This allows a reliable temperature recording, while, at the same time, maintaining thermal stability inside the oven since there is no need to open it during the test. The calibration setup is given in Figure 4.5. The sample is placed inside the oven at a distance that falls within the conical measurement span of the pyrometer so the laser can fall directly on the center of the surface. The oven is then programmed to reach and stabilize at the desired temperature. If the temperature readings of the pyrometer are different from those of the thermocouple, the emissivity value in the pyrometer is adjusted until the temperature readings are exactly the same.

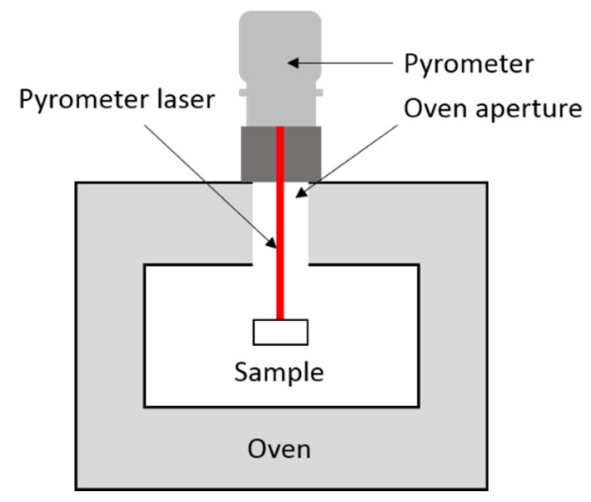

Figure 4.5 Set up for pyrometer calibration with aid of oven thermocouples.

The setup is very similar to the one employed in MW sintering in order to obtain a proper calibration of the equipment, including distance to sample and direct measurement on the sample surface. The heating rates during this calibration test have been set at $10{ }^{\circ} \mathrm{C} / \mathrm{min}$. A 3Y-TZP zirconia sample is heated until a temperature of $1100{ }^{\circ} \mathrm{C}$. After that, intervals are increased every $100^{\circ} \mathrm{C}$ with a $20 \mathrm{~min}$ dwell time at each temperature adjusting to the corresponding emissivity until $1400{ }^{\circ} \mathrm{C}$ is reached. 
The results obtained for the emissivity of 3Y-TZP zirconia are summarized in Table 4.2. A constant transmissivity value has been maintained throughout the selected temperature range.

Table 4.2 Emissivity values in temperature range $1100-1400^{\circ} \mathrm{C}$ for $3 Y-T Z P$ zirconia.

\begin{tabular}{cccc}
\hline $\begin{array}{c}\text { Thermocouple } \\
\left({ }^{\circ} \mathbf{C}\right)\end{array}$ & $\begin{array}{c}\text { Transmissivity } \\
\boldsymbol{t}\end{array}$ & $\begin{array}{c}\text { Emissivity } \\
\boldsymbol{\varepsilon}\end{array}$ & $\begin{array}{c}\mathbf{T}_{\text {pyrometer }} \\
\left({ }^{\circ} \mathbf{C}\right)\end{array}$ \\
\hline 1100 & 1.0 & 0.910 & 1100 \\
1200 & 1.0 & 0.942 & 1200 \\
1300 & 1.0 & 0.923 & 1300 \\
1400 & 1.0 & 0.939 & 1400 \\
\hline
\end{tabular}

\subsubsection{MATERIAL CHARACTERIZATION}

\subsubsection{Starting material composition}

Since the starting blocks and powders have been obtained from external sources, a compositional analysis has been performed in order to make sure that the zirconia materials have been fully stabilized in their $t$-configuration. The presence of zirconia phases has been assessed by means of X-ray diffraction. This technique is very common in materials engineering for qualitative phase determination. The next section briefly describes the fundamental aspects of the technique.

\section{X-ray diffraction}

X-rays are a form of high-energy electromagnetic radiation with short wavelengths of the size of interatomic spaces in solids that provides information about the spatial arrangement of atoms in a material. When an X-ray beam interacts with a solid, part of the beam is dispersed in all directions due to electrons associated to the atoms or ions that the beam encounters in its path. However, the non-dispersed part of the beam can induce the phenomenon of X-ray diffraction, which occurs when atoms are arranged with a characteristic periodicity along a crystallographic axis and their interatomic spaces satisfy the conditions of the X-ray wavelength with the incidence angle of the beam (Figure 4.6).

The geometric conditions that satisfy the X-ray diffraction phenomenon when studying crystalline structures is analogous to the light reflection that occurs in a plane mirror. The conditions for a set of parallel planes, separated by the same distance, $d$, to diffract an incident X-ray beam is known as Bragg's law and is given by the following relationship:

$$
2 d \sin \theta=n \lambda
$$




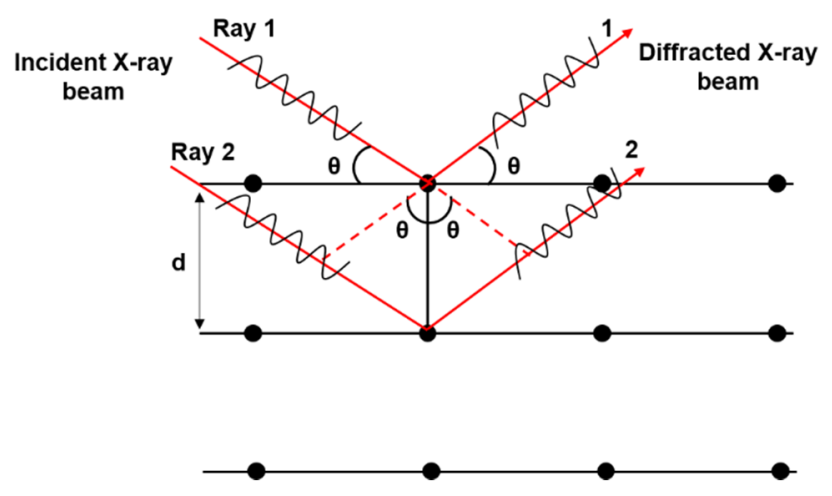

Figure 4.6 X-ray beam interaction with atoms in a solid at incident angle $\theta$.

In this work, a powder diffractometer with a Bragg-Brentano configuration, where filtered X-rays diverge from a source line and fall upon the powder sample, has been employed. Hence, the commercial material blocks have been carefully pulverized to prevent significant $t$-to- $m$ phase transformation. Rays diffracted by the crystalline planes are collected in the detector and converted into electrical pulses that are registered as a graph that is characteristic to the sample.

Samples have been measured with a BRUKER D8 Avance A25 diffractometer. The registered diffractogram encompasses the range $20^{\circ}<2 \theta<80^{\circ}$, with a $2 \theta$ step of $0.03^{\circ}$, and a measurement time per step of $0.02 \mathrm{~s}$, for phase identification purposes. The employed radiation source consist of a $\mathrm{Cu}-\mathrm{K} \alpha$ under $40 \mathrm{kV}$ and $30 \mathrm{~mA}$. The dispersive energy detector is a LYNXEYE that allows linear, as well as punctual measurements.

In the case of zirconia, each angle $2 \theta$ that results in a peak corresponds to one of its phases: monoclinic, tetragonal or cubic. The degree of $t$-phase stabilization of the starting zirconia materials can be effectively assessed in a qualitative manner, since the presence and intensity of a peak is directly related to the phase content. Several works have been published on X-ray diffraction characterization of Y-TZP materials, making it a powerful and widely applied tool when phase analysis is necessary [2025]. Peak overlapping may occur, which complicates the identification of phases. However, complimentary tools, such as Rietveld refinement, can offset the effect of overlapping and, at the same time, allow for quantification of the phases. A more comprehensive description of this method is given in Section 5.3.3.

\subsubsection{Densification of sintered materials}

The density of a material after sintering can be determined by different methods such as with the use of a gas pycnometer or applying Archimedes method. Moreover, it can be spoken of different density terms such as theoretical, apparent, geometric 
and global density. The theoretical, or "true", density corresponds to a perfectly solid body with no porosity. Apparent density is based on Archimedes principle and global, or "bulk", density is applied for porous materials.

The apparent density of a solid is the ratio of its dried mass divided by the apparent volume, which is the sum of the solid volume and the volume of enclosed pores, and is always expressed with respect to another substance, usually water, resulting in a non-dimensional property. Therefore, the apparent density can be considered an apparent specific gravity. Porosity has an important role in the apparent density of the material, since pores are empty cavities or channels that constitute void space within a consolidated solid body. Figure 4.7 shows a representation of different types of pores present in materials.

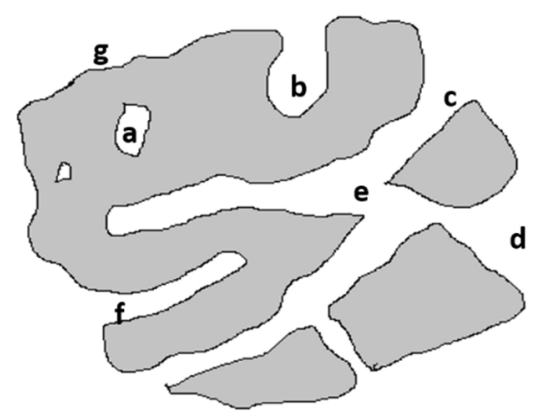

Figure 4.7 Different types of pores within a solid material. (a: enclosed or totally isolated pores; b, c, $d$, e and $f$ : open pores connected to the surface; $b$ and $f$ : connected only on one side; e: channeled porosity connected at both sides; g: usually roughness, but can be regarded as porosity when the depth of the irregularities is greater than the width).

In order to compare the densification of the sintered samples in this study, apparent density has been determined by Archimedes method, following ASTM-C-373 Standard. This method consists in measuring the dry weight, $D$, of the specimen and the submerged weight, $S$, in a liquid, which in this case is water with a density $\rho_{\text {water }}$ $=1 \mathrm{~g} / \mathrm{cm}^{3}$ at room temperature, and using the following relationship to obtain the apparent density, $\rho_{a p p}$, of the sample:

$$
\rho_{a p p}=\frac{D}{D-S} \times \rho_{w a t e r}
$$

For simplifying the comparison of densification among the specimens, the values of density after sintering are expressed in terms of relative density, $\rho_{\%}$, which is the ratio of the apparent density, $\rho_{a p p}$, to the theoretical, $\rho_{\text {theo }}$ (Equation 4.4 ).

$$
\rho_{\%}=\frac{\rho_{\text {app }}}{\rho_{\text {theo }}} \times 100
$$




\subsubsection{Mechanical properties}

In order to perform the mechanical characterization of the Y-TZP materials, all specimens have been mirror-polished with a colloidal diamond suspension down to $0.25 \mu \mathrm{m}$. Mechanical properties have been evaluated at a micro and nanoscale. Vickers hardness, $H_{v}$, and fracture toughness have been determined via microindentation technique, while nanoindentation hardness, or nanohardness, $H_{\text {nano, }}$ and Young's modulus, $E$, are measured by nanoindentation technique.

\section{Microindentation techniques}

Microindentation is a very common and useful tool for mechanical characterization of ceramic materials, such as alumina and zirconia, because direct measurement of the properties can be obtained in a fast and simple manner. Vickers hardness and fracture toughness are two fundamental properties for structural materials such as dental implants and replacements that may be obtained with this technique. The next sections describes microindentation testing for determining these properties.

\section{Vickers hardness}

Hardness is a very useful mechanical property that is defined as the resistance of a material to be deformed, indented or penetrated by another material. Several methods for measuring hardness have been proposed. One such methods, known as Vickers hardness indentation, consists on pressing a small diamond tip, regarded as the indenter, on the surface of the material to be investigated and measure the dimensions of the recently created imprint. Microindentation hardness tests are carried out with loads ranging from 1 - 5000 g (Figure 4.8). The microscopic indentation size is the main aspect that distinguishes this technique from others, such as Rockwell and Brinell [26]. In contrast to nanoindenters, which are considered instrumented indentation systems, microindentation hardness is a universal testing method. 


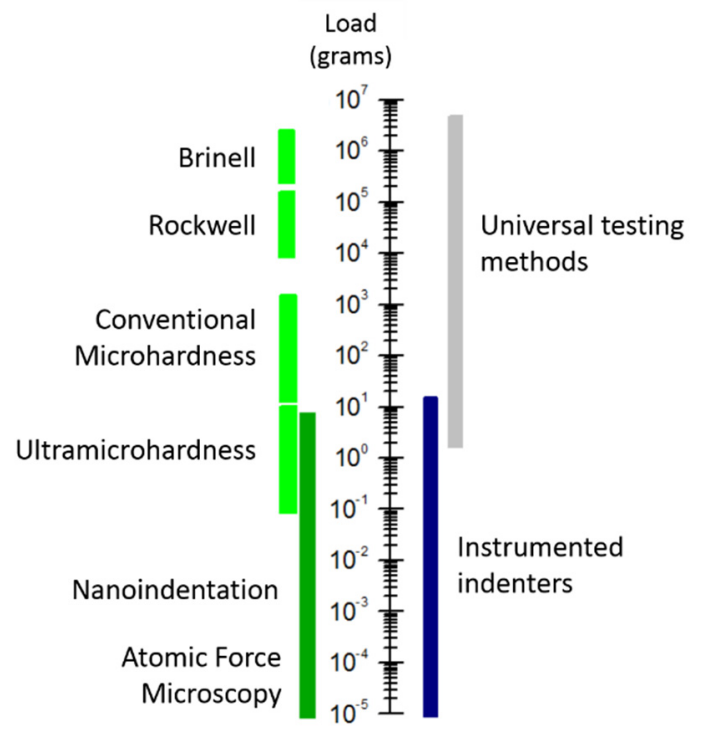

Figure 4.8 Load scale for the different types of indentation testing techniques.

A Vickers indenter consists of an inverted, square-base, pyramid-shaped tip with angles of $136^{\circ}$ among the faces (Figure 4.9a). A previously calibrated system applies the desired load perpendicular to the surface of the material, maintaining the load for a set amount of time. In this work, the applied load has been set to $500 \mathrm{~g}$ and the indentation time to $10 \mathrm{~s}$. At this load, indentations with dimensions in the order of 1 $-20 \mu \mathrm{m}$ are obtained in sintered zirconia materials. $H_{v}$ is calculated from the applied load, $P$, and the imprint diagonals $d_{1}$ and $d_{2}$ (Figure 4.9b), using the following equation:

$$
H_{V}\left[\frac{k g_{f}}{\mathrm{~mm}^{2}}\right]=1.8544 \cdot \frac{P}{\left(\frac{d_{1}+d_{2}}{2}\right)^{2}}
$$

The device employed for microindentation testing is an automated indenter from Shimadzu model HMV-20. An optical microscope is integrated into this system, as well as an image analysis program, that allows measurement of the diagonals and, hence, $H_{v}$, right after the indentation occurs. The units obtained with this method and given in Equation 4.5 are $\mathrm{kg}_{\mathrm{f}} / \mathrm{mm}^{2}$. In order to facilitate data analysis and comparison among the materials, these values are converted GPa using the following equation proposed by Yovanovich [27]:

$$
H_{V}[G P a]=0.009807 \cdot H_{V}\left[\frac{\mathrm{kg}_{f}}{\mathrm{~mm}^{2}}\right]
$$

In order to obtain a representative $H_{v}$ value, a total of 25 indentations has been performed for each specimen. 


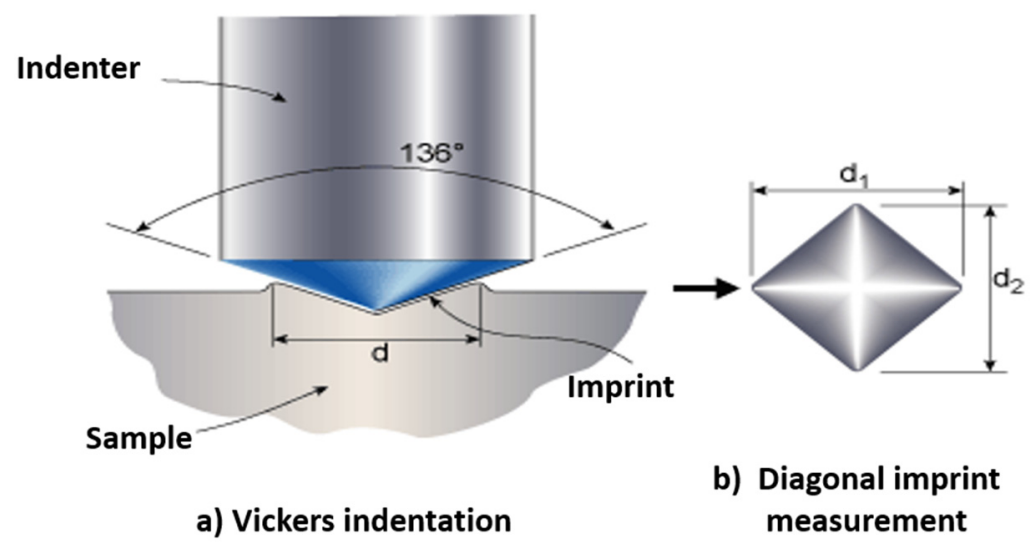

Figure 4.9 Vickers microindentation test: a) during indentation and b) resulting diagonals after removing load.

\section{Fracture toughness}

For brittle materials, such as ceramics, fracture toughness is an extremely important property, and even more important for the performance of structural components. This material property is generally defined as the resistance of a material to the propagation of fissures, or cracks. The theoretical basis of fracture mechanics and different methodologies aimed at determining an approximate value for different materials can be found elsewhere [28-32]. This property depends on several factors, such as temperature, speed of deformation and microstructure. Fracture toughness is commonly expressed as the critical stress intensity factor under a mode I load system (tensile stress), $K_{l c}$.

The relatively high $K_{/ C}$ values of zirconia ceramics is one of the most important reasons for its use as a structural ceramic and, therefore, in restorative dentistry. $K_{/ C}$ increases due to the $t$-to- $m$ phase transformation that occurs in zirconia materials and changes significantly depending on the phases present and the amount of their content.

In order to determine $K_{I C}$ of the sintered specimens, a traditional fracture indentation method has been employed. This method consists on directly determining the $K_{I C}$ value from the length of intentionally induced cracks from a microindentation test. It is based on standardized testing methods regulated by ASTM designation C 13279963. The fracture indentation method is performed by pressing a hard material, such as a diamond tip, on the material to be analyzed. A residual imprint characteristic of irreversible deformation processes is left on the sample surface, as in the Vickers hardness testing method (Figure 4.10a). However, in this case, cracks emerge from the indentation corners due to residual stresses until an equilibrium is 
reached. These fissures possess a particular morphology and dimensions (Figure $4.10 \mathrm{~b})$. This method relates the length of the cracks to the fracture toughness of the material when a load $P$ is applied.

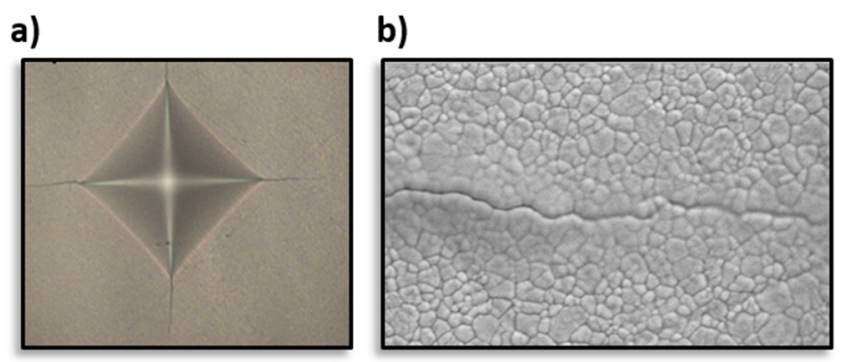

Figure 4.10 Method for determining $K_{I C}$ by microindentation: a) optical microscope image of indentation imprint with crack propagation in the corners and b) FE-SEM image of the crack in 3Y-TZP material.

In order to obtain cracks by means of microindentation, a load capable of generating cracks without damaging the sample significantly needs to be applied. Based on other works related to zirconia materials, a load of $2 \mathrm{~kg}$ has been chosen in order to obtain crack lengths encompassing $5-100 \mu \mathrm{m}$. The indentation is performed with the same equipment utilized for Vickers hardness microindentation. A total of ten indentations have been done for each sample to obtain a representative $K_{I C}$ value.

Subsequently, the indentations in the samples have been analyzed with a high resolution NIKON H550L optical microscope at a magnification that allows a clear and detailed observation of the cracks in all four directions. Finally, the length of the cracks has been determined from the microscope images with the image analysis software Image Pro Plus.

To calculate $K_{I C}$, the experimental equation proposed by Niihara, one of the most widely utilized formulas to determine fracture toughness in ceramic materials, has been employed:

$$
K_{I C}=0.0298 \cdot H \cdot \sqrt{a} \cdot\left(\frac{E}{H}\right)^{1 / 2} \cdot\left(\frac{c}{a}\right)^{-1.38}
$$

where:

$H=$ Vickers hardness at the applied load, $\mathrm{MPa}$

$E=$ Young's modulus, $\mathrm{MPa}$

$c=$ half-length of crack resulting from the indentation imprints (Figure 4.11), $\mu \mathrm{m}$

$a=$ half-length of the diagonal of the indentation (Figure 4.11), $\mu \mathrm{m}$ 


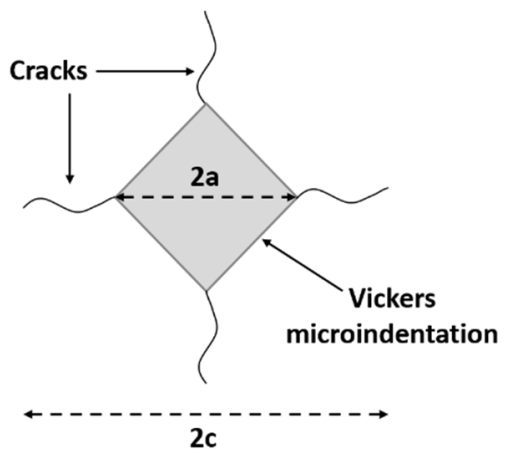

Figure 4.11 Diagram indicating the crack length parameters required for determining $K_{I C}$ by the microindentation method.

The morphology and crack dimension depend on the fracture toughness of the material and the applied load. For materials with low fracture toughness, induced indentation cracks tend to be connected sub-superficially and result in a semielliptical profile (Figure 4.12a). Materials with relative high fracture toughness, such as $t$-stabilized zirconia, result in the formation of low-depth radial cracks that, opposite to semielliptical cracks, are not connected between each other. These type of fissures are known as Palmqvist cracks (Figure 4.12b). In some cases, when very high loads are applied, semielliptical cracks can be induced in high fracture toughness materials.
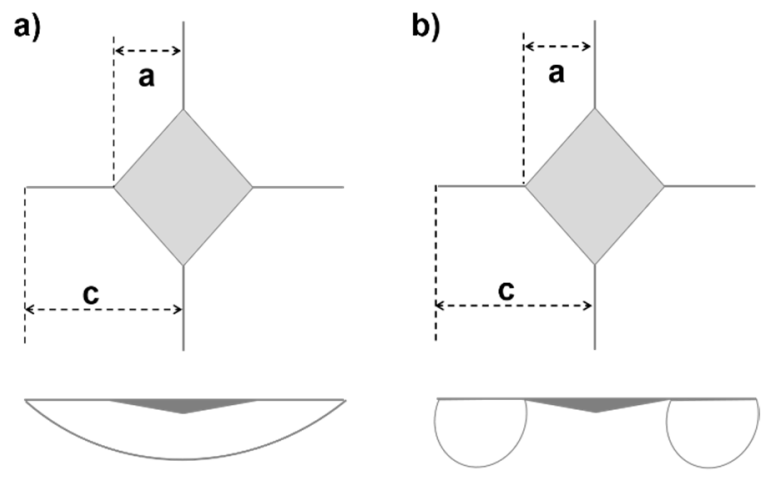

Figure 4.12 Schematic of the two type of cracks and sub-superficial morphologies that can be induced in materials with microindentation: a) semielliptical and b) Palmqvist.

These two type of cracks are difficult to distinguish with Vickers indenters because the imprint shape is basically the same and the cracks grow from the corner outwards and no information on the sub-superficial crack morphology is provided. Nonetheless, mathematical relationships have been established to predict the type of crack that may result. In that sense, if the ratio of $c / a>2$, the crack is inferred as semielliptical and if the ratio of $c / a<2$, the crack is regarded as Palmqvist [33]. 


\section{Nanoindentation techniques}

Instrumented Indentation Techniques (IIT), as shown in Figure 4.8, are mechanical testing techniques utilized to determine, among other properties, the hardness and Young's modulus of materials at nanometric scales without having to observe the indentation imprint after the test, that is, the measurements are real-time responses. Nanoindentation works under loads that range from $10^{2}-10^{-5} \mathrm{~g}$. The basic principle of the technique relies on the calculation of $H_{\text {nano }}$ and $E$ from recording the loading-unloading test curves ( $P$ - $h$ curves) and the maximum indentation depth, $h_{\max }$ (Figure 4.13). The resolution of the recorded load, $P$, and indentation depth is quite high, reaching magnitude as low as Armstrong range.

a)

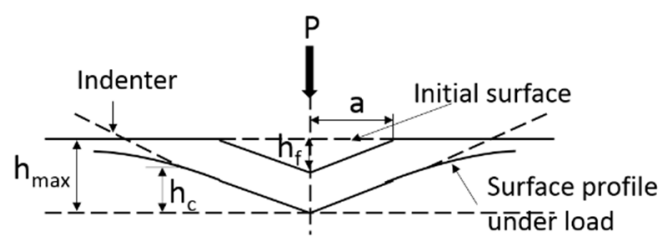

b)

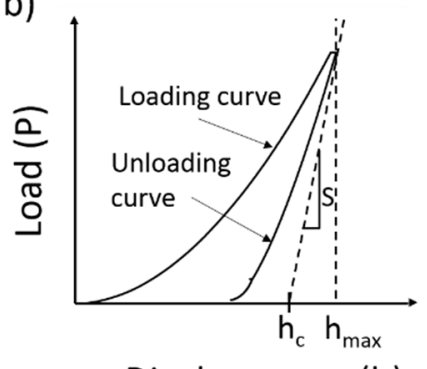

Displacement (h)

Figure 4.13 a) Main parameters of a nanoindentation test during loading and unloading. b) Typical Load-displacement curve obtained from a nanoindentation curve.

The depth reached by the indenter during loading is represented by $h_{c}$, while $h_{f}$ is the final displacement after unloading. $S$ is defined as the initial stiffness of contact during unloading, that is, the slope of the unloading curve at the top. From the $P$ - $h$ curve and applying the Oliver and Pharr method [34], the value of hardness, $H_{\text {nano, }}$ can be calculated according the following expression:

$$
H=\frac{P_{\max }}{A\left(h_{c}\right)}
$$

where:

$A\left(h_{c}\right)=$ contact area between the indenter and the material at $P_{\max }$

The Young's modulus is calculated from the contact stiffness measured during the initial unloading stage and applying the relationship determined by Sneddon [35] for the indentation of a semi-infinite elastic solid:

$$
E^{*}=\frac{1}{\beta} \frac{\sqrt{\pi}}{2} \frac{S}{\sqrt{A\left(h_{c}\right)}}
$$

where:

$\beta=$ constant that depends on indenter geometry. For Berkovich tip, the value is 1.034 
$E^{*}=$ apparent Young's modulus obtained in the nanoindentation test

Figure 4.14 shows a schematic of the main parts in a nanoindentation system. A nanoindenter consists of a: (i) step-by-step motorized sample-holder table for sample positioning, (ii) electromagnetic head for load control, (iii) load and displacement capacitance transducers for high resolution, (iv) some heads incorporate lateral force transducers to measure friction force in nano-scratch tests, (v) indenter tip with that can have different geometrical configurations, and, in some cases, (vi) an optical lens to visualize in real-time the positioning of the sample. Nanoindenters are usually installed over anti vibration tables and thermal isolated cabinets.

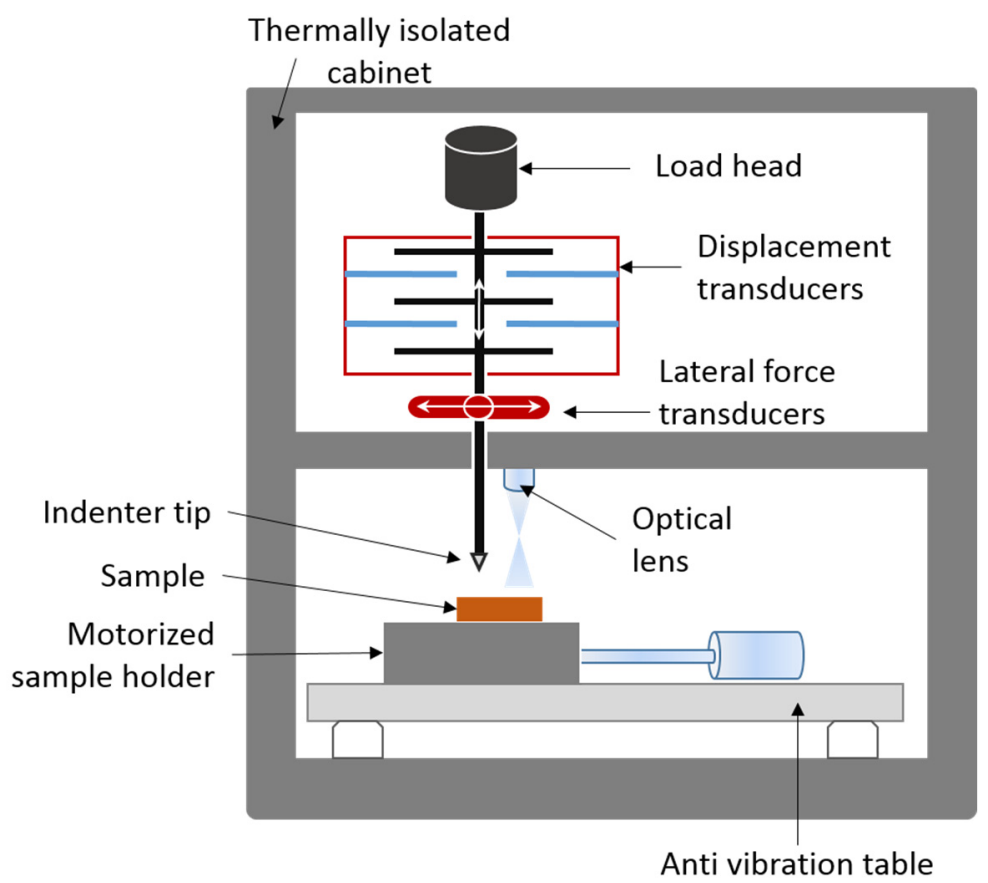

Figure 4.14 Schematic of the main elements in a nanoindenter.

The load cycle in a typical nanoindentation test that allows the determination of hardness and Young's modulus takes place in several stages (Figure 4.15):

1. The indenter tip approaches the sample surface until the tip detects, through a signal and a previously programmed sensitivity, the surface of the material.

2. The indenter penetrates the sample by increasing the load until a set depth or load is reached. 
3. The load is maintained for several seconds to give enough time for plastic deformation to occur.

4. Unloading takes place recording the elastic response until, approximately, $90 \%$ of the load is removed.

5. The load is again maintained constant for several seconds, which is used to determine the unwanted thermal drift by calculating the slope of at this section of the curve.

Nanoindentation tests in this work have been carried out to maximum depth, $h_{\max }$, of $2000 \mathrm{~nm}$ with a G-200 Agilent Tech nanoindenter. A Berkovich tip has been utilized and the indenter has been calibrated against a silica sample. Contact stiffness, $S$, has been determined by the Continuous Stiffness Measurement (CSM) technique, which allows the calculation of nanohardness, $H_{\text {nano }}$, and Young's modulus, $E$, as a function of the depth, $h$. The oscillation amplitude has been programmed at $2 \mathrm{~nm}$ with a 45 $\mathrm{Hz}$ frequency.

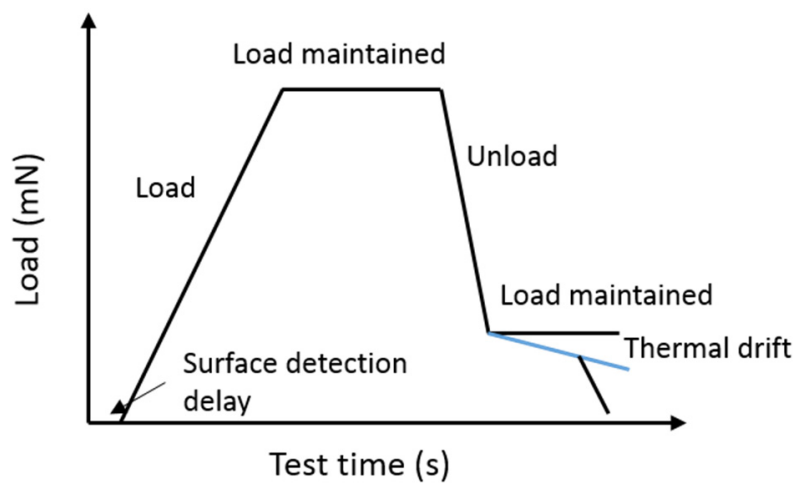

Figure 4.15 Load cycle for nanoindentation testing showing the influence of unwanted thermal drift.

\subsubsection{Microstructure}

\section{Field Emission Scanning Electron Microscopy}

Scanning Electron Microscopy (SEM) is an experimental technique widely utilized to characterize all types of materials, whether organic or inorganic, by means of a focalized electron beam that scans the surface of the sample to be analyzed. The morphology of the microstructure of the material is revealed with an extremely high resolution in the order of nanometers or even smaller. Elemental microanalyses can also be performed if the equipment possesses the adequate accessories. This type of microscope differs fundamentally from optical microscopes in the underlying operating principles because an electron beam instead of a light beam is employed to create a magnified image of the material. An electron microscope consists of an electron gun that acts as the source of the electron beam. The beam can be deflected 
by the action of scanning coils to provide a complete scan of the surface. Detectors record different types of interaction between the sample and the electron beam. These detectors are, in turn, connected to other devices that allow image reconstruction of the object, as well as being able to save these images.

A Field Emission SEM (FE-SEM) works by utilizing a field emission electron gun as an electron source, which allows the formation of highly focalized low and high energy beams. As a consequence, a better spatial resolution is obtained compared to traditional SEM systems. Electrical charges on the sample are also minimized, causing less damage on sensible samples (Figure 4.16).

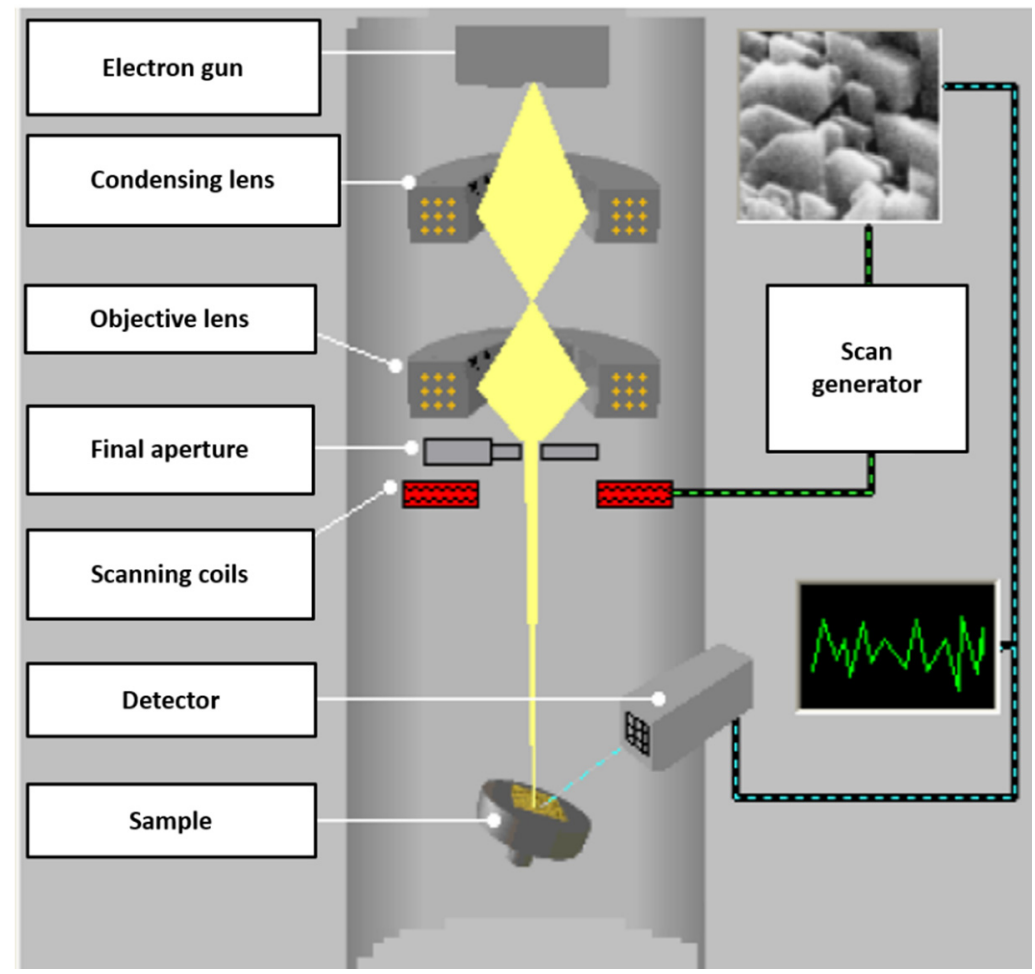

Figure 4.16 Schematic of SEM system highlighting main components

By means of FE-SEM, the microstructure of the sintered materials has been observed in order to determine grain size and morphology. FE-SEM analysis has been carried out in a Zeiss Gemini Ultra 55 system with a spatial resolution of $1.4 \mathrm{~nm}$ at $1 \mathrm{kV}$ and a back-scattered electron detector. Since Y-TZP materials are inherently electrical insulators, the samples have been prepared by coating them with an Au/Pd film in vacuum sputtering device. Previously, the samples have been thermally etched at $100{ }^{\circ} \mathrm{C}$ below the sintering temperature to effectively reveal the microstructure. Grain size has been measured from the micrographs with an image analysis program. 
The given grain size values correspond to an average of 50 grains measured in each sample using the linear intercept method.

\subsection{RESULTS AND DISCUSSION}

\subsubsection{SINTERING CONDITIONS}

A comparison of the overall processing time between conventional and microwave sintering at a dwell temperature of $1300{ }^{\circ} \mathrm{C}$ is given in Figure 4.17. The total time includes heating until dwell temperature is reached, dwell time and cooling of the material. Such behavior can effectively be extrapolated to the power consumption of the respective oven, where $\mathrm{MW}$ systems require a significantly lower power input, not just due to the shorter processing time but also to a more efficient conversion of delivered power into heat due to the mechanisms involved in dielectric heating. In a conventional oven heat is not only delivered to the sample but to several oven components as well, meaning that a substantial amount of energy is wasted. In contrast, during microwave sintering, the energy is directly provided to the material.

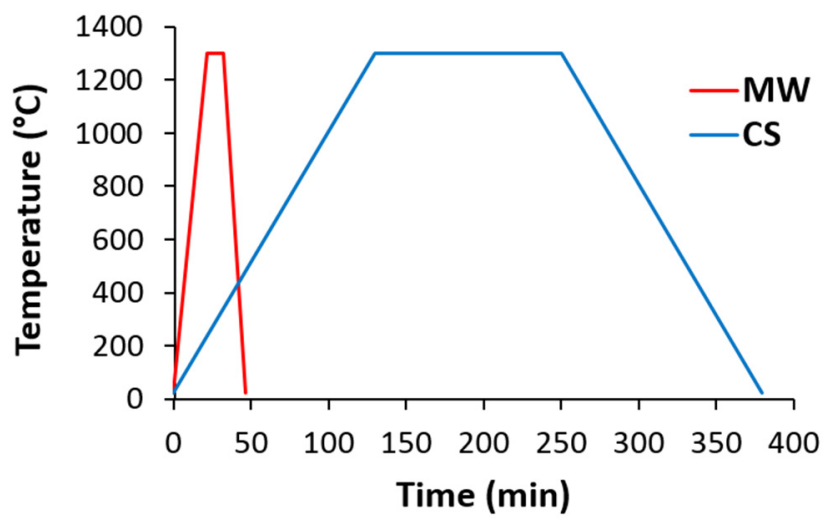

Figure 4.17 Processing time comparison at $1300{ }^{\circ} \mathrm{C}$ between $\mathrm{MW}$ and $\mathrm{CS}$ of zirconia materials.

As discussed in Section 3.3.5, the transparent behavior of zirconia when exposed to at a $2.45 \mathrm{GHz}$ microwave field at room temperature requires the use of a susceptor to raise the temperature of the sample to approximately $400{ }^{\circ} \mathrm{C}$. Once this temperature is reached, zirconia materials are able to absorb the microwave radiation and heat on their own. Nonetheless, the time that takes to reach this temperature is very short and the total processing time is not affected.

MW sintering parameters (heating/cooling rates, final dwell temperature, and dwell time) have been introduced in the control software. This software employs a control feedback system that adjusts the size of the sample cavity in real-time to regulate microwave absorption of the material. The pyrometer measures the temperature, which is used as the input parameter in the software, and the size of the cavity is 
adjust accordingly to effectively maintain the dwell temperature and heating rates. The heating rate for microwave sintered specimens has been set at $100{ }^{\circ} \mathrm{C} / \mathrm{min}$, which is significantly higher than the heating rate of $10^{\circ} \mathrm{C} / \mathrm{min}$ employed for CS of specimens. The slopes of the time processing profiles shown in Figure 4.17 reflect the difference between heating rates.

\subsubsection{PHASE DETERMINATION OF STARTING MATERIAL}

The phase-content of the starting materials has been qualitatively assessed by means of X-ray diffraction. Diffractograms are representations of angles at which diffraction in a crystalline material occurs given by intensity peaks at a corresponding angle. In the case of bulk zirconia materials, each peak corresponds to a specific phase. The $2 \theta$ angles corresponding to $t$ - and $m$-phases are given in Table 4.3 for the range $20^{\circ}<2 \theta<80^{\circ}$. Several works have been carried out extensively employing this technique to characterize phase transformations of zirconia materials [21,23,36-39]. Additionally, with the aid of the library of the International Centre for Diffraction Data $\left(I C D D^{\circledR}\right)$, which possesses a very complete diffraction angle database of many compounds, as well as crystallographic phases, the $m$-and $t$-phase diffraction angles have been clearly established.

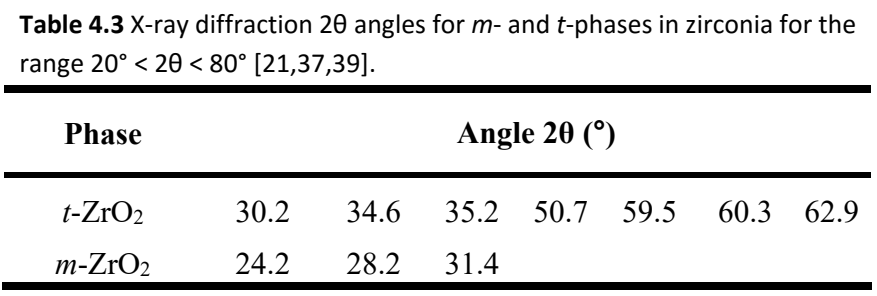

The purpose of X-ray diffraction characterization is to identify the phases that are present in the starting materials to make sure that these materials have been fully stabilized in the $t$-phase, or at least, that there is not a significant amount of $m$-phase content. It also allows a relative estimation of the proportion of the phases in multiphase zirconia materials by comparing intensities of the peaks attributed to each phase. The analysis must be carefully carried out considering the angles and overlapping of peaks.

Figure 4.18 shows the diffractograms of the materials studied in this work. Only peaks corresponding to $t$ - and $m$-phase zirconia have been identified, corresponding to the diffraction angles established in Table 4.3. No other compounds have been detected, which is relevant for the quality of commercial materials because it implies that they have been carefully synthesized and prepared, with no significant presence of impurities, and conforming to the zirconia grades provided in the manufacturer's specification sheets. 
The peak intensities indicate that both commercial materials, LAVA and VITA, as well as LAB are almost $100 \%$ stabilized in the $t$-phase as provided. Very low intensity $\mathrm{m}$ phase peaks can be observed at approximately 28.2 and $31.4^{\circ}$ for all Y-TZP starting materials. When comparing relative peak intensities among the $m$ - and $t$-phases, LAB material shows a slightly higher content of $m$-phase than its commercial counterparts. No quantitative phase determination has been carried in this study. However, Rietveld refinement of LAVA and LAB material has been performed in the study described in Chapter 5 to quantify zirconia phases of starting materials by means of X-ray diffraction.

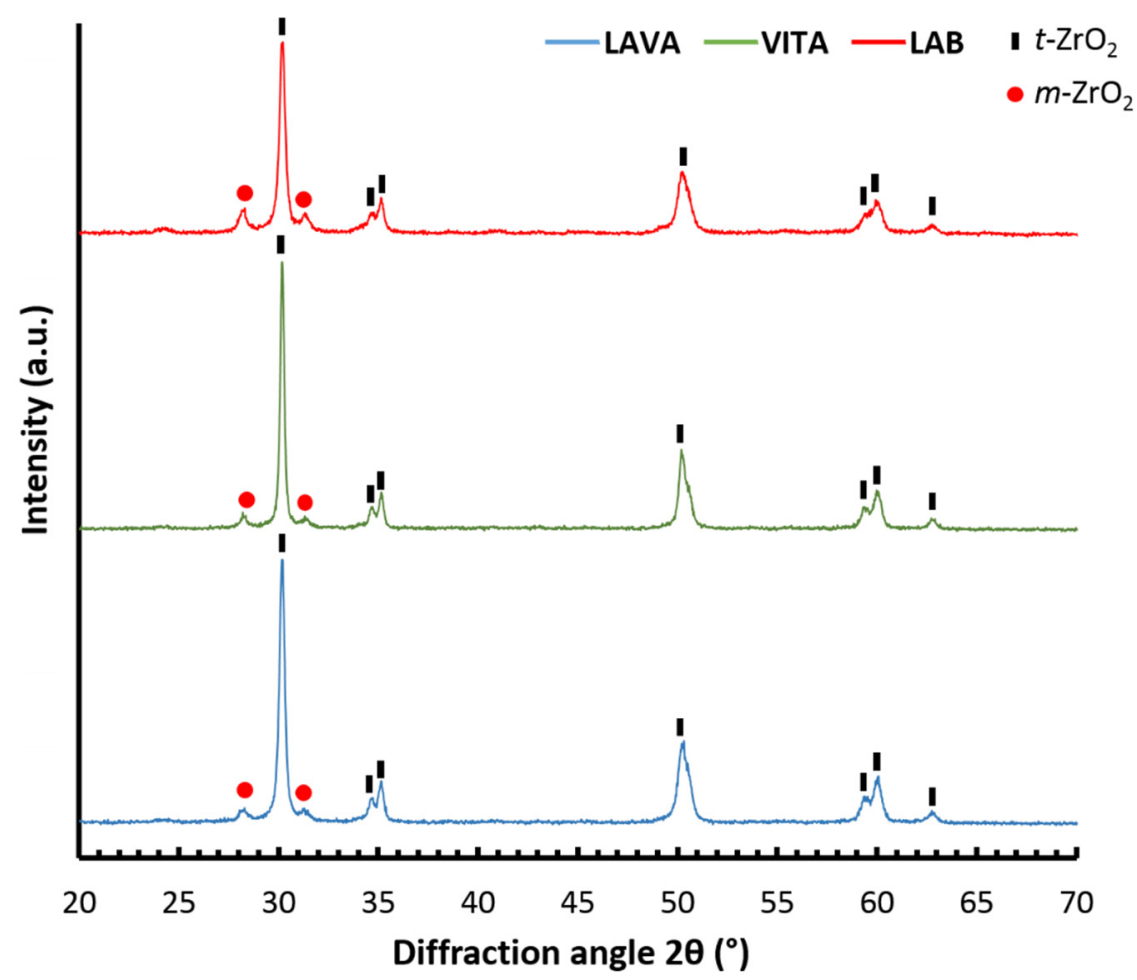

Figure 4.18 Diffractograms of the zirconia materials studied in this work as received before sintering with corresponding peak labels for phase identification.

\subsubsection{DENSIFICATION UPON SINTERING}

Green density of specimens obtained from pre-sintered blocks of commercial zirconia, LAVA and VITA, is between $50-60 \%$ of theoretical density, as measured with the same method employed for measuring apparent density, $\rho_{a p p}$, of sintered materials.

Relative density values for all samples sintered via microwave and conventional sintering are shown in Figure 4.19. MW-sintered LAVA material presents 
considerably high relative density values, approximately $99 \%$ of the theoretical density, for both sintering temperatures. $\mathrm{MW}$ sintering provides the highest relative density value at a sintering temperature of $1200^{\circ} \mathrm{C}$, even higher than CS at $1400^{\circ} \mathrm{C}$. For VITA material, the relative density values obtained are low for both sintering techniques at lower temperatures compared to the other materials, while relative density increases substantially when sintering temperature is increased by $100^{\circ} \mathrm{C}$ in both cases. $\mathrm{LAB}$ material also shows differences as the sintering temperature is increased by CS. MW sintering at 1200 and $1300{ }^{\circ} \mathrm{C}$ and $\mathrm{CS}$ at $1400{ }^{\circ} \mathrm{C}$ show significantly higher relative density values falling within the error range of each other. These results demonstrate that microwave sintering provides a high degree of densification at lower sintering temperatures and shorter processing times.

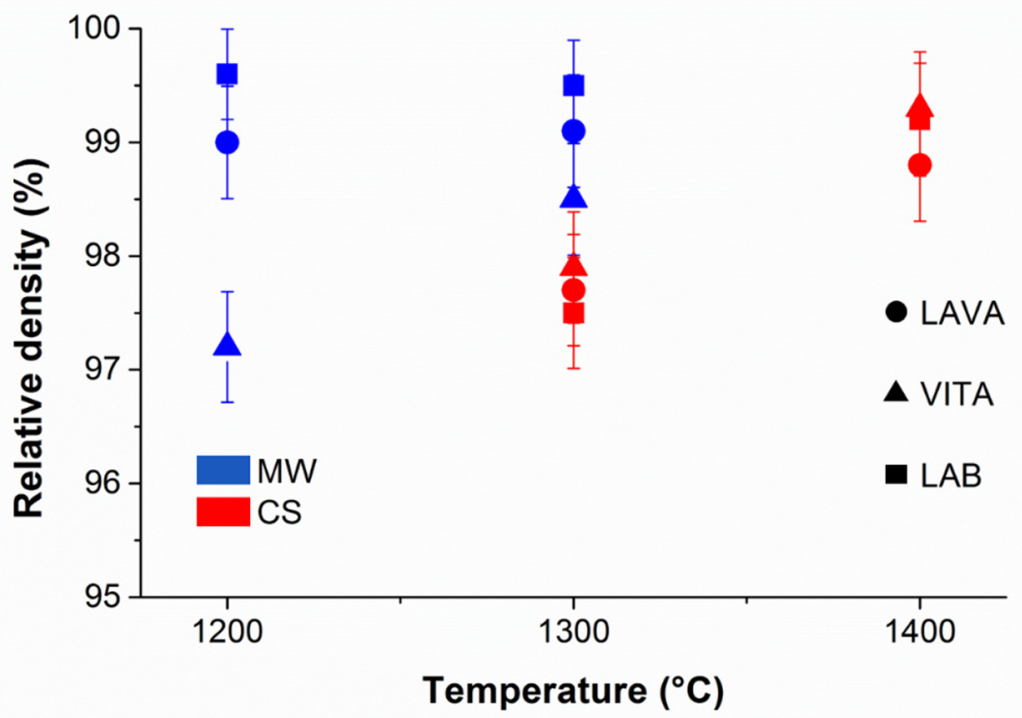

Figure 4.19 Relative density values for LAVA, VITA and LAB materials sintered via MW and CS.

The three materials characterized in this study have provided relevant results regarding the densification behavior of Y-TZP materials under different sintering conditions. For example, LAVA material sintered via MW heating shows a higher degree of densification (99.1\%) compared to CS (97.7\%) at the same sintering temperature of $1300{ }^{\circ} \mathrm{C}$, in a considerably shorter amount of final sintering time, which is $10 \mathrm{~min}$ for MW instead of $2 \mathrm{~h}$ for CS.

In terms of relative density, LAB material shows a higher degree of densification in most CS and MW specimens. Such behavior has been expected because the starting material is more homogeneous in terms of particle size as opposed to LAVA and VITA. Since a previous rheological study of the suspension for powder deagglomeration has been carried out, a more homogenous powder with no aggregate formation has 
been obtained, which translates into an enhanced densification process upon sintering.

\subsubsection{MICROSTRUCTURE AND GRAIN SIZE}

Table 4.4 summarizes the sintering conditions and the average grain size obtained for all specimens by image analysis and applying the linear-intercept method. As can be seen in Figure 4.20, the microstructure of LAVA material reveals significantly different grain sizes for samples sintered under different conditions. For MWsintered specimens, the average grain size is smaller than CS samples. As dwell times are shortened and heating rates are increased in microwave sintering, grain coarsening is substantially inhibited resulting in a finer microstructure. The wide range of initial particle size that is characteristic of this material in particular is also reflected on the significant variations in grain sizes that occur in the $\mathrm{MW}$-sintered sample at 1200 and $1300{ }^{\circ} \mathrm{C}$. In conventional sintering, however, longer sintering times and slower heating rates allow for the consolidation of bigger particles with a more homogeneous size distribution. As a result, the standard deviation values of the average grain sizes found in MW-sintered samples are bigger than their conventionally sintered counterparts.

Table 4.4 Average grain size results for all zirconia materials under various conditions.

\begin{tabular}{|c|c|c|c|c|c|}
\hline Material & $\begin{array}{l}\text { Sintering } \\
\text { method }\end{array}$ & $\begin{array}{c}\text { Final } \\
\text { temperature } \\
\left({ }^{\circ} \mathrm{C}\right) \\
\end{array}$ & $\begin{array}{c}\text { Dwell time } \\
(\mathrm{min})\end{array}$ & $\begin{array}{c}\text { Relative } \\
\text { Density } \\
(\%) \\
\end{array}$ & $\begin{array}{c}\text { Average } \\
\text { grain size } \\
(\mathrm{nm}) \\
\end{array}$ \\
\hline \multirow{4}{*}{ LAVA } & \multirow{2}{*}{$\mathrm{CS}$} & 1300 & 120 & 97.7 & $238 \pm 54$ \\
\hline & & 1400 & 120 & 98.8 & $343 \pm 43$ \\
\hline & \multirow{2}{*}{ MW } & 1200 & 10 & 99.0 & $146 \pm 64$ \\
\hline & & 1300 & 10 & 99.1 & $162 \pm 98$ \\
\hline \multirow{4}{*}{ VITA } & \multirow{2}{*}{$\mathrm{CS}$} & 1300 & 120 & 97.9 & $219 \pm 58$ \\
\hline & & 1400 & 120 & 99.3 & $286 \pm 68$ \\
\hline & \multirow{2}{*}{ MW } & 1200 & 10 & 97.2 & $179 \pm 61$ \\
\hline & & 1300 & 10 & 98.5 & $186 \pm 49$ \\
\hline \multirow{4}{*}{ LAB } & \multirow{2}{*}{$\mathrm{CS}$} & 1300 & 120 & 97.5 & $203 \pm 48$ \\
\hline & & 1400 & 120 & 99.2 & $199 \pm 85$ \\
\hline & \multirow{2}{*}{ MW } & 1200 & 10 & 99.6 & $174 \pm 67$ \\
\hline & & 1300 & 10 & 99.5 & $194 \pm 88$ \\
\hline
\end{tabular}



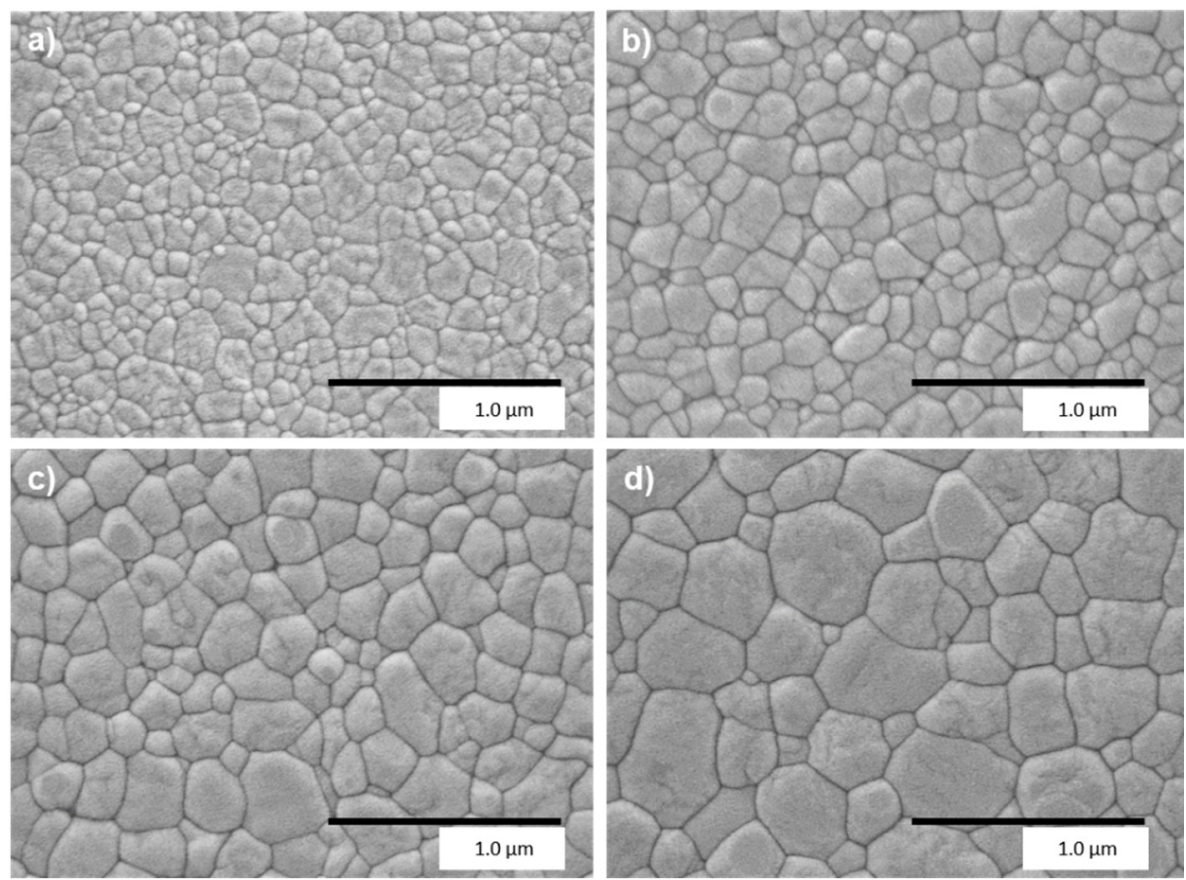

Figure 4.20 FE-SEM micrographs revealing the granular microstructure of LAVA zirconia material sintered via MW and CS methods at various temperatures: MW sintering for $10 \mathrm{~min}$ at a) $1200{ }^{\circ} \mathrm{C}$ and b) $1300{ }^{\circ} \mathrm{C}$; CS for $2 \mathrm{~h}$ at c) $1300^{\circ} \mathrm{C}$ and d) $1400{ }^{\circ} \mathrm{C}$.

FE-SEM micrographs for VITA material are shown in Figure 4.21. The average grain size of the MW-sintered samples is still smaller than the average grain size for CS samples. Average grain size changes with sintering temperature and also with the method employed due to the different heating mechanisms that take place and processing times that are required. 

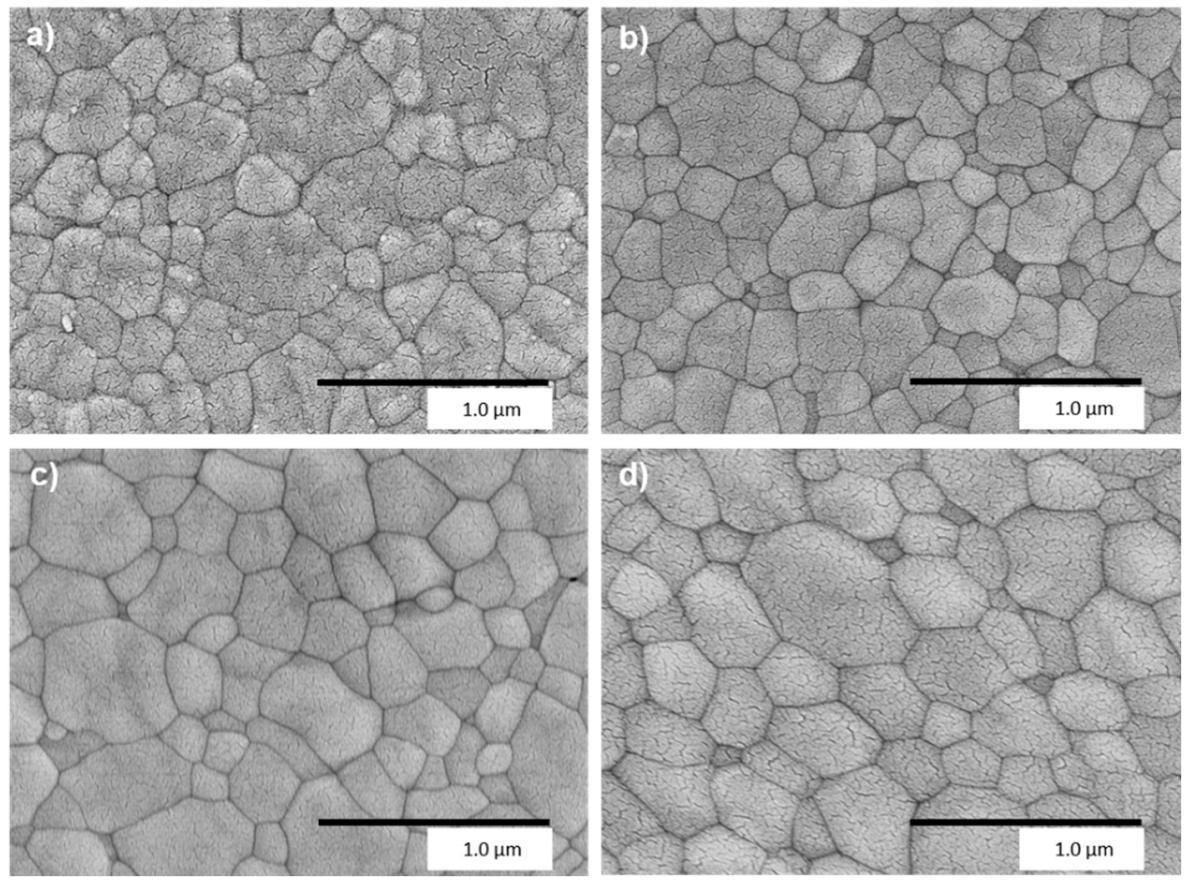

Figure 4.21 FE-SEM micrographs revealing the granular microstructure of VITA zirconia material sintered via MW and CS methods at two temperatures: $\mathrm{MW}$ sintering for $10 \mathrm{~min}$ at a) $1200{ }^{\circ} \mathrm{C}$ and b) $1300^{\circ} \mathrm{C}$; CS for $2 \mathrm{~h}$ at c) $1300^{\circ} \mathrm{C}$ and d) $1400^{\circ} \mathrm{C}$.

Figure 4.22 shows FE-SEM micrographs for LAB material samples. The average grain size of MW-sintered samples is $174 \mathrm{~nm}$ for $1200{ }^{\circ} \mathrm{C}$ and $194 \mathrm{~nm}$ for $1300{ }^{\circ} \mathrm{C}$, while that of CS samples is $203 \mathrm{~nm}$ and $199 \mathrm{~nm}$ for 1300 and $1400{ }^{\circ} \mathrm{C}$, respectively. The difference in grain size between $\mathrm{MW}$ and CS samples is less than $30 \mathrm{~nm}$. Additionally, micrographs of LAB material show the presence of porosity in CS-sintered specimens, which is not appreciated in their MW-sintered counterparts.

Grain size variation in LAVA material is quite significant, almost $80 \mathrm{~nm}$ when comparing MW sintering and CS at the same temperature (Fig. 4.20b and 420c). This behavior may be attributed to the material being obtained as a pre-sintered block, where the differences in grain size became quite pronounced due to processing under different sintering conditions. In a pre-sintered material, particles have already formed necks among each other and, as dwell time is increased, they are able to consolidate larger particles. 

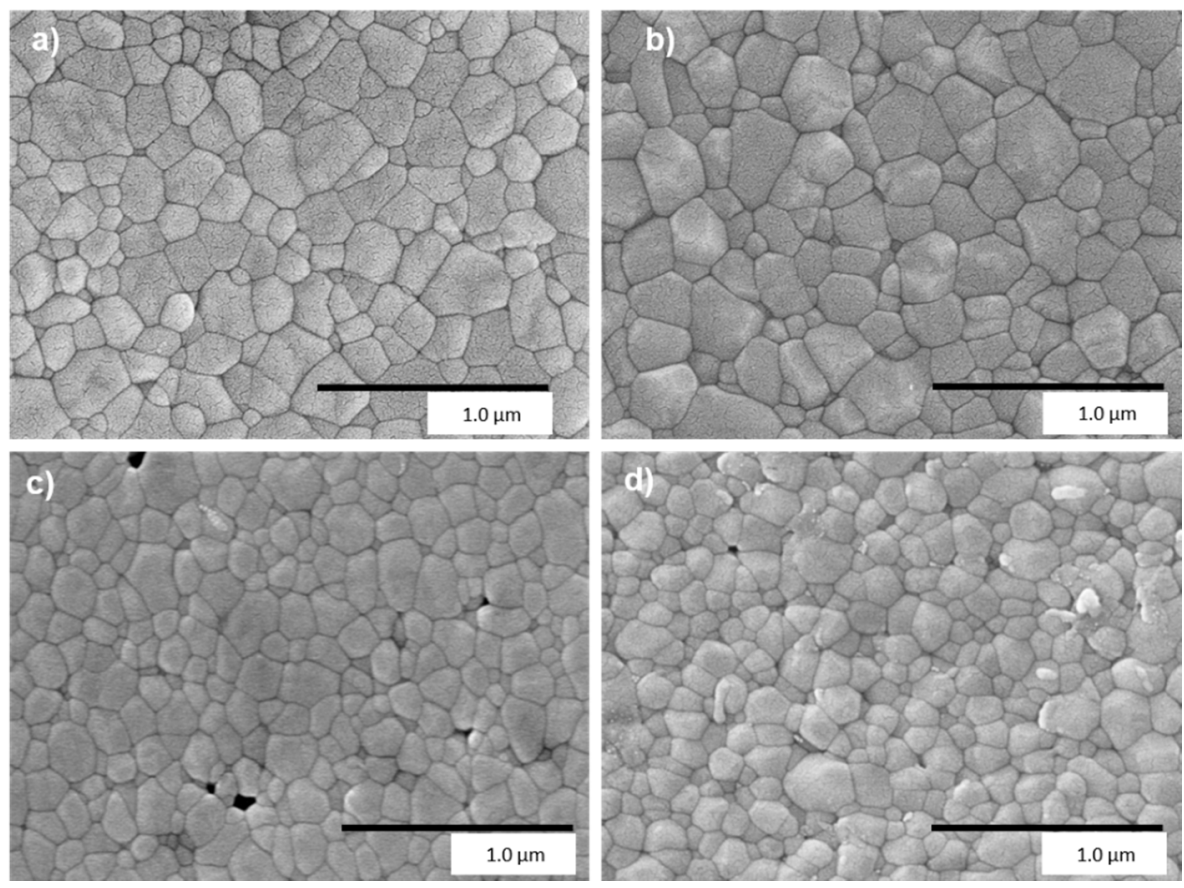

Figure 4.22 FE-SEM micrographs revealing the granular microstructure of LAB zirconia material sintered via MW and CS methods at two temperatures: MW sintering for $10 \mathrm{~min}$ at a) $1200{ }^{\circ} \mathrm{C}$ and b) $1300{ }^{\circ} \mathrm{C}$; CS for $2 \mathrm{~h}$ at c) $1300{ }^{\circ} \mathrm{C}$ and d) $1400^{\circ} \mathrm{C}$.

Also, the different heating mechanisms that take place in each method play a significant role. MW heating is a type of volumetric heating and, in this case, the grains are heated simultaneously creating a temperature gradient that allows heat flow from the inside to the surface because internal grains can heat more as they are surrounded by neighboring particles. As a consequence, one possibility is that the mass diffusion among particles at the grain boundaries occurs slower than for CS and smaller grains are obtained.

Additionally, heating rates also have a direct effect in the resulting microstructure. For the MW-sintered material, a heating rate of $100^{\circ} \mathrm{C} / \mathrm{min}$ was established, while for CS samples, the heating rate was $10^{\circ} \mathrm{C} / \mathrm{min}$. A lower heating rate allows more time for the grains to form wider bridges (necks), resulting in bigger particle sizes. Increasing temperature for both sintering methods also has an effect in the microstructure. Samples sintered at lower temperatures result in smaller grain sizes for both techniques.

According to the micrographs for VITA in Figure 4.21, there is also a significant variation in grain size between the samples sintered by $\mathrm{MW}$ and $\mathrm{CS}$ at the same temperature $\left(1300^{\circ} \mathrm{C}\right)$. Again, this is attributed to the heating rates, sintering time and heating mechanisms involved in MW sintering, as described above for LAVA. 
However, these differences are not as pronounced as those observed in LAVA. The differences in grain size of VITA material samples between MW and CS are no more than $40 \mathrm{~nm}$, which is different than those of LAVA, where differences of almost 80 $\mathrm{nm}$ are observed. This is a consequence of the state of the raw material, since a presintered block, LAVA and VITA, have already a previous heat treatment and particles have already been consolidated to some extent and the differences in size are more pronounced after processing.

The microstructure analysis reveals less variation in grain size when comparing both sintering methods in $L A B$, which is an important difference between this ceramic powder and the other commercial materials. In this case, this behavior may be explained by the characteristics of the starting material. As previously mentioned, LAB material consists of particles with no aggregates due to a carefully prepared suspension resulting in an initial average particle size that is more uniform compared to commercial materials.

\subsubsection{MICROINDENTATION MECHANICAL PROPERTIES}

Regarding characterization of the Vickers hardness via microindentation, $H_{v}$ values are presented in Figure 4.23. When comparing sintering methods, it is observed that MW-sintered Y-TZP materials result in higher $H_{v}$ values than CS, in general. However, the differences in $H_{v}$ tend to be less pronounced between both sintering methods than for the commercial materials. The highest $H_{v}$ value $(14.7 \mathrm{GPa})$ is obtained for MW sintering at $1200{ }^{\circ} \mathrm{C}$. This value is the highest of all materials and for both sintering methods. For this particular material, a sintering temperature above 1200 ${ }^{\circ} \mathrm{C}$ does not seem to improve $H_{v}$ significantly.

For LAVA material, $H_{v}$ values are between 12.7 and $14.0 \mathrm{GPa}$. In both sintering techniques, $H_{v}$ values do not change significantly after increasing sintering temperature. For VITA, $H_{v}$ values are very similar to those obtained for LAVA, ranging from 12.9 to $14.1 \mathrm{GPa}$ and with no significant changes as sintering temperature is increased. In the case of LAB material, the highest $H_{v}$ values of $14.7 \mathrm{GPa}$ are obtained for $\mathrm{MW}$ sintering. In CS, there is no significant variation in the $H_{v}$ values when increasing the sintering temperature from 1300 to $1400{ }^{\circ} \mathrm{C}$. 


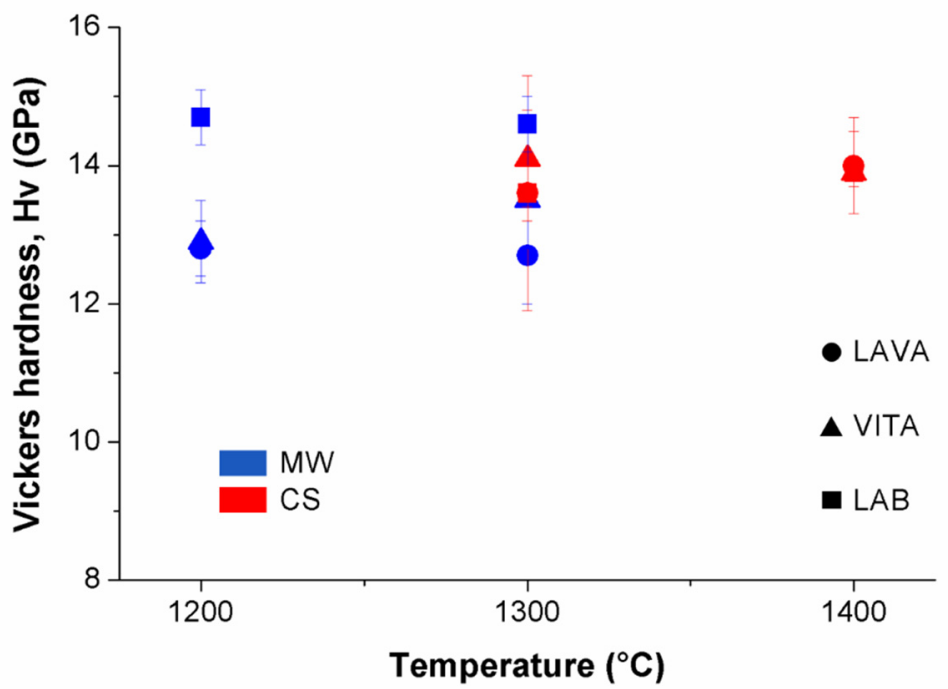

Figure 4.23 Vickers hardness values for LAVA, VITA and LAB materials sintered via MW and CS.

When comparing $H_{v}$ values of both sintering methods at the same sintering temperature $\left(1300{ }^{\circ} \mathrm{C}\right)$, the $\mathrm{MW}$ value $(12.7 \mathrm{GPa})$ is lower than the CS value (13.6 $\mathrm{GPa}$ ). These results contrast with those found in the literature [6], where it has been determined that Y-TZP materials sintered via MW heating at this same temperature result in higher $H_{v}$ values than those sintered by CS. To explain the results that were obtained, it is important to consider other factors, such as the sintered material not being homogeneous after the sintering process. This can be observed in the error value corresponding to this material sintered conventionally at $1300^{\circ} \mathrm{C}$, where the error range is quite significant. Since the material was obtained as a pre-sintered block, there was no complete control of the starting material and it is possible that block was not homogeneous when provided by containing regions with higher porosity than others and grains of different sizes.

The determined facture toughness values, $K_{I C}$, are presented in Figure 4.24. The results for samples sintered by MW are higher than those for CS in LAVA and LAB. For $\mathrm{MW}$ and $\mathrm{CS}, K_{I C}$ values are very close to each other for both temperatures. Regarding fracture toughness of VITA, an important difference in $K_{/ C}$ values exists. $\mathrm{MW}$-sintered samples have lower $K_{/ C}$ values, around $4.0 \mathrm{MPa} \cdot \mathrm{m}^{1 / 2}$, than those sintered by the conventional method, which are greater than $5.0 \mathrm{MPa} \cdot \mathrm{m}^{1 / 2}$. In the case of LAB material, the best value obtained corresponds to sample sintered at 1300 ${ }^{\circ} \mathrm{C}$ by $\mathrm{MW}$.

$K_{I C}$ values determined for LAVA show that MW sintering results in higher values at both sintering temperatures than those of CS. By directly comparing samples sintered at $1300{ }^{\circ} \mathrm{C}$, it is possible to determine that $\mathrm{MW}$ sintering improves fracture 
toughness of this material (7.0 MPa $\mathrm{m}^{1 / 2}$ for $\mathrm{MW}$ vs. $6.2 \mathrm{MPa} \cdot \mathrm{m}^{1 / 2}$ for $\mathrm{CS}$ ). These results coincide with those found in other studies under similar conditions, such as those of Guazzato et al. [40] and Vleugels et al. [22,41,42]. The $K_{/ C}$ values measured for VITA material via MW sintering contrast with those obtained for LAVA, since the values of VITA are significantly lower compared to those of LAVA. This is, again, explained by the pre-sintering that takes place in commercial materials, where the initial presence of density gradients in the pre-sintered materials are accentuated after the main sintering step occurs and might account for the lower $K_{l C}$ values of VITA.

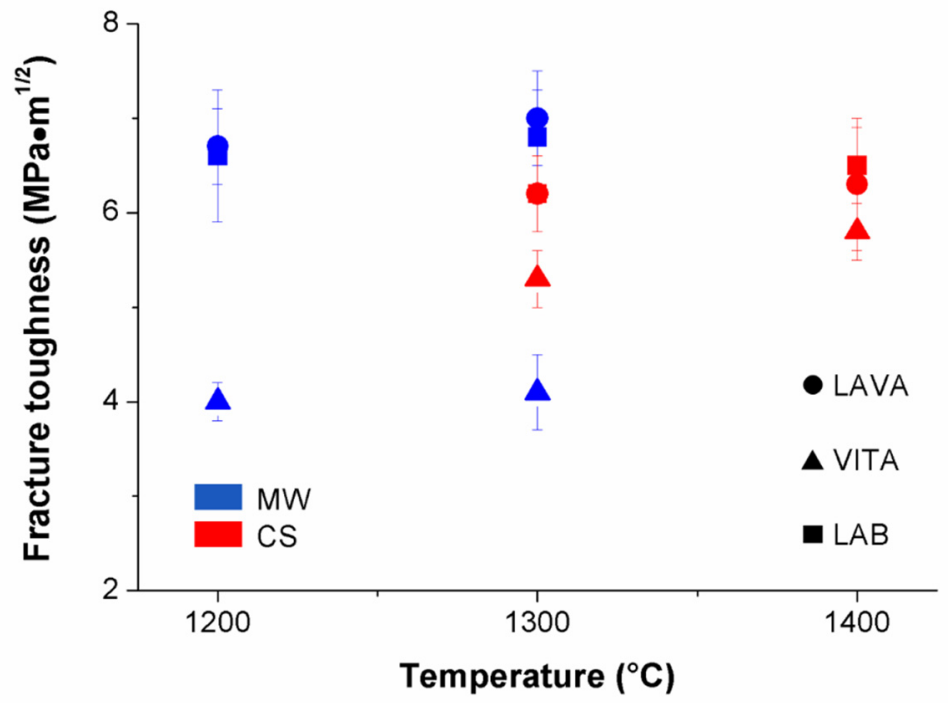

Figure 4.24 Fracture toughness values for LAVA, VITA and LAB materials sintered via MW and CS.

Regarding fracture toughness of $\mathrm{LAB}$ zirconia, $K_{/ C}$ values are quite similar when comparing both sintering techniques. At $1200^{\circ} \mathrm{C}$ by MW the value is the same than the material sintered at $1400{ }^{\circ} \mathrm{C}$ by $\mathrm{CS}$. These results are relevant from a processing perspective, since optimized $\mathrm{Y}$-TZP dental materials consolidated with $\mathrm{MW}$ radiation can greatly reduce process time and energy consumption. A similar claim can be asserted from $K_{I C}$ values of LAVA zirconia.

In general, materials in this work, whether sintered by MW or CS, possess $H_{v}$ and $K_{I C}$ values that fall within the admissible range of values that are typical for Y-TZP materials found in the literature. Table 4.5 compares the mechanical properties of zirconia materials stabilized with 3 mol\% $\mathrm{Y}_{2} \mathrm{O}_{3}$ from other bibliographical sources with those of the present study. These values also comply with the requirements established by dentistry standards for replacements and implants. Since all materials are Y-TZP, it would be expected that those sintered under the same conditions 
(sintering method, temperature, time) resulted in very similar mechanical properties. However, notable differences exist in the presented $H_{v}$ and $K_{I C}$ values due to the fact that the starting material has been obtained from different sources and under different conditions.

\begin{tabular}{|c|c|c|}
\hline Authors & $\begin{array}{c}H_{v} \\
(\mathrm{GPa})\end{array}$ & $\begin{array}{c}K_{I C} \\
\left(\mathbf{M P a} \cdot \mathbf{m}^{1 / 2}\right)\end{array}$ \\
\hline \multicolumn{3}{|c|}{ Conventional sintering } \\
\hline Guazzato et al. ${ }^{41}$ & $9-15$ & $3.0-8.0$ \\
\hline Inokoshi et al. ${ }^{39}$ & $12-14$ & $3.0-5.0$ \\
\hline Present study & $13-14$ & $5.0-6.5$ \\
\hline \multicolumn{3}{|c|}{ Microwave sintering } \\
\hline Wilson et al. ${ }^{42}$ & $11-12$ & 4.8 \\
\hline Upadhyaya et al. ${ }^{43}$ & $8-9$ & 8.6 \\
\hline Borrell et al. ${ }^{14}$ & $14-15$ & 4.5 \\
\hline Present study & $13-15$ & $4.0-7.0$ \\
\hline
\end{tabular}

\subsubsection{NANOINDENTATION MECHANICAL PROPERTIES}

The use of more sophisticated indentation techniques, such as instrumented testing methods, allows the assessment of other relevant mechanical properties that would otherwise not be possible to determine with microindentation. The elastic modulus, or Young's modulus, is one such property. Additionally, the evaluation of the hardness of a material can change depending on the scale of the measurement. Nanoindentation can also provide nanohardness measurements that are fundamentally different from Vickers hardness in two aspects: the loads applied and the penetration depth [45]. Therefore, nanohardness can be used as a complimentary tool for the evaluation of the mechanical properties of Y-TZP ceramics that have been processed differently. Moreover, nanoindentation is considered a non-destructive mechanical testing technique.

Results of the mechanical properties determined by nanoindentation are shown in Table 4.6. Young's modulus, $E$, and nanohardness, $H_{\text {nano, }}$ measurements have been obtained as an average of at least 25 indentations. The values indicate the differences arising among the two sintering methods and the dwell temperatures. $H_{\text {nano }}$ values are different from those obtained for $H_{V}$ because of the contact area inherent to each indentation method. In this manner, the contact area involved in 
Vickers indentation is quite larger than in nanoindentation providing a more general measurement of the hardness of the material involving several grains. In contrast, nanoindentation is seen as a more punctual measurement that can even be targeted on specific grains $[46,47]$. The substantial difference between $H_{v}$ and $H_{\text {nano }}$ is therefore attributed to the deformation mechanisms that accompany micro- and nanoindentation testing.

Table 4.6 $H_{\text {nano }}$ and $E$ values of 3Y-TZP ceramics determined by the nanoindentation technique.

\begin{tabular}{cccc}
\hline Material & Sintering & $\begin{array}{c}\text { Hardness } \\
\text { (GPa) }\end{array}$ & $\begin{array}{c}\text { Young's } \\
\text { Modulus } \\
\text { (GPa) }\end{array}$ \\
\hline \multirow{3}{*}{ LAVA } & $\mathrm{MW} / 1200{ }^{\circ} \mathrm{C}$ & $15.3 \pm 0.9$ & $249 \pm 14$ \\
& $\mathrm{MW} / 1300{ }^{\circ} \mathrm{C}$ & $15.1 \pm 0.7$ & $241 \pm 10$ \\
& $\mathrm{CS} / 1300{ }^{\circ} \mathrm{C}$ & $17.9 \pm 2.4$ & $285 \pm 26$ \\
& $\mathrm{CS} / 1400{ }^{\circ} \mathrm{C}$ & $14.7 \pm 2.5$ & $255 \pm 19$ \\
\hline \multirow{2}{*}{ VITA } & $\mathrm{MW} / 1200{ }^{\circ} \mathrm{C}$ & $14.5 \pm 2.3$ & $222 \pm 19$ \\
& $\mathrm{MW} / 1300{ }^{\circ} \mathrm{C}$ & $15.2 \pm 1.8$ & $247 \pm 15$ \\
& $\mathrm{CS} / 1300{ }^{\circ} \mathrm{C}$ & $14.2 \pm 2.7$ & $225 \pm 26$ \\
& $\mathrm{CS} / 1400{ }^{\circ} \mathrm{C}$ & $16.4 \pm 2.3$ & $259 \pm 26$ \\
\hline \multirow{2}{*}{$\mathrm{LAB}$} & $\mathrm{MW} / 1200{ }^{\circ} \mathrm{C}$ & $16.1 \pm 1.6$ & $269 \pm 12$ \\
& $\mathrm{MW} / 1300{ }^{\circ} \mathrm{C}$ & $16.7 \pm 1.6$ & $260 \pm 13$ \\
& $\mathrm{CS} / 1300^{\circ} \mathrm{C}$ & $16.8 \pm 3.2$ & $253 \pm 26$ \\
& $\mathrm{CS} / 1400{ }^{\circ} \mathrm{C}$ & $17.4 \pm 0.2$ & $262 \pm 13$ \\
\hline
\end{tabular}

Taking into consideration the variation is grain size regarding LAVA material after MW and CS, some important differences arise in the measured values of $E$ and $H_{\text {nano. }}$. MW sintering at $1200{ }^{\circ} \mathrm{C}$ resulted in higher $E$ and $H_{\text {nano }}$ values than at $1300{ }^{\circ} \mathrm{C}$, suggesting that better properties can be obtained at lower sintering temperatures in MW due to the smaller grain sizes following a Hall-Petch relationship. This pattern also applies for CS LAVA material, as the properties decrease with increasing sintering temperature and grain size.

In the case of VITA, a different behavior is observed with respect to LAVA. For MW sintered specimens, the measured mechanical properties are higher at $1300^{\circ} \mathrm{C}$ than at $1200{ }^{\circ} \mathrm{C}$. A similar behavior occurs in CS material. The variations in grain size between MW and CS are not as pronounced as in the case of LAVA. However, different patterns in nanoindentation mechanical properties are found. Nonetheless, the values fall within an acceptable range for Y-TZP ceramics. 
Lastly, LAB material possesses the highest values of mechanical properties measured with nanoindentation when compared to the other two commercial materials. This behavior is attributed to the nature of the starting powder, which is more homogeneous due to a more thorough preparation, and, consequently, grain sizes are not very different between sintering methods and dwell temperatures. $\mathrm{MW}$ sintering at $1200{ }^{\circ} \mathrm{C}$ yields very high $H_{\text {nano }}$ and $E$ values. As the temperature is increased to $1300^{\circ} \mathrm{C}$, these properties are further enhanced. The same occurs with CS material. As sintering temperature is increased, the mechanical properties also increase. When comparing sintering methods at the same temperature, the values of $\mathrm{E}$ and $H_{\text {nano }}$ are quite similar.

\subsection{CONCLUSIONS}

The sintering time and heating rates applied in MW sintering of $\mathrm{Y}$-TZP dental materials significantly shortened the overall processing time compared to conventional sintering methods. The modification in densification mechanisms that accompanies microwave heating has changed the microstructure of Y-TZP ceramics. The resulting materials reach a very high degree of densification and the microstructure presents significant differences in grain size.

The results obtained in this work suggest that MW sintering of 3Y-TZP dental materials, generally, results in better mechanical properties in terms of fracture toughness than conventional sintering. It has also been established that the LAB material had the highest $H_{v}$ and $K_{I C}$ values, as well as that of relative density and the least variation in average particle size when sintered at lower temperatures. This result is a consequence of the rheological study that has been previously carried out that allows for a more homogeneous starting powder free of aggregates, emphasizing the importance of the raw material. This has a direct effect on the final properties of sintered materials. The resulting microstructure for all samples could be compared in terms of particle size. Smaller grain sizes were obtained for MWsintered samples than for CS samples in all materials.

Overall, microwave sintering is a very good alternative for sintering and consolidating Y-TZP commercial materials for dental applications due to the resulting finer microstructure, enhanced mechanical properties and reduction in processing times and energy consumption. 


\section{REFERENCES}

[1] Guazzato M, Albakry M, Ringer SP, Swain MV. Strength, fracture toughness and microstructure of a selection of all-ceramic materials. Part II. Zirconiabased dental ceramics. Dent Mater 2004;20:449-56.

[2] McMeeking RM, Evans AG. Mechanics of transformation-toughening in brittle materials. J Am Ceram Soc 1982;65:242-6.

[3] Anselmi-Tamburini U, Garay JE, Munir ZA. Fast low-temperature consolidation of bulk nanometric ceramic materials. Scr Mater 2006;54:8238.

[4] Hall EO. The deformation and ageing of mild steel: III Discussion of Results. Proc Phys Soc Sect B 1951;64:747-53.

[5] Petch NJ. The cleavage strength of polycrystals. J Iron Steel Inst 1953;174:258.

[6] Nightingale SA, Worner HK, Dunne DP. Microstructural development during the microwave sintering of yttria-zirconia ceramics. J Am Ceram Soc 1997;80:394-400.

[7] Patil DS, Mutsuddy BC. Microwave sintering of yttria-containing tetragonal zirconia polycrystal (Y-TZP) ceramics. Bull Mater Sci 1994;17:1441-6.

[8] Goldstein A, Travitzky N, Singurindy A, Kravchik M. Direct microwave sintering of yttria-stabilized zirconia at 2.45 GHz. J Eur Ceram Soc 1999;19:2067-72.

[9] Bodhak S, Bose S, Bandyopadhyay A. Densification study and mechanical properties of microwave-sintered mullite and mullite-zirconia composites. J Am Ceram Soc 2011;94:32-41.

[10] Semenov V, Rybakov I. What type of transport phenomena can be induced by microwave field in solids and how these phenomena contribute to materials processing. In: Novel Materials Processing by Advanced Electromagentic Energy Sources: Proceedings of the International Symposium on Novel Materials Processing by Advanced Electromagnetic Energy Sources. Elsevier; 2005, p.111.

[11] Menezes RR, Kiminami RHGA. Microwave sintering of alumina-zirconia nanocomposites. J Mater Process Technol 2008;203:513-7.

[12] Park SS, Meek TT. Characterization of $\mathrm{ZrO}_{2}-\mathrm{Al}_{2} \mathrm{O}_{3}$ composites sintered in a 2.45 GHz electromagnetic field. J Mater Sci 1991;26:6309-13.

[13] Oghbaei M, Mirzaee O. Microwave versus conventional sintering: A review of fundamentals, advantages and applications. J Alloys Compd 2010;494:17589. 
[14] Borrell A, Salvador MD, Peñaranda-Foix FL, Cátala-Civera JM. Microwave sintering of zirconia materials: Mechanical and microstructural properties. Int J Appl Ceram Technol 2013;10:313-20.

[15] Tsakaloudi V, Papazoglou E, Zaspalis VT. Microwave firing of MnZn-ferrites. Mater Sci Eng B 2004;106:289-94.

[16] Clark DE, Sutton WH. Microwave processing of materials. Annu Rev Mater Sci 1996;26:299-331.

[17] Borrell A, Salvador MD, Rayón E, Peñaranda-Foix FL. Improvement of microstructural properties of 3Y-TZP materials by conventional and nonconventional sintering techniques. Ceram Int 2012;38:39-43.

[18] Rayón E, Moreno R, Alcázar C, Salvador MD, Manjón FJ, Jiménez-Piqué E, et al. Enhanced hydrothermal resistance of $Y$-TZP ceramics through colloidal processing. J Am Ceram Soc 2013;96:1070-6.

[19] Borrell A, Salvador MD, Peñaranda-Foix FL, Plaza-Gonzalez PJ, Garcia-Baños B, Garcia-Nieto S. Adaptive microwave system for optimum new material sintering. Microw Symp Dig (IMS), 2013 IEEE MTT-S Int, 2013, p. 1-4.

[20] Reyes-Rojas A, Torres-Moye E, Solís-Canto O, Aguilar-Elguézabal A, Bocanegra-Bernal $\mathrm{MH}$. X-ray diffraction and atomic force microscopy study in aged zirconia-toughened alumina composite with dispersion of $m-\mathrm{ZrO}_{2}$ nanoparticles. Int J Refract Met Hard Mater 2012;35:270-8.

[21] Callon GJ, Goldie DM, Dibb MF, Cairns JA, Paton J. X-ray diffraction analysis of yttria stabilized zirconia powders produced by an organic sol-gel method. J Mater Sci Lett 2000;19:1689-91.

[22] Zhang F, Vanmeensel K, Inokoshi M, Batuk M, Hadermann J, Van Meerbeek $\mathrm{B}$, et al. 3Y-TZP ceramics with improved hydrothermal degradation resistance and fracture toughness. J Eur Ceram Soc 2014;34:2453-63.

[23] Muñoz-Tabares JA, Anglada MJ. Quantitative analysis of monoclinic phase in 3Y-TZP by raman spectroscopy. J Am Ceram Soc 2010;93:1790-5.

[24] Chevalier J, Cales B, Drouin JM. Low-temperature aging of Y-TZP ceramics. J Am Ceram Soc 1999;82:2150-4.

[25] Vasudevan R, Karthik T, Ganesan S, Jayavel R. Effect of microwave sintering on the structural and densification behavior of sol-gel derived zirconia toughened alumina (ZTA) nanocomposites. Ceram Int 2013;39:3195-204.

[26] Chinn RE. Ceramography: Preparation and analysis of ceramic microstructures. ASM International; 2002.

[27] Yovanovich M. Micro and macro hardness measurements, correlations, and contact models. In: Collection of technical papers - 44th AIAA Aerospace 
Science Meeting; 2006, p. 11702-29.

[28] Anstis GR, Chantikul P, Lawn BR, Marshall DB. A critical evaluation of indentation techniques for measuring fracture toughness: I, Direct crack measurements. J Am Ceram Soc 1981;64:533-8.

[29] Barker LM. A simplified method for measuring plane strain fracture toughness. Eng Fract Mech 1977;9:361-9.

[30] Niihara K, Morena R, Hasselman DPH. Evaluation of $K_{I C}$ of brittle solids by the indentation method with low crack-to-indent ratios. J Mater Sci Lett 1982;1:13-6.

[31] Evans AG, Charles EA. Fracture toughness determinations by indentation. J Am Ceram Soc 1976;59:371-2.

[32] Ritchie RO, Knott JF, Rice JR. On the relationship between critical tensile stress and fracture toughness in mild steel. J Mech Phys Solids 1973;21:395-410.

[33] Cook RF, Pharr GM. Direct observation and analysis of indentation cracking in glasses and ceramics. J Am Ceram Soc 1990;73:787-817.

[34] Oliver WC, Pharr GM. Measurement of hardness and elastic modulus by instrumented indentation: Advances in understanding and refinements to methodology. J Mater Res 2004;19:3-20.

[35] Sneddon IN. The relation between load and penetration in the axisymmetric boussinesq problem for a punch of arbitrary profile. Int J Eng Sci 1965;3:4757.

[36] Camposilvan E, Marro FG, Mestra A, Anglada MJ. Development of a novel zirconia dental post resistant to hydrothermal degradation. In: IOP Conference Series: Materials Science and Engineering. IOP Publishing; 2012;31:012016.

[37] Srinivasan R, De Angelis RJ, Ice G, Davis BH. Identification of tetragonal and cubic structures of zirconia using synchrotron X-radiation source. J Mater Res 1991;6:1287-92.

[38] Chintapalli R, Mestra A, García Marro F, Yan H, Reece M, Anglada M. Stability of nanocrystalline spark plasma sintered 3Y-TZP. Materials 2010;3:800.

[39] Li X, Shimizu Y, Pyatenko A, Wang H, Koshizaki N. Tetragonal zirconia spheres fabricated by carbon-assisted selective laser heating in a liquid medium. Nanotechnology 2012;23:115602.

[40] Guazzato M, Albakry M, Swain MV, Ironside J. Mechanical properties of InCeram alumina and In-Ceram zirconia. Int J Prosthodont 2002;15:339-46.

[41] Inokoshi M, Zhang F, De Munck J, Minakuchi S, Naert I, Vleugels J, et al. Influence of sintering conditions on low-temperature degradation of dental 
zirconia. Dent Mater 2014;30:669-78.

[42] Zhang F, Vanmeensel K, Inokoshi M, Batuk M, Hadermann J, Van Meerbeek $\mathrm{B}$, et al. Critical influence of alumina content on the low temperature degradation of 2-3mol\% yttria-stabilized TZP for dental restorations. J Eur Ceram Soc 2015;35:741-50.

[43] Wilson J, Kunz SM. Microwave sintering of partially stabilized zirconia. J Am Ceram Soc 1988;71:C40-C41.

[44] Upadhyaya DD, Ghosh A, Dey GK, Prasad R, Suri AK. Microwave sintering of zirconia ceramics. J Mater Sci 2001;36:4707-10.

[45] Fischer-Cripps AC. Nanoindentation. Springer; 2011.

[46] Fujikane M, Setoyama D, Nagao S, Nowak R, Yamanaka S. Nanoindentation examination of yttria-stabilized zirconia (YSZ) crystal. J Alloys Compd 2007;431:250-5.

[47] Lian J, Garay JE, Wang J. Grain size and grain boundary effects on the mechanical behavior of fully stabilized zirconia investigated by nanoindentation. Scr Mater 2007;56:1095-8. 




\section{CHAPTER 5: MICROWAVE SINTERING AND HYDROTHERMAL DEGRADATION OF $\mathrm{ZrO}_{2}$}



In this chapter, a study of the effect of microwave sintering on the low-temperature hydrothermal degradation (LTD) behavior of zirconia materials is presented. A thorough characterization of the induced changes in mechanical properties, phase transformation evolution, surface topography modifications and penetration depth of the degraded layer is performed to understand the influence of a novel and inherently different material consolidation technique such as microwave sintering. This influence is assessed, again, by comparing microwave-sintered materials to the same materials sintered by the conventional method after simultaneously exposing them to accelerated degradation conditions. Additionally, an analysis of the crack propagation of degraded and non-degraded Y-TZP materials by means of Focused Ion Beam (FIB) is performed as part of this study. Chapter 2 covered the fundamental principles and possible mechanisms involved in hydrothermal degradation of $t$-phase stabilized zirconia materials, as well as different concepts related to this phenomenon. Chapter $\mathbf{4}$ showed that materials sintered via microwave heating at lower dwell temperatures compared to conventional sintering resulted in fully consolidated bodies with a very high degree of densification and similar, or even higher, hardness and fracture toughness.

Several authors have investigated the basic principles of LTD and proposed mechanisms to explain the role of water or the effect of external factors in the kinetics of degradation transformation. A lot of effort has also been put into developing innovative approaches to increase the resistance of zirconia materials to LTD. Some works have focused in new synthesis routes of Y-TZP powders or the addition of other compounds to increase the resistance to this ageing phenomenon. However, very few have focused on alternative processing techniques, such as nonconventional sintering methods, that may enhance the resistance to LTD. Specifically, no studies have been found in the literature review that address the effect that microwave sintering may have in LTD. The significance of this study relies on exploring the effect of microwave sintering on the resistance to LTD of Y-TZP ceramics for dental applications.

\subsection{INTRODUCTION}

Since yttria-stabilized zirconia is one of the most widely utilized bioceramics due to its high degree of biocompatibility, a constant interaction with human fluids is inevitable. Such is the case of Y-TZP ceramics employed in dentistry as implants and prostheses, which are exposed to humid environments in the oral cavity throughout their entire lifetime while in service. The advantageous $t$ - to $m$-phase toughening mechanism, which provides zirconia with outstanding fracture toughness characteristics, however, has also become counterproductive when these materials are exposed to humid environments at temperatures of $20^{\circ} \mathrm{C}-300{ }^{\circ} \mathrm{C}$, due to a 
hydrothermal aging phenomenon known as low-temperature degradation (LTD) [13].

Different approaches and theories have been proposed on the interaction and effects of water in LTD [4-6] but the mechanisms that trigger this phenomenon have not been completely understood yet. Nonetheless, it is well established that the degradation starts from the surface and proceeds to the material bulk inwards. The $t-m$ transformation is accompanied by a change in volume that results in the introduction of defects in the material such as surface uplifts and microcracks [7]. As a consequence, surface roughening and macrocracking arises and the mechanical and aesthetic properties are severely affected [8-10].

There are different factors that affect the LTD behavior in zirconia materials including grain shape and size, stabilizer content and distribution, cubic phase content, porosity, and effect of residual stresses [2,11-14]. Particularly, grain size and shape are strongly influenced by the sintering process and its conditions $[15,16]$. In ceramics, sintering is a common thermal treatment that allows the consolidation of dense materials and plays a significant role in the resulting microstructure and mechanical properties. Sintering of Y-TZP materials consists on the heating of "green" bodies at temperatures ranging from $1200-1500^{\circ} \mathrm{C}$ for periods of time that may add up to several hours. Conventional sintering is a very energy intensive process because of the heating rates, temperatures, and long times that are required.

However, during the past decade, a significant part of undergoing research is focusing on innovative approaches for sintering ceramic materials. These approaches are regarded as nonconventional sintering methods. One such approach is microwave heating technology. It differs greatly from CS because heat-transfer mechanisms are not the driving force for densification but rather the conversion of electromagnetic energy into thermal energy within the material.

Several authors [17-20] have determined that highly dense materials without substantial grain coarsening may be obtained with microwave sintering as dwell times are considerably shortened and heating rates can be substantially increased. In the previous chapter, as well as in other works, lower sintering temperatures have been applied while obtaining materials with relative densities comparable to those of CS at higher temperatures. As Y-TZP materials with a finer microstructure and a high degree of densification can be obtained, mechanical properties may be enhanced, improving the overall quality of the resulting material [19]. The modified microstructure and lower temperatures employed in microwave sintering are very likely to affect the behavior of Y-TZP materials against hydrothermal degradation. 


\subsection{OBJECTIVES}

As the sintering process and its conditions can be an important factor in the behavior of Y-TZP materials against LTD, it is very important to investigate the influence of microwave sintering on this phenomenon. Since no comprehensive studies have been found in the literature that relate microwave processing of zirconia to LTD behavior, the general purpose of this study is to evaluate the effect of material consolidation via microwave heating on LTD susceptibility of Y-TZP dental ceramics by comparing them with materials sintered by conventional methods.

In order to assess the degree of resistance to LTD, the investigation has been performed by exposing the sintered materials to simulated LTD conditions, increasing exposure time (see Section 5.3). Four specific objectives have been established accordingly:

- Characterization of mechanical properties via nanoindentation techniques to evaluate the deleterious impact on hardness and Young's modulus

- Analysis of the topographical changes and surface roughness induced by the $t$ - to $m$-phase transformation

- Evaluation of the progression of phase transformation and quantification of phases

- Determination of the penetration depth of the transformed layer.

In addition to these objectives, an analysis of crack propagation in degraded and nondegraded materials is presented in order to highlight the significance of enhancing LTD resistance of Y-TZP ceramics.

\subsection{MATERIALS AND METHODS}

\subsubsection{MATERIALS}

The materials considered are two of the 3Y-TZP dental ceramics sintered and studied in Chapter 4: LAVA and LAB. On one hand, LAVA is a widely utilized commercial material obtained as a pre-sintered block with the characteristics given in Table 4.1. On the other hand, LAB is a ceramic powder resulting from a careful pre-treatment in a suspension with optimized rheological properties that prevent particle agglomeration in order to obtain a more homogenous starting material. Therefore, susceptibility to LTD between starting materials can also be contrasted. The reason for choosing LAVA over VITA has to do with the higher degree of densification obtained in LAVA in MW-sintered specimens, which can be used to better contrast the effects of sintering methods in highly dense materials. 
In this particular study, MW-sintered LAVA and LAB specimens at $1200{ }^{\circ} \mathrm{C}$ and conventionally sintered ones at $1400{ }^{\circ} \mathrm{C}$ are investigated. The reason for selecting this particular samples is to compare fully consolidated materials via microwave sintering at a lower sintering temperature than those sintered by conventional methods at a significantly higher temperature. As shown in the previous chapter, LAVA and LAB reach a very high degree of densification and mechanical properties expected for Y-TZP ceramics at $1200{ }^{\circ} \mathrm{C}$. These resulting characteristics are comparable to those of conventional sintering at $1400{ }^{\circ} \mathrm{C}$. In this sense, one of the most important advantages of microwave sintering, which is the ability to apply lower dwell temperatures for sintering, can be effectively explored and compared to conventional sintering in 3Y-TZP dental materials.

Sample preparation previous to sintering, as well as sintering equipment and conditions, can be found in Section 4.3.2.

\subsubsection{SIMULATED DEGRADATION CONDITIONS}

LTD of Y-TZP materials is carried out under conditions that simulate and accelerate the hydrothermal aging process. Specimens are mirror polished with colloidal silica solution to achieve highly smooth surfaces so topographical changes induced by degradation transformation can be effectively evaluated. The samples are then autoclaved in steam at $125^{\circ} \mathrm{C}$ and 1.6 bar (Figure 5.1). These conditions are based on several studies stating that $1 \mathrm{~h}$ corresponds to approximately 3 years in contact with human fluids. However, this autoclave test has not been standardized and, in many cases, the time equivalence varies due to external factors and also depends on the autoclave equipment configuration. Nonetheless, this test is considerably useful for the comparative purposes addressed in this study. Additionally, the LTD simulation can be easily performed and allows the investigation of the effects of zirconia ageing without having to perform in vivo experiments. It is widely utilized for studying the susceptibility of zirconia materials for dental and orthopedic applications. A comprehensive review by Pereira et al. [21] collects data of the conditions employed in several LTD-related studies to determine whether methodological parameters in autoclave influence degradation kinetics.

Characterization of aged samples is performed after every $20 \mathrm{~h}$ of exposure to LTD conditions until $200 \mathrm{~h}$ is reached and consists of phase content analysis, surface topography and roughness, evaluation of mechanical properties, and microstructure assessment. This relatively high time of exposure has been achieved in order to evaluate the progression of LTD until a saturation limit of phase transformation has been reached. 


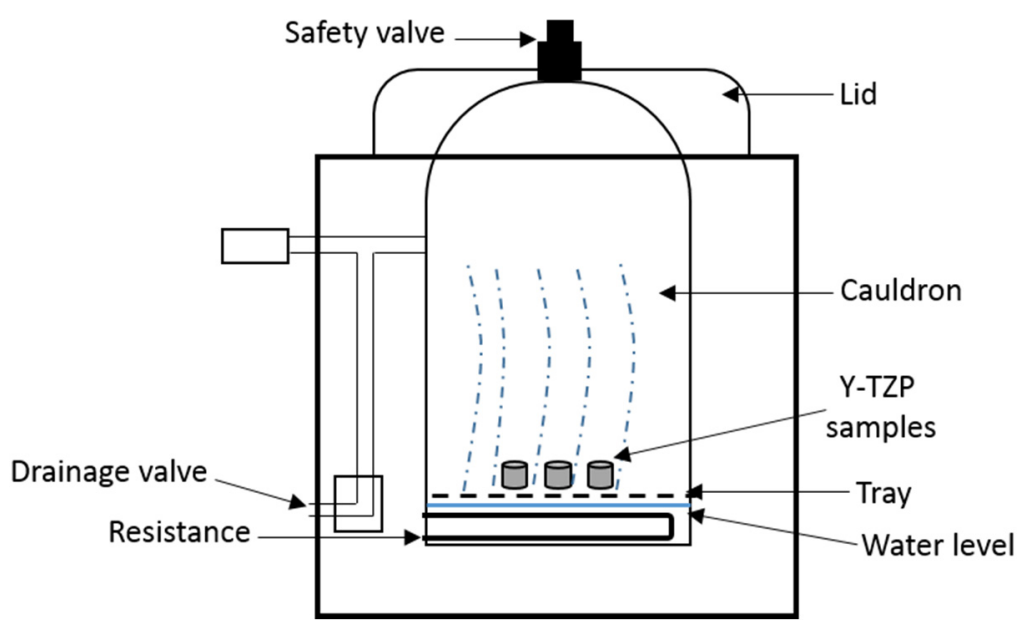

Figure 5.1 Autoclave diagram for performing accelerated LTD tests on Y-TZP zirconia samples.

\subsubsection{SPECTROSCOPIC TECHNIQUES}

Spectroscopic techniques are utilized to study the interaction between electromagnetic waves and matter. As a result of this interaction, information about the composition of the studied matter can be obtained. The next section describes the spectroscopic techniques applied in this study and how they have been used for the characterization of phase transformation in zirconia materials.

\section{X-ray diffraction Rietveld refinement}

This section describes refinement of X-ray diffraction diffractograms by the Rietveld method in order to quantify the phase content of starting materials and after specific LTD exposure times to compliment the Raman spectroscopy analysis, described in the next section. For information about the fundamentals of X-ray diffraction see Section 4.3.3.

The Rietveld method allows the refinement of crystalline structures of moderate complexity and consists on adjusting a theoretical model to an experimental X-ray pattern utilizing a least squares approach until the best fitting between both is found. The calculated X-ray pattern is based on a model that includes structural (spatial group, atoms in an asymmetric cell, thermal effect), microstructural (concentration crystal sizes, deformations) and instrumental aspects (full width at half maximum (FWHM), slit width, sample, X-ray penetration). The goodness of fit is expressed according to several factors, including $\chi^{2}, R_{P}, R_{W P}, R_{B}$, and $R_{E}[22]$.

The X-ray diffraction patterns recorded for all the different samples have been analyzed with the FullProf software [23]. In all cases, the analysis has started with 
the relative position of the experimental diffraction maximums and those registered in the Powder Diffraction File (PDF) of the databases, where a data correspondence can be observed. Afterwards, a complete profile refinement of the diagram without a structural model has been performed. In this refinement, several factors have been modified, including cell parameters, displacement of the sample with respect to the origin, the Gaussian-Lorentzian shape relationship of the peaks, the variation of the FWHM with $2 \theta$, and the asymmetric behavior of the diffraction peaks. The following step consists on a refinement of the diffraction pattern implementing a structural model, which is known as Rietveld refinement. Such refinement has been initiated with the unit cell parameters previously refined in the first stage and the atomic coordinates taken from the Inorganic Crystal Structure Database (ICSD).

Peak broadening is an important feature in X-ray diffraction patterns because it allows the estimation of crystalline domain (crystallite) size and microstresses. The main factors that contribute to the integral peak broadening $(\beta)$ are:

- Instrumental broadening, $\beta_{\text {instr }}$

- Broadening due to crystallite size, $\beta_{\tau}$

- $\quad$ Broadening due to stresses in the unit cell, $\beta_{\varepsilon}$

In addition, a Thompson-Cox-Hastings pseudo-Voigt function is applied to fit each peak in the diffractogram profile. In order to calculate the broadening due to the sample, it is necessary to correct the integral width by subtracting the instrumental broadening. $\beta_{\text {instr }}$ has been determined experimentally with a $\mathrm{LaB}_{6}$ standard.

Crystallite size has been determined according to the Scherrer equation:

$$
\tau=\frac{K \cdot \lambda}{\beta_{\tau} \cdot \cos \theta_{\beta}}
$$

where:

$\tau=$ half size of the ordered crystalline domain, $\AA$

$\lambda=$ wavelength of the copper source radiation, in this case equals $1.54050 \AA$

$\theta_{\beta}=$ incident angle of diffraction, ${ }^{\circ}$

$K=$ Scherrer shape factor related to the particle sphericity; $K=1$ corresponds to

perfect spherical particles. A value of $K=0.9$ is used assuming a slight diversion from full sphericity.

Another approach frequently used for quantification of phases of zirconia materials from X-ray diffractograms is the one proposed by Toraya [24], which consists on using the peak intensities to determine relative phase contents. 


\section{Raman spectroscopy}

In this work, Raman spectroscopy has been utilized to evaluate the transformation kinetics attributed to LTD of zirconia materials after every $20 \mathrm{~h}$ of exposure to simulated degradation conditions. This spectroscopic technique is commonly utilized for qualitative characterization of Y-TZP phases. Additionally, by using statistical curve fitting on specific peaks, phase content can also be quantified. A very important advantage of this technique is the fact the no previous preparation of the sample is required, which could result in a modification of the physical properties.

Raman spectroscopy is based on the principle of inelastic scattering of light by a solid. When the monochromatic light interacts with the sample, most photons are scattered elastically and, as a consequence, at the same frequency of the incident photons, in what is known as Rayleigh scattering. However, a small fraction of the photons is scattered at different frequencies. The change in frequency is characteristic to each material and independent of the frequency of the incident light. The difference between the frequency of incident photons and inelastically scattered photons must coincide with the frequency of any of the vibrational or rotational modes of the material to be analyzed.

For the purposes of this study, a micro-Raman configuration has been employed. Such configuration is very useful because it allows the combination of a Raman spectrometer with an optical microscope, which makes it possible to obtain spectra in very small regions $(<1 \mu \mathrm{m})$. The Raman spectrometer setup is provided in Figure 5.2. The equipment utilized is a LabRam HR UV, HORIBA Jobin Yvon, Longjumeau Cedex, France coupled with a thermoelectrically cooled multichannel charge coupled device (CCD) detector. Measurements have been carried out on the exposed, polished surface. Raman spectra has been recorded for a Raman shift range from $120-700 \mathrm{~cm}^{-1}$. An average of two successive measurements, each with an integration time of $2 \mathrm{~min}$, has been performed to obtain a well-defined spectrum. A laser wavelength of $532 \mathrm{~nm}$ through a 509 objective with a lateral resolution of approximately $2 \mu \mathrm{m}$ has been employed. The spectrometer has been calibrated with a silica standard to control shift displacement of Raman spectrograms. 


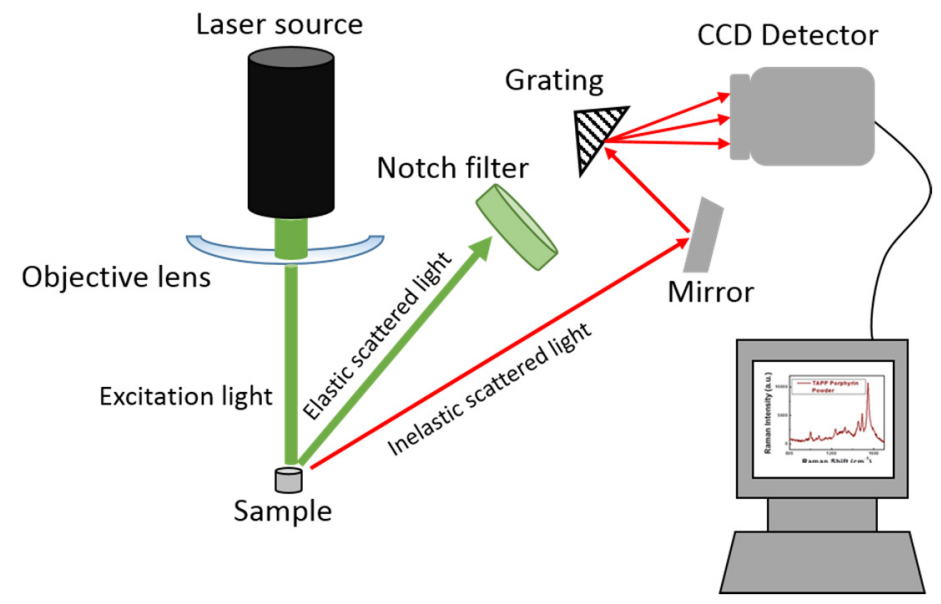

Figure 5.2 Raman spectrometer schematic showing main components, as well as scattered light beams from interaction with the sample.

To obtain information about the degradation kinetics, the $m$-phase content in aged specimens is determined with the following linear model proposed by Lim et al. [25]:

$$
V_{m}=\frac{I_{m}^{181}+I_{m}^{190}}{0.33\left(I_{t}^{147}+I_{t}^{265}\right)+I_{m}^{181}+I_{m}^{190}}
$$

where:

$V_{m}=m$-phase volume fraction

$I=$ integrated peak intensity (area under peak)

$m, t=$ subscript referencing the $m$ - and $t$-phase, respectively

Peak intensities of the characteristic $t$-phase bands at 147 and $265 \mathrm{~cm}^{-1}$ and $m$-phase bands at 181 and $190 \mathrm{~cm}^{-1}$ have been quantified with the spectroscopic analysis function in Origin 8 software. A lineal background signal, which was subtracted, has been assumed, whereas the integrated intensity of each peak has been calculated by fitting Lorentzian distribution curves to the spectrum.

\subsubsection{MICROSCOPY TECHNIQUES}

Microscale analysis of materials provides useful information about the phenomena observed at a macroscopic level. Therefore, in order to study the microstructural changes in materials induced by LTD, microscopy techniques have been employed. The following section addresses the basic principles of the microscopic techniques employed, as well as their relevance to this study.

\section{Atomic Force Microscopy (AFM)}

In order to evaluate the topographical changes induced by LTD on zirconia materials, AFM has been performed. Surface modifications are more pronounced during the 
early transformation stages due to the nature of LTD progression. As the $t$ - to $m$ transformation is accompanied by a change in volume of approximately $4 \%$, the expansion of the grains generates tension among each other that results in pushing the grains towards the surface. Therefore, this technique serves as a complimentary tool for the analysis of the material initial degradation.

Scanning Probe Microscopy (SPM) techniques use the basic principle of scanning a surface with a very sharp probe to image and measure different properties of a sample. AFM is a type of SPM technique that provides a 3D profile on a micro or nanoscale by measuring attractive and repulsive forces between a sharp probe and the surface of the material to be characterized at a very short distance of less than $10 \mathrm{~nm}$. The tip is located at one of the ends of a flexible cantilever and the AFM tip gently touches the surface and records the small force between probe and surface. A laser is used to record the interactions by falling upon the cantilever and being reflected towards a photodetector that is connected to a computer where the signals are converted into topographical maps.

An AFM system consists of the probe, the cantilever, a piezoelectric scanner, the laser, a photodetector and a computer. A schematic can be observed in Figure 5.3. The topography of the sample is determined from the deflections of the cantilever resulting from tip-sample interaction. The scanning is performed with the aid of a piezoelectric system that controls the movement of the tip or sample in $x, y$ and $z$ directions. As the laser falls upon the cantilever, the variations in height from the deflections are recorded with the photodetector and interpreted with a computer system. The surface of the zirconia sample needs to be perfectly smooth, so as to record any small variations in height during the initial stages of the LTD process.

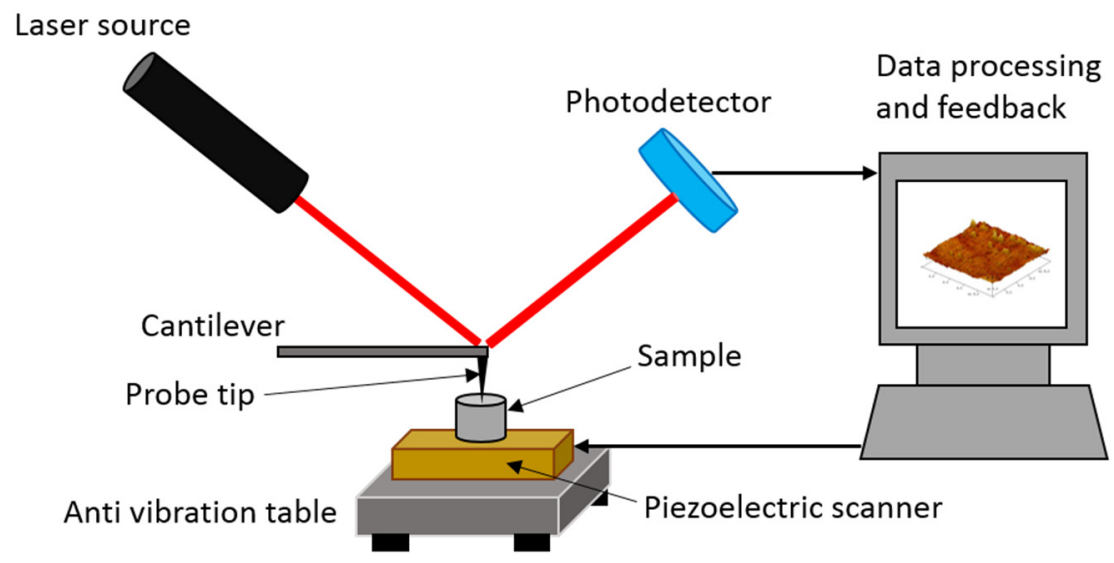

Figure 5.3 AFM setup for sample imaging, including its main components. 
One of the most important parameters that can be characterized with AFM and allows the quantification of surface texture, to some extent, is surface roughness. An important factor to keep in mind is that the value of surface roughness depends on the scale of measurement. Several roughness indicators can be determined from AFM profiles. In particular, average roughness, $R_{a}$, is the most widely used because of its simple calculation yet useful information. This roughness indicator is defined as the arithmetic mean of the absolute values of the height of the surface profile and is described by the following expression:

$$
R_{a}=\frac{1}{L} \int_{0}^{L}|Z(x)| d x
$$

where:

$Z(x)=$ function that describes the surface profile analyzed in terms of height $Z$ at position $x$ over the evaluation length $L$

AFM characterization of zirconia specimens has been performed in tapping mode with an AFM Multimode system from Veeco, New York, USA. Two topographic images have been taken for each sample: one with a $1 \mu \mathrm{m} \times 1 \mu \mathrm{m}$ scan area to have a detailed view of grains and another with a $5 \mu \mathrm{m} \times 5 \mu \mathrm{m}$ scan area to provide a representative roughness value. A doped silicon probe of $10 \mathrm{~nm}$ tip radius has been utilized. Image processing and roughness calculations are performed with Nanoscope Analysis software.

\section{Focused Ion Beam (FIB)}

The depth of degraded layer penetration has been determined by means of FE-SEM. A comprehensive review of this technique is given in Section 4.3.3.4. The depth has been measured with the image analysis software Image Pro Plus.

In order to investigate the effects of degradation and analyze the microstructure and crack propagation on the sub-superficial zone of zirconia materials, FE-SEM in combination with FIB has been performed on degraded and non-degraded specimens. Compared to other characterization techniques, FIB is a relatively new tool in materials science that can be particularly useful to characterize the microstructure [26] and sub-superficial damage of materials [27]. Also, with the aid of tomographic reconstruction, a 3D model of the microstructure can be constructed.

FIB is commonly employed for localized milling, deposition of conductors and insulators with high precision, implantation for surface modification and imaging for material characterization. Additionally, FIB is also employed for precision fabrication at micro and nanoscale, especially in the semiconductor industry. In the case of milling, this technique has become widely utilized for the preparation of specimens 
for Transmission Electron Microscopy (TEM) [28] as material samples can be trimmed and a very thin layer of the material can be obtained.

The operating principle of FIB is based on the complicated ion-solid interaction. In this technique, Ga ions are generally used as the ion beam source. These ions are accelerated by an energy between 5 and $50 \mathrm{keV}$. The ion beam is focused inside a column by electrostatic lenses, instead of the electromagnetic ones used in SEM, as $\mathrm{Ga}$ ions are heavier and require more potent focusing lenses than those utilized for focusing electrons. The most important part of the column is the beam-limiting aperture, which serves to control the beam current incident on the sample and, consequently, the milling rate [29]. As the energetic ions hit the surface of a solid, they lose energy to the electrons of the solid as well as to its atoms and generate an elastic collision cascade resulting in the following physical effects [30]: 1) sputtering of neutral ionized and excited surface atoms, 2) electron emission (used for imaging if sample does not charge up), 3) displacement of atoms in a solid, 4) emission of photons, and 5) chemical reactions that can break chemical bonds (used during film deposition).

Current FIB systems incorporate a dual beam configuration that consists of an ion column and electron beam column. In this sense, FIB milling can be coupled with FESEM imaging. A schematic of the dual column layout is shown in Figure 5.6. The electron column is mounted in a vertical position on the vacuum chamber, while the ion column lies at an angle of around $52^{\circ}$ to the electron column. With this arrangement, both beams can be coincident on the same region of the sample and is quite straightforward to observe cross-sections in situ. Additionally, 3D visualizations of the material microstructure are also possible in a relatively simple manner.

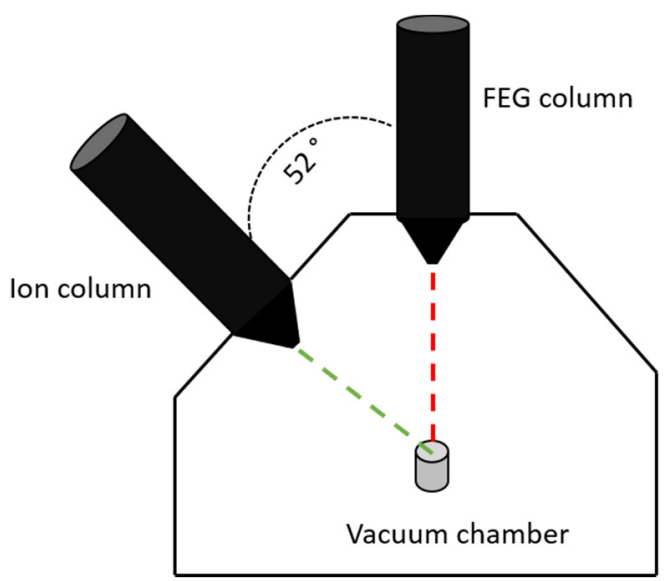

Figure 5.4 Schematic showing the dual beam column configuration of a FIB system as the beams fall upon a sample Taken and modified from [29]. 
As LTD of zirconia initiates on the surface and propagates inward, FIB allows subsuperficial assessment of the effects of degradation. Particularly, in this study, the microcracking under a Vickers indentation has been evaluated in degraded and nondegraded zones. By understanding the cracking mechanisms in transformed and non-transformed zirconia ceramics, the importance of enhancing the resistance to LTD is highlighted. A trench is milled with the FIB while, at the same time, the SEM system allows real-time imaging and reveals the cross-section microstructure of the sample.

\subsubsection{EVALUATION OF MECHANICAL PROPERTIES}

An important consequence of LTD is the changes in mechanical properties that occur due to the $t$ - to $m$-transformation. The mechanical performance of Y-TZP materials is significantly diminished by this phenomenon. When considering and comparing different processing techniques, the characterization of mechanical properties as a function of exposure time to LTD conditions is a critical step in the evaluation of LTD resistance. In this study, nanohardness, $H_{\text {nano, }}$ and Young's modulus, $E$, are determined by means of nanoindentation techniques. The fundamental aspects of nanoindentation are described in Section 4.3.3.3.

\subsection{RESULTS AND DISCUSSION}

\subsubsection{PHASE COMPOSITION}

Table 5.1 shows the values of $m$-, $t$ - and $c$-phase weight percent (wt\%) obtained from Rietveld refinement of $X$-ray diffractograms before sintering, after sintering and after $200 \mathrm{~h}$ of LTD exposure. As can be observed, the content of $m-, t-$, and $c-\mathrm{ZrO}_{2}$ is very similar in both materials before sintering takes place. After sintering, differences in phase content arise due, primarily, to the sintering method employed. The $m$-phase content is quite low in both materials after microwave (MW) and conventional sintering (CS), at approximately 1 wt\%. However, $t$ - and $c$-phase content show significant differences when comparing sintering methods. The weight percentage of $t$-phase is above $90 \mathrm{wt} \%$ in all cases, but is higher by more than $5 \mathrm{wt} \%$ in $\mathrm{MW}$ sintering and, as a consequence, $c$-phase content is lower than in conventionally sintered samples.

After $200 \mathrm{~h}$ of LTD exposure, $m$-phase content is substantially increased in all specimens, with the exception of the MW-sintered LAB sample. This particular sample remains untransformed, as there is only an almost imperceptible increase in $m-\mathrm{ZrO}_{2}$ content from the as-sintered specimen. CS LAB shows a significant $t$-to- $m$ phase transformation, decreasing from 90.4 to $21.2 \mathrm{wt} \%$ of $t-\mathrm{ZrO}_{2}$ content. In this particular sample, the amount of $c$-phase remains almost unchanged. In the case of 
LAVA material, samples from both sintering methods underwent a significant phase transformation, as the content of $t$-ZrO2 drops from more than $90 \mathrm{wt} \%$ to less than $20 \mathrm{wt} \%$. The difference between this two samples regarding $m$-phase content after $200 \mathrm{~h}$ is approximately $8 \mathrm{wt} \%$, being higher in the MW-sintered sample. The content of c-phase for LAVA sintered via MW is slightly lower than CS.

Table 5.1 X-ray diffraction Rietveld refinement results for determining phase weight percent of LAVA and $\mathrm{LAB}$ materials before and after microwave and conventional sintering and after $200 \mathrm{~h}$ LTD.

\begin{tabular}{|c|c|c|c|c|c|c|c|c|c|c|}
\hline \multirow{3}{*}{$\begin{array}{c}\text { Material } \\
\text { LAVA }\end{array}$} & \multicolumn{3}{|c|}{$\begin{array}{c}\text { Before sintering } \\
m-\mathrm{ZrO}_{2} t-\mathrm{ZrO}_{2} c-\mathrm{ZrO}_{2} \\
\end{array}$} & & \multicolumn{3}{|c|}{$\begin{array}{c}\text { As-sintered } \\
m-\mathrm{ZrO}_{2} \quad t-\mathrm{ZrO}_{2} c-\mathrm{ZrO}_{2} \\
\end{array}$} & \multicolumn{3}{|c|}{$\begin{array}{c}\text { After } 200 \mathrm{~h} \text { LTD } \\
m-\mathrm{ZrO}_{2} \boldsymbol{t}-\mathrm{ZrO}_{2} c-\mathrm{ZrO}_{2}\end{array}$} \\
\hline & & & & $M W$ & 1.0 & 95.8 & 3.2 & 80.7 & 13.6 & 5.7 \\
\hline & 19.9 & & 12.1 & $C S$ & 0.8 & 90.3 & 8.9 & 72.3 & 19.6 & 8.1 \\
\hline \multirow{2}{*}{ LAB } & \multirow{2}{*}{19.5} & \multirow{2}{*}{66.1} & \multirow{2}{*}{14.4} & $M W$ & 1.4 & 95.7 & 2.9 & 1.8 & 94.8 & 3.4 \\
\hline & & & & $C S$ & 0.2 & 90.4 & 9.4 & 69.3 & 21.2 & 9.5 \\
\hline
\end{tabular}

Overlap between $c$-and $t$-phase occurs in the zirconia DRX spectrograms shown in Figure 4.18 and is therefore difficult to determine the presence of c-phase and its corresponding peaks are more intense in some specimens than in others. However, with the aid of Rietveld refinement, the resolution of overlapped peaks has been improved and the content of $c$-phase in LAVA and LAB could be quantified.

Figure 5.5 shows Raman spectra for the LAVA samples sintered by MW heating and CS methods. The incident laser fell upon sample surface exposed to LTD. In both cases, no $m$-peaks are observed in the specimens after sintering $(0 \mathrm{~h})$ and even after $20 \mathrm{~h}$ of exposure to the given LTD conditions. As the LAVA specimens accumulated more time of exposure to LTD, the intensity of $m$-peaks increased. At $40 \mathrm{~h}, m$-peaks can already be distinguished and, after $60 \mathrm{~h}$, the transformation has become quite significant with a clear presence of the doublet $m$-peak at $181-190 \mathrm{~cm}^{-1}$. At this particular time, a significant difference in the intensity of the doublet $m$-peak arises between MW and CS spectrograms. The doublet is more pronounced in the CS specimen suggesting a higher vulnerability to LTD- induced transformation at the initial degradation stages. The $t$-phase peaks become less and less intense as LTD time increases until $t$-peaks are almost non-existent after $200 \mathrm{~h}$. 
a)

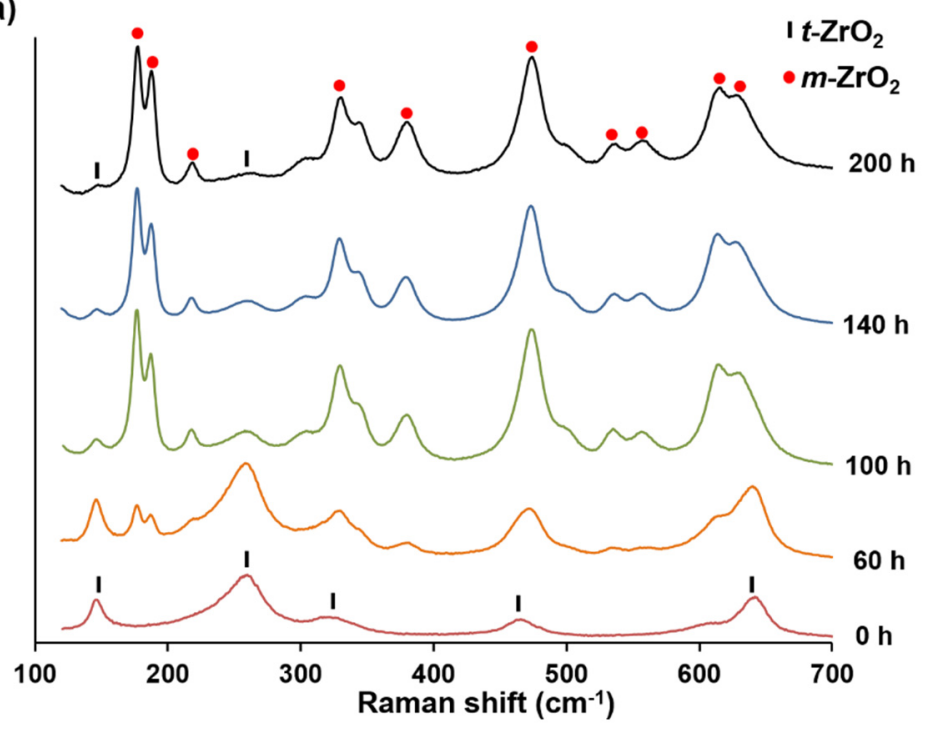

b)

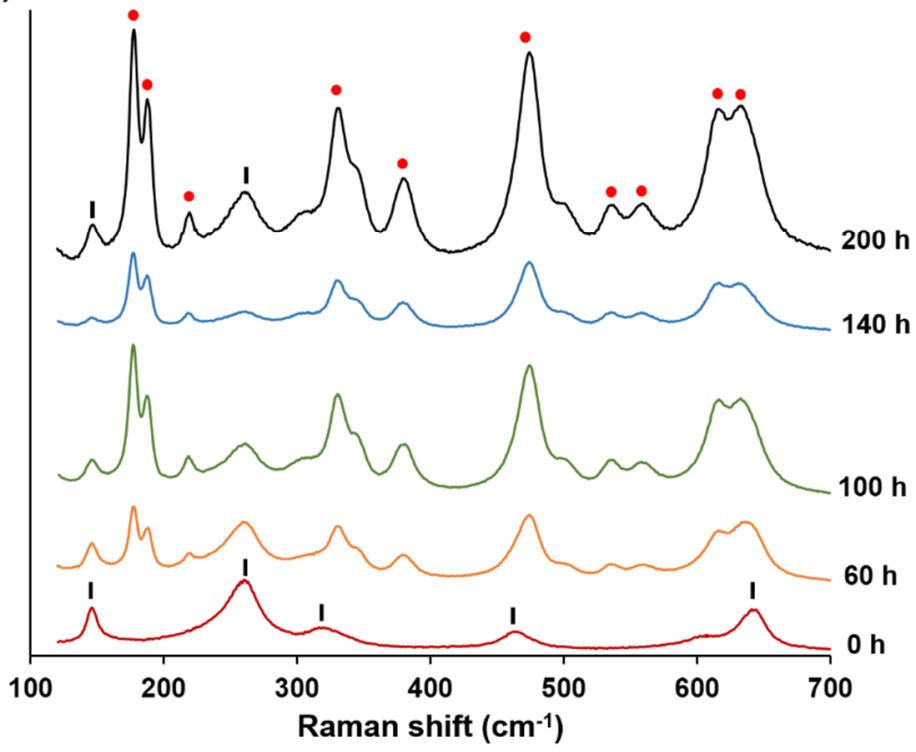

Figure 5.5 Raman spectra for several LTD exposure times for LAVA material sintered via a) microwave sintering and b) conventional sintering.

The Raman spectra for MW and CS LAB material after several LTD exposure times is given in Figure 5.6. In this material, the Raman spectrograms contrast substantially when comparing sintering methods. Whereas the presence of $m$-phase peaks is already evident after $40 \mathrm{~h}$ of LTD exposure in CS specimens and, as time increases, $t$ to $m$-phase transformation progresses (Figure 5.8b), no $m$-phase peaks are observed in the MW material even after $200 \mathrm{~h}$ of LTD exposure (Figure 5.8a). These results 
support the phase content analysis performed with Rietveld refinement of X-ray diffractograms showing that $t$-phase content is almost unchanged in microwave sintered LAB material despite a significant prolonged exposure to degradation conditions.
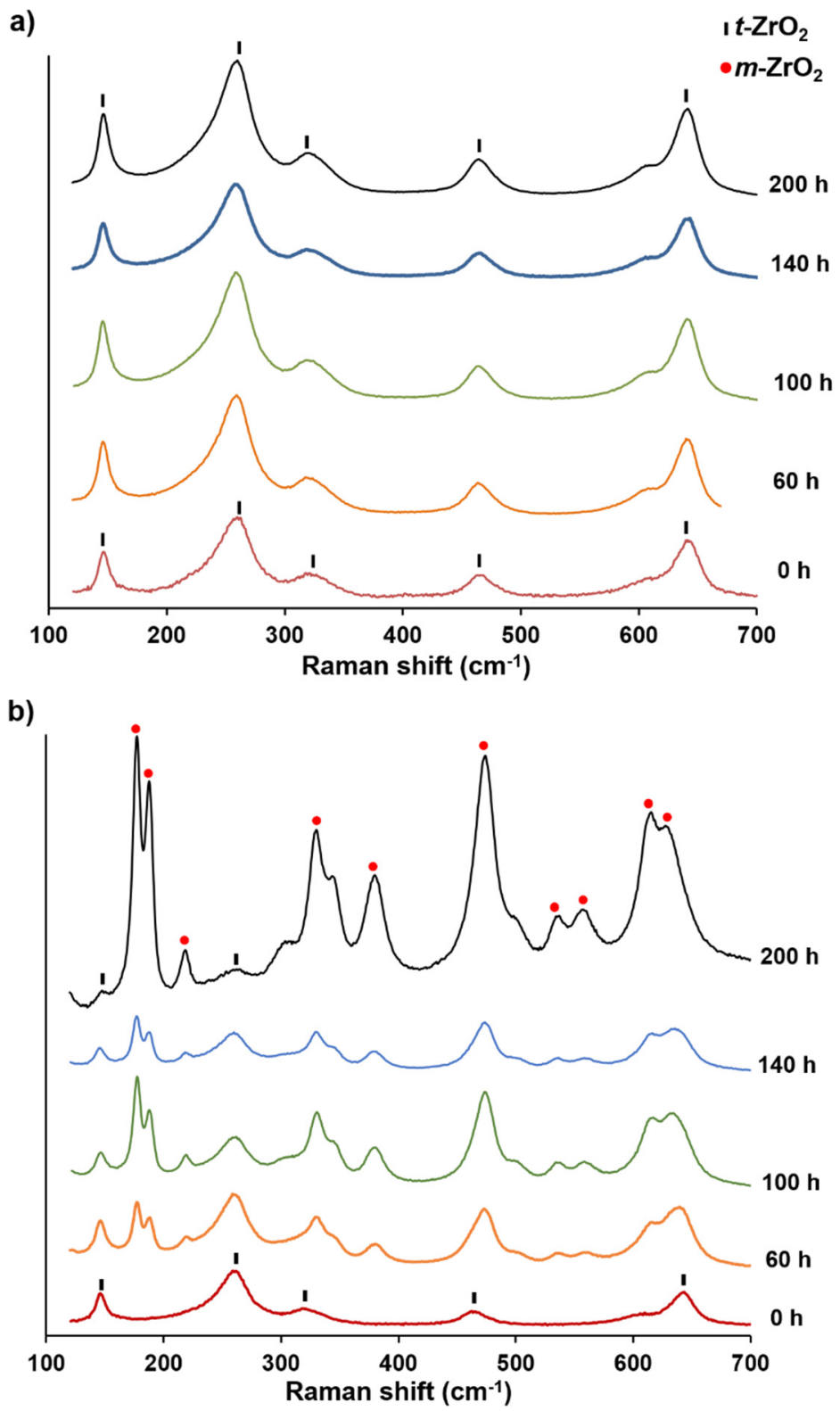

Figure 5.6 Raman spectra for several LTD exposure times for LAB material sintered via a) microwave sintering and b) conventional sintering. 
The sintering method and type of Y-TZP material had an important influence on the amount of transformed phase, which is given by the $m$-phase volume fraction, $V_{m}$, calculated from the intensities of Raman spectra, because it progressed at different rates in all four samples. The results for the quantification of $V_{m}$ are shown in Figure 5.7, where a curve has also been fit using Equation 2.5 on each data set of specimens undergoing significant phase transformation. These curves demonstrate different behaviors in the kinetics of phase transformation. In LAVA material, MW sintering resulted in slower degradation before $100 \mathrm{~h}$ compared to CS. At $100 \mathrm{~h}$, the $V_{m}$ of both LAVA samples appear to stabilize and reach a maximum $V_{m}$ value of $90 \%$ at $140 \mathrm{~h}$. In the case of MW LAB, the specimen shows no susceptibility to LTD, strongly contrasting with the conventionally sintered counterpart, which definitely affected by degradation, as it already contains a $V_{m}$ of $28 \%$ after $40 \mathrm{~h}$ of hydrothermal degradation exposure, despite both sintered materials have similar properties and microstructure.

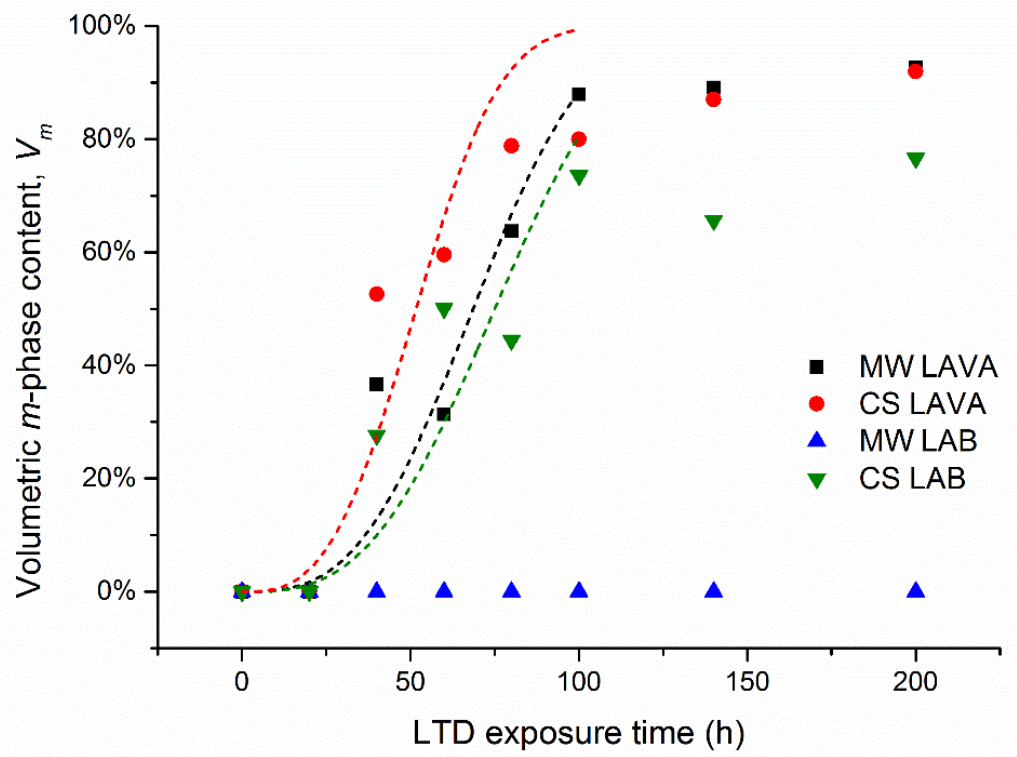

Figure 5.7 Monoclinic phase volume content, $V_{m}$, as a function of hydrothermal degradation exposure time for materials under both sintering conditions. A non-linear curve fit using Equation 2.5 has been added in all specimens with a significant content of transformed phase.

When conventionally sintered materials are compared between each other, LAVA shows a higher susceptibility to $m$-phase transformation than LAB. When comparing microwave sintered specimens, the LTD behavior of LAVA material is quite different from $L A B$. LAVA is substantially affected by this ageing phenomenon, while $L A B$ is not transformed at all, even though they have been sintered under the same conditions. Nonetheless, MW LAVA still shows a higher resistance to LTD at exposure times below $100 \mathrm{~h}$ than its conventionally sintered counterpart. 
The asymptotic behavior of the data reaches a stabilization point after approximately $100 \mathrm{~h}$ in LAVA material for both sintering methods and in LAB material for the CS case, suggesting a transformation saturation limit has been reached. This limit is between $80-85 \%$ in the LAVA specimens and between $65-70 \%$ in CS LAB. X-ray diffraction phase quantification values indicate that the presence of $c$-phase after $200 \mathrm{~h}$ of LTD exposure is also an important factor for reaching a maximum $m$-phase volume fraction lower than $100 \%$ as the c-phase remains untransformed. Additionally, traces of $t$-phase $\mathrm{ZrO}_{2}$ are still present.

\subsubsection{TOPOGRAPHY AND SURFACE ROUGHENING}

In order to analyze superficial changes induced by phase transformation, AFM techniques have been employed to characterize the superficial hydrothermal aging process of the samples. The mean surface roughness, $R_{a}$, has also been determined as a means of quantifying this change. Figure 5.8 shows AFM images of the surface of the LAB material samples for both of sintering techniques studied in this work at different degradation times. After $40 \mathrm{~h}$ of LTD exposure, transformed zones can already be observed. As exposure time is increased, the topography becomes more irregular and surface roughening increases.

It is important to consider that AFM can only detect if transformation has occurred. However, it is not able to determine the amount of $m$-phase that has been transformed, which means that, even if substantial roughening can be observed, it does not imply that the surface has been totally transformed. Nonetheless, AFM serves as a complimentary tool for assessing the phase transformation at a superficial and sub-superficial level.

In order to compare the $R_{a}$ values of materials obtained with both sintering methods after increasing ageing times, the roughness values have been determined and are presented in Figure 5.9. MW LAB zirconia has clearly resulted in the lowest roughening values when exposed to LTD conditions at all times. The other samples show bigger variations in roughness, especially after the first $20 \mathrm{~h}$. For example, CS LAB shows a sharp increase after the first $20 \mathrm{~h}$ and further surface roughening until a value of approximately $5 \mathrm{~nm}$ is reached after $60 \mathrm{~h}$. This behavior indicates that the most significant topographical changes occur during the initial stages. Even though the $R_{a}$ values before exposure to LTD conditions are not set at the same initial value, the change in $R_{a}$ after each degradation stage gives important information on how LTD affects the specimens, particularly during the initial degradation stages. 
a)

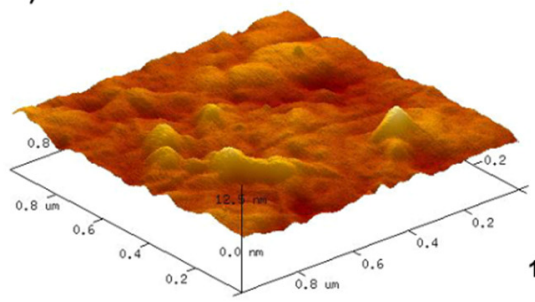

c)

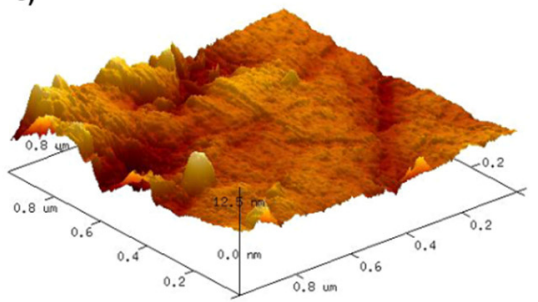

e)

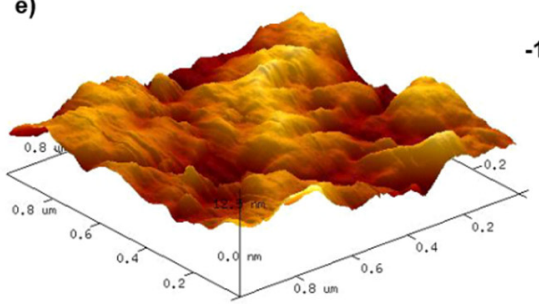

b)

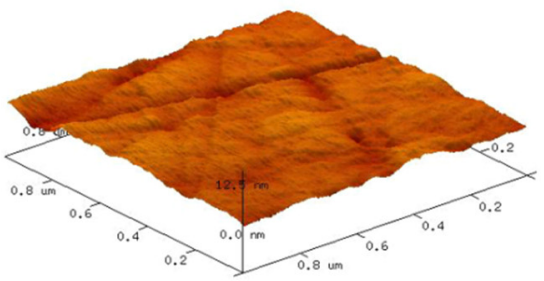

d)

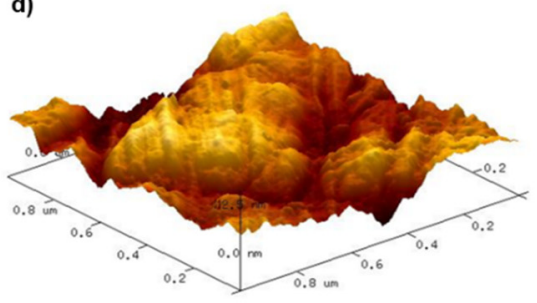

f)

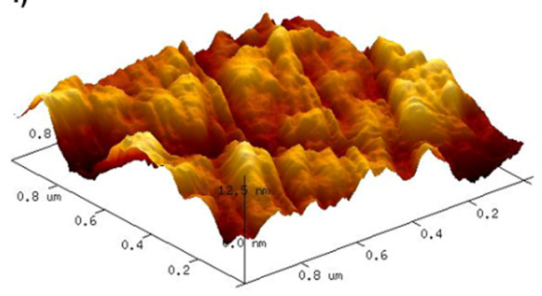

Figure 5.8 Topographical AFM images of LAB material specimens at several LTD exposure times for MW: a) $0 \mathrm{~h}$, c) $40 \mathrm{~h}$, and e) $140 \mathrm{~h}$; and CS b) $0 \mathrm{~h}$, d) $40 \mathrm{~h}$ and f) $140 \mathrm{~h}$.

The results agree with the evolution of $t$ - to $m$-phase transformation, increasing significantly in the initial stages. Even though Raman spectra of all specimens resulted in no $m$-peaks after $20 \mathrm{~h}$ of LTD exposure, analyzing surface modifications at a sub-micron level with AFM indicates changes in the microstructure are already occurring. As LTD exposure time is increased, so does the irregularity of the topography in the materials as a consequence of grains pushing towards the surface to account for volumetric expansion. This has been particularly important in assessing transformation in the microwave-sintered LAB material where no $m$-phase transformation has been detected with Raman spectroscopy and X-ray diffraction, but topographical changes indicate that transformation has occurred to some degree as the $R_{a}$ values after $60 \mathrm{~h}$ are higher compared to the initial $R_{a}$ value. In addition, the AFM images clearly demonstrate that the topography of the exposed surface of this sample has been modified and roughened after $140 \mathrm{~h}$. 


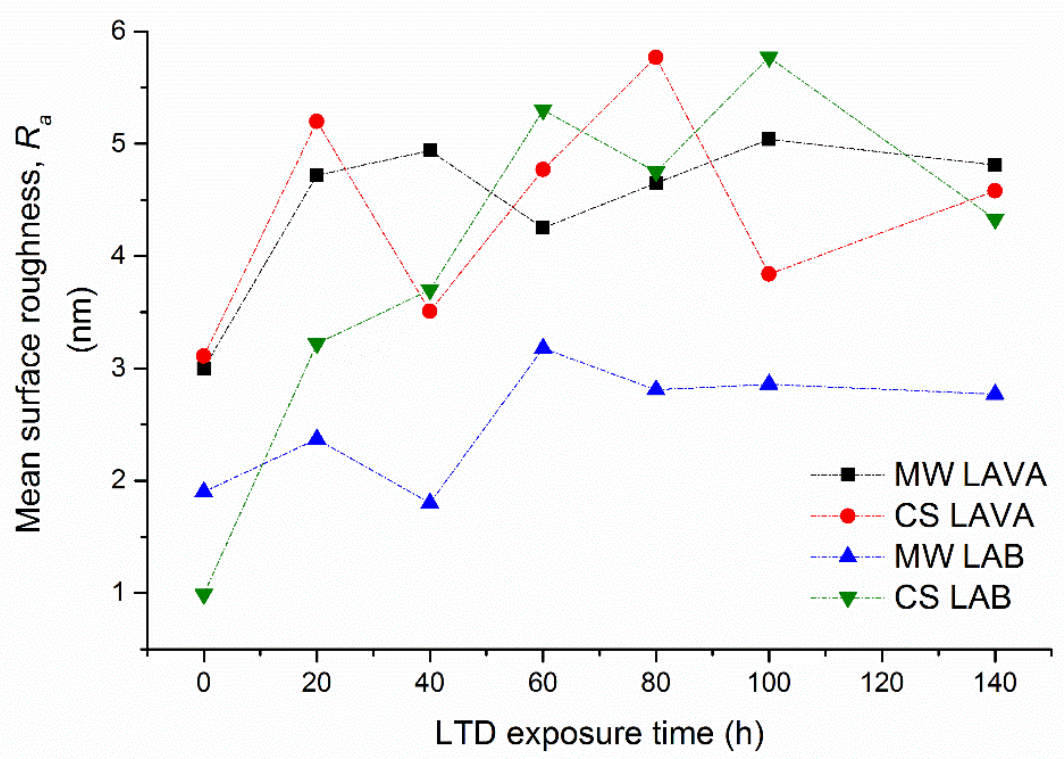

Figure 5.9 Mean surface roughness at various hydrothermal degradation exposure times for all specimens.

\subsubsection{MICROSTRUCTURE AND PENETRATION DEPTH}

Analysis at a microscopic scale of the degraded surfaces has been performed by means of Nomarski optical microscopy. Figure 5.10 shows images of the exposed surfaces right after sintering and after $140 \mathrm{~h}$ of LTD. The effects of degradation appear as surface roughening and are clearly visible in the CS samples (Figures 5.10d and 5.10h), as well as the MW commercial material (Figure 5.10b). MW LAVA appears to have the most degraded surface, as a very irregular surface, which is characteristic of this ageing process, can be observed. The surface of CS LAB shows bubble-like protuberances that are not observed in other samples. An explanation for this behavior has not been found. However, it is possible that these features arise from the volume change induced by the $t$ - to $m$-transformation occurring in a particular manner, characteristic to this material only. MW LAB still holds a flat smooth surface, as there has not been a significant degradation of this specimen, which is in agreement with the results obtained from other characterization techniques. Degradation also modifies the surface microstructure by reducing porosity, as can be observed in the highly degraded specimens before and after degradation. The less degraded specimen, MW LAB, still shows some degree of porosity on the surface due to a higher resistance to the effects of LTD but is nonetheless affected. A plausible explanation for this decrement in surface porosity has to do with the change in volume associated with the $t$ - to $m$-transformation that requires the expansion of grains to accommodate for the $m$-phase configuration. 

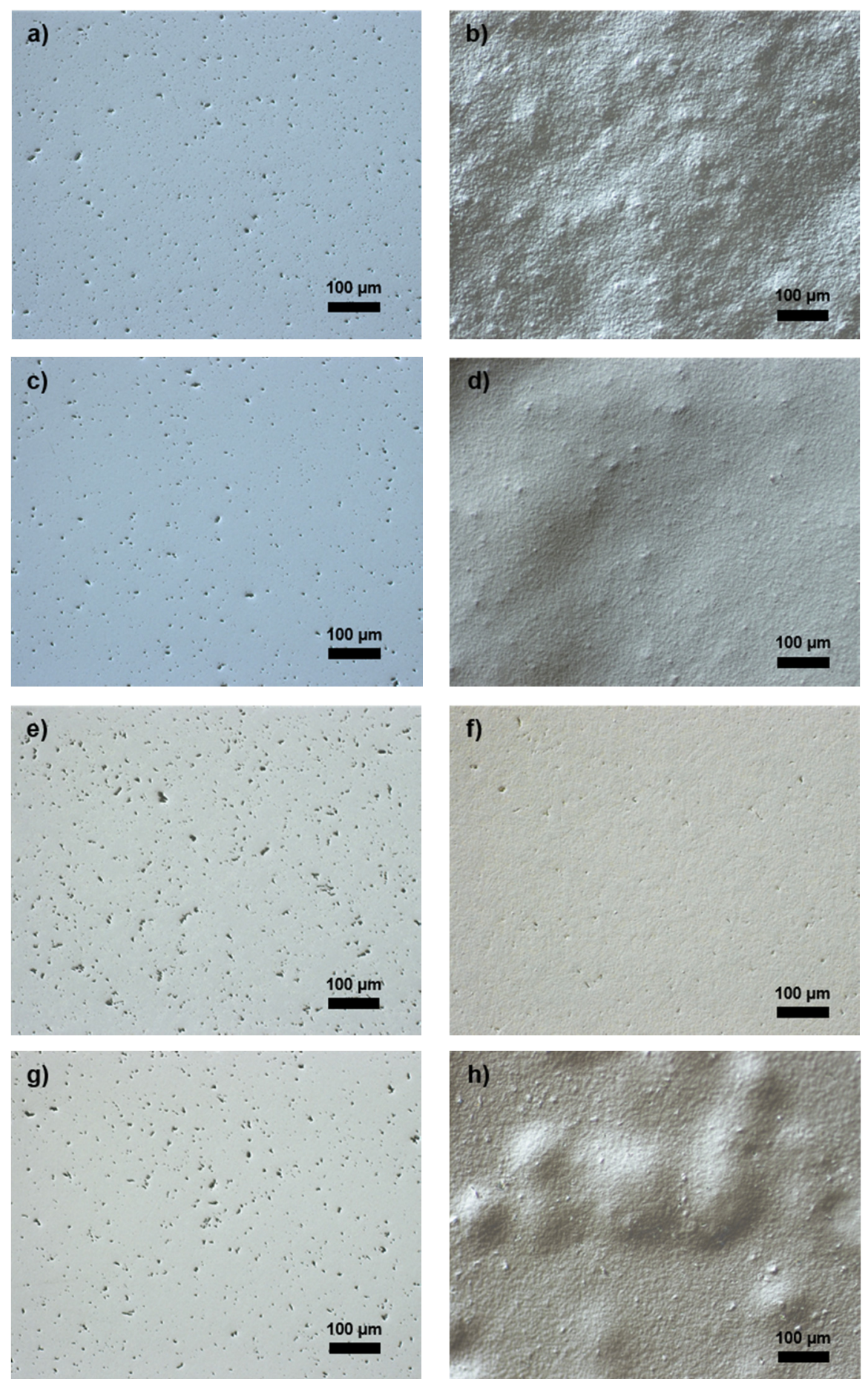

Figure 5.10 Nomarski microscopy images of the surface of Y-TZP materials for: MW LAVA at a) $0 \mathrm{~h}$ and b) $140 \mathrm{~h}$ of LTD; CS LAVA at c) $0 \mathrm{~h}$ and d) $140 \mathrm{~h}$ of LTD; MW LAB at e) $0 \mathrm{~h}$ and f) $140 \mathrm{~h}$ of LTD; and CS LAB at g) $0 \mathrm{~h}$ and $\mathrm{h}) 140 \mathrm{~h}$ of LTD; 
In order to determine the penetration depth of the zirconia-transformed layer after $140 \mathrm{~h}, \mathrm{FE}-\mathrm{SEM}$ images of cross-sections have been obtained and are shown in Figure 5.11. The layer observed in the micrographs is a result of the grain detachment of the transformed zone that occurs during the polishing stage of sample preparation. Grains in the degraded zone that have expanded due to the volume change induced by phase transformation are pulled off from the material during the abrasive treatment resulting in an increase of porosity in this zone.

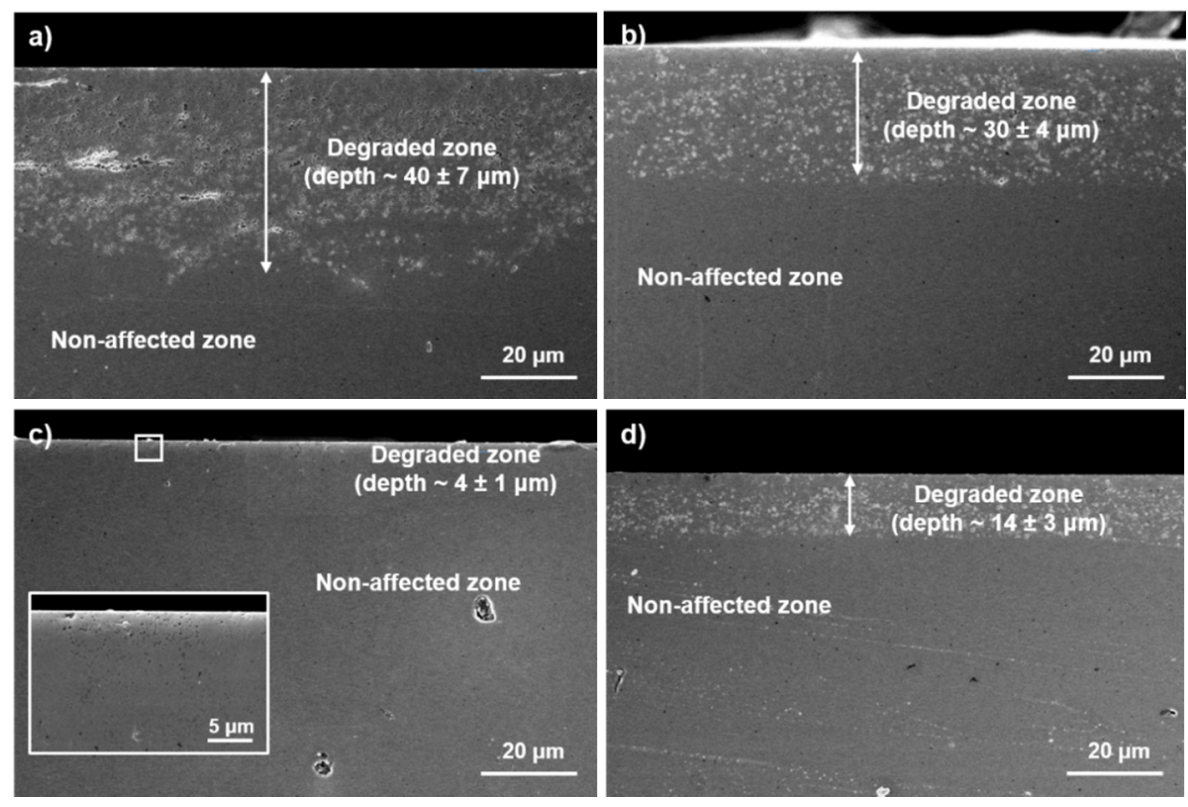

Figure 5.11 FE-SEM micrographs of the degraded cross-section profiles after $140 \mathrm{~h}$ of LTD for a) MW LAVA, b) CS LAVA, c) MW LAB, and d) CS LAB.

As can be seen in the micrographs, the penetration depth of the transformed zone varies significantly depending on the material and the sintering method. The depth of the degraded zone in MW and CS LAVA (Figure 5.13a and 5.13b, respectively) is approximately $30-40 \mu \mathrm{m}$. However, the degraded layer in MW LAVA does not seem uniform, as depths between a range of 24 and $40 \mu \mathrm{m}$ have also been measured. CS LAVA results in a more uniform degradation layer, with a depth of approximately 30 $\mu \mathrm{m}$ after $140 \mathrm{~h}$. In LAB material, the microwave-sintered sample shows a significantly higher resistance to degradation penetration than the conventionally sintered sample.

The depth of the transformed layer is also important to understand the kinetics of LTD in Y-TZP dental ceramics. LAVA clearly shows transformed zones progressing deeper into the material bulk than LAB material. Microwave-sintered specimens result in very different penetration depths after $140 \mathrm{~h}$ of LTD. Even though the results 
from Raman spectroscopy indicate the absence of $m$-phase zirconia in MW LAB material, the FE-SEM image indicates a very slight, sub-superficial degraded zone of less than $5 \mu \mathrm{m}$. On the other hand, LAVA shows that the transformed layer is quite thick, but is not constant throughout the material, as some areas are significantly thicker than others.

\subsubsection{EFFECT ON MECHANICAL PROPERTIES}

As a mean for assessing the structural quality of the material after exposure to LTD, two important mechanical properties, $E$ and $H$, have been determined as a function of hydrothermal degradation time. The measurements were carried out on the LTDexposed surfaces. These properties are affected by the sintering method that has been employed and the zirconia materials used. The results are summarized in Figure 5.12 .

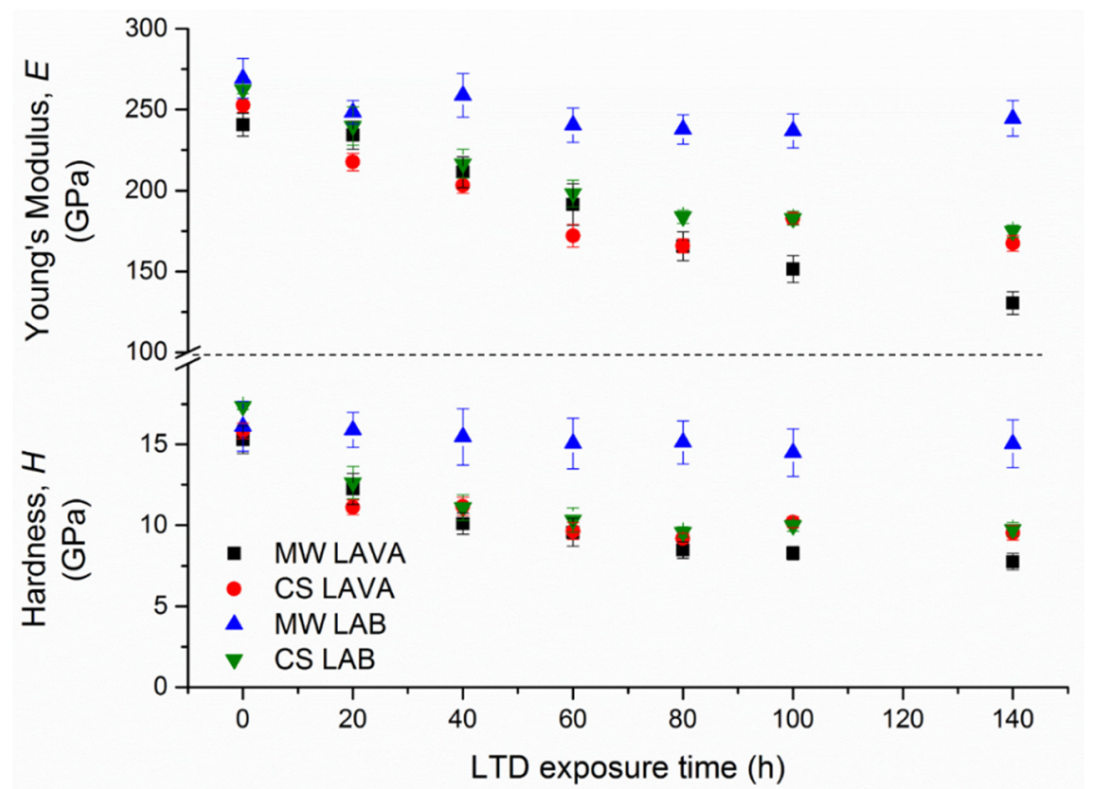

Figure 5.12 Young's modulus and hardness values for all specimens as a function of LTD exposure time.

The determined values corroborate the high resistance to LTD of the microwave sintered $L A B$ zirconia as $E$ and $H$ remain almost unaffected. Even after $140 \mathrm{~h}, \mathrm{E}$ is still around $250 \mathrm{GPa}$ and $\mathrm{H}$ is approximately $15 \mathrm{GPa}$. The properties of the other sintered samples are, however, notably degraded as hydrothermal exposure time progresses. After $20 \mathrm{~h}$, the values of $\mathrm{E}$ and $\mathrm{H}$ of the conventionally sintered samples are similar than for the LAVA-MW sample and remains so until $80 \mathrm{~h}$ has been reached, after LAVA-MW sample is what has the worst mechanical behaviour. When $80 \mathrm{~h}$ is reached, the $E$ values have decayed almost one-third from the AS value. This suggests that a decrease of mechanical properties may occur faster during the first 
degradation stages. In both materials sintered by the conventional method, the values of $\mathrm{E}$ and $\mathrm{H}$ stabilize at approximately $180 \mathrm{GPa}$ and $10 \mathrm{GPa}$, respectively.

In order to correctly interpret the values of $E$ and $H$ that have been determined, it is important to consider the depth of penetration of the transformed zone. The indenter penetration depth is set at approximately $2 \mu \mathrm{m}$. Therefore, during the initial degradation stages, where it is very likely that a combination of tetragonal and monoclinic zirconia can be found at such sub-superficial depth, the $E$ and $H$ values that have been calculated depend on the amount of transformed zirconia and result from a combination of both phases. For example, Figure 5.15 shows the depth profile of the Young's modulus in CS LAB and MW LAB specimens, where different LTD times are represented. As can be seen, the initial degradation stages (40 and $60 \mathrm{~h}$ ) result in lower $E$ values at sub-superficial depths less than $800 \mathrm{~nm}$. However, as the indenter penetrates deeper into the material, $E$ increases because the presence of $m$-zirconia decreases. This behavior is expected as phase transformation begins on the surface and progresses into the material bulk. At $140 \mathrm{~h}$, the value of $E$ stabilizes throughout the whole penetration range of $2 \mu \mathrm{m}$ indicating that, after such a long LTD exposure time, all the $t$-phase zirconia at this depth has been transformed.
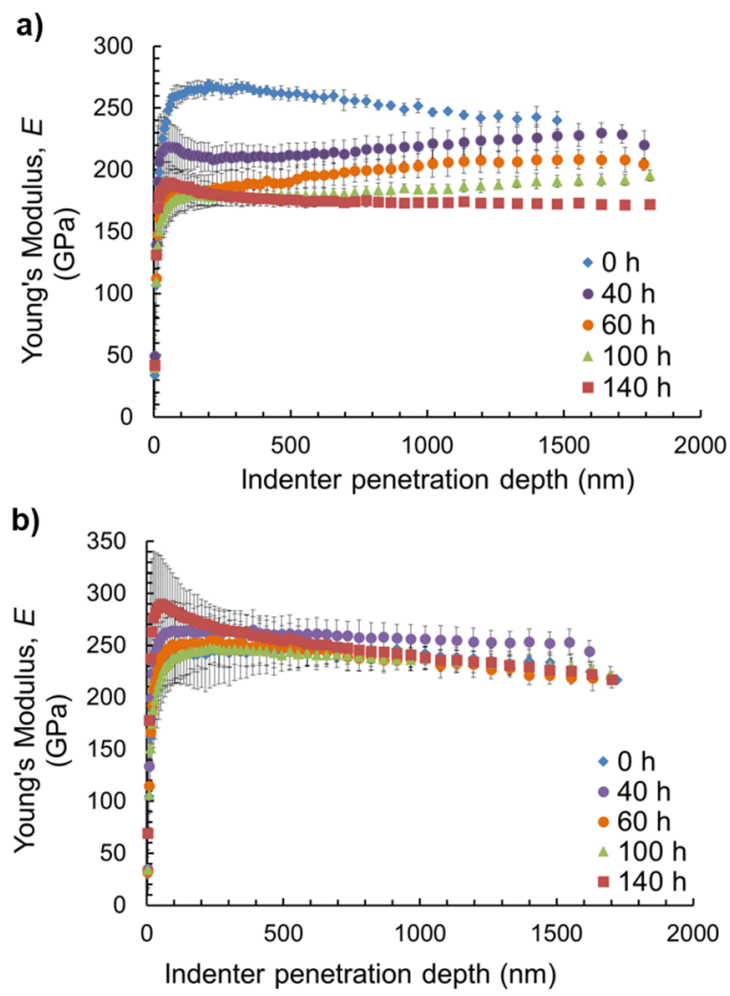

Figure 5.13 Young's modulus as a function of indenter penetration depth profile for a) MW LAB and b) CS LAB at several LTD exposure times. 


\subsubsection{INFLUENCE OF MICROWAVE SINTERING ON RESISTANCE TO DEGRADATION}

From the results obtained in this work, microwave sintering directly affects the resulting microstructure and mechanical performance of the studied Y-TZP materials due to two main factors: the selected processing conditions (heating rate, final temperature, sintering time) and the heating mechanisms that are involved. Both factors differ greatly from those in conventional sintering.

In Chapter 4, it has been demonstrated that the chosen parameters in microwave sintering have allowed full consolidation of the materials with mechanical properties comparable to those obtained via conventional methods at higher temperatures and lower heating rates. Specifically, LAVA material clearly shows significant differences in grain size when comparing microwave and conventional sintering. Faster heating rates, shorter sintering times and lower final temperature, in combination with the volumetric heating that takes place in microwave sintering, resulted in a finer microstructure. Consequently, LTD has been delayed in the microwave-sintered material, as $m$-phase content is below the conventionally sintered sample during the initial stages. In the case of LAB material, microstructural differences are less pronounced, since grain sizes are very similar in both methods. Nonetheless, the behavior against LTD is clearly superior in the microwave-sintered specimens, as an almost imperceptible ageing process has occurred even after $200 \mathrm{~h}$ of LTD exposure. In contrast, CS LAB already presents a substantial degraded condition after $40 \mathrm{~h}$.

The presence of $c$-phase plays an important role in understanding the higher LTD resistance of microwave-sintered specimens. Since conventional sintering is performed at a higher temperature of $1400^{\circ} \mathrm{C}, c$-phase zirconia content is more likely to increase after sintering, as can be observed in the values of $c-\mathrm{ZrO}_{2}$ obtained in Table 5.1. Inokoshi et al. [31] and Gaillard et al. [32] have demonstrated that higher sintering temperatures increase the content of c-phase in accordance with the zirconia phase diagram. The presence of $c-\mathrm{ZrO}_{2}$ accelerates the transformation of $t$ to $m$-phase, as $t$-grains are depleted from $\mathrm{Y}_{2} \mathrm{O}_{3}$ due to the migration of the stabilizer into cubic grains $[3,33]$. As microwave sintering requires lower temperatures for the full consolidation of Y-TZP ceramics than conventional sintering, the amount of $c$ phase content is reduced and the resistance to LTD is enhanced. This idea may also serve to explain the higher and interesting resistance to LTD of the specimens sintered via microwaves at $1200^{\circ} \mathrm{C}$ against conventional sintered ones at $1400{ }^{\circ} \mathrm{C}$.

Starting material also plays a significant role in the evolution of microstructure during sintering and, hence, in LTD resistance. From the results obtained, the behavior against LTD between LAVA and LAB is quite different. While microwavesintered LAB material does not show any significant signs of degradation after $200 \mathrm{~h}$, 
MW LAVA is quite degraded after $80 \mathrm{~h}$. Also, the $m$-phase content of CS LAB is lower after each degradation stage than its LAVA counterpart. Such difference is attributed to the pre-treatment given to $L A B$, which provides a more homogenous starting material.

The mechanical properties obtained from microwave and conventional sintering of the Y-TZP materials demonstrate that the selected conditions in each case resulted in highly densified materials with considerably high Young's modulus and hardness values. Moreover, micro-Raman spectroscopy and X-ray diffraction of the materials after sintering have served to determine that the presence of $\mathrm{m}$-phase is almost nonexistent before exposure to LTD. Smooth and uniform surfaces have also been obtained after sample preparation in order to adequately assess the topographical changes induced by the initial stages of LTD.

Mechanical properties have been affected in such a way that when LTD exposure time is increased, $E$ and $H$ values decrease. Such effect on mechanical properties is extremely relevant since their high Young's modulus and hardness values are one of the main reasons Y-TZP materials are considered for odontological applications. LTD resistance of the lab-prepared material obtained by microwave sintering is very high since no detectable $m$-phase transformation has occurred and mechanical properties are maintained even after $200 \mathrm{~h}$ of LTD exposure. In the case of LAVA, the susceptibility to LTD in the initial stages has been decreased, as $m$-phase content is lower and mechanical properties are higher at LTD exposure times less than $80 \mathrm{~h}$ compared to the conventionally sintered specimen. However, at higher degradation times, a significant amount of $m$-phase content has been found and an important loss of mechanical properties occurred, with $H$ values lower than $10 \mathrm{GPa}$ and $E$ values that are a less than $180 \mathrm{GPa}$ after $60 \mathrm{~h}$. The differences between the commercial and lab-prepared material may be attributed to the characteristics of the starting material. Besides, other important factors may also have an influence on the hydrothermal degradation behavior such as $\mathrm{Y}_{2} \mathrm{O}_{3}$ distribution and c-phase content of the starting material $[15,16]$.

Microwave sintering allows the consolidation of materials with a finer particle size since dwell times are considerably shortened when compared to conventional sintering (10 vs $120 \mathrm{~min}$, respectively). Also, heating rates employed during microwave sintering are significantly higher (100 vs $\left.10{ }^{\circ} \mathrm{C} / \mathrm{min}\right)$ and final temperatures are lower $\left(1200\right.$ vs $\left.1400{ }^{\circ} \mathrm{C}\right)$ than in conventional sintering, which inhibit grain coarsening. Finer microstructures obtained via microwave sintering have resulted in improvement of mechanical properties as reported elsewhere $[19,20,34]$. Furthermore, other sources [15,35-37] have established that reducing the average grain size enhances the resistance against hydrothermal degradation of 
Y-TZP materials because reducing the particle size increases the ratio between surface area and volume and, hence, the effectiveness of the interphase to constrain the change in shape that accompanies the transformation [38]. An alternative approach indicates that the monoclinic variants that may be accommodated when a grain is transformed decrease with its diameter [39]. Grains rich in c-phase content are responsible for a detrimental effect on aging resistance because they deplete neighboring $t$-grains from yttrium and turn them into more vulnerable sites for $t$ - to $m$-transformations. Therefore, as lower sintering temperatures can be employed in microwave sintering, the presence of $c$-phase can be reduced and the resistance to $m$-transformation of $t$-grains is not compromised.

When fabricating Y-TZP materials for odontological applications by the nonconventional microwave technique, it is important to consider the fact that the material needs to be of a white color, because other non-conventional sintering techniques, such as spark plasma sintering (SPS), may not be suitable for sintering of dental pieces due to blackening of the zirconia product [20]. This is due to the required vacuum atmosphere and carbon diffusion within the Y-TZP ceramics when processed by SPS, which is linked to the carbon rich atmosphere in which it is performed. As the sintering of the compact takes place inside a graphite die, the carbon diffuses into the sample and the diffusion is further promoted by the applied pressure.

\subsubsection{SUB-SUPERFICIAL CRACK PROPAGATION IN DEGRADED $Y$-TZP DENTAL CERAMICS}

The structural performance of Y-TZP dental materials is severely affected by the effects of LTD. Mechanical properties, such as hardness, fracture toughness, Young's modulus and mechanical resistance decrease significantly because $m-\mathrm{ZrO}_{2}$ has lower values than $t-\mathrm{ZrO}_{2}$ regarding these properties. In particular, fracture toughness, which inhibits crack propagation and prevents mechanical failure, is one of the most important reasons that have allowed Y-TZP ceramics find useful applications in many areas, being dentistry one of them.

FIB technology coupled with an FE-SEM system has been used to analyze the subsuperficial microstructure resulting from cracks induced by microindentation testing on degraded and non-degraded specimens. The microindentation tests have been performed on the specimens' cross section. The loads applied have been high enough to generate cracks at the corners of the imprint. In the case of the degraded material, exposure to LTD has been $200 \mathrm{~h}$ in order to produce a layer deep enough for carrying out the microindentation test and the load applied has been $4.9 \mathrm{~N}$ (Figure 5.14). For the non-degraded material, the load must be increased to $19.6 \mathrm{~N}$, so as to generate cracks of a comparable length to those in degraded material. 


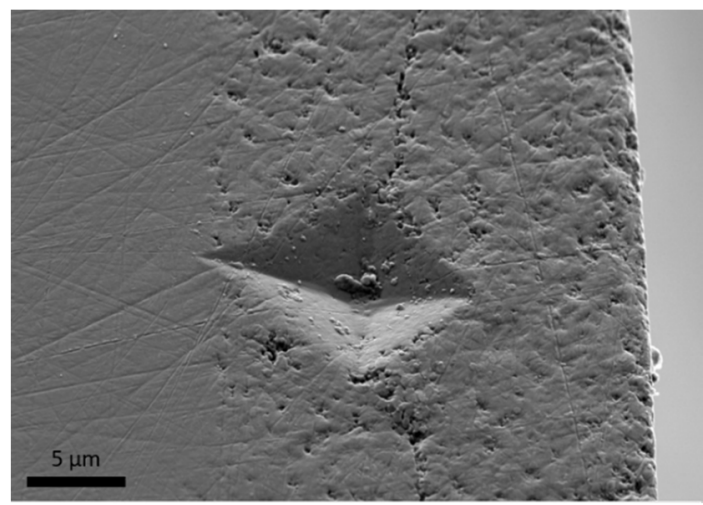

Figure 5.14 FE-SEM micrograph of the imprint on the affected zone of the degraded material after 200 h LTD exposure.

In the first step, trenches have been created with the FIB system, as shown in Figure 5.15. In Figure 5.15a, the degraded and non-degraded zones in this material can be clearly identified by the severe roughening that occurs in the degraded zone and increased porosity due to grain pull-out during sample preparation. Additionally, the imprint is located very close to the edge of the cross-section since degradation progresses from the surface inwards. A superimposed imprint-shaped element has been added in both images to show the size and location of the imprint edges since the material removal caused by the creation of the trench with the FIB eliminated a significant part of the imprint. The size of the imprints is considerably different between degraded and non-degraded material due to the loads applied. A higher load resulted in a bigger imprint, as can be seen in Figure 5.15b for the non-degraded material. The reason for using different loads is to maintain a comparable crack length between both scenarios.

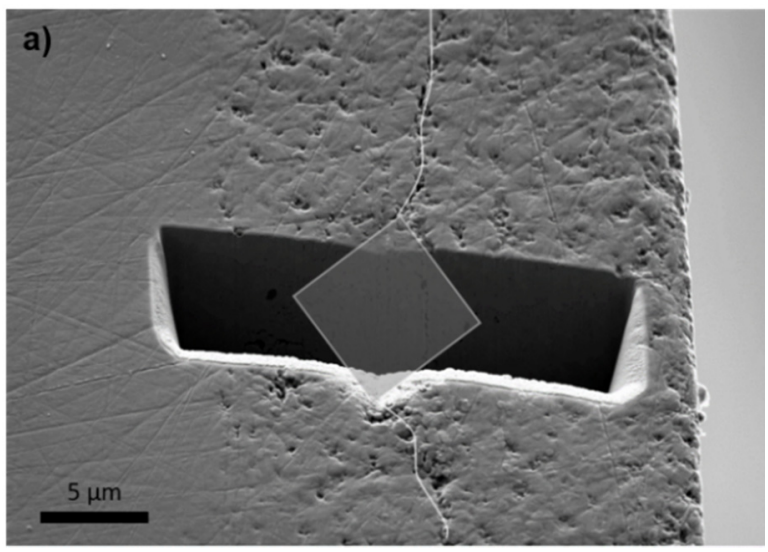




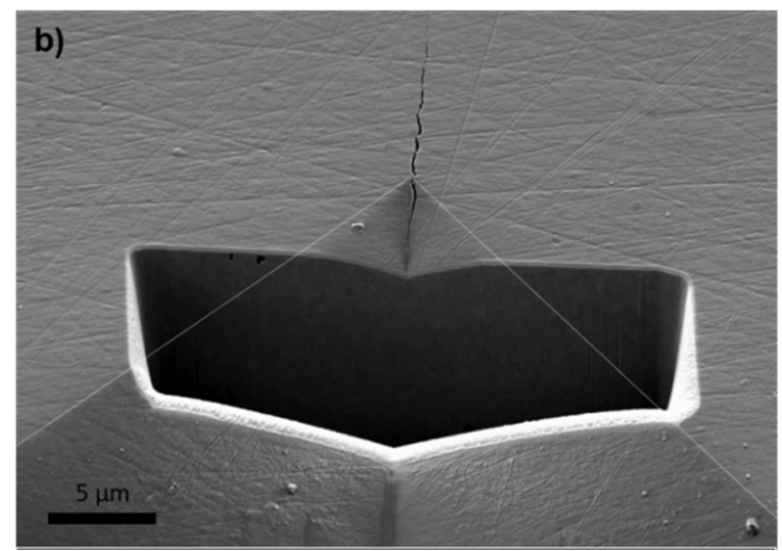

Figure 5.15 FE-SEM micrographs of the trenches created with FIB technology on microindentation imprints for a) degraded and b) non-degraded material.

The crack propagation behavior is very different between degraded and nondegraded material. Figure 5.16 shows FE-SEM micrographs obtained with FIB of the sub-superficial cross-sections of degraded and non-degraded specimens as a sequence of frames, which have been numerated accordingly. In both cases, the initial frame corresponds to the cross-section at the farthest from the corner of the imprint and, hence, from the crack. At this point, no cracks are observed on the nondegraded material cross-section. However, the degraded material already results in a significant presence of cracks that propagate in several directions. This crack network remains present in all frames as the micrograph sequence moves towards the corner of the imprint. Such crack propagation behavior corresponds to that observed in semielliptical cracking, described in Section 4.3.3.3. Semielliptical cracks are characteristic of low fracture toughness materials ( $K_{I c}$ of $m-\mathrm{ZrO}_{2}$ falls within $2-3$ $\mathrm{MPa} \cdot \mathrm{m}^{-1 / 2}$ ) and result in indentation cracks connected sub-superficially.

In contrast, the crack behavior observed in non-degraded material suggest a Palmqvist crack behavior, characteristic of high fracture toughness materials. In this case, a well-defined, relatively straight crack appears in the second frame and propagates inwards. This frame is almost at the corner of the crack imprint. The third frame shows a slightly longer crack, which is even closer to the imprint corner. And finally, the fourth frame, which is taken after the corner of the imprint has been surpassed, the crack is significantly longer but remains constrained to one single direction instead of the crack network in several directions observed in the degraded material. The underlying cracks at the different corners of the imprint do not seem to be connected corresponding to the behavior observed in Palmqvist cracks. In contrast, the micrographs obtained on the degraded material indicate that the crack network below the imprint could be connected to the different cracks emerging from the corners of the indentation imprint. 


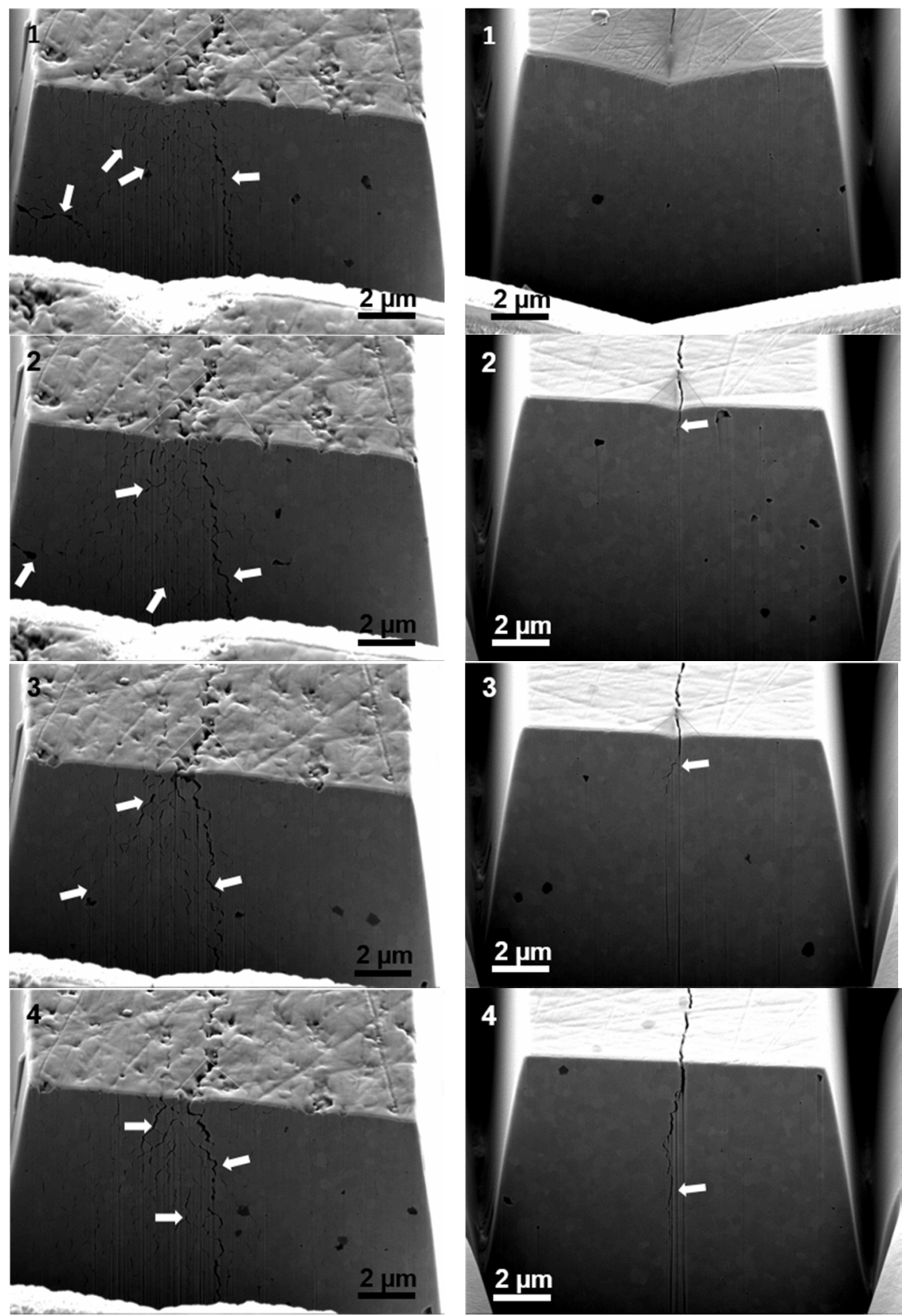

Figure 5.16 FE-SEM micrographs of sub-superficial crack propagation in degraded material after $200 \mathrm{~h}$ (left column) and non-degraded material (right column). 


\subsection{CONCLUSIONS}

Microwave sintering has a significant influence on the resulting microstructure of $Y$ TZP sintered ceramics and, hence, on their hydrothermal degradation susceptibility. Fully-dense materials may be obtained via microwave heating technology and at lower sintering temperatures than with the conventional method, resulting in a finer microstructure and lower $c$-phase content. The resulting microstructure and material phase composition provide a higher resistance to LTD. In the LAB material sintered via microwave, the presence of $m$-phase was almost non-existent even after $200 \mathrm{~h}$ of exposure to LTD conditions and the initial mechanical properties have been maintained.

By combining a carefully prepared starting material with a homogeneous particle size and microwave heating technology as the sintering method, Y-TZP ceramics for odontological application with very high resistance against LTD may be obtained. In the commercial material, hydrothermal degradation was slowed down at the initial stages. Other factors that influence the behavior against LTD, such as type, amount and distribution of stabilizer and the effects that microwave sintering mechanism could have in them need to be further studied. There is not previous works published regarding the influence of microwave sintering on LTD, therefore this work is an approach to know the LTD behavior of dental materials obtained by the nonconventional microwave method.

With the aid of FIB, the different cracking behaviors observed in degraded and nondegraded Y-TZP dental ceramics have been confirmed. It has also been possible to highlight the importance of increasing the resistance to LTD in order to decrease the probability of mechanical failure. 


\section{REFERENCES}

[1] Chevalier J, Cales B, Drouin JM. Low-temperature aging of Y-TZP ceramics. J Am Ceram Soc 1999;82:2150-4.

[2] Chevalier J, Gremillard L, Deville S. Low-temperature degradation of zirconia and implications for biomedical implants. Annu Rev Mater Res 2007;37:132.

[3] Lawson S. Environmental degradation of zirconia ceramics. J Eur Ceram Soc 1995;15:485-502.

[4] Sato T, Shimada M. Crystalline phase change in yttria-partially-stabilized zirconia by low-temperature annealing. J Am Ceram Soc 1984;67:C212C213.

[5] Lange FF, Dunlop GL, Davis BI. Degradation during aging of transformationtoughened $\mathrm{ZrO}_{2}-\mathrm{Y}_{2} \mathrm{O}_{3}$ materials at $250{ }^{\circ} \mathrm{C}$. J Am Ceram Soc 1986;69:237-40.

[6] Guo X, Schober T. Water incorporation in tetragonal zirconia. J Am Ceram Soc 2004;87:746-8.

[7] Lughi V, Sergo V. Low temperature degradation-aging- of zirconia: A critical review of the relevant aspects in dentistry. Dent Mater 2010;26:807-20.

[8] Roy ME, Whiteside LA, Katerberg BJ, Steiger JA. Phase transformation, roughness, and microhardness of artificially aged yttria- and magnesiastabilized zirconia femoral heads. J Biomed Mater Res A 2007;83:1096-102.

[9] Flinn BD, deGroot DA, Mancl LA, Raigrodski AJ. Accelerated aging characteristics of three yttria-stabilized tetragonal zirconia polycrystalline dental materials. J Prosthet Dent 2012;108:223-30.

[10] Ban S, Sato $H$, Suehiro $Y$, Nakanishi H, Nawa M. Biaxial flexure strength and low temperature degradation of $\mathrm{Ce}-\mathrm{TZP} / \mathrm{Al}_{2} \mathrm{O}_{3}$ nanocomposite and $\mathrm{Y}-\mathrm{TZP}$ as dental restoratives. J Biomed Mater Res B Appl Biomater 2008;87:492-8.

[11] Paul A, Vaidhyanathan B, Binner JGP. Hydrothermal aging behavior of nanocrystalline Y-TZP ceramics. J Am Ceram Soc 2011;94:2146-52.

[12] Wang J, Stevens R. Surface toughening of TZP ceramics by low temperature ageing. Ceram Int 1989;15:15-21.

[13] Chevalier J, Deville S, Münch E, Jullian R, Lair F. Critical effect of cubic phase on aging in 3 mol\% yttria-stabilized zirconia ceramics for hip replacement prosthesis. Biomaterials 2004;25:5539-45.

[14] Schmauder S, Schubert H. Significance of internal stresses for the martensitic transformation in yttria-stabilized tetragonal zirconia polycrystals during degradation J Am Ceram Soc 1986;69:534-40.

[15] Inokoshi M, Zhang F, De Munck J, Minakuchi S, Naert I, Vleugels J, et al. Influence of sintering conditions on low-temperature degradation of dental 
zirconia. Dent Mater 2014;30:669-78.

[16] Binner J, Vaidhyanathan B, Paul A, Annaporani K, Raghupathy B. Compositional effects in nanostructured yttria partially stabilized zirconia. Int J Appl Ceram Technol 2011;8:766-82.

[17] Park SS, Meek TT. Characterization of $\mathrm{ZrO}_{2}-\mathrm{Al}_{2} \mathrm{O}_{3}$ composites sintered in a 2.45 GHz electromagnetic field. J Mater Sci 1991;26:6309-13.

[18] Oghbaei M, Mirzaee O. Microwave versus conventional sintering: A review of fundamentals, advantages and applications. J Alloys Compd 2010;494:17589.

[19] Borrell A, Salvador MD, Peñaranda-Foix FL, Cátala-Civera JM. Microwave sintering of zirconia materials: Mechanical and microstructural properties. Int J Appl Ceram Technol 2013;10:313-20.

[20] Borrell A, Salvador MD, Rayón E, Peñaranda-Foix FL. Improvement of microstructural properties of $3 Y$-TZP materials by conventional and nonconventional sintering techniques. Ceram Int 2012;38:39-43.

[21] Pereira GKR, Venturini AB, Silvestri T, Dapieve KS, Montagner AF, Soares FZM, et al. Low-temperature degradation of Y-TZP ceramics: A systematic review and meta-analysis. J Mech Behav Biomed Mater 2015;55:151-63.

[22] Rietveld HM. A profile refinement method for nuclear and magnetic structures. J Appl Crystallogr 1969;2:65-71.

[23] Rodríguez-Carvajal J. Recent advances in magnetic structure determination by neutron powder diffraction. Phys B Condens Matter 1993;192:55-69.

[24] Toraya $\mathrm{H}$, Yoshimura $\mathrm{M}$, Somiya S. Calibration curve for quantitative analysis of the monoclinic-tetragonal $\mathrm{ZrO}_{2}$ system by $X$-ray diffraction. J Am Ceram Soc 1984;67:C119-C121.

[25] Lim CS, Finlayson TR, Ninio F, Griffiths JR. In-situ measurement of the stressinduced phase transformations in magnesia-partially-stabilized zirconia using raman spectroscopy. J Am Ceram Soc 1992;75:1570-3.

[26] Velichko A, Mücklich F. Microstructure tomography - An essential tool to understand 3D microstructures and degradation effects. In: Haug R, editor. Advances in Solid State Physics. Springer; 2009, p. 331-42.

[27] Jeanvoine N, Holzapfel C, Soldera F, Mücklich F. Microstructure characterisation of electrical discharge craters using FIB/SEM dual beam techniques. Adv Eng Mater 2008;10:973-7.

[28] Sugiyama M. A review of focused ion beam technology and its applications in transmission electron microscopy. J Electron Microsc (Tokyo) 2004;53:52736.

[29] Munroe PR. The application of focused ion beam microscopy in the material sciences. Mater Charact 2009;60:2-13. 
[30] Kim CS, Ahn SH, Jang DY. Review: Developments in micro/nanoscale fabrication by focused ion beams. Vacuum 2012;86:1014-35.

[31] Zhang F, Vanmeensel K, Inokoshi M, Batuk M, Hadermann J, Van Meerbeek $\mathrm{B}$, et al. Critical influence of alumina content on the low temperature degradation of 2-3 mol\% yttria-stabilized TZP for dental restorations. J Eur Ceram Soc 2015;35:741-50.

[32] Gaillard Y, Jiménez-Piqué E, Soldera F, Mücklich F, Anglada M. Quantification of hydrothermal degradation in zirconia by nanoindentation. Acta Mater 2008;56:4206-16.

[33] Chevalier J. Critical effect of cubic phase on aging in 3mol\% yttria-stabilized zirconia ceramics for hip replacement prosthesis. Biomaterials 2004;25:5539-45.

[34] Rayón E, Moreno R, Alcázar C, Salvador MD, Manjón FJ, Jiménez-Piqué E, et al. Enhanced hydrothermal resistance of $Y$-TZP ceramics through colloidal processing. J Am Ceram Soc 2013;96:1070-6.

[35] Vasudevan R, Karthik T, Ganesan S, Jayavel R. Effect of microwave sintering on the structural and densification behavior of sol-gel derived zirconia toughened alumina (ZTA) nanocomposites. Ceram Int 2013;39:3195-204.

[36] Jue JF, Chen J, Virkar AV. Low-temperature aging of t-zirconia: The role of microstructure on phase stability. J Am Ceram Soc 1991;74:1811-20.

[37] Gremillard L, Chevalier J, Epicier T, Deville S, Fantozzi G. Modeling the aging kinetics of zirconia ceramics. J Eur Ceram Soc 2004;24:3483-9.

[38] Li J, Watanabe R. Phase transformation in $\mathrm{Y}_{2} \mathrm{O}_{3}$-partially-stabilized $\mathrm{ZrO}_{2}$ polycrystals of various grain sizes during low-temperature aging in water. J Am Ceram Soc 1998.

[39] Jeong WC, Matlock DK, Krauss G. Observation of deformation and transformation behavior of retained austenite in a $0.14 \mathrm{C}-1.2 \mathrm{Si}-1.5 \mathrm{Mn}$ steel with ferrite-bainite-austenite structure. Mater Sci Eng A 1993;165:1-8. 



\section{CHAPTER 6: FRETTING WEAR OF MICROWAVE SINTERED $\mathrm{ZrO}_{2}$ MATERIALS}



The following chapter focuses on the study of the tribological behavior under fretting wear conditions of Y-TZP ceramics processed via microwave sintering by comparing it to that of conventional sintering methods. Mechanical properties, microstructure and densification are assessed previous to fretting exposure as a means of evaluating proper consolidation of the materials under the selected sintering conditions. Characterization of fretting wear parameters consists of measurements of the coefficient of friction (COF), pit depth and wear volume loss, as well as a qualitative evaluation of wear track shape and size. The effect on fracture toughness and average grain size on wear volume loss has also been explored, as these properties can be directly affected by the processing method. The influence of humidity has also been analyzed. Chapter $\mathbf{2}$ addressed the most important characteristics of fretting wear in Y-TZP materials, as well as the various testing configurations and the different fretting regimes that arise during sliding contact. In Chapter 4 a thorough characterization of microwave sintered zirconia ceramics has been carried out. The influence of microwave sintering on microstructure and mechanical properties, which play an important role in the wear behavior of ceramic materials, has been established.

Research efforts have been carried out to understand the effect of microstructure and mechanical properties on the wear resistance of zirconia ceramics for different applications. Processing plays a critical role on the resulting microstructural features of the consolidated ceramic, such as grain size, phase content and degree of densification, which directly affect the resulting mechanical properties. Therefore, evaluating the influence of processing on the tribological behavior of zirconia materials is critical, particularly in dental applications as they require high wear resistance due to the surface contact and loads they are exposed to. Fretting is a type of wear mechanism that can be encountered when considering structural performance in the oral cavity. Some reports have addressed the influence of different materials processing techniques, such as conventional and microwave sintering as well as spark plasma sintering, but none of them have focused on fretting wear as the driving wear mechanism. The significance and novelty of this study relies on exploring the influence of microwave sintering on fretting wear of zirconia materials for dental applications.

\subsection{INTRODUCTION}

Wear resistance of biomaterials aiming to replace functional and structural elements in the human body is critical for an optimum long-term performance and durability. Particularly, the study of tribological behavior is very important in orthopedic and odontological uses, as interactions between surfaces and friction are quite common. The characteristics and performance under wear conditions of Y-TZP ceramics allow 
these materials to become an interesting alternative as structural bioceramics. Restorative dentistry has adopted zirconia-based ceramics for applications as prostheses and implants due to their biocompatibility and physical and mechanical properties, such as hardness and fracture toughness [1,2]. Since teeth are subjected to contact and friction between surfaces due to grinding during the mastication process and, in some cases, due to mouth disorders such as bruxism, there is a need to investigate the wear resistance of Y-TZP materials that are required to act as replacements of teeth. Moreover, the effects of external factors, such as humidity and low temperature hydrothermal degradation (LTD), under constant wear conditions need to be assessed since these materials are exposed to high levels of humidity in the human mouth.

Fretting wear is characterized by the constant sliding motion between two bodies at a low amplitude, usually no more than a few hundred micrometers $[3,4]$. Due to the small displacements involved, removed material can be trapped between contacting surfaces potentiating the wear damage caused [4]. During the fretting process, three wear regimes arise as wear progresses: stick, partial slip and gross slip [5,6]. Moreover, surface damage is produced over most of the contact where slip occurs. Several configurations based on displacement modes can be used to describe fretting wear, being linear, radial and circumferential three of the most commonly encountered in engineering applications. From these three, radial and linear mode can be applied to describe wear on dental systems due to the nature of the contact. Linear mode corresponds to a tangential displacement resulting in high friction and tangential forces between the interacting surfaces, while radial mode is concerned with exerting a normal force as the contact between surfaces is perpendicular. Linear mode can result in a higher rate of material removal due to the high friction force that results from tangential sliding and is representative of the grinding processes that teeth are subjected to. Hence, the focus of this study is based on linear mode on a ball-on-plate setup.

Since microwave sintering allows for a modified microstructure, especially by significantly reducing grain size, due to the heating mechanisms involved, changes in the wear behavior of Y-TZP ceramics are likely to occur. In general, the literature suggests that microwave sintering of zirconia can result in comparable mechanical properties and high degrees of densification comparable to those achieved with conventional sintering systems at lower dwell temperatures and significantly shorter sintering times [7-11]. Moreover, some studies have demonstrated that microwave sintered specimens exhibit enhanced crystallinity [12] and improved mechanical properties [13-15]. Additionally, some authors have suggested that smaller grain sizes can enhance the wear resistance of ceramics [16-18]. As observed in Chapter 4 , the grain size of commercial Y-TZP obtained via microwave heating technology is 
considerably smaller than in conventional sintering. This difference in grain size, among other factors, suggests that microwave sintering can alter the wear behavior of Y-TZP materials under fretting wear conditions.

\subsection{OBJECTIVES}

This study aims to further expand the understanding of the tribological behavior of Y-TZP dental ceramics processed by conventional and microwave sintering methods and to assess the variations that may arise due to modified microstructure and properties, as described in the previous chapters. The main purpose of this work is to evaluate fretting wear of microwave sintered Y-TZP materials by comparing wear parameters with those of conventional sintering. A thorough analysis of the relationship between wear volume and factors that can be influenced by the sintering process, such as grain size and fracture toughness, has been carried out. Two materials are considered: a dental commercial material and a lab-optimized $Y$ TZP powder. The influence of humidity in conventionally sintered specimens is also considered because dental materials are exposed to very humid environments. Additionally, the effect of degradation on these materials has also been evaluated.

The research approach consists of a quantitative and qualitative analysis of wear parameters. Microstructure and mechanical properties of the materials have been characterized upon sintering in Chapter 4. The fretting parameters have been established so as to allow significant material removal and wear pits of considerable size and controlled shapes under reasonable testing time. The selected parameters also resulted in gross slip fretting wear for these materials. A ball-on-plate configuration has been utilized, with Y-TZP balls employed as counter material. Finally, characterization of wear tracks is performed. In this manner, the specific objectives have been set as follows:

- Performing fretting wear testing under selected conditions and analysis of the development of fretting loops and coefficient of friction

- Wear track characterization, including wear shape and size, wear volume and wear rate, as well as analysis of the relationship between wear rate and grain size/fracture toughness

- Assessment of the effect of humidity on fretting wear

- Evaluation of the influence of hydrothermal degradation on the wear resistance 


\subsection{MATERIALS AND METHODS}

\subsubsection{MATERIALS}

The selected materials are LAVA and LAB and the sintering conditions that have been chosen include a dwell temperature of $1200{ }^{\circ} \mathrm{C}$ for microwave sintering (MW) and two dwell temperatures, 1300 and $1400{ }^{\circ} \mathrm{C}$, for conventional sintering (CS). By employing two different dwell temperatures in CS, it can also be determined whether conventional thermal effects can influence the wear behavior of the materials. Details of the sintering conditions and resulting physical and mechanical properties are given in Sections 4.3 and 4.4.

In Section 6.4.2, tested materials include those described above in ambient humidity conditions. In Sections 6.4.3 and 6.4.4, which include the study of the influence of humidity and LTD, respectively, only conventional sintered materials have been studied because the fretting wear behavior of microwave sintered specimens could not be characterized under high humidity conditions due to the very low wear experienced by these materials.

\subsubsection{FRETTING TESTS SETUP}

Fretting tests have been carried out on a ball-on-plate configuration, as shown in Figure 6.1. Y-TZP balls with a diameter of $10 \mathrm{~mm}$ are used as counter material in all tests. The system consist of a computer-controlled tribometer where the sample to be evaluated is mounted on a translation table, which oscillates at a set frequency. The balls remain fixed so only tangential fretting wear occurs. Specimens are fixed to the sample holder that allows movement in $x$ and $y$ directions. Fretting experimental parameters are kept constant for comparative reasons and are as follows: normal load $=8 \mathrm{~N}$, frequency $=5 \mathrm{~Hz}$, number of cycles $=100,000$, and displacement $=200 \mu \mathrm{m}$ on the $x$ direction. These fretting conditions have been selected based on preliminary studies indicating that these conditions allow for wear tracks of considerable size and depth for reasonable test times. Additionally, the combination of these parameters are expected to yield a gross slip fretting behavior.

Previous to the fretting wear tests, Y-TZP specimens have been mirror-polished with colloidal diamond suspension down to $0.25 \mu \mathrm{m}$. The equipment utilized for fretting tests is a home-made tribometer designed and constructed at the Department of Metallurgy and Materials Engineering in KU Leuven with the aim of producing a linear relative reciprocating oscillatory motion. According to Zheng et al. [19], friction and wear tests of dental components should be carried out ideally in a reciprocating sliding mode, instead of any other tribological mode, to better simulate the mastication behavior. Fretting parameters have been previously introduced in the computer that controls the tribometer. Tests are carried out at room temperature. 


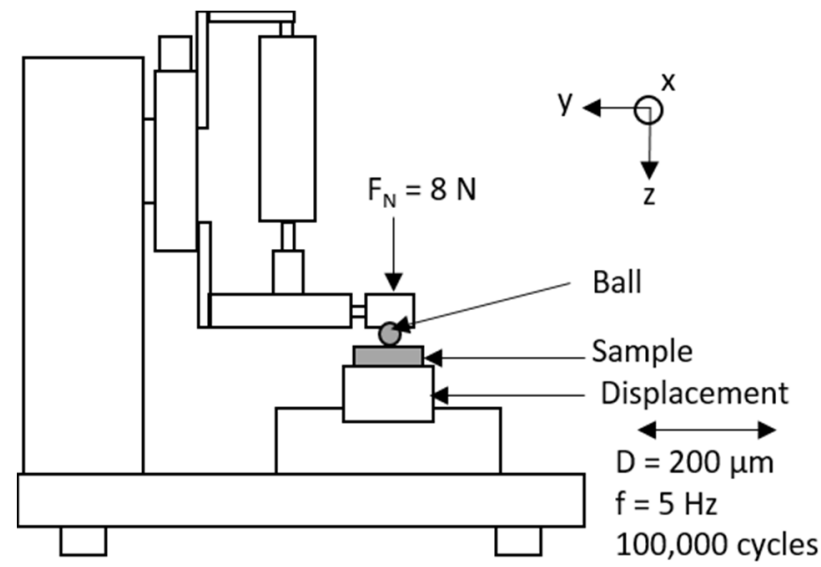

Figure 6.1 Fretting wear setup and conditions.

A complimentary study evaluating the influence of highly humid environments has also been performed in conventional sintered specimens, LAVA and LAB at 1300 and $1400{ }^{\circ} \mathrm{C}$. Two humidity conditions are assessed. The first one consists on carrying out the tests in ambient relative humidity, r.h., conditions. The r.h. in these tests oscillated between 45 and $60 \%$. For the second one, an r.h. of $100 \%$ has been selected. In this scenario, a reservoir has been filled with distilled and the flat has been submerged. The contact between flat and ball has always been kept under water. Also, for these materials a LTD study has been carried out after exposure to $25 \mathrm{~h}$ of accelerated degradation conditions. Setup for LTD tests is described in Section 5.3.2.

Coefficient of friction, COF, is calculated from the on-line measured tangential force. Fretting loops are obtained at several specific cycles. After fretting wear tests have been performed, flat specimens have been rinsed in an ultrasonic bath in ethanol for $5 \mathrm{~min}$ to remove any debris left on the sample an in the wear pits.

\subsubsection{WEAR TRACK CHARACTERIZATION}

Qualitative and quantitative analysis of the wear tracks have been performed utilizing several characterization techniques commonly employed in tribology. The following sections describe the fundamental principles and important aspects related to the usefulness of these techniques for characterizing Y-TZP materials.

\section{Confocal Scanning Laser Microscopy}

One of the most valuable tools for characterizing wear pits in a qualitative and semiquantitative manner is Confocal Scanning Laser Microscopy (CSLM) due to its straightforward and relatively simple image acquisition method. Additionally, specimen preparation does not require complex procedures when compared to 
other microscopy systems. This microscopic techniques allows for detailed topographical images in 3-D of the wear pits. Information about the wear mechanisms involved can be inferred based on the topographical features observed, as well as information on pit depth and length. This technique has been employed in other works to characterize the wear behavior of dental ceramic materials [20-22].

The main characteristic in confocal microscopy is the utilization of a pinhole between specimen and detector to select the information from a single focal plane. This approach is different from standard microscopy, where no pinhole is used and areas below and above the specimens contribute to out of focus blur. By focusing on only one focal plane, a sharp optical image can be acquired. Taking a series of optical slices from different focus levels in the specimen generates a 3-D data set [23].

In CLSM, a laser passes through a diaphragm (excitation pinhole) and is focused on a small point of the sample where, with the aid of scanning mirrors, the interested area of the specimen is scanned point by point on the focal plane. Reflection light from the focal plane passes through an emission pinhole rejecting out of focus light, goes through a filter and finally reaches the detector, generating optical sections. Finally, point by point information is compiled in a computer and a final image is composed. A diagram illustrating the main elements and light path of a CLSM system is shown in Figure 6.2.

The main advantages of CLSM are the ability to control the depth of field, elimination or reduction of background information away from the focal plane, serial production of thin and noninvasive optical sections (maximum axial resolution $=0.5 \mu \mathrm{m}$ ) and elimination of scattered light thanks to the point-by-point illumination (laser source) [24]. Modern CLSM instruments are equipped with 3-5 laser systems controlled by high-speed acousto-optic tunable filters (AOTFs), which allow a very precise regulation of wavelength and excitation intensity. Most of the software packages for image analysis accompanying commercial confocal instruments are capable of generating composite and multi-dimensional views of optical-section data acquired from stacks of optical section (often termed a z-series).

In this study, images at equally-spaced intervals (z-steps) have been acquired in confocal mode with a LEXT 1300 Olympus confocal microscope. Wear pit profiling across the image have been made with the image analysis software provided to determine depth of the wear pit. 
a)

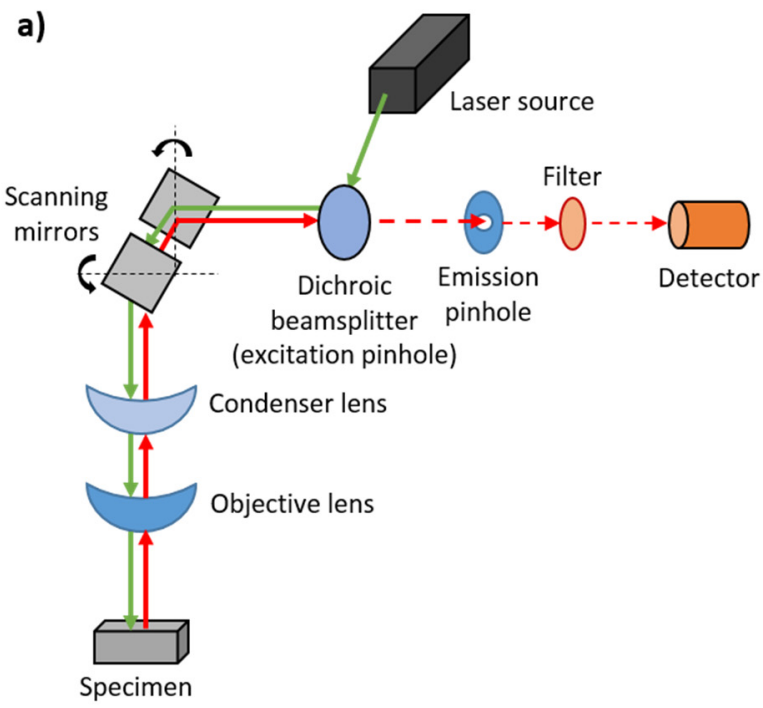

b)

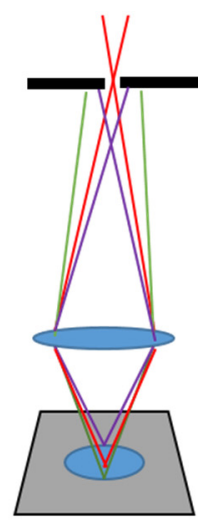

Figure 6.2 a) CLSM schematic showing the path of laser. b) Pinholes allow for selectivity of focal planes for acquisition of a sharp image by eliminating out-of-focus planes and, after taking several images at different focus levels, a 3-D representation can be generated.

\section{White Light Interferometry}

Another common characterization technique employed in tribology based on surface profilometry is white light interferometry. This technique allows for an accurate profile measurement of wear pits. Just like CSLM, it is a non-contact optical method for surface height measurements with profiles varying between tens of nanometers to a few centimeters. More reliable wear pit measurements can be obtained compared to CSLM and provides quantitative complimentary information to the other wear pit characterization methods.

The operating principle of white light interferometry consists in applying the rules that govern wave superposition phenomena to form a topographical map of the surface of the specimen. An interferometer is an optical device that divides a beam of light exiting a single source into two beams and them recombines them to create an interference pattern. Surface profiling begins with an expanded light beam exiting the light source and then passing through a beam splitter where it is divided into two beams: one that falls upon a reference mirror and the other one reaching the sample. Due to topographical variations on the specimen, the test beam is reflected at a different phase. As the reference and test beams are reflected back, they are recombined by the beam splitter causing interference since the test beam is now out of phase. The inference pattern of the beams is passed through an objective lens in order to finally reach a CCD camera. Depending on the width and frequency of the 
reflected light wave, the CCD system is able to extract this information to generate a model of the topography of the sample.

The main elements that comprise a white light interferometer are: a light source, the beam splitter, a reference mirrors and objective lens and the CCD camera. A schematic of the trajectories of the beams as well as the most important components is shown in Figure 6.3. In order to visualize microscopic structures, interferometers are usually coupled with an optical system similar to an optical microscope. However, this optical system consists of two other elements that differentiate it from a standard optical microscope an interferometric objective lens and an accurate positioning stage to move the objective vertically.

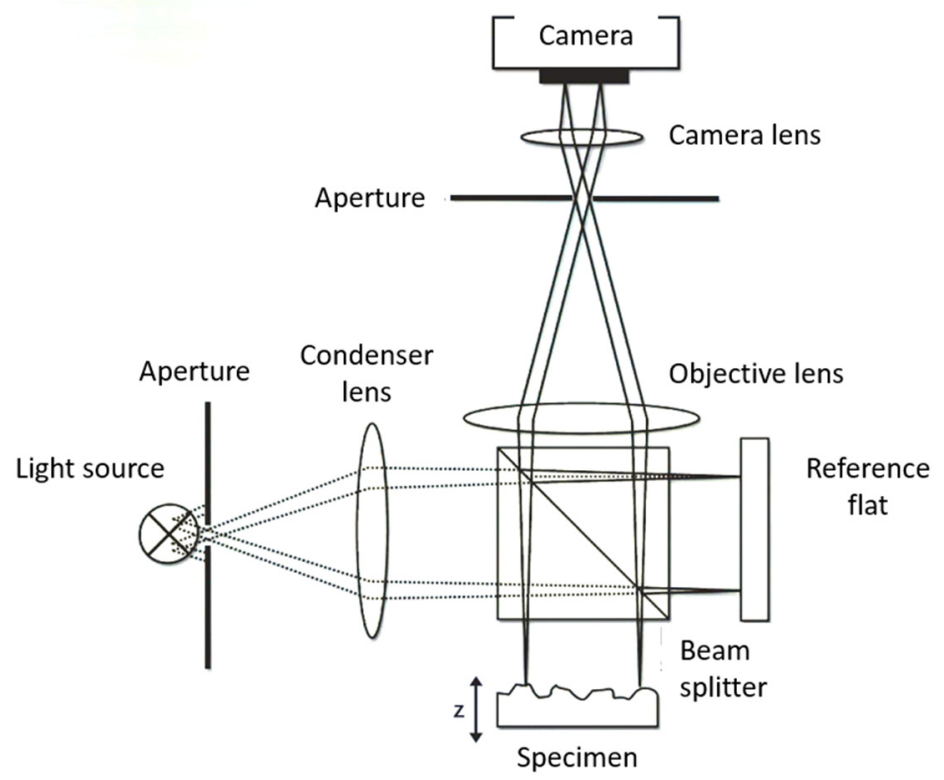

Figure 6.3 White light interferometry schematic showing beam slitting and recombination, as well as the main components of the apparatus.

The system employed in this work to carry out wear pit profiling and model imaging of the wear pits has been a Wyco NT 1100 optical profilometer (Veeco, Plainview, USA). A vertical shift interference mode has been utilized. This mode uses a neutral density filter for white light and the objective actually moves through focus. The height variations on the specimen surface are processed by fringe modulation data from the intensity signal. The measurable topography in this mode ranges from a few hundred $\mathrm{nm}$ up to $1 \mathrm{~mm}$. Interferometry measurements have been performed following the ISO/DIS 25178-604:2010 standard. An analysis software that 
accompanies the equipment allows the calculation of the dimensions of the wear pits from the obtained profiles.

The calculated wear pit dimensions from interferometry have been used to determine the wear volume. An empirical equation modified from Klaffke [25] and reported in Reference [26] has been employed as a geometrical approximation (Equation 6.1). The shape of the wear tracks consists of an elongated round cap due to the fretting conditions applied, which means that the parallel diameter , $d_{\|}$, is not the same as the perpendicular one, $d_{\perp}$ (Figure 6.4).

$$
V=\pi h_{c a p}^{2}\left(R-\frac{h_{c a p}}{3}\right)+\left(\frac{d_{\perp}-d_{\|}}{2}\right)\left[R^{2} \sin \left(\frac{k}{R}\right)-\left(R-h_{c a p}\right) k\right]
$$
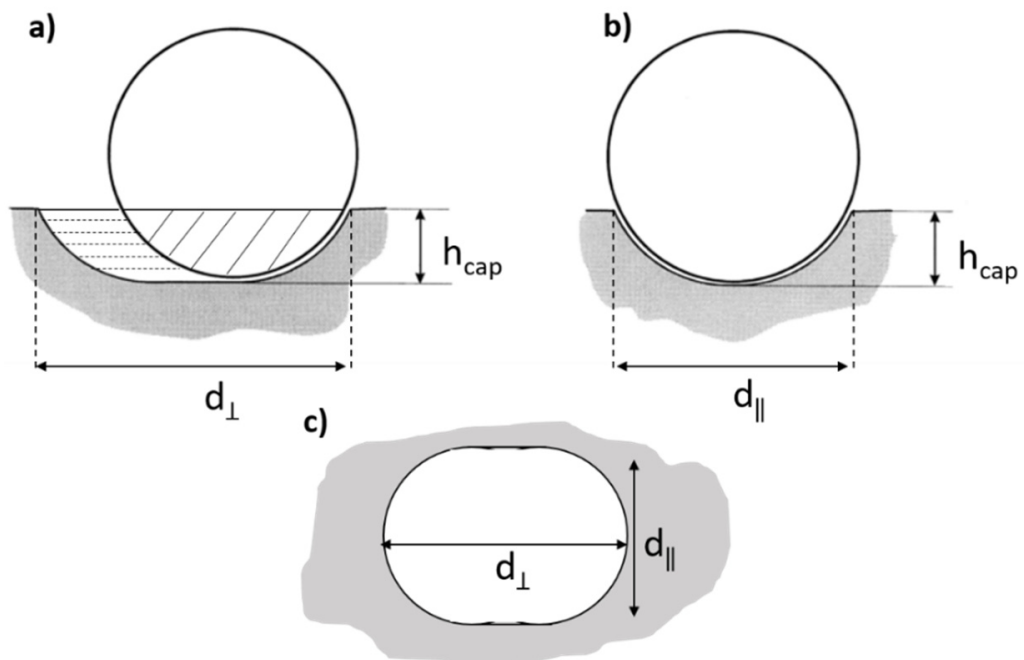

Figure 6.4 Schematic of different views of fretting wear setup for a ball-on-plate configuration used to determine geometrical parameters for wear volume calculation. a) and b) correspond to parallel and perpendicular cross-section views to the sliding direction, respectively, and c) is a top view of the wear track. Taken and modified from [26].

The approach to calculate the wear volume must consider two volumes. The first one corresponds to a ball cap of height $h_{\text {cap }}$, which is the wear pit maximum depth that can be determined from the interferometry wear pit profiles. This volume corresponds to the first part of Equation 6.1. The second one is the portion that results from the oscillating amplitude direction. In this case, the length difference between the diameters can be used to calculate the remaining volume, which is given in the second part of Equation 6.1. The measurement of the diameters has been carried out with the Gwyddion image analysis software. Other parameters considered are the radius of the ball $R$ and the factor $k$, which takes into account the irregular geometrical section of the elongated side and is given in Equation 6.2. 


$$
k=\sqrt{2 R h_{c a p}-h_{c a p}^{2}}
$$

Another important tribological parameter that can be obtained once the wear volume has been calculated is the wear rate, also known as wear coefficient, which is given in Equation 6.3. The wear rate, $W_{\text {rate }}$, can be used to verify whether a gross slip regime has been reached with the selected conditions by comparing it to the fretting regimes proposed by Vingsbo et al. [6].

$$
W_{\text {rate }}=\frac{V}{F_{N} d}
$$

where:

$V=$ Wear volume, $\left[\mathrm{mm}^{3}\right]$

$F_{N}=$ Normal force, $[\mathrm{N}]$

$d=$ sliding distance, $[\mathrm{m}]$

\section{Nomarski Optical Microscopy}

Also known as differential interference contrast (DIC), Nomarski microscopy is another method for qualitatively characterizing wear tracks with depths of a few micrometers. The images obtained from this type of microscopy differ from those of standard optical microscopes in the sense that height variations of a few micrometers due to contrast difference can be revealed giving a 3-D visualization of the specimen's topography. Nomarski contrast is usually available in advanced optical microscopes by including a light polarizer and a special prism.

DIC applies the same physical principles used in interferometry. However, in this case, the sample and reference rays are created after the beam traverses and is phase-distorted by the sample, whereas in interferometry the beam is split before in order to have a beam that falls upon the reference mirror and the other on the sample that are later recombined. The phased beam is split into a two equally phased, but spatially separated beams by the action of a Wollastom prism [27]. Finally, the beam-pair passes through a polarizing filter where they are recombined in a vibrational manner and interact at the image plane. Wave interference of these two beams is responsible for creating these contrast.

An important consideration when analyzing specimen topography with Nomarski microscopy arises from the fact that DIC utilizes optical path differences within the specimen, which is a product of refractive index and geometric path lengths, to generate contrast and, as a consequence, the 3-D appearance may not represent reality. The 3-D relief of DIC imaged specimens is an optical instead of a geometrical relief. Therefore, in this work, DIC has been used as a complimentary imaging tool to the more sophisticated profilometry technique of white light interferometry, which 
provides a more reliable 3-D representation of wear pits. The system utilized to perform DIC imaging of specimens is an Eclipse LV 100 (Nikon, Tokyo, Japan) optical microscope enabling a light polarizer and a DIC lens.

\subsection{RESULTS AND DISCUSSION}

\subsubsection{Y-TZP CERAMICS DENSIFICATION AND MECHANICAL PROPERTIES UPON SINTERING}

Table 6.1 summarizes the properties determined in Chapter 4 for both materials after microwave (MW) and conventional sintering (CS). A designation for identifying specimens have been given with regard to material, sintering method and dwell temperature. The results indicate that all specimens have reached substantial high degrees of densification at the selected sintering conditions, as most relative densities are above $97 \%$. Particularly, LABMW material has resulted in a significantly higher relative density value compared to specimens sintered by CS reaching $99.6 \%$ by using less time and energy during the sintering process. All specimens result in $H$ and $E$ values above $12 \mathrm{GPa}$ and $240 \mathrm{GPa}$, respectively. Since full consolidation of both materials has been achieved with microwave sintering, $K_{/ C}$ values are also in the same range of conventionally sintered counterparts. Values around $6 \mathrm{MPa} \cdot \mathrm{m}^{1 / 2}$ are typical for Y-TZP materials, as reported in other works [28-30]. Fracture toughness plays an important role in the wear behavior of ceramic materials due to their brittle nature. This property can be used to understand the propensity to microcracking and volume wear loss.

Table 6.1 Summary of physical and mechanical properties determined in Chapter 4 for LAVA and LAB materials after microwave and conventional sintering.

\begin{tabular}{|c|c|c|c|c|c|c|}
\hline Material & & $L A V A$ & & & $L A B$ & \\
\hline $\begin{array}{l}\text { Sintering method } \\
\left(\text { Temperature, }{ }^{\circ} \mathrm{C} \text { ) }\right.\end{array}$ & $\begin{array}{c}\text { MW } \\
(1200)\end{array}$ & $\begin{array}{c}\text { CS } \\
(1300)\end{array}$ & $\begin{array}{c}\text { CS } \\
(1400)\end{array}$ & $\begin{array}{c}\text { MW } \\
(1200)\end{array}$ & $\begin{array}{c}\text { CS } \\
(1300)\end{array}$ & $\begin{array}{c}\mathrm{CS} \\
(1400)\end{array}$ \\
\hline Designation & LVMW & LVCS13 & LVCS14 & LABMW & LABCS13 & LABCS14 \\
\hline Relative density, $\%$ & 99.0 & 97.7 & 98.8 & 99.6 & 97.5 & 99.2 \\
\hline Hardness, GPa $\left(\mathrm{HV}_{10}\right)$ & $13.6 \pm 0.3$ & $12.4 \pm 0.1$ & $12.9 \pm 0.2$ & $13.4 \pm 0.4$ & $12.1 \pm 0.2$ & $13.0 \pm 0.1$ \\
\hline $\begin{array}{l}\text { Fracture toughness, } \\
\mathrm{MPa} \cdot \mathrm{m}^{1 / 2}\end{array}$ & $6.7 \pm 0.4$ & $6.2 \pm 0.4$ & $6.3 \pm 0.7$ & $6.6 \pm 0.7$ & $6.2 \pm 0.4$ & $6.5 \pm 0.4$ \\
\hline Elastic modulus, $G P a$ & $249 \pm 14$ & $285 \pm 26$ & $255 \pm 19$ & $269 \pm 12$ & $253 \pm 26$ & $262 \pm 13$ \\
\hline Average grain size, $\mathrm{nm}$ & $146 \pm 64$ & $238 \pm 54$ & $343 \pm 43$ & $174 \pm 67$ & $203 \pm 48$ & $199 \pm 85$ \\
\hline
\end{tabular}


The most significant differences are given by the average grain size of the specimens, which arise due to the sintering method. In the case of LAVA, grain size variations are notably large. The conditions employed for MW sintering and the densification mechanisms involved result in smaller grain sizes, with more than $100 \mathrm{~nm}$ difference when compared to $\mathrm{CS}$ at $1300{ }^{\circ} \mathrm{C}$. Several works have reported a similar behavior where $\mathrm{MW}$ sintering results in smaller grain sizes due to the conditions and mechanisms involved [31-33]. However, the behavior of LAB material in terms of this parameter is very different. The differences are not as pronounced between MW and CS. The small differences in average grain size are due to the pretreatment that the starting powder undergoes providing a more homogeneous material in terms of particle size [34].

\subsubsection{WEAR BEHAVIOR UNDER FRETTING CONDITIONS AT AMBIENT RELATIVE HUMIDITY}

Physical and mechanical properties of the Y-TZP balls that have been employed as counter material in the tangential fretting test are shown in Table 6.2. This information is useful to understand the wear mechanisms involved in a ball-on-plate configuration. As can be seen, the hardness of the ball is lower than the values obtained for the sintered samples. In contrast, fracture toughness is notably higher for Y-TZP balls.

Table 6.2 Physical and mechanical properties of counter material balls used for fretting tests

\begin{tabular}{l|c}
\hline Manufacturer & Tosoh \\
Material & Y-TZP \\
Diameter, $\boldsymbol{m m}$ & 10 \\
Density, $\mathbf{g} / \mathbf{c m}^{3}$ & $5.95^{*}$ \\
Hardness, $\mathbf{G P a}$ & 13.2 \\
Fracture toughness, $\mathbf{M P a} \cdot \boldsymbol{m}^{\mathbf{1 / 2}}$ & $7.7^{*}$ \\
Elastic modulus, $\mathbf{G P a}$ & $>210$ \\
\hline \multicolumn{2}{c}{ *Obtained from manufacturer's specification sheet }
\end{tabular}

Fretting loops have been analyzed to identify the fretting wear slip regime resulting from the applied conditions under ambient relative humidity. From Figure 6.5, the hysteresis loop indicates the presence of gross slip after 20,000 cycles for MW sintered LAB material. A second loop at the $11^{\text {th }}$ cycle is shown to illustrate the behavior of the tangential force during the initial stages of the fretting test. In this case, the tangential force is limited within -2 and $2 \mathrm{~N}$. During the first few cycles, a partial slip regime is observed indicated by a thinner loop. As the number of cycles increases, the loop expands giving rise to gross slip and the tangential force increases 
substantially leading to considerable wear damage. The displacement of $200 \mu \mathrm{m}$ appears to remain constant throughout all cycles. This tribological behavior is expected on self-mated Y-TZP materials under these wear conditions. Similar results have been obtained for CS specimens suggesting that MW sintered Y-TZP materials result in a similar wear pattern at the selected processing conditions (dwell temperature, sintering time and heating rates) with respect to the development of tangential forces involved and friction between sample and counter material.

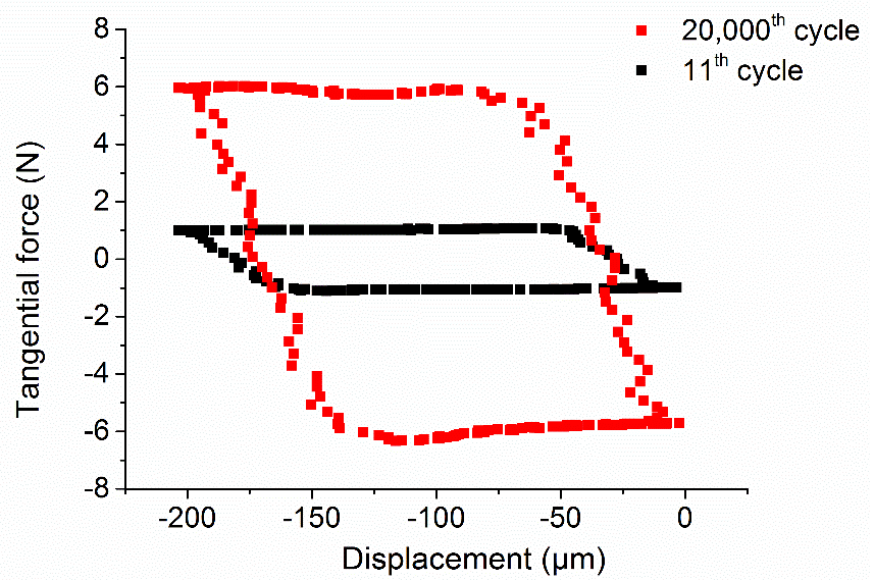

Figure 6.5 Fretting hysteresis loops of the $11^{\text {th }}$ and $20,000^{\text {th }}$ cycle for LAB material sintered by MW heating revealing that both regimes, partial slip and gross slip, occur at the selected wear conditions.

Results of the mean coefficient of friction, COF, determined for all specimens during fretting tests are shown in Figure 6.6. The values correspond to test carried out under ambient relative humidity conditions. Nath et al. have reported COF values of approximately 1.0 in self-mated Y-TZP materials on ball-on-plate configurations at similar loads under ambient humidity [30]. The COF values calculated in this work fall within $0.7-0.85$. Significant differences arise between both materials. For LAVA, MW sintered Y-TZP has a significantly lower COF compared to CS. As the dwell sintering temperature is increased from 1300 to $1400^{\circ} \mathrm{C}$, a slight increase of the COF occurs.

In contrast, LAB material shows very similar COF values at approximately 0.78 , despite different sintering methods and temperatures. This difference can be attributed to the starting material, as LAB is a more carefully prepared powder with a more homogeneous particle size, which is also reflected on the grain size. A relationship between COF and grain size shows that as grain size increases so does COF in LAVA material and, since grain size variations among LAB specimens are very small, COF values also remain constrained to a narrow range. In LAVA, even though 
mechanical properties are similar to $L A B$, the background of the material and the sintering conditions have an influence on the tribological behavior of the consolidated body, leading to grains of variable sizes and, consequently, variations in the COF and sliding interaction between flat and counter material.

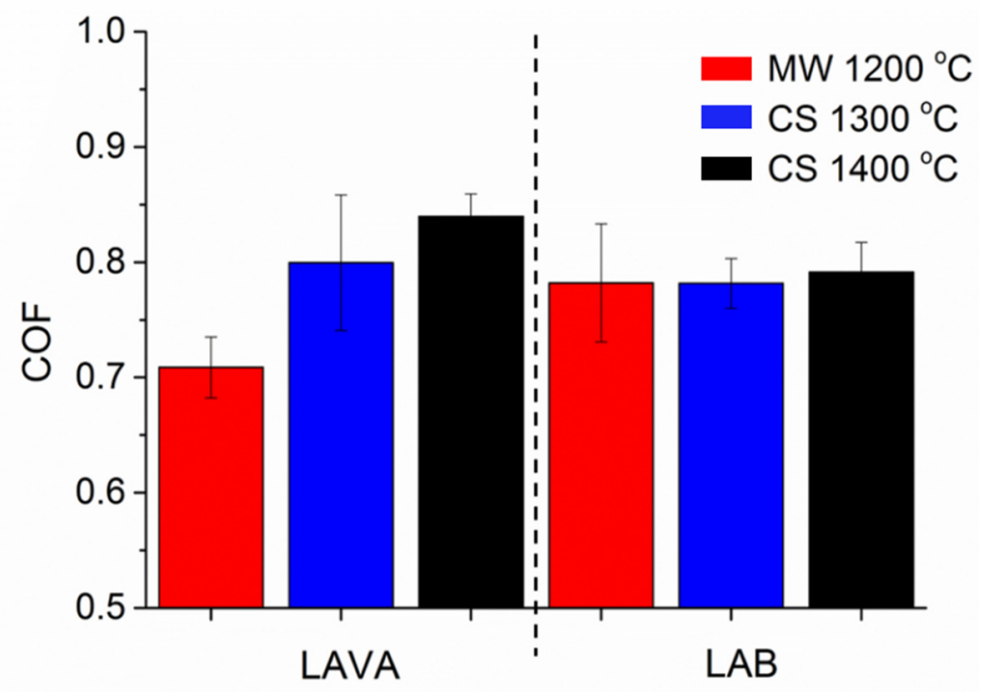

Figure 6.6 COF determined for all specimens during tangential fretting tests.

In order to measure the wear volume resulting from the fretting tests, the depth of the wear tracks and the length of the radius have been determined by means of light interference profilometry. Figure 6.7 shows profilometry images and Nomarski contrast micrographs of the wear tracks on LVMW and LVCS14. These specimens have resulted in the largest difference in COF and, additionally, they have been sintered by different methods. An approximate radius $a$ has been calculated as the average of two measurements perpendicular to each other since the tracks are not totally round. In this manner, Equation 6.1 can be used to determine wear volume. The measured radiuses, obtained from profilometry measurements, are shown in Figures 6.7a and 6.7c. As can be seen, a deviation from zero eccentricity is quite significant. Nonetheless, for comparative purposes, the proposed method for calculation of wear volume is still be valid, as all specimens resulted in similar wear track shapes.

The size and shape differences between wear tracks of LVMW and LVCS14 are significant. The maximum depth of LVMW has been measured at $4.5 \mu \mathrm{m}$, while that of LVCS14 is $5.9 \mu \mathrm{m}$. Additionally, LVMW has considerably shorter radiuses indicating that a smaller volume of material has been removed due to fretting. A higher degree of roundness can also be observed on the wear track of LVMW. Similar shapes and 
depths ranging from 1 to $7 \mu \mathrm{m}$ have been determined for the other specimens. The variation in wear track radius in quite clear in these two examples.
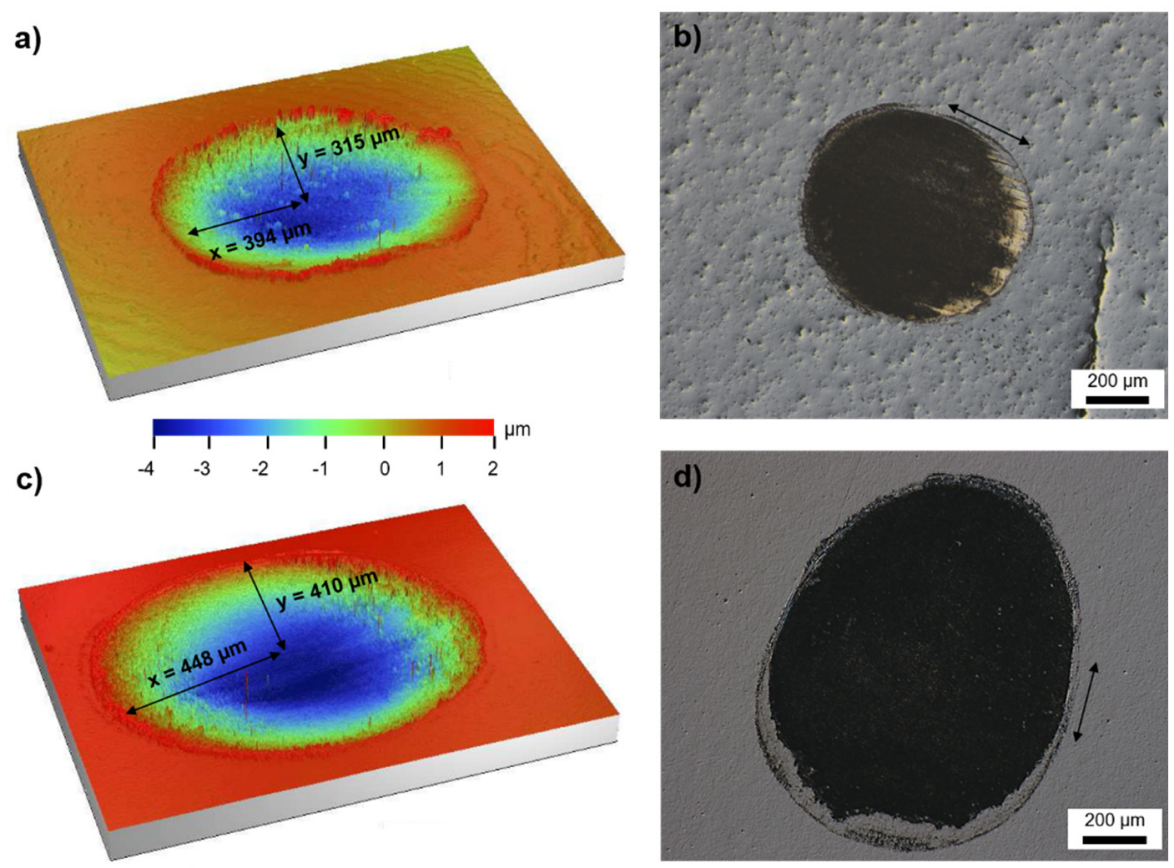

Figure 6.7 Profilometry images of a) LVMW and c) LVCS14 with measurements of radius at two different points and Nomarski interference contrast micrographs for b) LVMW and d) LVCS14.

Even though the displacement of the fretting tests has been set to $200 \mu \mathrm{m}$, the wear damage is not only restricted to this length because the contact region and sliding interaction between ball and sample also depends on the microstructure and the properties of the sintered material. In LAVA material, these properties are different due to the different sintering conditions, as can be seen in Table 6.1. Therefore, the length of the wear tracks also varies. Radiuses of more than $360 \mu \mathrm{m}$ have been measured with profilometry and microscopy techniques (Figure 6.7c).

For comparative purposes among sintering methods and temperatures, the wear volume has been determined from wear track geometrical features by assuming an elongated round cap shape, as described in Section 6.3.3. The estimated values of wear volume are shown in Figure 6.8. Most values are within the same order of magnitude $\left(10^{5} \mu \mathrm{m}^{3}\right)$. Similar wear volumes have also been found in other studies of self-mated Y-TZP ceramics [35]. However, some notable variations can be seen with respect to processing method, temperature and material. When comparing sintering methods in LAVA material, the wear volume of MW material sintered at a lower temperature is between both CS specimens. There is a significant wear volume difference between CS at 1300 and $1400{ }^{\circ} \mathrm{C}$ corresponding to more than an order of 
magnitude. This behavior can be attributed again to the pre-sintered nature of LAVA material, as was observed in the COF values. These COF values, however, do not necessarily correspond to a directly proportional relationship, meaning that if the COF increases the wear volume increases. In this case, the highest COF does indicate a higher wear volume (LVCS14), but the smallest wear volume does not result from the lowest COF.

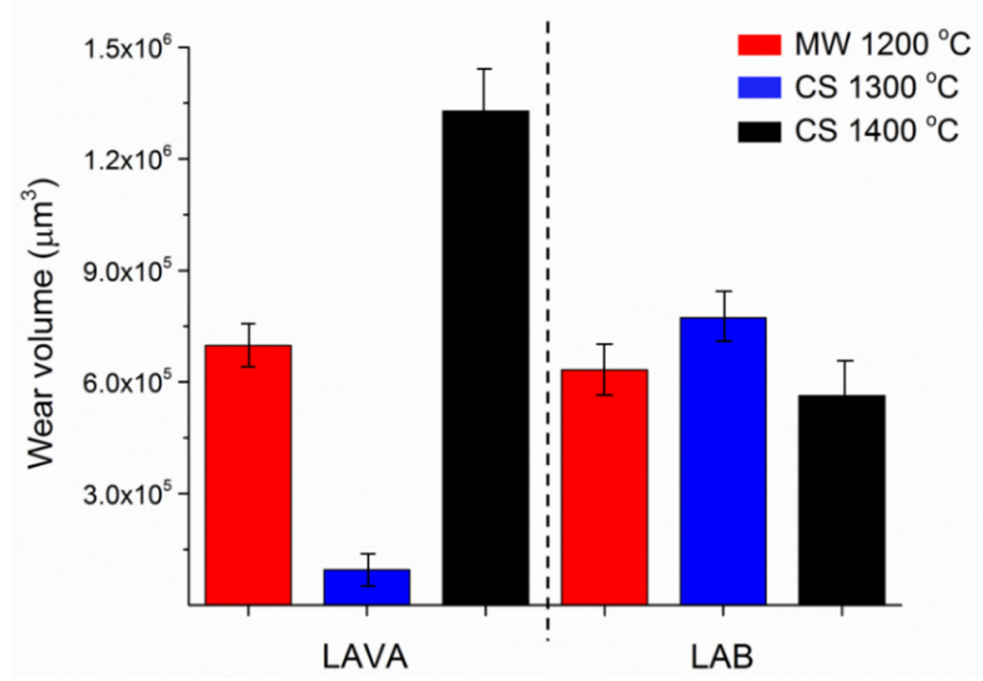

Figure 6.8 Wear volume for LAVA and LAB specimens sintered under different conditions.

Regarding LAB material, the differences in wear volume are less pronounced. The wear volume falls within a narrower range going from $5 \times 10^{5}$ to $8 \times 10^{5} \mu \mathrm{m}^{3}$. Again, the MW sintered material has resulted at the mid-value between the CS specimens. However, in this case, $\mathrm{CS}$ at $1400^{\circ} \mathrm{C}$ resulted in the lowest wear volume value. These results suggest that a lower sintering temperature in CS specimens might enhance the resistance to wear under fretting conditions of LAVA material. On the other hand, for CS LAB material, higher sintering temperatures seem to decrease the amount of volume lost due to wear. In any case, MW sintering at lower dwell temperatures with shorter processing times and lower energy consumption provides a more environmental-friendly ceramic processing method that allows the consolidation of materials with a tribological behavior comparable to those of CS. An important consideration is that the error in wear volume calculations increases with bigger tracks due to the approximation approach employed. Nonetheless, the calculated values can be used for the comparison purposes established in this study.

In order to corroborate whether the slip regime under the evaluated fretting conditions corresponds to gross slip, the wear rate of each specimen has been calculated from the wear volume and contrasted with a fretting regime model taken 
from [36], as shown Figure 6.9. The results indicate that a gross slip regime has been achieved at the selected fretting conditions in almost all cases as the wear rates fall within this regime at $200 \mu \mathrm{m}$ amplitude. Due to the similar properties of the sintered bodies, particularly fracture toughness, after MW and CS processing, the wear rates fall within a very close range. This behavior indicates that $\mathrm{MW}$ sintering at the selected conditions is able to provide Y-TZP materials for dental applications with the same wear rates as those obtained by CS. In this sense, the durability under fretting wear conditions of the material is not compromised by this novel processing technology.

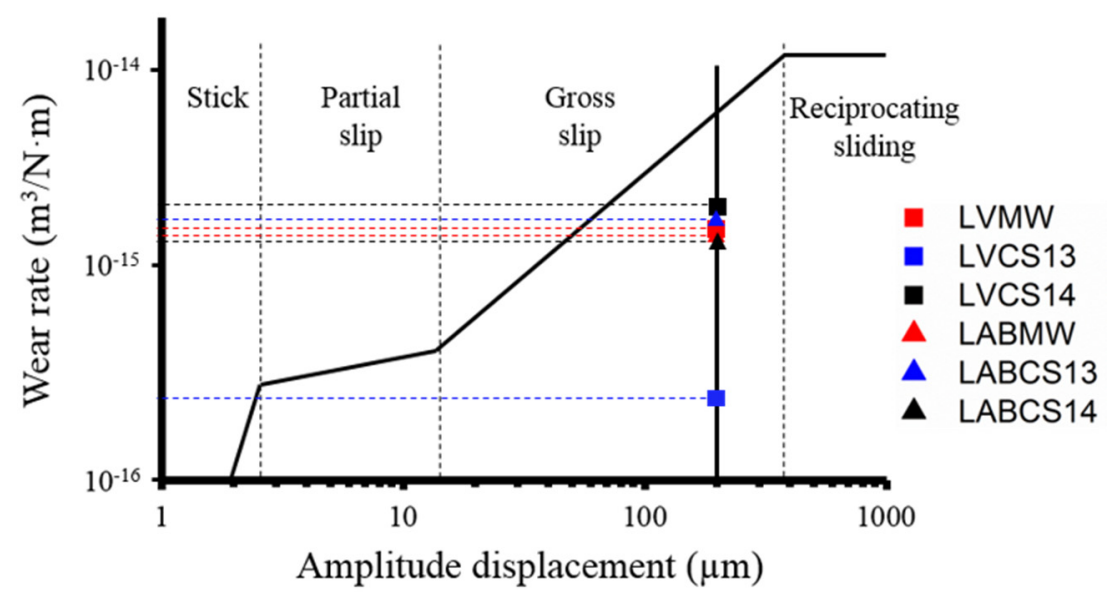

Figure 6.9 Fretting wear regimes given by amplitude and wear rate of all specimens at $200 \mu \mathrm{m}$ of fretting amplitude.

LVCS14, which has the highest COF, also has the highest wear rate. LABCS13, however, does not seem to correspond to gross slip because it has a significantly lower wear rate in comparison with the other specimens.

Morphology analysis of the fretting pits and damage has been performed by means of confocal microscopy (Figure 6.10). The micrographs illustrate some of the most important microstructural characteristics of fretting wear in Y-TZP ceramics such as delamination, microcracking and abrasive grooving. Also, information regarding the wear mechanisms involved can be obtained. In these materials, fretting wear on ballon-plate configurations begins with abrasive grooving parallel to the fretting displacement direction due to sliding contact. This mechanism is characterized by increasing surface roughness substantially. It is then followed by delamination, which corresponds directly to the removal of material occurring from the plastic deformation induced by wear exposure. Finally, microcracking at the fretting contacts is responsible for severe wear damage due to the cracking-activated spalling and could lead to complete failure of the structural ceramic under higher 
loads and/or by increasing the number of cycles. Microcracking occurs perpendicular to the fretting displacement direction and might be due to a phenomenon arising from oscillatory motion of contacting surfaces known as fretting fatigue [37].

\section{LAVA}
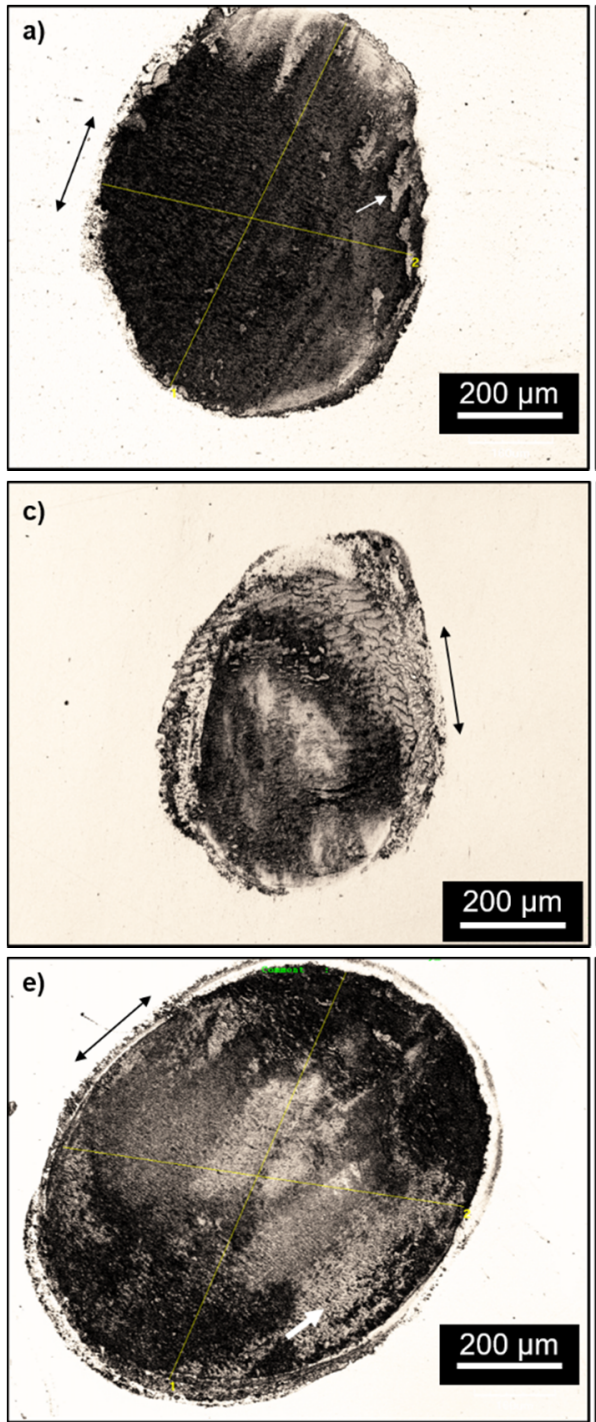

$L A B$
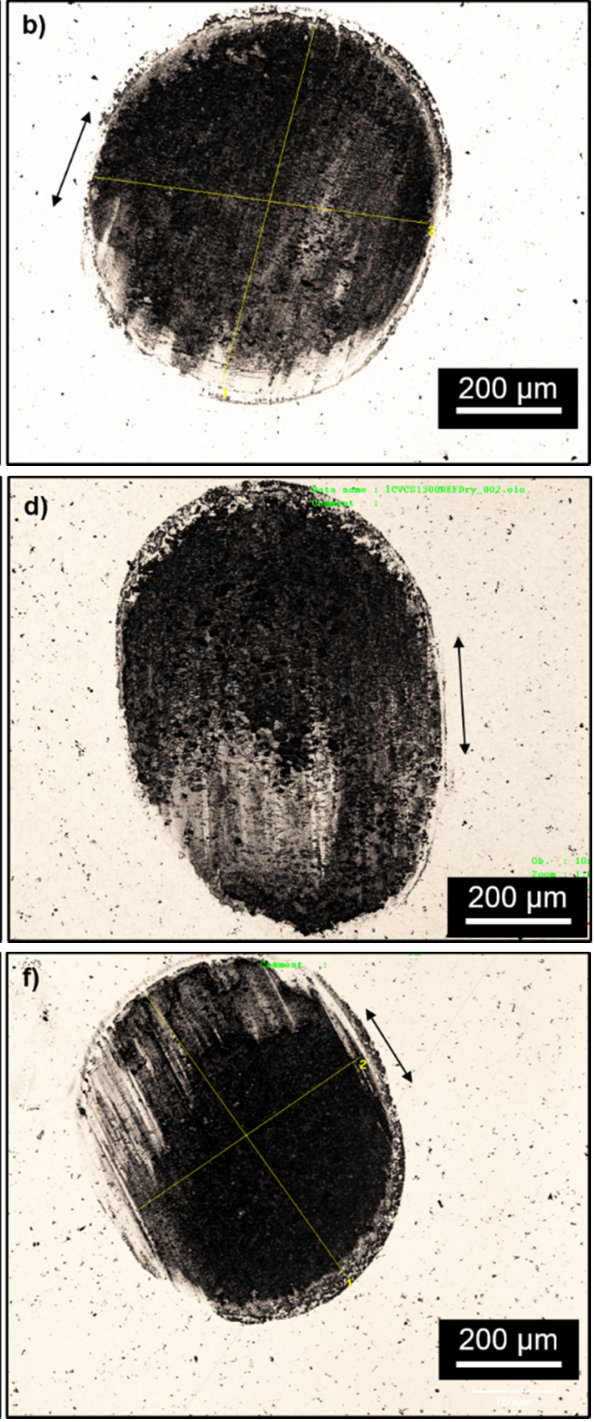

Figure 6.10 Confocal microscopy images of wear pits for a) LVMW, b) LABMW, c) LVCS13, d) LABCS13, e) LVCS14 and f) LABCS14 showing delamination and microcracking.

Figures 6.10a and 6.10b correspond to MW sintered LAVA and LAB, respectively, while Figures $6.10 \mathrm{c}, 6.10 \mathrm{~d}, 6.10 \mathrm{e}$ and $6.10 \mathrm{f}$ belong to their CS counterparts. Figure 6.10a shows morphological features corresponding to residual delamination, which is the mechanism responsible for material removal in self-mated zirconia ceramics. 
The morphology of the fretting pits is quite different among the specimens shown. However, abrasive grooving in a parallel direction to fretting displacement can be observed in all cases. The fretting pits of specimens sintered via MW heating are more similar between each other than those of CS. For example, LABCS14, which corresponds to the lowest wear volume loss and has a maximum pit depth of $1 \mu \mathrm{m}$, is mostly affected by abrasive grooving and no significant microcracking can be appreciated. The darkened appearance inside the pit reflects the roughness generated by ball sliding during the first fretting stages.

On the other hand LVCS14, which has the biggest wear volume loss coupled with the deepest groove of almost $6 \mu \mathrm{m}$, indicates the presence of microcracking and significant delamination. The predominantly whitened center of this fretting pit corresponds to the lowest depth. MWLV and MWLAB result in fretting pits with similar features as microcracking, delamination and abrasive grooving can be found in both of them with maximum pit depths of 4.5 and $4.1 \mu \mathrm{m}$, respectively. However, fretting damage is not as pronounced as in LVCS14.

As mentioned previously, LVCS13 does not reach the gross slip regime and seems quite far from it. Therefore, the wear pit depth and morphology has been analyzed. Figure $6.10 \mathrm{c}$ and Figure 6.11 shows the profilometry model and confocal microscopy image of this specimen, respectively. The wear pit is shallow, reaching a maximum depth of $1.5 \mu \mathrm{m}$, as measured with white light interferometry profilometry. The parallel and perpendicular diameters are also small compared to the other specimens. The confocal micrograph also indicates the low depth of the pit due to the absence of intense dark spots, as observed in other specimens. Superficial microcracking is also present, which can result from the transition from stick to partial slip. This behavior confirms that a gross slip regime has not been reached in LVCS13.

a)

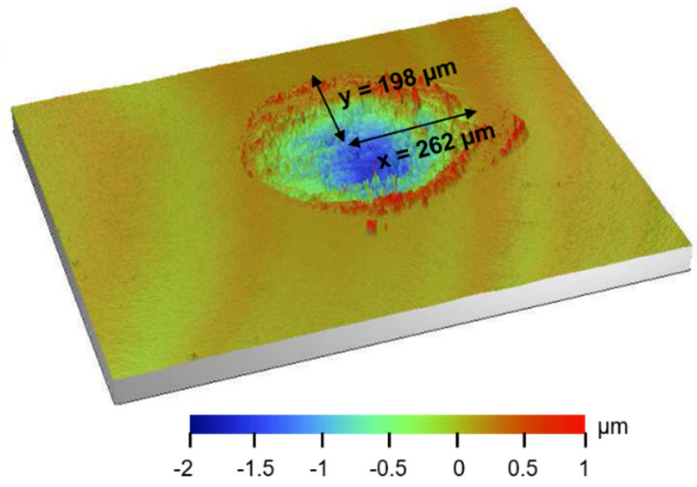

Figure 6.11 Wear pit characterization of LVCS13, specimen with lowest fretting wear rate, showing a) white light interferometry profile and b) confocal micrograph. 
Y-TZP ceramics are characterized by the tetragonal-to-monoclinic phase transformation that substantially increases fracture toughness and inhibits crack growth. Therefore, fracture toughness can be an important factor when assessing wear damage in these materials, particularly when it comes to microcracking. Grain size has also been found to influence the wear loss volume [36,38]. Therefore, both factors need to be taken into consideration. As previously stated, fracture toughness does not seem to be influenced significantly by the sintering method used or the increase in dwell temperature. However, grain size has shown significant variations, especially in LAVA material.

Figure 6.12 shows fracture toughness and average grain size against wear volume loss. Fretting wear studies on Y-TZP ceramics have established that lower fracture toughness values result in decreasing wear rates [39]. However, in this case no particular correlation has been found due to very similar $K_{/ C}$ values determined upon sintering as most values fall within the error range of each other. For example, LVCS14 and LVCS13, which correspond to the highest and lowest wear volume loss, respectively, are within the fracture toughness error range of each other. The differences in wear volume loss are therefore attributed to other factors.

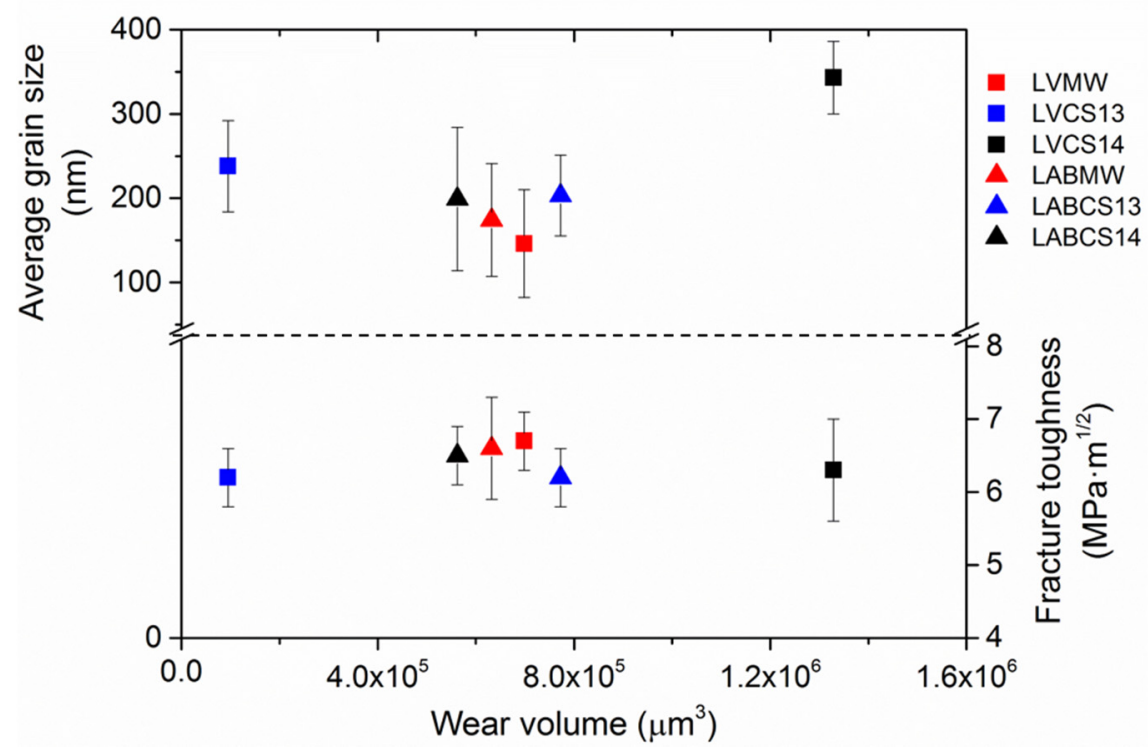

Figure 6.12 Plot of the average grain size and fracture toughness against wear volume loss for the studied Y-TZP materials under different sintering conditions.

In the case of grain size, a tendency of increasing wear volume with increasing grain size has been found for CS specimens. For MW sintering, wear volume is observed to slightly increase for smaller grain sizes, although the approximated values are very 
close to each other and makes it difficult to establish a relationship. Grain size of LAB material falls within a narrow range (150 -200 nm) and does not exhibit significant variations in wear volume. However, grain size has significant effects on the calculated wear volumes of LAVA material. A grain size of $238 \mathrm{~nm}$ of LVCS13 shows higher resistance to fretting wear since the calculated wear volume is an order of magnitude lower than LVMW and LVCS14 suggesting that grain size needs to be constrained to a mid-sized value in order to optimize fretting wear performance of this commercial material. On the other hand, similar grain sizes that have been obtained with LAB material under the different sintering conditions demonstrate that wear volume losses barely vary, which is expected.

An average wear volume under these fretting conditions considering all specimens results in a value of $6.8 \times 10^{5} \mu \mathrm{m}^{3}$, which fall within a close range of values found in other studies for zirconia ceramics. Therefore, the geometrical approximation approach employed for wear volume calculations results in a relatively good estimation for this quantitative characterization of wear behavior.

\subsubsection{INFLUENCE OF HUMIDITY ON FRETIING WEAR BEHAVIOR}

The influence of humidity on fretting wear behavior has also been assessed under highly wet environments, which is the type of conditions that dental materials are exposed to. In this case, a comparison under ambient relative humidity and $100 \%$ relative humidity levels has been performed. Section 6.3.2 describes the experimental setup for high humidity conditions. Results of the determined COF are shown in Figure 6.13. The analysis has been carried out with conventionally sintered materials, LAVA and LAB, for both dwell temperatures: 1300 and $1400{ }^{\circ} \mathrm{C}$. Relative humidity, r.h., has been labeled using "wet" for $100 \%$ r.h, and "dry" for ambient conditions.

A clear pattern can be established, where COF for wet conditions result in lower average COF values. The variations in COF among dry specimens are less pronounced than for wet specimens, as COF values for wet tests range from 0.55 to 0.75 , while in the case of dry values fall within 0.77 and 0.85 . This means that the COF is reduced, in average, by $20 \%$ in wet when compared to dry. In the case of LAVA at $1400{ }^{\circ} \mathrm{C}$, the difference is more than $30 \%$. This pattern is in agreement with many studies that indicate that the lubricating effect of water significantly reduces the COF in wear fretting, particularly in ball-on-plate configurations under sliding reciprocating conditions $[35,40]$. 


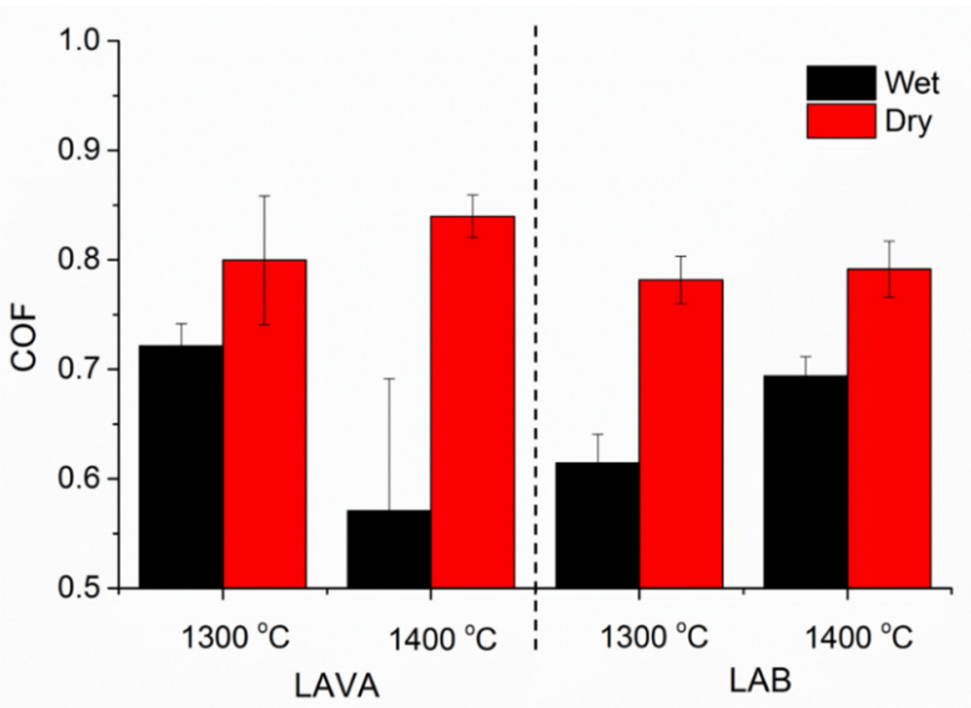

Figure 6.13 COF comparison between wet and dry specimens for LAVA and LAB materials sintered under two different temperatures.

Even though both materials result in a lower COF in the wet scenarios, LAVA shows a contrasting outcome and a bigger difference between specimens sintered at 1300 and $1400{ }^{\circ} \mathrm{C}$. The higher temperature shows a bigger difference between wet and dry scenarios than for the lower temperature. At $1300^{\circ} \mathrm{C}$, the COF in the wet scenario is significantly higher than all the other wet COF values. This behavior differs from the dry case, where the COF from the higher sintering temperature is greater than at $1300{ }^{\circ} \mathrm{C}$. On the other hand, LAB specimens from the dry and wet cases follow a similar trend that indicates that a higher sintering temperature results in a higher COF. In this case, the COF difference between wet and dry is more pronounced in the lower sintering temperature, contrasting with the observed pattern in LAVA.

Wear tracks after 100,000 cycles have been characterized qualitatively using the same tools as the ones from the previous section. Nomarski micrographs and while light interferometry profile models of LAVA and LAB sintered at $1400{ }^{\circ} \mathrm{C}$ are shown in Figure 6.14. The images indicate the significantly reduced fretting wear effect under wet conditions compared to the dry environment, where deeper grooves with higher amounts of wear loss resulting from delamination have been observed in the previous section. The diameters of the wear pit are smaller and the reached depth is decreased. Nomarski contrast microscopy also reveals the wear mechanisms taking place under these fretting conditions. No significant material loss occurs, as only abrasive grooving in the direction parallel to sliding displacement is observed in both materials. The same behavior occurs in the $1300{ }^{\circ} \mathrm{C}$ sintered specimens, as shown in Figure $6.14 \mathrm{a}$ and $6.14 \mathrm{~b}$ for $\mathrm{LAB}$ material. If materials are compared between each 
other, the effect of wear fretting on LAB material is less pronounced in terms of a qualitative evaluation, as the pit diameters are smaller and is not as deep as in LAVA.
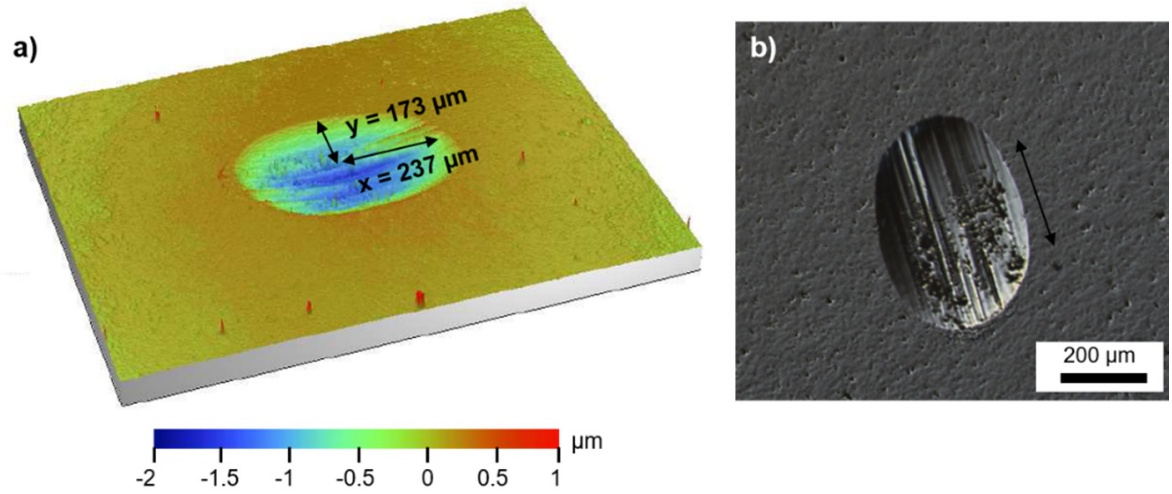

c)
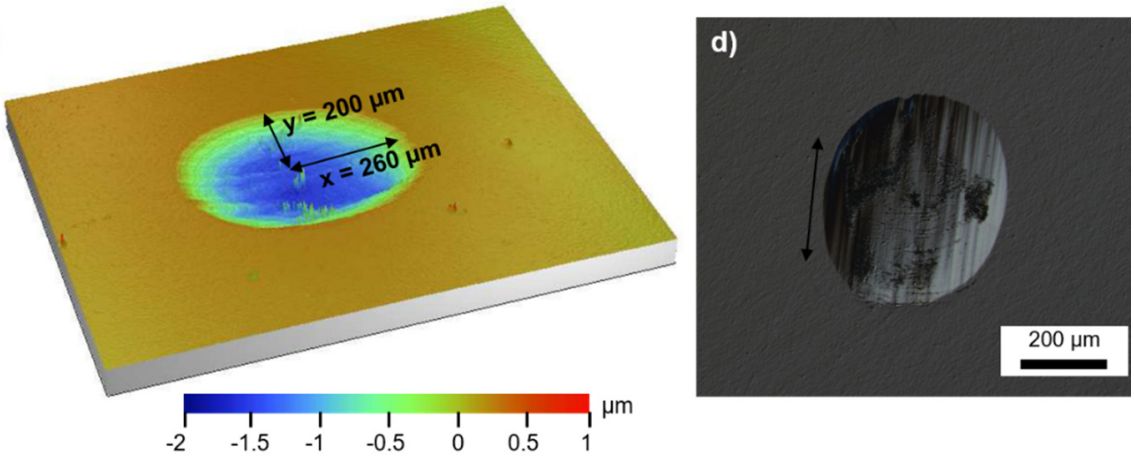

e)
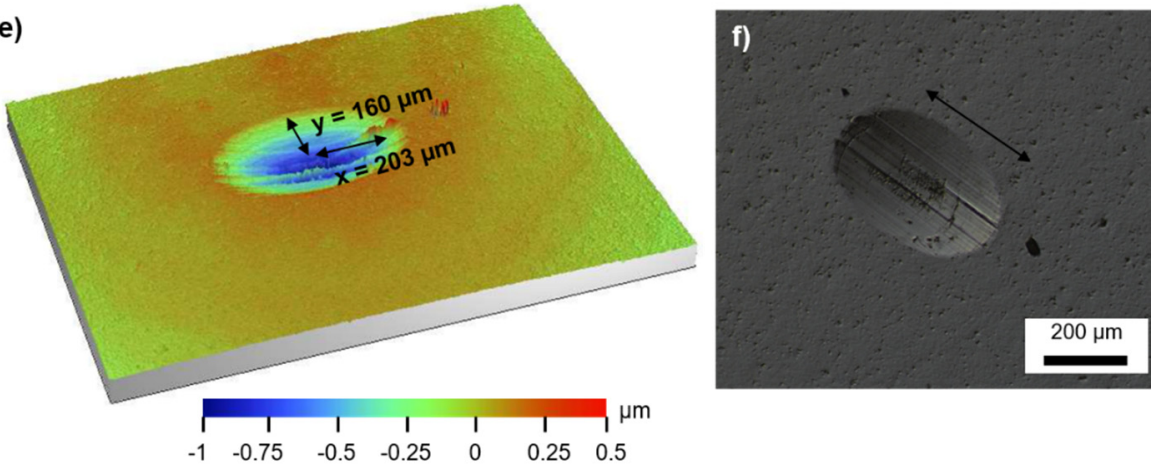

Figure 6.14 Wear track profilometric model and Nomarski interference contrast micrographs for $L A B$ sintered at $1300{ }^{\circ} \mathrm{C}$ ( $a$ and $b$, respectively) and LAVA (c and d, respectively) and LAB (e and f, respectively) sintered at $1400^{\circ} \mathrm{C}$.

The shape of the wear pit also differs from those obtained in dry conditions. In the wet case, the tracks possess generally a higher parallel to perpendicular diameter ratio, and, consequently, appear more elongated than their dry counterparts. This change from a circular to an elliptical geometry is due to the lubricative effect of high r.h. levels that decrease the COF and produce only abrasive grooving, the first stage 
in fretting wear. Hence, it can be established that the presence of water delay the effects of fretting wear on self-mated zirconia ceramics.

The wear scars on the counter body have also been characterized by means of optical microscopy with the aid of a multi-image capture mode due to the spherical nature of the counter material. Figure 6.15 shows the damage on the ball after fretting wear tests for dry and wet conditions of LAB material sintered at $1400^{\circ} \mathrm{C}$. The differences are quite significant between humidity levels and correspond to the degree of wear damage from those found in their flat counterparts. Such behavior can be attributed to the self-mating nature of the test as both materials consist of Y-TZP zirconia with similar properties. In the dry scenario, significant wear damage is caused by abrasive grooving and delamination leaving a rougher contact area and a wear pit diameter of approximately $600 \mu \mathrm{m}$. The wear scar on the ball used for fretting testing under wet conditions has a diameter half the size of its dry counterpart and the wear damage has been substantially constrained to only scratches in the sliding direction. The circular shape of these wear tracks can be attributed to the sphericity of the counter material ball. Due to the complexity of the counter material's spherical shape, white light interferometry could not be performed to obtain wear track profiles and hence wear volume has not been calculated.
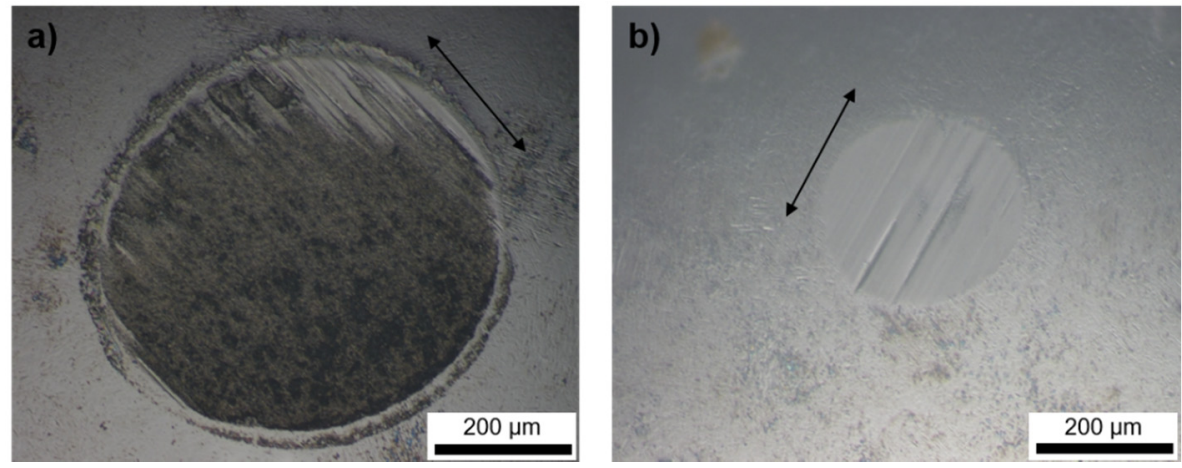

Figure 6.15 Micrographs of wear scars on zirconia balls employed as counter material for a) dry and b) wet conditions corresponding to fretting tests on LAB material sintered at $1400^{\circ} \mathrm{C}$.

The wear volume of the pits under wet conditions has been calculated with the same approach used for dry specimens. The results are given in Figure 6.16. A very clear pattern is observed, as wear volume loss under dry conditions is notably higher than in the case of wet. The differences correspond to more than order of magnitude between humidity conditions within each material. The wear volume of LAVA sintered at $1300{ }^{\circ} \mathrm{C}$ could not be calculated since no wear pit could be identified on the specimen. The surface profile showed that only a rougher circular area could be observed and microscopy images indicate that the high lubricative effect of water almost completely inhibited wear damage. In the case of LAVA at the higher sintering 
temperature, the greatest difference between wet and dry has been observed, as a difference of two orders of magnitude has been determined. For LAB material, the wear volume decreases in the same manner for wet and dry conditions, meaning that as the sintering temperature is increased the material resistance to wear is enhanced and less material is removed.

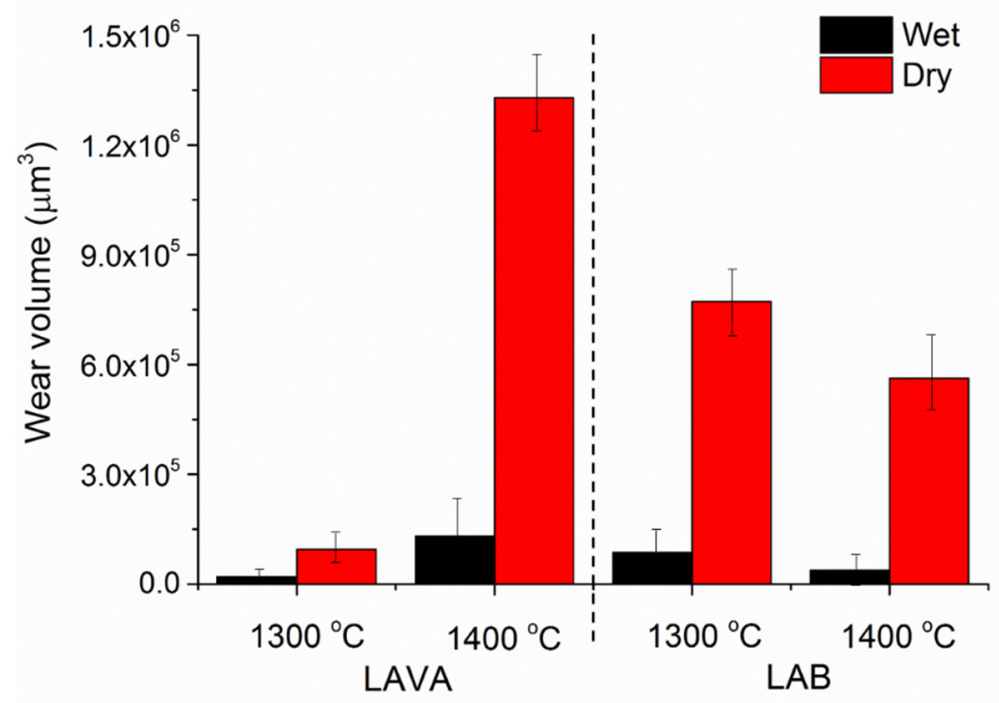

Figure 6.16 Wear volume determined for LAB and LAVA material sintered conventionally at two different temperatures under wet and dry conditions.

\subsubsection{EFFECT OF LTD ON RESISTANCE TO FRETTING WEAR}

As no literature has been found on the fretting wear behavior of hydrothermally degraded zirconia materials, the relevance of this study relies on providing new and relevant information about this topic. In order to investigate the effect of LTD, the COF and wear volume under ambient relative humidity conditions have been evaluated in zirconia materials processed by conventional sintering at 1300 and 1400 ${ }^{\circ} \mathrm{C}$ and exposed to $25 \mathrm{~h}$ of accelerated degradation conditions. The time of exposure has been selected based on the degradation study carried out in the previous chapter where $t$ - to $m$-phase transformation has been detected first with Raman spectroscopy after $20 \mathrm{~h}$ and before $40 \mathrm{~h}$ of exposure. In addition, using the relationship that $1 \mathrm{~h}$ translates into 2-3 years in service for zirconia, $25 \mathrm{~h}$ would correspond to approximately 60-75 years, a realistic maximum time for an implant or prosthesis to be required to last. Moreover, microwave sintered specimens have not been considered because, according to the results obtained in the previous chapter, these materials demonstrated a higher resistance to LTD before $40 \mathrm{~h}$ of LTD exposure and since the aim is to evaluate the effect of degradation on fretting wear after $25 \mathrm{~h}$, they have been discarded. 
LTD induced changes have been characterized by Raman spectroscopy (described in Section 5.3.3) to determine the presence of $m$-phase and Nomarski microscopy for evaluating the changes in surface topography resulting from phase transformation. The results for Raman spectroscopy are shown in Figure 6.17. The spectrograms reveal the lack of $m$-phase in all specimens after $25 \mathrm{~h}$ of LTD exposure. Only $t$-phase peaks have been identified in both materials for both sintering conditions. These results are in agreement with those obtained in Chapter 5, where after $20 \mathrm{~h}$ of LTD exposure no $m$-phase peaks have been found by this technique.

a)

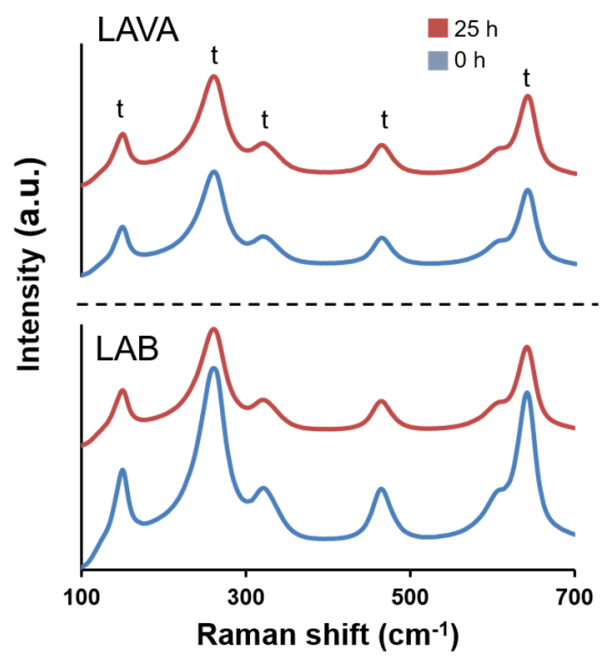

b)
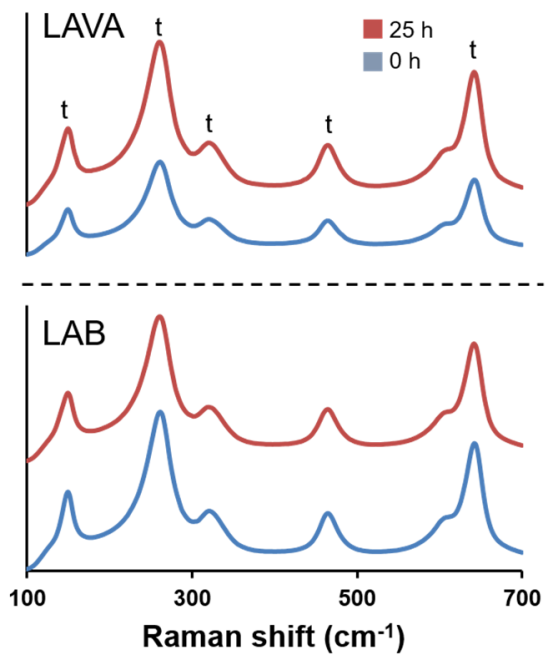

Figure 6.17 Raman spectrograms of LAVA and LAB material sintered at a) $1300^{\circ} \mathrm{C}$ and b) $1400^{\circ} \mathrm{C}$ before and after exposure to LTD.

If the specimens have experienced very low levels of phase transformation, these phase changes might not be revealed in the Raman spectrograms. Therefore, other tools are necessary to assess whether transformation has occurred at a subsuperficial level. In this case, LTD induced changes in the surface have been characterized by means of Nomarski microscopy and the images that have been obtained are shown in Figure 6.18. The images reveal that no significant topographical changes have occurred in LAB specimens (Figure $6.18 \mathrm{f}$ and $6.18 \mathrm{~h}$ ) as well as LAVA sintered at $1300^{\circ} \mathrm{C}$ (Figure 6.18b). However, LAVA sintered at $1400^{\circ} \mathrm{C}$ results in increased surface roughness after $25 \mathrm{~h}$ of LTD exposure time, as shown in Figure $6.18 \mathrm{~d}$, indicating that this specimen is particularly susceptible to phase transformation and, hence, material degradation. The need for evaluating LTD with complimentary tools have been demonstrated, as topographical analysis of the surface indicates that transformation degradation has taken place in at least one of the specimens, but Raman spectroscopy has not been able to detect such transformation. 
Oh

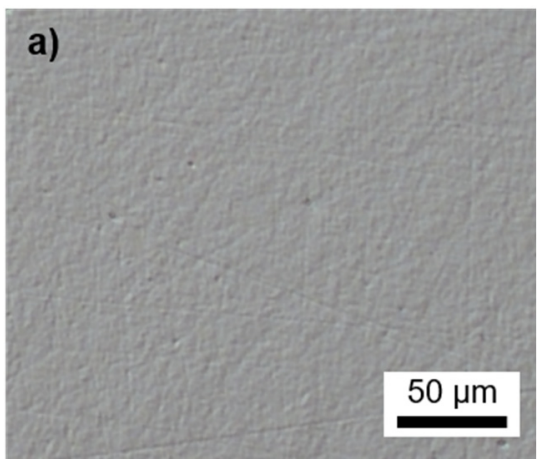

c)

$50 \mu \mathrm{m}$
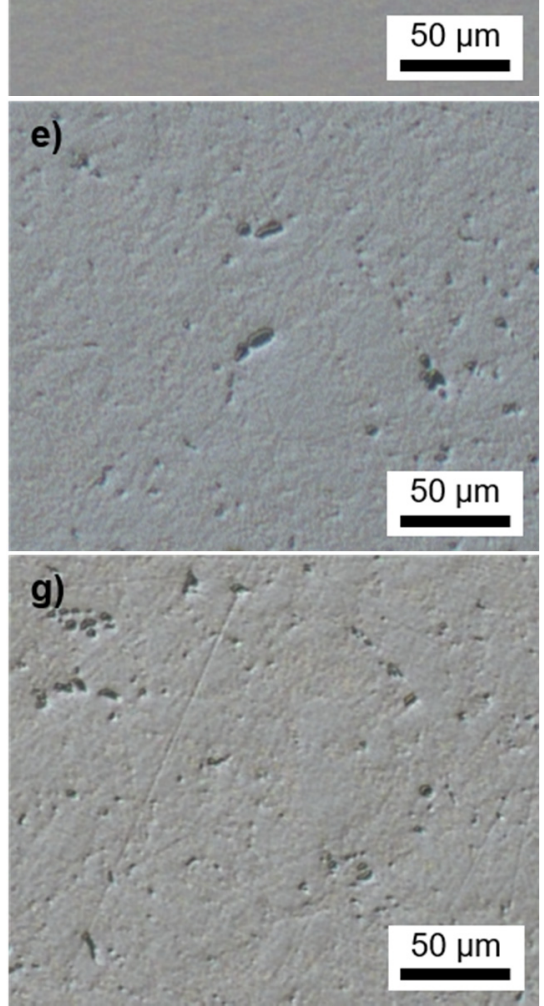

Figure 6.18 Surface micrographs of LAVA and LAB sintered at $1300^{\circ} \mathrm{C}(\mathrm{a}, \mathrm{b}, \mathrm{e}$, and $\mathrm{f}$, respectively) and $1400{ }^{\circ} \mathrm{C}(\mathrm{c}, \mathrm{d}, \mathrm{g}$ and $\mathrm{h}$ ) before and after $25 \mathrm{~h}$ of LTD exposure.
$25 h$

\section{b)}
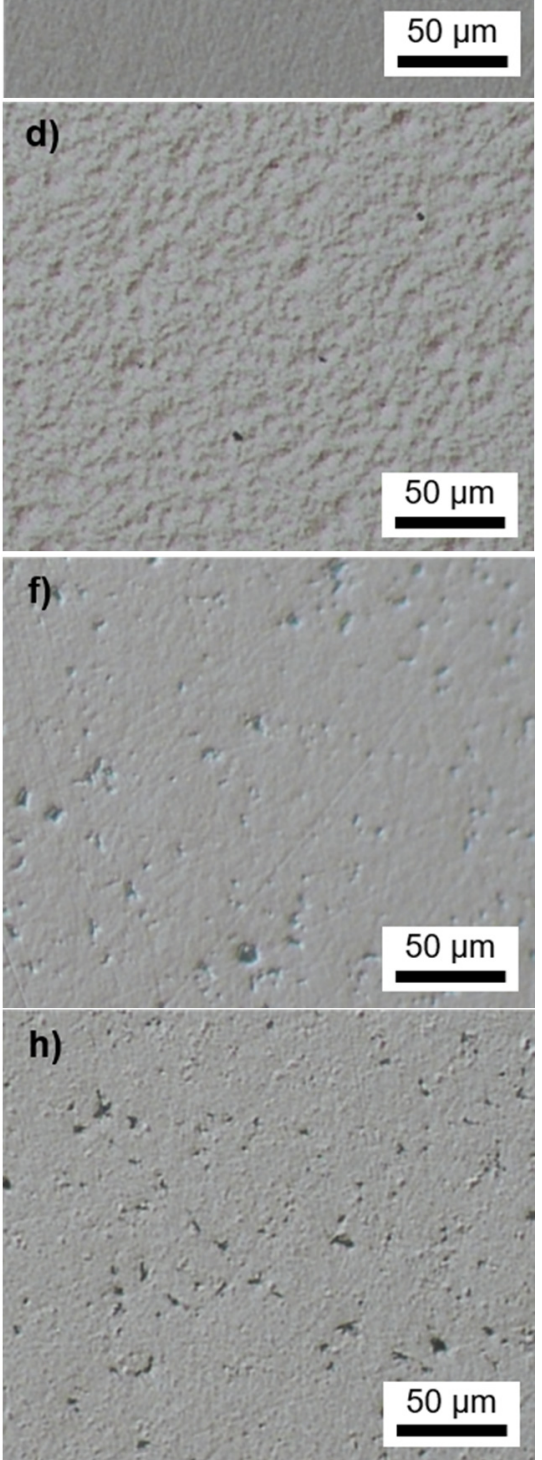
According to the grain size results, LAVA at $1400^{\circ} \mathrm{C}$ consists of the largest grain size value upon sintering $(343 \mathrm{~nm})$ from all the materials and sintering conditions considered in this work. Some studies have reported a critical particle size for $t$ stabilized zirconia ceramics in the range of $300-370 \mathrm{~nm}$ on LTD experimental data [41-43]. Exceeding this critical grain size significantly increases the susceptibility to LTD. The grain size of the other specimens do not exceed $250 \mathrm{~nm}$ and are therefore able to withstand the effects of LTD in a more effective manner.

Once LTD characterization has been performed, specimens have been exposed to fretting wear conditions, as described in Section 6.3.2. The results of COF are shown in Figure 6.19. A direct comparison between degraded and non-degraded material after $25 \mathrm{~h}$ shows that variations in COF are not too pronounced, with the exception of LAVA sintered at $1300{ }^{\circ} \mathrm{C}$. The degraded surface observed for LAVA sintered at $1400{ }^{\circ} \mathrm{C}$ in the micrograph above (Figure 6.18d) does not seem to influence the friction behavior, since the COF values are within the error range between degraded and non-degraded material. The pattern observed in most materials indicates that the COF of non-degraded material is greater than degraded material. However, LAB sintered at $1400{ }^{\circ} \mathrm{C}$ contrasts with this pattern. Nonetheless, the COF values fall within the error range.

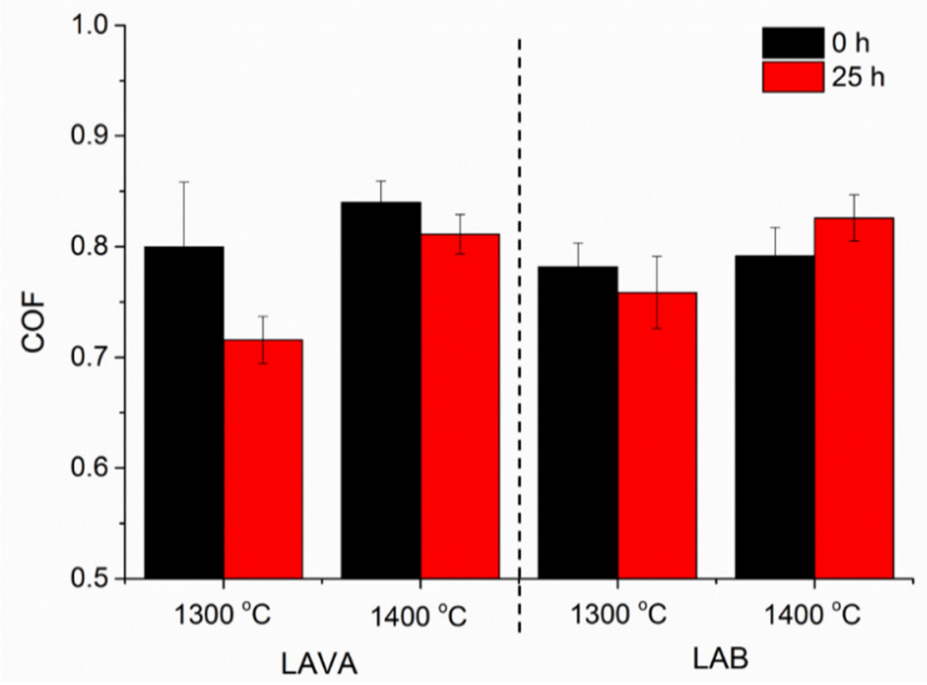

Figure 6.19 COF for LAVA and LAB material sintered conventionally at two different temperatures before and after $25 \mathrm{~h}$ of exposure to accelerated LTD conditions.

The wear volume for degraded and non-degraded material has been calculated and the results are given in Figure 6.20. The most notable wear volume difference occurs for LAVA sintered at $1400{ }^{\circ} \mathrm{C}$, which, according to the LTD characterization results, showed a rougher surface after $25 \mathrm{~h}$ of degradation exposure and higher 
susceptibility to this ageing phenomenon. In this case, wear volume loss is significantly reduced in the degraded material, from $1.4 \times 10^{6}$ to $3.1 \times 10^{5}$. A plausible explanation for this behavior consists on the contribution of LTD to the loss of mechanical properties such as hardness and fracture toughness that increases the amount of debris generated during wear tests. A higher vulnerability to wear damage and material loss is constrained mostly to the sub-superficial zone where the $\mathrm{m}$ phase layer has emerged. As fretting progresses, the debris accumulates and is trapped inside the wear track at the ball-plate interface and acts as a protective layer between material and counter material reducing the amount of material loss. In the case of $L A B$, the calculated wear volumes are not too different between degraded and non-degraded specimens, which highlights the stability of this material due to its lab-optimized nature.

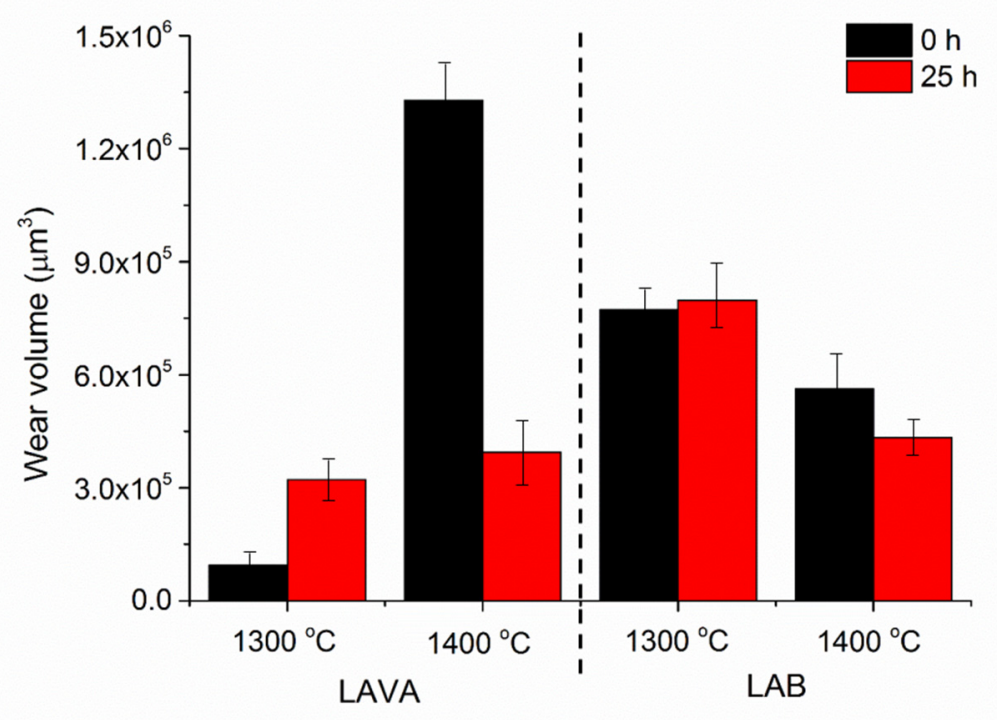

Figure 6.20 Wear volume for LAVA and LAB material sintered conventionally at two different temperatures before and after $25 \mathrm{~h}$ of exposure to accelerated LTD conditions.

Characterization of the wear tracks has been performed in a similar manner as for non-degraded material in previous sections. Surface models obtained from white light interferometry and Nomarski micrographs for LAVA and LAB sintered at 1400 ${ }^{\circ} \mathrm{C}$ after degradation are shown in Figure 6.21. A rougher surface can be observed in LAVA due to the effects of degradation. The shape of the wear track is similar to those observed in non-degraded material: an elongated circular cap in the parallel direction to fretting displacement. For the LAVA specimen, which from the degradation characterization results appear to have been the only one affected by degradation, a more elongated wear track can be observed. The difference in measured diameters and pit depth is not too pronounced when compared to the LAB 
specimen, which is in agreement with the similar calculated wear volume loss between these two specimens.
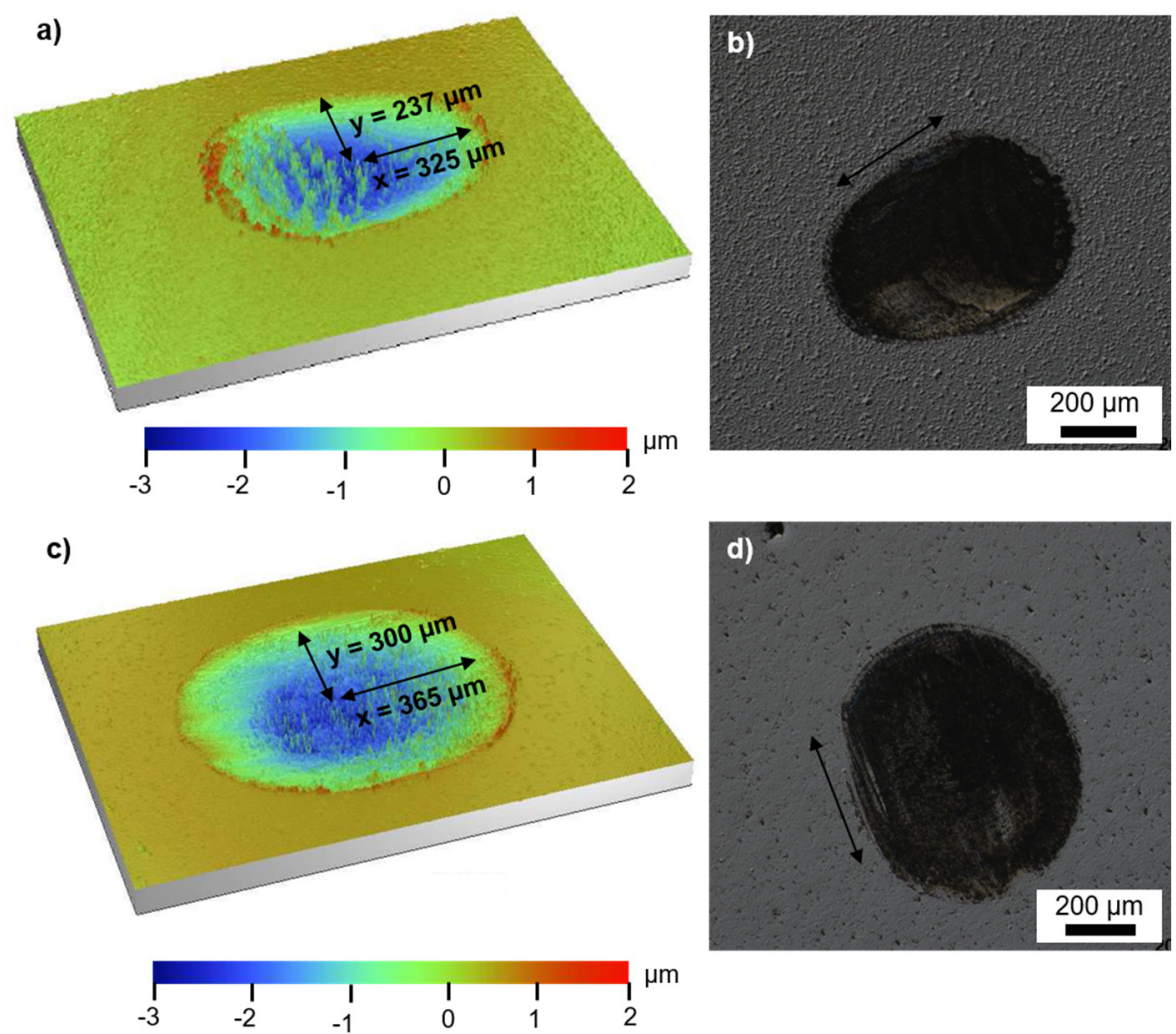

Figure 6.21 Wear track profilometric model and Nomarski interference contrast micrographs of degraded LAVA sintered at $1400{ }^{\circ} \mathrm{C}$ ( $a$ and b, respectively) and LAB sintered at $1400{ }^{\circ} \mathrm{C}$ ( $\mathrm{c}$ and d, respectively).

The confocal microscopy images presented in Figure 6.22 revels the mechanism responsible for wear damage in LAVA and LAB sintered at $1400{ }^{\circ} \mathrm{C}$ after $25 \mathrm{~h}$ of LTD exposure. $L A B$ material, which appears to have not been affected by degradation, exhibits similar wear mechanisms as those found in non-degraded material, such as delamination, microcracking and abrasive grooving. In the case of LAVA, however, an interesting element has been found inside the wear track. The formation of microscopic wave-like features (pointed by the red arrow) perpendicular to the displacement direction might indicate the accumulation of debris that has accumulated and been grinded by the ball. These features have not been observed in the other degraded specimens and could be an indication of the presence of a protective layer that results from a sub-superficial loss of $m$-phase material that reduces the wear volume loss significantly. 

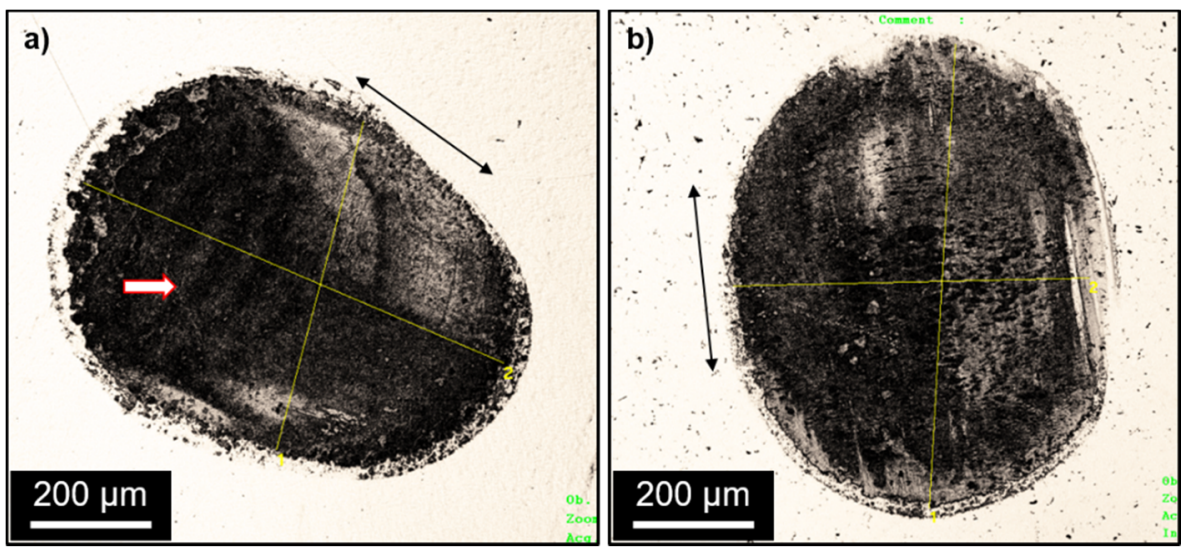

Figure 6.22 Confocal microscopy images of the wear tracks on LAVA (a) and LAB (b) sintered at 1400 ${ }^{\circ} \mathrm{C}$ after $25 \mathrm{~h}$ of LTD exposure.

The degradation that occurs in LAVA upon sintering at $1400^{\circ} \mathrm{C}$ is a consequence of the large particle size exceeding a critical value. As a consequence, the emergence of a sub-superficial $m$-phase layer can favor the generation of debris that can get trapped inside the ball and the plate and act as protective layer that reduces the overall fretting wear damage resulting in a smaller wear volume loss. Therefore, degradation can change the behavior of zirconia ceramics against fretting wear and increase resistance to material removal. More studies need to be carried out to understand the mechanism involved in the fretting wear behavior of degraded zirconia material and a more thorough understanding of the effects of LTD.

\subsection{CONCLUSIONS}

The tribological behavior under fretting wear conditions of two Y-TZP materials for dental applications consolidated through the non-conventional microwave sintering technique has been studied. A comparative analysis with conventional sintering has been performed. Sintered materials at the selected conditions provide highly densified materials and mechanical properties, such as hardness, fracture, toughness and elastic modulus, typical of Y-TZP ceramics. LAVA, a commonly utilized $Y$-TZP dental commercial material, shows significant variation in grain size after sintering under different process conditions. In contrast, LAB material, a carefully prepared Y-TZP powder, results in a more homogeneous grain size distribution even when sintered with different methods and dwell temperatures.

With respect to the influence of sintering conditions on the fretting wear behavior of Y-TZP ceramics, the results in LAVA material indicate that grain sizes might lead to variations in resistance to fretting wear. A larger grain size, and higher COF, resulting from CS at $1400^{\circ} \mathrm{C}$ is responsible for the highest wear volume loss. CS at $1300{ }^{\circ} \mathrm{C}$, 
with a mid-range particle size, has provided a lower wear volume loss. In this particular case, an even smaller grain size resulting from MW sintering at $1200{ }^{\circ} \mathrm{C}$ does not correspond to a lower wear volume loss. Therefore, further evaluations need to be carried out on the influence of grain size variations emerging from microwave sintered materials. Determined wear rates indicate that a gross slip regime have been achieved in both $\mathrm{MW}$ and CS specimens. Wear track shapes and morphology of MW sintered materials indicate a similar wear behavior as that of CS because abrasive grooving, delamination and microcracking are also present. The influence of the sintering method employed on the wear volume is more pronounced for LAVA material than for LAB regarding fretting wear behavior. In addition, the effect of utilizing different dwell temperatures in conventionally sintered specimens is more noticeable in Y-TZP LAVA. A relationship between wear volume and fracture toughness could not be observed in Y-TZP ceramics. Differences in fracture toughness are not too pronounced among specimens and is difficult to assess the role of fracture toughness in wear behavior of these Y-TZP materials. It can be concluded that MW sintering at lower dwell temperature and sintering time can still provide materials with fretting wear resistance comparable to those obtained by CS at higher temperatures and longer processing times.

Since Y-TZP ceramics studied in this work are meant for dental applications, the effects of humidity are a key factor in evaluating their performance under fretting wear. In the case of the materials considered in this work under reciprocating selfmating conditions, increasing humidity to a $100 \%$ r.h. reduces the effects of wear due to the lubricative effect of water contained in highly humid environments, contrasting with those of drier conditions at $45-60 \%$ r.h. COF, material volume loss and wear damage are considerably lowered at a r.h. of $100 \%$. Counter material wear tracks also reflect this behavior.

Exposure to LTD for $25 \mathrm{~h}$ demonstrated a change in the fretting wear behavior of LAVA sintered at $1400^{\circ} \mathrm{C}$. Exceeding the critical grain size of $300 \mathrm{~nm}$ in this specimen has increased the vulnerability to $m$-phase transformation. A significantly lower material volume loss compared to its non-degraded counterpart has been determined. Such behavior might be attributed to the loss of mechanical properties resulting from the emergence of a degraded sub-superficial layer that leads to a faster generation of debris. This debris is accumulated and trapped at the ball-plate interface. Consequently, a protective layer arises and reduces the fretting wear damage. However, more studies are necessary to further evaluate and understand the influence of LTD on fretting wear behavior.

As revealed in this study, several factors influence the fretting wear behavior of zirconia materials, such as processing with non-conventional methods, humidity and 
LTD, in different ways. Each factor affect the fretting wear behavior on a specific manner. Therefore, it is important to understand the wear mechanisms influenced by each factor to have a more comprehensive understanding of the resistance to wear of dental zirconia materials. 


\section{REFERENCES}

[1] Guazzato M, Albakry M, Ringer SP, Swain MV. Strength, fracture toughness and microstructure of a selection of all-ceramic materials. Part II. Zirconiabased dental ceramics. Dent Mater 2004;20:449-56.

[2] Denry I, Kelly JR. State of the art of zirconia for dental applications. Dent Mater 2008;24:299-307.

[3] Waterhouse RB. Fretting corrosion. Pergamon Press; 1972.

[4] Stachowiak G, Batchelor A. Engineering Tribology. Butterworth-Heinemann; 2006.

[5] Vingsbo O, Söderberg S. On fretting maps. Wear 1988;126:131-47.

[6] Vingsbo O, Schön J. Gross slip criteria in fretting. Wear 1993;162-164:34756.

[7] García-Gañán C, Meléndez-Martínez JJ, Gómez-García D, DomínguezRodríguez A. Microwave sintering of nanocrystalline YTZP (3 mol\%). J Mater Sci 2006;41:5231-4.

[8] Borrell A, Salvador MD, Miranda M, Peñaranda-Foix FL, Catalá-Civera JM. Microwave technique: A powerful tool for sintering ceramic materials. Curr Nanosci 2014;10:32-5.

[9] Ai Y, Xie X, He W, Liang B, Chen W. Microstructure and properties of $\mathrm{Al}_{2} \mathrm{O}_{3}$ $\mathrm{ZrO}_{2}$ ceramics prepared by microwave sintering. Key Eng Mater 2014;633:193-7.

[10] Benavente R, Salvador MD, Peñaranda-Foix FL, Pallone E, Borrell A. Mechanical properties and microstructural evolution of alumina-zirconia nanocomposites by microwave sintering. Ceram Int 2014;40:11291-7.

[11] Borrell A, Salvador MD, Peñaranda-Foix FL, Plaza-Gonzalez PJ, Garcia-Baños $\mathrm{B}$, Garcia-Nieto S. Adaptive microwave system for optimum new material sintering. Microw Symp Dig (IMS), 2013 IEEE MTT-S Int., 2013, p. 1-4.

[12] Vasudevan R, Karthik T, Ganesan S, Jayavel R. Effect of microwave sintering on the structural and densification behavior of sol-gel derived zirconia toughened alumina (ZTA) nanocomposites. Ceram Int 2013;39:3195-204.

[13] Borrell A, Salvador MD, Rayón E, Peñaranda-Foix FL. Improvement of microstructural properties of 3Y-TZP materials by conventional and nonconventional sintering techniques. Ceram Int 2012;38:39-43.

[14] Borrell A, Salvador MD, Peñaranda-Foix FL, Cátala-Civera JM. Microwave sintering of zirconia materials: Mechanical and microstructural properties. Int J Appl Ceram Technol 2013;10:313-20. 
[15] Monaco C, Prete F, Leonelli C, Esposito L, Tucci A. Microstructural study of microwave sintered zirconia for dental applications. Ceram Int 2015;41:1255-61.

[16] Basu B, Lee JH, Kim DY. Development of nanocrystalline wear-resistant Y-TZP ceramics. J Am Ceram Soc 2004;87:1771-4.

[17] Cho SJ, Hockey BJ, Lawn BR, Bennison SJ. Grain-size and R-curve effects in the abrasive wear of alumina. J Am Ceram Soc 1989;72:1249-52.

[18] Guiberteau F, Padture NP, Lawn BR. Effect of grain size on Hertzian contact damage in alumina. J Am Ceram Soc 1994;77:1825-31.

[19] Zheng J, Zhou Z., Zhang J, Li H, Yu H. On the friction and wear behaviour of human tooth enamel and dentin. Wear 2003;255:967-74.

[20] Zhu MH, Yu HY, Cai ZB, Zhou ZR. Radial fretting behaviours of dental feldspathic ceramics against different counterbodies. Wear 2005;259:9961004.

[21] Zhu MH, Yu HY, Zhou ZR. Radial fretting behaviours of dental ceramics. Tribol Int 2006;39:1255-61.

[22] Kim MJ, Oh SH, Kim JH, Ju SW, Seo DG, Jun SH, et al. Wear evaluation of the human enamel opposing different Y-TZP dental ceramics and other porcelains. J Dent 2012;40:979-88.

[23] Price R, Jerome W. Basic confocal microscopy. Springer Science \& Business Media; 2011.

[24] Murphy DB, Davidson MW. Confocal Laser Scanning Microscopy. In: Murphy DB. Fundamentals of Light Microscopy and Electronic Imaging. John Wiley \& Sons, Inc.; 2012, p. 265-305.

[25] Klaffke D. Fretting wear of ceramics. Tribol Int 1989;22:89-101.

[26] Kalin M, Vižintin J. Use of equations for wear volume determination in fretting experiments. Wear 2000;237:39-48.

[27] Ruzin S. Plant microtechnique and microscopy. New York:Oxford University Press; 1999.

[28] Guazzato M, Albakry M, Swain MV, Ironside J. Mechanical properties of InCeram Alumina and In-Ceram Zirconia. Int J Prosthodont 2002;15:339-46.

[29] Magnani G, Brillante A. Effect of the composition and sintering process on mechanical properties and residual stresses in zirconia-alumina composites. J Eur Ceram Soc 2005;25:3383-92.

[30] Nath S, Sinha N, Basu B. Microstructure, mechanical and tribological properties of microwave sintered calcia-doped zirconia for biomedical 
applications. Ceram Int 2008;34:1509-20.

[31] Oghbaei M, Mirzaee O. Microwave versus conventional sintering: A review of fundamentals, advantages and applications. J Alloys Compd 2010;494:17589.

[32] Charmond S, Carry CP, Bouvard D. Densification and microstructure evolution of Y-tetragonal zirconia polycrystal powder during direct and hybrid microwave sintering in a single-mode cavity. J Eur Ceram Soc 2010;30:121121.

[33] Upadhyaya DD, Ghosh A, Dey GK, Prasad R, Suri AK. Microwave sintering of zirconia ceramics. J Mater Sci 2001;36:4707-10.

[34] Rayón E, Moreno R, Alcázar C, Salvador MD, Manjón FJ, Jiménez-Piqué E, et al. Enhanced hydrothermal resistance of $Y$-TZP ceramics through colloidal processing. J Am Ceram Soc 2013;96:1070-6.

[35] Basu B, Vitchev RG, Vleugels J, Celis JP, Van der Biest O. Influence of humidity on the fretting wear of self-mated tetragonal zirconia ceramics. Acta Mater 2000;48:2461-71.

[36] Basu B, Kalin M. Tribology of Ceramics and Composites: A Materials Science Perspective. John Wiley and Sons; 2011.

[37] Giannakopoulos AE, Suresh S. A three-dimensional analysis of fretting fatigue. Acta Mater 1998;46:177-92.

[38] Krell A, Klaffke D. Effects of grain size and humidity on fretting wear in finegrained alumina, $\mathrm{Al}_{2} \mathrm{O}_{3} / \mathrm{TiC}$, and zirconia. J Am Ceram Soc 1996;79:1139-46.

[39] Basu B, Vleugels J, Van der Biest O. Microstructure-toughness-wear relationship of tetragonal zirconia ceramics. J Eur Ceram Soc 2004;24:203140.

[40] Takadoum J, Houmid-Bennani H, Mairey D. The wear characteristics of silicon nitride. J Eur Ceram Soc 1998;18:553-6.

[41] Watanabe M, lio S, Fukuura I. Ageing behaviour of $Y$-TZP. Advances in ceramics, 1984;12:391-8.

[42] Chen SY, Lu HY. Low-temperature ageing map for $3 m o l \% \mathrm{Y}_{2} \mathrm{O}_{3}-\mathrm{ZrO}_{2}$. J Mater Sci 1989;24:453-6.

[43] Muñoz-Saldaña J, Balmori-Ramírez H, Jaramillo-Vigueras D, Iga T, Schneider GA. Mechanical properties and low-temperature aging of tetragonal zirconia polycrystals processed by hot isostatic pressing. J Mater Res 2011;18:241526. 




\section{CHAPTER 7: CONCLUSIONS AND FUTURE WORK}



In this work, the full consolidation of Y-TZP dental materials via microwave sintering (Chapter 4) and the effects of this non-conventional method on low-temperature hydrothermal degradation (Chapter 5 ) and wear behavior under fretting conditions (Chapter 6) has been investigated. The following chapter describes the general conclusions and perspectives on future work derived from this thesis.

\subsection{CONCLUSIONS}

\section{MECHANICAL AND MICROSTRUCTURE CHARACTERIZATION OF MICROWAVE SINTERED DENTAL ZIRCONIA MATERIALS}

Three different dental Y-TZP materials have been sintered via microwave and conventional methods and their microstructure and mechanical properties have been evaluated and compared. The resulting materials from microwave sintering possess a very high degree of densification (relative density $>97 \%$ ) at lower dwell temperatures and shorter processing times, in some cases exceeding those obtained in conventionally sintered materials. Moreover, the microstructure has been significantly affected as a consequence of the densification mechanisms that are involved. Variations in grain size have been observed between sintering methods and among materials. Microwave sintering of commercial materials LAVA and VITA results in significantly smaller grain sizes than their conventional sintering counterparts due to the employed processing conditions. On the other hand, a labprepared material, such as LAB, presents more uniform grain sizes between sintering methods. Mechanical properties of microwave sintered Y-TZP ceramics, such as fracture toughness (> $4.0 \mathrm{MPa} \cdot \mathrm{m}^{1 / 2}$ ), hardness (> $12 \mathrm{GPa}$ ) and Young's modulus (> $210 \mathrm{GPa}$ ) are highly admissible and comply with values expected for structural applications, such as the odontological field. These properties are comparable to those obtained by conventional sintering.

\section{INFLUENCE OF MICROWAVE SINTERING ON HYDROTHERMAL DEGRADATION OF Y-TZP CERAMICS}

Low-temperature hydrothermal degradation affects Y-TZP materials when exposed to humid environments of $100 \%$ r.h. and is therefore relevant for dental applications. The influence of microwave sintering on the progression of this ageing phenomenon on two Y-TZP materials, commercial LAVA and lab-prepared LAB, has been studied. The evolution of the phase composition as a function of hydrothermal degradation time indicates that microwave sintering delays or can even inhibit the phase transformation that accompanies the hydrothermal degradation of zirconia ceramics. Lower dwell temperatures and shorter processing times in microwave sintered materials prevent a higher content of $c$-phase, which is responsible from 
depriving neighboring $t$-phase grains of yttria stabilizer and, therefore, augmenting the susceptibility to LTD of Y-TZP ceramics.

The initial stages of degradation are reflected on the surface topography due to the volume increase that occurs as a consequence of phase transformation. Surface texture also demonstrates that materials from conventional sintering have been affected by LTD to a higher extent than those from microwave sintering in the nucleation stage. The degraded layer depth has also been measured and indicates that, even though no phase transformation has been detected with spectroscopic techniques, a small degradation layer has been observed in microwave sintered LAB.

A significant loss of mechanical properties has been observed in the materials affected by degradation. However, the non-affected microwave sintered material is able to maintain hardness and Young's modulus even after exposure to $200 \mathrm{~h}$ of LTD. The importance of degradation resistance has been highlighted by the study of crack propagation of degraded and non-degraded materials, showing that degraded material significantly reduces fracture toughness of Y-TZP ceramics because of the decrease in $t$-phase content and subsequent loss of the transformation toughening mechanism. The combination of a carefully prepared starting material such as LAB and processing by microwave sintering can significantly enhanced the resistance to LTD of zirconia ceramics.

Crack propagation in degraded and non-degraded zones has been analyzed to highlight the significance of increasing hydrothermal degradation resistance. A network of cracks emerges on degraded material below the indentation and superficial cracks giving rise to what is known as semielliptical cracking. On the other hand, non-degraded material constraints the cracking damage into a single crack initiating at the indentation edge due to the transformation toughening mechanism as a consequence of the $t$ - to $m$-transformation and resulting in Palmqvist cracking.

\section{FRETTING WEAR BEHAVIOR UPON MICROWAVE SINTERING AND EFFECT OF HUMIDITY AND HYDROTHERMAL DEGRADATION}

Self-mating fretting wear conditions have been applied to study the influence of sintering conditions, humidity and hydrothermal degradation in the durability and long-term wear resistance of Y-TZP ceramics. In the case of sintering conditions, microwave sintering results in a similar fretting wear behavior as that observed in conventional sintering because the wear rates calculated fall within gross slip regime and the volume wear loss is also within a comparable order of magnitude. Studied parameters that might influence wear behavior include particle size and fracture toughness. The former indicates that large particle sizes $(340 \mathrm{~nm})$ results in an 
increased wear volume loss and that a higher resistance to fretting wear is constrained to a mid-range particle size. Due to very similar values among all materials, the influence of the latter could not be effectively assessed.

Regarding the influence of humidity, highly humid environments ( $100 \%$ r.h.) reduce the effect of fretting wear on zirconia materials compared to drier conditions (45$60 \%$ r.h.) because water acts as a lubricant and significantly reduces the coefficient of friction. The difference in wear volume loss can exceed, in some cases, $10^{6} \mu \mathrm{m}^{3}$. Most damage is due to abrasive grooving and the gross slip regime is never reached in high humidity conditions. With respect to the variations in wear resistance in degraded zirconia after $25 \mathrm{~h}$ of hydrothermal degradation exposure and nondegraded material, degradation can lower the wear volume loss due to the accumulation of residues from sub-superficial $m$-phase material that act as a protective layer between the ball and the flat.

\subsection{FUTURE WORK}

The results and conclusions obtained in this work have relevant implications for the utilization of microwave sintering for the fabrication of Y-TZP ceramics for dental applications. However, other aspects still need to be investigated to have a full understanding of the parameters and conditions that affect the driving mechanisms for zirconia powder consolidation during microwave sintering. Moreover, comparative analyses against conventional methods in other environments and tests conditions related to dental applications should be studied, such as in vivo studies or the use artificial saliva for hydrothermal degradation and fretting wear instead of water. Additionally, temperatures closer to human body temperature $\left(36-38^{\circ} \mathrm{C}\right)$ can be investigated as well.

Also, efforts in our group are also being directed toward design improvement and optimization of the microwave cavity to allow the processing of several zirconia bodies at once. One of the most important limitations in the current microwave system configuration is that only single samples have been processed at a time. In order to optimize time and resources, the cavity needs to be modified to effectively couple several zirconia bodies with microwaves. Some studies are already being carried out regarding processing of multiple samples of carbide materials inside one microwave cavity. However, none have focused in zirconia. Another approach consist on the implementation of a circular cavity instead of a rectangular one to homogenize the distribution of microwave radiation and coupling a Raman probe for in-situ characterization of phase changes. Therefore, this is another important research line for future investigations. 
The next steps are directed towards the fabrication of actual dental pieces. Utilizing CAD-CAM system for dimensioning and shaping of specific restorative implants, a zirconia green body can be obtained. After this body is sintered, the changes in dimensioning due to shrinkage need to be investigated because the driving mechanisms for densification are different compared to conventional sintering. The nature of dielectric heating can result in higher variations of volume upon sintering. Since dental pieces need to be specifically shaped to the patient needs, it is important to consider this volume changes.

Exploring the sintering by microwave heating technology of other zirconia-based materials such as ATZ composites is also another important aspect to consider. Several low alumina concentrations need to be considered because these composites can combine the physical properties of two ceramic material and improve the mechanical performance of the resulting body. Moreover, the resistance to hydrothermal degradation can be increased since alumina is not vulnerable to this phenomenon. Also, ATZ composites can provide a larger spectrum of aesthetic properties due to the coloring they can provide, which is very important for dental applications, as professional must often match the teeth coloring of their patients. Other Y-TZP commercial dental materials should also be investigated because each manufacturer has a specific procedure for preparing their materials. As shown in this work, the final properties of Y-TZP materials vary depending also on the preparation of the starting material. 

